\title{
On some Lomechusini of the Palaearctic and Oriental regions (Coleoptera: Staphylinidae: Aleocharinae)
}

\author{
With 475 figures and 2 maps
}

VOLKER ASSING ${ }^{1}$

${ }^{1}$ Gabelsbergerstraße 2, 30163 Hannover, Germany. - vassing.hann@t-online.de Published on 2016-06-30

\section{Summary}

Types and additional material of twelve genera, one of them new, of Lomechusini from the Palaearctic and Oriental regions are revised. In all, 70 species are (re-)described and/or illustrated, 51 of them new: Orphnebius bakeri Bernhauer, 1929; O. breviceps CAmeron, 1946; O. opticus Cameron, 1946; O. bicuspis spec. nov. (Laos; India: Arunachal Pradesh); O. biformis spec. nov. (Indonesia: Sumatra); O. cernens spec. nov. (Laos); O. dilatatus spec. nov. (Laos); O. effeminatus spec. nov. (Malaysia); O. extensus spec. nov. (Laos); O. fodens spec. nov. (Malaysia: Sabah); O. fuscapicalis spec. nov. (Laos); O. fusicollis spec. nov. (Laos); O. grandicollis spec. nov. (Laos); O. integer spec. nov. (Laos); O. latitibialis spec. nov. (Laos); O. lunatus spec. nov. (Laos); O. nigrapicalis spec. nov. (Laos); O. reductus spec. nov. (Laos); O. retunsus spec. nov. (Laos); O. serratus spec. nov. (Laos); O. spinans spec. nov. (India: Arunachal Pradesh); Orphnebius (Deroleptus) falagrioides Bernhauer, 1929; O. (D.) laticeps CAmeron, 1925; O. (D.) multimpressus Assing, 2015; O. (D.) niger (CAMERon, 1939); O. (D.) siamensis CAMEron, 1939; O. (D.) baccillatus spec. nov. (Laos); O. (D.) biimpressus spec. nov. (Indonesia: Sumatra); O. (D.) carinatus spec. nov. (Laos); O. (D.) cultellatus spec. nov. (Thailand, Laos); O. (D.) discrepans spec. nov. (China: Yunnan); O. (D.) dispar spec. nov. (India: Arunachal Pradesh); O. (D.) gracilior spec. nov. (India: Arunachal Pradesh); O. (D.) septemcuspis spec. nov. (Laos); O. (D.) sexcarinatus spec. nov. (Indonesia: Sumatra); O. (D.) spoliatus spec. nov. (Laos); O. (D.) tortus spec. nov. (India: Meghalaya); O. (D.) triapicalis spec. nov. (China: Sichuan); O. (D.) ulcerosus spec. nov. (Malaysia: Sabah); O. (D.) vates spec. nov. (Laos); Drusilla bifida spec. nov. (Thailand); Rabdotodrusilla pectinata spec. nov. (Thailand); Amaurodera meorum PACE, 1992; A. thailandensis PACE, 1986; A. arunica spec. nov. (Nepal); A. dentata spec. nov. (Thailand); A. disparicollis spec. nov. (Indonesia: Sumatra); A. fasciata spec. nov. (Thailand); A. gilvios spec. nov. (Thailand); A. parvoculata spec. nov. (Thailand); A. reticulata spec. nov. (Thailand); A. spinans spec. nov. (Indonesia: Sumatra); A. varicollis spec. nov. (Indonesia: Sumatra); Tetrabothrus borneensis Cameron, 1943; T. indicus Cameron, 1939; T. inflexus Assing, 2015; T. neoguineensis Pace, 2012; T. pubescens Bernhauer, 1915; T. breviatus spec. nov. (China: Sichuan); T. collucatus spec. nov. (Laos); T. nilgiricus spec. nov. (India: Tamil Nadu); T. punctiventris spec. nov. (Malaysia: Sabah); T. sulawesicus spec. nov. (Indonesia: Sulawesi Utara); Zyras (Zyras) gibbus PACE, 2010; Z. (Z.) illecebrosus LAst, 1982; Z. (Z.) quasar DvoŘAK, 1996; Z. (Z.) porrectus spec. nov. (China: Sichuan); Z. (Z.) wunderlei spec. nov. (Indonesia: Bali); Pedinopleurus notabilis (Silvestri, 1946); Aenictoides gen. nov. derivata spec. nov. (Thailand). The intrageneric affiliations of Orphnebius Мотsснulsky, 1858 and the subgeneric concept currently in use are discussed, and new species (sub-)groups are proposed. The following synonymies are proposed: Deroleptus Bernhauer, $1915=$ Megalocephalobius BERnHAuer, 1929, syn. nov.; Orphnebius breviceps CAMERon, 1946 = O. vorax PACE, 2000, syn. nov.; Orphnebius niger (CAMERON, $1939)=$ O. turensis PACE, 2012, syn. nov.; Drusilla canaliculata (FABRICIUs, 1787) = Myrmedonia polyporina GISTEL, 1857, syn. nov.; Drusilla erichsoni (Peyron, 1857) = Myrmedonia aptera Peyron, 1858, syn. nov.; Drusilla zyra- 
soides Dvořak, 1988 = D. truncatella PACE, 2004, syn. nov.; Amaurodera kraepelini FAuvel, $1905=$ A. rougemonti PACE, 1987, syn. nov., = A. smetanai PACE, 1992, syn. nov., = A. yaoana PACE, 1992, syn. nov.; Tetrabothrus bicolor Cameron, 1939 = T. chinensis PAce, 2012, syn. nov.; Tetrabothrus puetzi Assing, $2009=$ T. taiwanensis Pace, 2010, syn. nov.; Tetrabothrus clavatus Bernhauer, $1915=$ T. quadricollis CAMEron, 1950, syn. nov., = T. japonicus NAKANe, 1991, syn. nov., = T. vietnamiculus PACE, 2013, syn. nov., = T. rubricollis Assing, 2015, syn. nov.; Zyras fratrumkadooriorum PACE, $1998=$ Z. chumphonensis PACE, 2004, syn. nov.; Pedinopleurus notabilis (SILvestrI, 1946) = P. setosicauda Dvořák, 1996, syn. nov. Lectotypes are designated for Deroleptus niger Cameron, 1939, Orphnebius falagrioides Bernhauer, 1929, Myrmedonia aptera Peyron, 1858, and Tetrabothrus indicus Cameron, 1939. Orphnebius krypticola PACE, 2007 is designated as the correct original spelling. Updated catalogues of Amaurodera FAUvel, 1905 and Tetrabothrus Bernhauer, 1915, as well as keys to the Orphnebius species of Laos and to the Amaurodera species of Thailand are provided. Additional records of 41 named and several unnamed species are reported, among them numerous new country and province records. The distributions of Amaurodera kraepelini and Tetrabothrus clavatus are mapped.

\section{Key words}

Coleoptera, Staphylinidae, Aleocharinae, Lomechusini, Palaearctic region, Oriental region, taxonomy, new genus, new species, new synonymies, lectotype designations, keys to species, catalogues, additional records, distribution maps.

\section{Zusammenfassung}

Typen und weiteres Material von zwölf Gattungen, davon eine neu, der Tribus Lomechusini aus der Paläarktis und der Orientalis werden revidiert. Insgesamt 70 Arten, davon 51 neu, werden beschrieben bzw. redeskribiert und/ oder abgebildet: Orphnebius bakeri Bernhauer, 1929; O. breviceps Cameron, 1946; O. opticus Cameron, 1946; O. bicuspis spec. nov. (Laos; Indien: Arunachal Pradesh); O. biformis spec. nov. (Indonesien: Sumatra); O. cernens spec. nov. (Laos); O. dilatatus spec. nov. (Laos); O. effeminatus spec. nov. (Malaysia); O. extensus spec. nov. (Laos); O. fodens spec. nov. (Malaysia: Sabah); O. fuscapicalis spec. nov. (Laos); O. fusicollis spec. nov. (Laos); O. grandicollis spec. nov. (Laos); O. integer spec. nov. (Laos); O. latitibialis spec. nov. (Laos); O. lunatus spec. nov. (Laos); O. nigrapicalis spec. nov. (Laos); O. reductus spec. nov. (Laos); O. retunsus spec. nov. (Laos); O. serratus spec. nov. (Laos); O. spinans spec. nov. (Indien: Arunachal Pradesh); Orphnebius (Deroleptus) falagrioides Bernhauer, 1929; O. (D.) laticeps CAmeron, 1925; O. (D.) multimpressus Assing, 2015; O. (D.) niger (CAmeron, 1939); O. (D.) siamensis Cameron, 1939; O. (D.) baccillatus spec. nov. (Laos); O. (D.) biimpressus spec. nov. (Indonesien: Sumatra); O. (D.) carinatus spec. nov. (Laos); O. (D.) cultellatus spec. nov. (Thailand, Laos); O. (D.) discrepans spec. nov. (China: Yunnan); O. (D.) dispar spec. nov. (Indien: Arunachal Pradesh); O. (D.) gracilior spec. nov. (Indien: Arunachal Pradesh); O. (D.) septemcuspis spec. nov. (Laos); O. (D.) sexcarinatus spec. nov. (Indonesien: Sumatra); O. (D.) spoliatus spec. nov. (Laos); O. (D.) tortus spec. nov. (Indien: Meghalaya); O. (D.) triapicalis spec. nov. (China: Sichuan); O. (D.) ulcerosus spec. nov. (Malaysia: Sabah); O. (D.) vates spec. nov. (Laos); Drusilla bifida spec. nov. (Thailand); Rabdotodrusilla pectinata spec. nov. (Thailand); Amaurodera meorum PACE, 1992; A. thailandensis PACE, 1986; A. arunica spec.nov. (Nepal); A. dentata spec. nov. (Thailand); A. disparicollis spec. nov. (Indonesien: Sumatra); A. fasciata spec. nov. (Thailand); A. gilvios spec. nov. (Thailand); A. parvoculata spec. nov. (Thailand); A. reticulata spec. nov. (Thailand); A. spinans spec. nov. (Indonesien: Sumatra); A. varicollis spec. nov. (Indonesien: Sumatra); Tetrabothrus borneensis CAmeron, 1943; T. indicus Cameron, 1939; T. inflexus Assing, 2015; T. neoguineensis PACE, 2012; T. pubescens Bernhauer, 1915; T. breviatus spec. nov. (China: Sichuan); T. collucatus spec. nov. (Laos); T. nilgiricus spec. nov. (Indien: Tamil Nadu); T. punctiventris spec. nov. (Malaysia: Sabah); T. sulawesicus spec. nov. (Indonesien: Sulawesi Utara); Zyras (Zyras) gibbus PACE, 2010; Z. (Z.) illecebrosus LAst, 1982; Z. (Z.) quasar DvoŘAK, 1996; Z. (Z.) porrectus spec. nov. (China: Sichuan); Z. (Z.) wunderlei spec. nov. (Indonesien: Bali); Pedinopleurus notabilis (Silvestri, 1946); Aenictoides gen. nov. derivata spec. nov. (Thailand). Die phylogenetischen Beziehungen innerhalb der Gattung Orphnebius Мотschulsky, 1858 sowie das derzeit gebräuchliche Untergattungssystem werden diskutiert; mehrere neue Artengruppen werden charakterisiert. Folgende Namen werden synonymisiert: Deroleptus Bernhauer, 1915 = Megalocephalobius Bernhauer, 1929, syn. nov.; Orphnebius breviceps CAMERon, 1946 = O. vorax PACE, 2000, syn. nov.; Orphnebius niger (CAMERON, $1939)=$ O. turensis PACE, 2012, syn. nov.; Drusilla canaliculata (FABRICIUs, 1787) = Myrmedonia polyporina GISTEL, 1857, syn. nov.; Drusilla erichsoni (Peyron, 1857) = Myrmedonia aptera Peyron, 1858, syn. nov.; Drusilla zyrasoides DvořAK, 1988 = D. truncatella PACE, 2004, syn. nov.; Amaurodera kraepelini FAuvel, $1905=$ A. rougemonti PACE, 1987, syn. nov., = A. smetanai PACE, 1992, syn. nov., = A. yaoana PACE, 1992, syn. nov.; Tetrabothrus bicolor Cameron, 1939 = T. chinensis PaCe, 2012, syn. nov.; Tetrabothrus puetzi Assing, $2009=$ T. taiwanensis Pace, 2010, syn. nov.; Tetrabothrus clavatus Bernhauer, $1915=$ T. quadricollis CAMEron, 1950, syn. nov., = T. japonicus 
NAKAne, 1991, syn. nov., = T. vietnamiculus PACE, 2013, syn. nov., = T. rubricollis Assing, 2015, syn. nov.; Zyras fratrumkadooriorum PACE, 1998 = Z. chumphonensis PACE, 2004, syn. nov.; Pedinopleurus notabilis (Silvestri, 1946) = P. setosicauda Dvořák, 1996, syn. nov. Für Deroleptus niger CAMERon, 1939, Orphnebius falagrioides Bernhauer, 1929, Myrmedonia aptera Peyron, 1858 und Tetrabothrus indicus Cameron, 1939 werden Lectotypen designiert. Orphnebius krypticola PACE, 2007 wird als korrekte originale Schreibweise festgelegt. Für Amaurodera FAuvel, 1905 und Tetrabothrus Bernhauer, 1915 werden aktualisierte Kataloge, für die Orphnebius-Arten von Laos und die Amaurodera-Arten Thailands werden Bestimmungstabellen erstellt. Weitere Nachweise von 41 beschriebenen und einigen unbenannten Arten werden gemeldet, darunter zahlreiche Erstnachweise. Die derzeit bekannte Verbreitung von zwei Arten wird anhand von Karten illustriert.

\section{Introduction}

In a recent catalogue HLAváč et al. (2011) list 2205 species and subspecies of Lomechusini worldwide. Numerous additional species have been described in the meantime. The speciose polyphyletic tribe is represented in the Palaearctic region by approximately 400 species (Assing 2015, 2016, Schülke \& Smetana 2015). The fauna of the Oriental region is even more diverse (HLAvÁč et al. 2011).

The vast majority of lomechusine species has been described in articles containing descriptions of miscellaneous Staphylinidae or Aleocharinae. Taxonomic revisions have been conducted only for some genera and for certain regions in the Palaearctic, such as Pella Stephens, 1835 (Maruyama 2006), West Palaearctic and Middle Asian Drusilla LeACH, 1819 (Assing 2005b, c), Lomechusa Gravenhorst, 1806 (Hlaváč 2005), Lomechusoides Tottenham, 1939 (JÁszay \& Hlaváč 2013), Himalayan and Chinese Tetrabothrus Bernhauer, 1915 (Assing 2006d, 2015b, YAN \& Li 2015b), Himalayan and Chinese Amaurodera FAuvel, 1905 (Assing 2003, 2005d, 2006a, YAN \& Li 2015a), Palaearctic Orphnebius Motschulsky, 1858 (Assing 2006b, c, 2015e), and Chinese Zyras StePhens, 1835 (sensu strictu) species (Assing 2016). Aside from studies on the Orphnebius fauna of Borneo (PACE 2007) and on the Lomechusini of Vietnam (Assing 2015d), modern revisions of speciose lomechusine genera in the Oriental region are practically absent.

The extent to which the lomechusine faunas of the East Palaearctic and Oriental regions have been studied differs significantly between regions. As many as approximately 140 species are known from China, Taiwan, and Hong Kong, 62 species have been reported from Thailand, 29 species have been recorded from Vietnam, but only three from Laos Assing (2015d, 2016).

The present paper is based on material of Lomechusini received from various public and private collections. Identification and interpretation of this material necessitated the study of types of various previously described species, yielded numerous new species, and also revealed several synonymies. Special focus is given to taxa and regions of/from which abundant material was available, such as Amaurodera from Thailand and Orphnebius from Laos.

\section{Material and methods}

The material treated in this study is deposited in the following collections:

BMNH The Natural History Museum, London (R. G. Booth)

CAS Chinese Academy of Sciences, Beijing

FMNH Field Museum of Natural History, Chicago (C. Maier)

MCSNV Museo Civico di Storia Naturale, Verona (L. Latella, via A. Zanetti)

MHNG Muséum d'Histoire Naturelle, Genève (G. Cuccodoro)

NHMB Naturhistorisches Museum Basel (M. Geiser, I. Zürcher)

NME Naturkundemuseum Erfurt (M. Hartmann)

NMP National Museum of Natural History, Praha (J. Hájek)

SMNS Staatliches Museum für Naturkunde, Stuttgart (W. Schawaller)

ZFMK Zoologisches Forschungsmuseum Alexander Koenig, Bonn (D. Ahrens)

cAss author's private collection

cFel private collection Benedikt Feldmann, Münster

cSme private collection Aleš Smetana, Ottawa

cSch private collection Michael Schülke, Berlin

cWun private collection Paul Wunderle, Mönchengladbach

The morphological studies were conducted using a Stemi SV 11 microscope (Zeiss Germany) and a Jenalab compound microscope (Carl Zeiss Jena). The images of the external characters were created using a photographing device constructed by Arved Lompe (Nienburg) and CombineZ software. A digital camera (Nikon Coolpix 995) was used for the remaining photographs. The maps were created using MapCreator 2.0 (primap) software.

Body length was measured from the anterior margin of the labrum to the apex of the abdomen, the length of the forebody from the anterior margin of the labrum to the posterior margin of the elytra, head length from the anterior margin of the clypeus (without ante-clypeus) to the posterior constriction of the head, the length of 
the elytra along the suture from the apex of the scutellum to the posterior margin of the elytra, the length of the median lobe of the aedeagus from the apex of the ventral process to the base of the aedeagal capsule, and the length of the spermatheca is given as the maximal extension (measured from the apex of the distal portion of the capsule). The "parameral" side of the median lobe of the aedeagus (i.e., the side where the sperm duct enters) is referred to as the ventral, the opposite side as the dorsal aspect.

\section{Results}

\subsection{Genus Orphnebius MotschulskY, 1858}

\subsubsection{Diversity, subgenera, species groups, and identification}

According to Huaváč et al. (2011), the lomechusine genus Orphnebius included 148 valid species in eight subgenera. Additional 13 species were listed in Deroleptus Bernhauer, 1915 and three in Strabocephalium Bernhauer, 1911. The status of Deroleptus and Strabocephalium has been treated controversially. HLAváč et al. (2011) regard them as distinct genera, whereas PACE (2007) and Assing (2015a, present paper) treat them as subgenera of Orphnebius. Since the publication of the catalogue by HLAváč et al. (2011), 20 additional species of Orphnebius and Strabocephalium have been described from the Oriental and Palaearctic regions, and one species was moved from Orphnebius to Zyras (Assing 2011, 2015a, b; PACE 2012b, c, 2013, 2014, 2015). Thus, Orphnebius of the present interpretation previously included 183 species. The observations that a revision of only a few hundred specimens dealt with in the present paper yielded as many as 32 new species and that a considerable number, probably the majority of named species, is known only from their respective holotypes suggest that the true diversity of Orphnebius at least in the Oriental region is probably enormous and that numerous additional species remain to be discovered.

The suitability of external and sexual characters for a reliable diagnosis at the species level strongly depends on the species group in question. While in the O. hauseri group the external and particularly the female sexual characters are generally of little or no taxonomic signficance, they (especially the spermatheca) usually offer the best characters for a diagnosis of Deroleptus species. The male primary sexual characters, particularly the shape of the paramere, are often the only reliable character for an identification of the representatives of the O. hauseri group, whereas they are of little use in Deroleptus. In many species, the pronotum, the elytra, the abdominal sternites and paratergites III-V, tergites VI-VII, and/ or tergite and sternite VIII may be conspicuously modified. These modifications, however, are not sexually dimorphic, as was believed by some previous authors (e.g., Cameron 1939). Instead, intraspecific variation of such characters, particularly of the modifications of sternites and paratergites III-V in some Deroleptus species, is strongly related to body size rather than sex. In some species (see the O. reductus subgroup below), the antennae and eye size may be subject to a pronounced sexual dimorphism.

As has repeatedly been emphasized earlier (Assing 2006b, c, 2015), the current subgeneric concept is highly artificial, and at least some of the taxa listed as subgenera in HLAváč et al. (2011) may eventually have to be synonymized. Orphnebius ventricosus MоTschulsky, 1858 , the type species of the genus, was described from the Neotropical region, suggesting that none of the species distributed in the East Palaearctic and Oriental regions may belong to the nominal subgenus. Five of the remaining subgenera have a type species distributed in the Oriental region. One of them, Megalocephalobius Bernhauer, 1929, is synonymized with Deroleptus below. An examination of the type species of Mesocephalobius Bernhauer, 1929, Orphnebius bakeri Bernhauer, 1929, revealed that this species belongs to the $O$. hauseri group. Thus, Mesocephalobius would be eligible as a subgeneric name for the O. hauseri group. However, before designating a senior subgeneric name for this group, the type species of Aulacothoracobius Bernhauer, 1929 (type species: O. wasmannianus BERNHAUER, 1929 from the Philippines), Microcephalobius Bernhauer, 1929 (type species: O. miricornis Bernhauer, 1929 from the Philippines), and Thoracobius Bernhauer, 1929 (type species: O. brevicollis BERNHAUER, 1929 from Singapore) should be revised. In the meantime, all the revised Orphnebius species that do not belong to either Deroleptus or Strabocephalium are assigned to the O. hauseri group (see Assing 2006b).

In the past, only few species - those of large body size, slender habitus, with conspicuously long appendages, and with distinctly modified anterior abdominal sternites have been attributed to Deroleptus because the (sub-) generic assignment mainly relied on external characters. However, the present study has shown that, based on the sexual characters, as well as on the shapes and chaetotaxy of the posterior abdominal tergites, Deroleptus also includes numerous smaller and less conspicuous species, suggesting that eventually more than half of the unrevised Oriental species currently listed in one of the other subgenera or as incertae sedis may have to be moved to Deroleptus. It is also for this reason that, until more is known about the intrageneric affiliations of Orphnebius, a conservative approach is favoured and Deroleptus is regarded as a subgenus, thus avoiding numerous new combinations.

The monophyly of the O. hauseri group is constituted principally by the derived shape of the paramere (condylite nearly completely separated from paramerite) and the 
derived morphology and chaetotaxy of the abdominal segments IX and X: tergites IX and X with conspicuously dense and long pubescence; tergite IX strongly modified, ventrally connected by a thin, sclerotized, clasp-shaped structure, very long in females (only exceptionally so in males) (e.g., Assing 2006b: figures 19, 44, 59, 73, 90), generally shorter and ventrally with long and thin sclerotized projections in males (e.g., Assing 2006b: figures $81,113,119,141,152)$. In addition, the species of the $O$. hauseri subgroup mostly have a distinctly bicoloured body (forebody dark-brown to black; abdomen reddish, sometimes with tergite VIII infuscate), often more or less distinctly asymmetric antennae, usually sharply edged paratergites, a flat tergite VIII with a convex (rarely serrate, but never concave) posterior margin and with long lateral projections anteriorly (without sexual dimorphism), and a posteriorly broadly convex posterior margin of sternite VIII (without sexual dimorphism). The aedeagus is characterized by a more or less large median lobe with a bulbous capsule (exception: O. reductus subgroup) and parameres with a paramerite and a condylite of highly diverse shapes. The spermatheca differs between subgroups, but is remarkably uniform within subgroups and unsuitable for a reliable identification at the species level. The diversity of antennal morphology, eye size, and of the shape of the head and pronotum among the species of the O. hauseri group is enormous. The most reliable character for an identification at the species level, however, is the shape of the paramere (Assing 2006b, c, 2015a).

Within the O.hauseri group, several subgroups have been identified. The O. hauseri subgroup (also referred to as O.hauseri group sensu strictu in previous papers) is significantly more speciose than other subgroups and characterized particularly by a remarkably uniform shape of the spermatheca (e.g., Assing 2006b: figures 45, 63, 74, $91,104,125)$, a large and moderately uniform median lobe of the aedeagus with a bulbous capsule, and parameres with a broad paramerite. A reliable identification of the species of the O. hauseri subgroup is often possible only based on the shape of the paramere.

The O. bakeri subgroup currently includes only one species (O. bakeri) and is characterized by a conspicuously large median lobe of the aedeagus with a very small ventral process (Fig. 223), relatively small parameres with a long and very slender condylite (Fig. 224), and by a strongly sclerotized spermatheca with a long proximal portion (Fig. 225).

The O. dilatatus subgroup is consituted primarily by a conspicuously transversely wedge-shaped head, strongly convex and prominent eyes situated in posterior portion of the head (Figs 28, 30-31), a conspicuously elongate antennomere I (approximately as long as combined length of II-IV; Figs 5-6, 15), and an often more or less distinctly modified labrum with a broad anterior margin. Body size and other external characters are subject to considerable intraspecific variation. In addition, the species of this subgroup are characterized as follows: pronotum small in relation to head, strongly transverse, and with three stout, long, and erect setae in anterior portion of lateral margin (Figs 28, 30-31); pronotal disc with a median pair of punctures, with or without few scattered additional punctures; paramere with both paramerite and condylite long and slender (Figs 228, 231, 235). The following species are included in the O. dilatatus subgroup: O. dilatatus spec. nov., O. extensus spec. nov., O. breviceps CAMERon, 1940 (Thailand; body length $2.5-2.8 \mathrm{~mm}$ ), O. semivorax PACE, 2000 (Thailand; male unknown; $2.3 \mathrm{~mm}$ ), and O. incertus PACE, 2004 (Thailand; male unknown; $3.5 \mathrm{~mm})$.

The species of the O. serratus subgroup share the following diagnostic characters, most of them derived: head of transversely quadrangular shape (Figs 32-33, 34); antennomeres $\mathrm{V}-\mathrm{X}$ distinctly transverse and asymmetric (Figs 7-8); pro- or mesotibiae sometimes modified (Figs 38-39); clypeus largely membranous; tergite VIII in most species with serrate posterior margin (Figs 240, 249-250, 252), laterally with a cluster of thin setae on either side; median lobe of aedeagus usually strongly sclerotized, dark; ventral process short, in most species bifid (Figs 237, 254), more rarely undivided (Fig. 245); condylite of paramere slender (Figs 239, 247, 256); spermatecal capsule with proximal portion often modified (Figs 241-243, 257). Included species are O. serratus spec. nov., O. integer spec. nov., O. latitibalis spec. nov., O. bicuspis spec.nov., O. rougemonti PACE, 1986 (Burma), O. chiangmaiensis PACE, 2000 (Thailand; male unknown), and O. incisus PACE, 2000 (Thailand; Yunnan?).

The species of the O. conicornis subgroup are characterized primarily by the synapomorphically derived, albeit uniform shape of the spermatheca (Fig. 268) and additionally as follows: head distinctly angled posteriorly in lateral view (Fig. 47); antennae nearly symmetric and with antennomeres $\mathrm{V}-\mathrm{X}$ of more or less distinctly conical shape (Fig. 11); pronotum large and strongly transverse (Fig. 46); ventral process of aedeagus curved or bent in lateral view (Fig. 263). Species assigned to this group: O. conicornis Assing, 2007 (China: Daba Shan), O. incrassatus Assing, 2015 (China: Yunnan: Gaoligong Shan), and O. fusicollis spec. nov.

The O. reductus subgroup is constituted primarily by a pronounced sexual dimorphism of the antennae (Figs 18-20), weakly convex or truncate posterior margins of the abdominal tergites (Figs 272, 275) and sternites VIII, a relatively massive ventral process of the aedeagus of highly species-specific shape (Figs 269-270, 277-278), a curved and slender paramerite (Figs 272, 274), and a very similar shape of the spermatheca (Figs 273, 276). Included species are O. reductus spec. nov., O. biformis spec. nov., and O. krypticola PACE, 2007.

The O. retunsus subgroup (including O. retunsus spec. nov. and O.fodens spec. nov.) is characterized by the coloration (antennae, pronotum, and elytra of pale coloration) (Figs 12, 45, 48), small body size, 
enormous eyes (Figs 45, 48), strongly transverse antennomeres IV-X (Fig. 12), the sculpture of tergite VII (predominantly composed of coarse oblong striae, the slender and apically acute ventral process of the aedeagus (Figs 279-280, 283-284), the absence of strongly sclerotized structures in the internal sac of the aedeagus, and the shape of the parameres (paramerite and condylite basally broad, gradually tapering apicad; Figs 281, 285).

The monotypical O. effeminatus subgroup currently includes only O.effeminatus spec.nov. and is distinguished from all the revised species of the O.hauseri group particularly by conspicuously bicoloured antennae (the pale-reddish antennomeres I-V strongly contrasting with the black antennomeres VI-XI; Fig. 21), a practically impunctate disc of the pronotum (Fig. 41), much longer male hemi-tergites IX (Fig. 292), the shape and internal structures of the median lobe of the aedeagus (Figs 287-288), and the shape of the parameres (Fig. 289). In addition, it is characterized by large eyes, a nearly impunctate dorsal surface of the head, a large pronotum (in relation to the head), strongly developed and sharply edged sternites and paratergites III-VI, and conspicuously dense fine gland openings on tergite and sternite VIII (Fig. 291). The similar shape and internal structures of the median lobe of the aedeagus suggest that O. biapicalis PACE, 2007 from Borneo, a species described from a single male without head, may belong to this subgroup, too.

The species assigned to Deroleptus are distinguished from the representatives of the $O$. hauseri group primarily by the absence of pronounced modifications of tergites IX and $\mathrm{X}$, as well as by the simple morphology of the aedeagus (median lobe relatively small, dorso-ventrally somewhat flattened, weakly sclerotized, with simple blade-shaped ventral process, and without sclerotized internal structures; parameres of simple and rather uniform shape). In addition they are distinguished by an often more or less slender body with usually more or less elongate legs and antennae, symmetric and usually slender antennae, a usually not distinctly bicoloured body, often rather large size, often more or less distinctly modified sternites and paratergites III-V, the presence of tubercles on tergite VI, a tergite VIII with more or less pronounced tooth-like posterior projections or with a serrate and a usually more or less distinctly concave posterior margin, and with more or less extensive clusters of gland openings anteriorly, and a sternite VIII with lateral clusters of stout setae. The revised species of Deroleptus can be assigned to three species groups.

The $O$. draco group includes two species, O. draco Assing, 2010 and O. multimpressus Assing, 2015, which share a conspicuously derived shape of the abdominal sternite VIII (with three pronounced posterior processes). In addition, they are characterized by large body size, dark coloration, a tergite VIII with extensive non-setiferous punctation and with a serrate posterior margin, moderately modified sternites III and IV, and a strongly modified sternite V (with pronounced postero-lateral processes).

The O. niger group contains O. niger (CAMERoN, 1939), O. ceylonicus (CAMERon, 1939), O. siamensis CAMERon, 1946, O. nanlingensis PACE, 2004, O. loeiensis PACE, 2004, O. tridentatus Assing, 2015, O. tricuspis Assing, 2009, O. triapicalis spec. nov., O. spoliatus spec. nov., O. cultellatus spec. nov., O. gracilior spec. nov., O. sexcarinatus spec. nov., and $O$. discrepans spec. nov., all of which share a synapomorphic shape of the abdominal tergite VIII (posteriorly with three more or less pronounced toothlike processes; Figs 302, 310-311, 314). They are additionally characterized by slender legs and antennae (Figs 52, 54-59), a slender pronotum (weakly transverse; Figs 50, 70-73), eyes of moderate size; the abdominal sternites III-V may be modified or unmodified.

The remaining revised species belong to the O. siwalikensis group, which, aside from $O$. siwalikensis CAMERoN, 1939 and the species treated in the species sections below, includes O.tuberipennis Assing, 2008, O.drugmandi PACE, 2004, O.grootaerti PACE, 2004, and probably numerous additional unrevised species. The representatives of this group are characterized by often large eyes, a mostly less slender body, a tergite VIII with a serrate posterior margin (Figs 345, 348, 351), and a transverse sternite VIII with a cluster of stout setae on either side (Figs 346, 349, 352).

Unlike the species of the O.hauseri group, the representatives of Deroleptus are best distinguished based on external characters and above all by the shape of the spermatheca, which is often of intricate shape and highly species-specific. In some species, the median lobe and the parameres of the aedeagus, too, are of distinctive shapes. 


\subsubsection{Key to the named Orphnebius species of Laos}

Since as many as 20 Orphnebius species are described from Laos, a country from where the genus had not been reported before, a key to species is provided.

1. Abdominal tergites IX and X strongly modified, with conspicuously dense and long pubescence; hemi-tergites IX strongly elongated in female, ventrally connected by thin sclerotized clasp-shaped structure, antero-ventrally with thin sclerotized projections in male. Posterior margin of tergite VIII mostly smooth, rarely coarsely serrate. Median lobe of aedeagus large in relation to body and with bulbous capsule (exception: O. reductus); paramere of more or less distinctly derived shape. Body in nearly all species distinctly bicoloured, with the forebody dark-brown to black (in one species only head blackish-brown and the remainder of the body reddish) and the abdomen reddish (occasionally with segment VIII infuscate). Antennae often more or less distinctly asymmetric. Sternites and paratergites III-V without distinct postero-lateral processes. Orphnebius hauseri group.

- Abdominal tergites IX and X not distinctly modified, short and without conspicuously dense pubescence, not distinctly elongated in female. Posterior margin of tergite VIII finely serrate or with two to three more or less pronounced tooth-like projections (in one species with additional short teeth). Median lobe of aedeagus small in relation to body, usually more or less dorso-ventrally depressed, with blade-shaped ventral process, and without sclerotized internal structures; paramere not distinctly modified. Body in most species of different coloration. Antennae symmetric. Sternites and paratergites III-V often with conspicuous postero-lateral processes. Deroleptus.

2. Head blackish-brown, distinctly contrasting with the reddish pronotum, elytra, and abdomen (Fig. 45). Antennae uniformly reddish (Fig. 12). Eyes large, occupying all of lateral margins of head (Fig. 45). Median lobe of aedeagus with very acute ventral process (Figs 279-280); paramere as in Fig. 281. Orphnebius retunsus subgroup.

retunsus spec. nov.

- Pronotum (nearly) as dark as head. Antennae with at least antennomeres VI-X dark-brown to blackish. Eyes usually smaller. Aedeagus of different morphology.

3. Head conspicuously transversely wedge-shaped; eyes strongly convex or somewhat wedge-shaped, situated at posterior margin of head (Figs 28, 31). Antennomere I strongly elongate, longer than the combined length of antennomeres II-IV (Figs 6, 8). Orphnebius dilatatus subgroup.

- Head not transversely wedge-shaped; eyes less strongly convex, not wedge-shaped. Antennomere I much shorter than the combined length of antennomeres II-IV.

4. Eyes somewhat wedge-shaped (Fig. 31). Labrum with median tubercle and truncate anterior margin. Antennomeres V-X more transverse and more distinctly asymmetric (Fig. 6). Tibiae reddish. Median lobe of aedeagus and paramere as in Figs 233-235. extensus spec. nov.

- Eyes strongly convex, but not wedge-shaped (Fig. 28). Labrum without tubercle, anterior margin convexly produced in the middle. Antennomeres V-X weakly transverse and not distinctly asymmetric (Fig. 15). Tibiae brown. Median lobe of aedeagus and paramere as in Figs 229-231. Spermatheca as in Fig. 232. dilatatus spec. nov.

5. Head of transversely quadrangular shape. Antennomeres V-X distinctly transverse and distinctly asymmetric. Clypeus largely membranous. Tergite VIII laterally with a cluster of thin setae on either side, posterior margin smooth or distinctly serrate. Pro- or mesotibiae sometimes modified (distinctly dilated). Median lobe of aedeagus distinctly sclerotized, dark, with short and mostly bifid ventral process. Paramere with slender condylite. Spermatheca with modified proximal portion. Orphnebius serratus subgroup.

- Head of more or less orbicular shape. Clypeus with larger sclerotized portion. Tergite VIII without lateral clusters of thin setae, posterior margin never serrate. Pro- and mesotibiae unmodified. Median lobe of aedeagus less strongly sclerotized, ventral process never bifid. Spermatheca of different shape.

6. Posterior margin of tergite VIII smooth (Fig. 260). Median lobe of aedeagus and paramere as in Figs 253-256, 258-259. Spermatheca as in Fig. 257. bicuspis spec. nov.

- Posterior margin of tergite VIII serrate (Figs 240, 249, 252).

7. Protibia dilated (Fig. 39); mesotibia unmodified. Median lobe of aedeagus with bifid ventral process (Figs 236-238). Paramere as in Fig. 239. Spermatheca as in Figs 241-243. serratus spec. nov.

- Protibiae unmodified. Mesotibia smoothly dilated or strongly dilated. 
8. Mesotibia smoothly dilated. Ventral process of aedagus not bifid (Figs 244-246). Paramere as in Fig. 247.

integer spec. nov.

- Mesotibia conspicuously modified, strongly dilated and posterior surface with pronounced longitudinal excavation (Fig. 38). Spermatheca with very long and thin proximal portion (Fig. 251). latitibialis spec. nov.

9. Posterior margins of tergite and sternite VIII truncate in the middle (Fig. 272). Eyes very large, occupying nearly all of lateral margins of head (Fig. 49). Antenna with pronounced sexual dimorphism, longer in male $(1.3-1.4 \mathrm{~mm})$ than in female $(1.1-1.2 \mathrm{~mm})$, male antenna with longer antennomere XI and with less transverse antennomeres VI-X. Median lobe of aedeagus with relatively small capsule and with ventral process of distinctive shape (Figs 269-270). Condylite of paramere strongly reduced (Fig. 274). Spermatheca as in Fig. 273. Orphnebius reductus subgroup. reductus spec. nov.

- Posterior margins of tergite and sternite VIII convex. Eyes in most species smaller. Antenna without pronounced sexual dimorphism. Median lobe of aedeagus with large capsule and a ventral process of completely different shape. Spermatheca of different shape.

10. Antennomeres V-X conspicuously coniform, brown to dark-brown (Fig. 11). Pronotum strongly transverse, approximately 1.45 times as broad as long, and 1.3 times as broad as head (Fig. 46). Median lobe of aedeagus, paramere, and spermatheca as in Figs 263-265, 268. Orphnebius conicornis subgroup. fusicollis spec. nov.

- Antennomeres V-X not coniform and more or less distinctly flattened, dark-brown to black. Pronotum less transverse and smaller in relation to head (exception: O. grandicollis). Male and female primary sexual characters different. O. hauseri subgroup.

11. Abdominal segment VIII infuscate (Fig. 35). Antennomere XI conspicuously elongate (Fig. 16). Sculpture of tergite VII composed primarily of dense longitudinal striae. 12

- Abdomen uniformly reddish. Antennomere XI less strongly elongate. Sculpture of tergite VII composed primarily of non-setiferous punctation (exception: O. grandicollis).

12. Antennomeres I-III reddish. Tibiae dark-reddish. Ventral process of aedeagus longer, more slender in ventral view (Figs 216-217). Paramere as in Figs 218-219. fuscapicalis spec. nov.

- Antennomeres I-III blackish-brown. Tibiae dark-brown. Ventral process of aedeagus shorter, broader in ventral view (Figs 220-221). Paramere as in Fig. 222. nigrapicalis spec. nov

13. Pronotum large in relation to head, 1.4 times as broad as long and approximately 1.25 times as broad as head (Fig. 22). Antenna $1.4 \mathrm{~mm}$ long (Fig. 17). Sculpture of tergite VII predominantly composed of dense longitudinal striae. Median lobe of aedeagus and paramere as in Figs 212-215. grandicollis spec. nov.

- Pronotum distinctly smaller in relation to head, 1.3 times as broad as long and 1.2 times as broad as head at most. Antenna much shorter, $<1.2 \mathrm{~mm}$ long. Sculpture of tergite VII predominantly composed of non-setiferous punctation. Male primary sexual characters different.

14. Eyes much larger, occupying all of lateral margins of head, approximately three times as long as distance from posterior margin of eye to posterior constriction of head (Fig. 24). Median lobe of aedeagus and paramere as in Figs 202-204. Spermatheca as in Fig. 206. cernens spec. nov.

- Eyes distinctly smaller, approximately as long as distance from posterior margin of eye to posterior constriction of head (Fig. 25). Median lobe of aedeagus and paramere as in Figs 208-210. lunatus spec. nov.

15. Sternites III-V without, or with inconspicuous, postero-lateral processes 16

- At least sternite III, IV, or V with long postero-lateral processes.

16. Head and pronotum weakly transverse; elytra without tubercle near suture (Fig. 85). Sternites III-V unmodified (Fig. 91). Antenna very slender, 1.9-2.2 mm long; antennomeres V-VII oblong, IX-X weakly transverse (Fig. 58). Metafemur distinctly bicoloured, with the basal half yellowish and the apical half blackish. Tergite VIII oblong and with two large tooth-like projections posteriorly (Fig. 320). Median lobe of aedeagus, paramere, and spermatheca as in Figs 317-318, 324. spoliatus spec. nov.

- Head and pronotum more transverse; elytra with a small tubercle near suture (Fig. 102). Sternite IV and paratergite IV with a short postero-lateral process on either side (Fig. 117). Antenna much shorter, $1.2 \mathrm{~mm}$ long, distinctly incrassate apically, and with distinctly transverse antennomeres V-X (Fig. 64). Metafemur blackishbrown. Tergite VIII transverse, posterior margin distinctly concave and finely serrate (Fig. 351). Spermatheca as in Fig. 353.

carinatus spec. nov. 
17. Head truncate or even weakly concave posteriorly; posterior angles marked (Figs 89-90). Eyes enormous, nearly reaching posterior margin of head and more than twice as long as distance from posterior margin of eye to posterior constriction of head in dorsal view (Fig. 89-90).

- Head convex posteriorly, lateral and posterior margin practically forming a semi-circle, posterior angles obsolete. Eyes much smaller, approximately as long as, or slightly longer than distance from posterior margin of eye to posterior constriction of head in dorsal view (Figs 86-87).

18. Sternite V with long lateral process; sternites III-IV weakly modified (Fig. 97). Antenna shorter and finer, $1.2 \mathrm{~mm}$ long (Fig. 61). Posterior margin of tergite VIII with a long lateral tooth and two shorter sublateral teeth on either side (Fig. 343). Small species, length of forebody $1.6 \mathrm{~mm}$. Median lobe of aedeagus and paramere as in Figs 340-342. vates spec. nov.

- Sternite V unmodified; paratergite IV and sternite IV each with a pronounced postero-lateral process on either side, these processes contiguous (Fig. 101). Antenna longer and more massive, approximately $1.8 \mathrm{~mm}$ long (Fig. 63). Posterior margin of tergite VIII concave and serrate (Fig. 348). Larger species, length of forebody $2.5 \mathrm{~mm}$. Spermatheca as in Fig. 350. baccillatus spec. nov.

19. Sternites III and IV each with a long postero-lateral process on either side (Figs 92-94). Elytral punctation very fine and sparse (Fig. 86). Antenna shorter, approximately $1.5 \mathrm{~mm}$ long; antennomeres VI-VII not flattened and VI-X not oblong (Fig. 59). Metafemur not distinctly bicoloured, dark-brown. Tergite VIII transverse, with a posterior excision, in postero-median portion with a tubercle (Fig. 328). Sternite VIII conspicuously pointed posteriorly (Figs 329-331). Median lobe of aedeagus of distinctive shape, ventral process knife-shaped (Figs 325-326). Spermatheca as in Fig. 333-334. cultellatus spec. nov.

- Only sternite III with a long postero-lateral process on either side (Fig. 95). Elytral punctation conspicuously coarsely granulose and rather dense (Fig. 87). Antenna much longer, approximately $2.0 \mathrm{~mm}$ long; antennomere I conspicuously club-shaped, strongly dilated apically; antennomeres III-VII distinctly flattened and VI-IX oblong (Fig. 60). Metafemur distinctly bicoloured, blackish with the basal third pale-yellowish. Tergite VIII oblong, posteriorly with a long median, two even longer lateral, and four smaller teeth (Fig. 338). Sternite VIII convex posteriorly (Fig. 339). Median lobe of aedeagus and paramere as in Figs 335-337. septemcuspis spec. nov.

\subsubsection{Orphnebius hauseri group}

\subsubsection{Orphnebius hauseri subgroup}

\section{Orphnebius jumlaicus Assing, 2006}

Material examined: India: 4 exs., Himachal Pradesh, Manali, 2000-2300 m, leg. Wittmer \& Brancucci (NHMB, cAss).

Comment: This species is distributed in the Himalayan region from Kashmir in the west to West Nepal in the east (Assing 2015a).

\section{Orphnebius depressicollis Assing, 2006}

Material examined: Nepal: 2 exs., Bagmati province, Sarmatang, 2500 m, 4.VI.1989, leg. Holzschuh (NMP, cAss); 1 ex., Bagmati province, Sindhupalchok, Gangjwal, 2500 m, 6.-7.VI.1989, leg. Brancucci (NHMB).

Comment: The above specimens represent the first record of this species since the original description, which is based on type material from several localities in Bagmati province (Assing 2006b).

\section{Orphnebius gibber Assing, 2006}

Material examined: China: 3 exs., Shaanxi, Qinling Shan, $33^{\circ} 52^{\prime} \mathrm{N}, 108^{\circ} 59,2000-2600 \mathrm{~m}$, sifted, 15.V.2011, leg. Grebennikov (cSme, cAss).

Comment: Orphnebius gibber was previously known from the type locality in northern Yunnan and one locality in Shaanxi (Assing 2006b). In the key in Assing (2015a), the distribution is erroneously given as Shaanxi and West Sichuan (rather than Shaanxi and Yunnan).

\section{Orphnebius schuelkei Assing, 2006}

Material examined: China: $1 \sigma^{\star}, 2$ 우, Sichuan, Emei Shan, $29^{\circ} 34^{\prime} \mathrm{N}, 103^{\circ} 21^{\prime} \mathrm{E}, 1800-2400 \mathrm{~m}$, sifted, 27.VI.-5.VII.2009, leg. Grebennikov; $10^{\star}, 1$ ㅇ, Sichuan, Emei Shan, $29^{\circ} 34^{\prime} \mathrm{N}, 103^{\circ} 21^{\prime} \mathrm{E}, 1830 \mathrm{~m}$, sifted, 26.V.2011, leg. Grebennikov (material in CAS, cSme, cAss). 


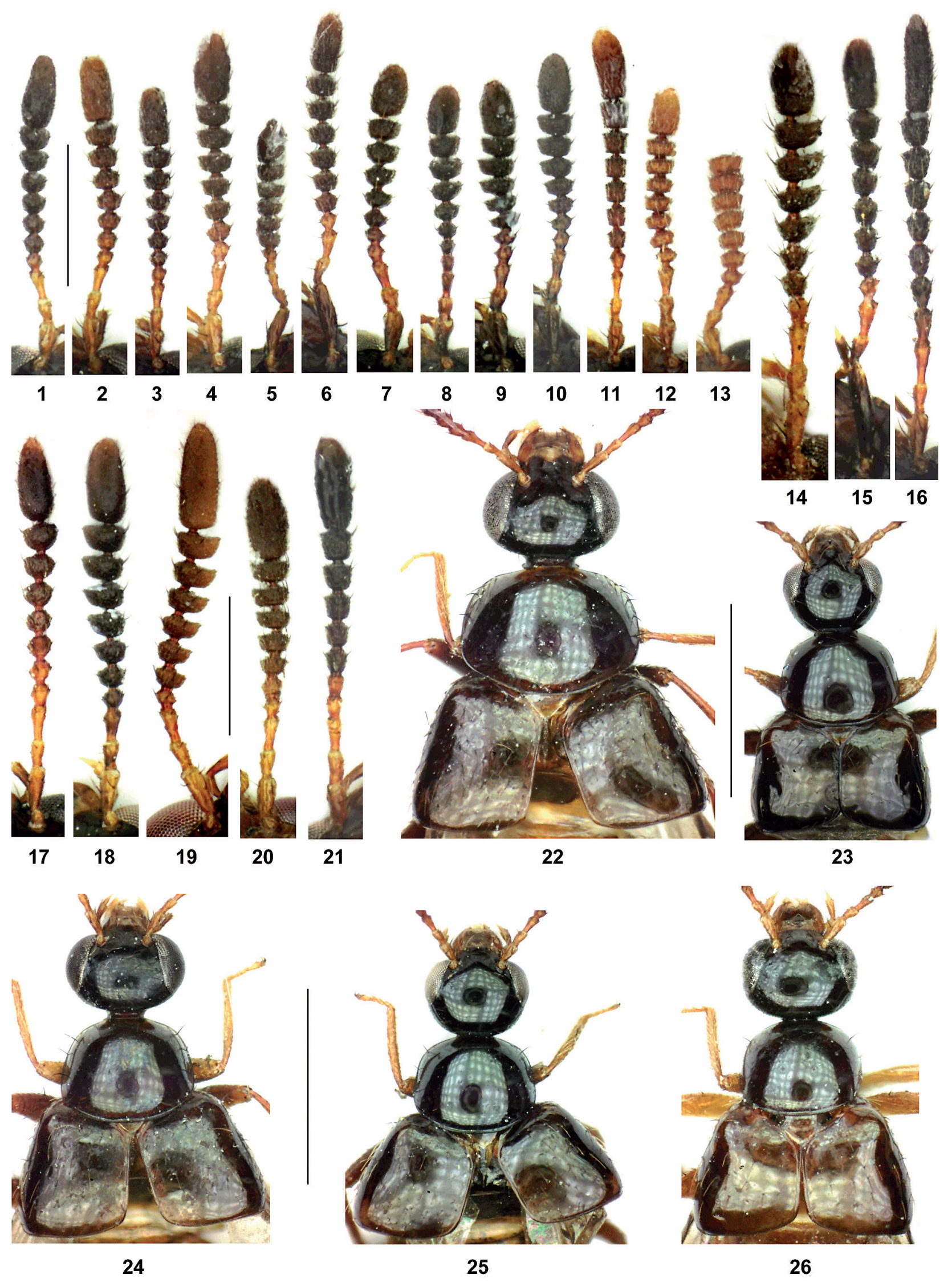

Figs 1-26. Antenna (1-21) and forebody (22-26) of Orphnebius spp. of the O. hauseri group: spinans $(1,23)$, cernens $(2,24)$, lunatus (3, 25), bakeri $(4,26)$, breviceps (5), extensus (6), serratus (7), integer (8), bicuspis, Laos (9), bicuspis, NE India (10), fusicollis (11), retunsus (12), fodens (13), opticus (14), dilatatus (15), fuscapicalis (16), grandicollis (17, 22), reductus (18), biformis, male (19), biformis, female (20), effeminatus (21). Scale bars: 22-26: $1.0 \mathrm{~mm}$; 1-21: $0.5 \mathrm{~mm}$. 


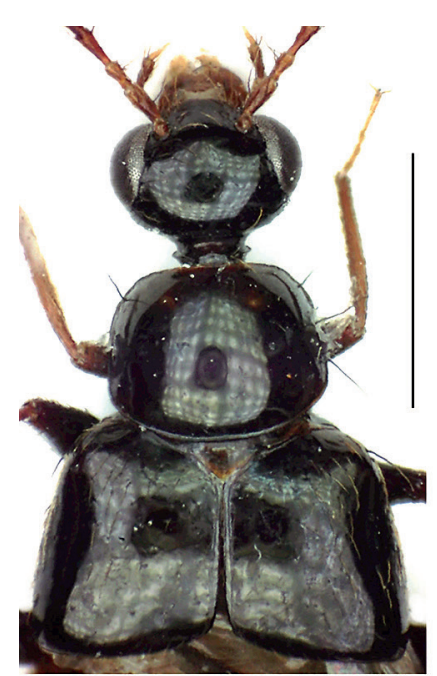

27

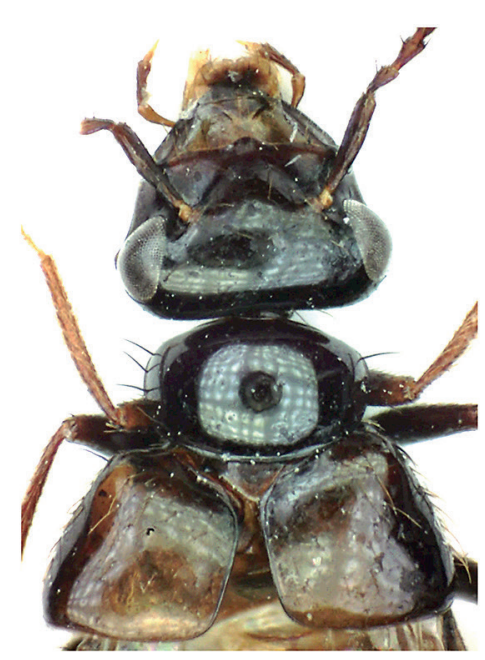

28

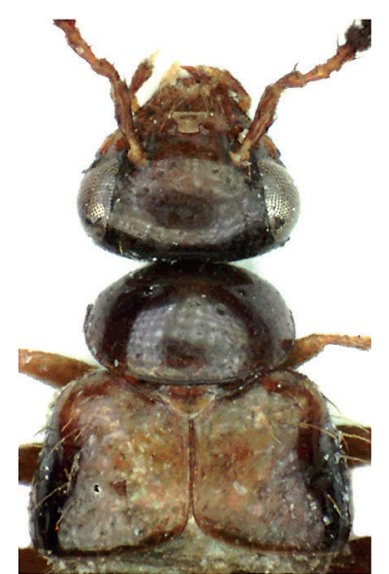

30

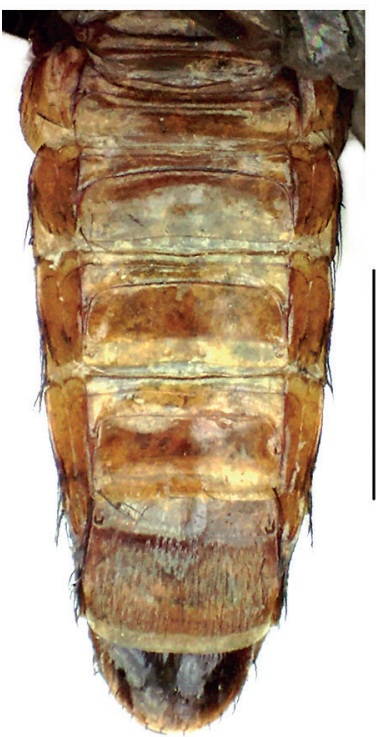

35

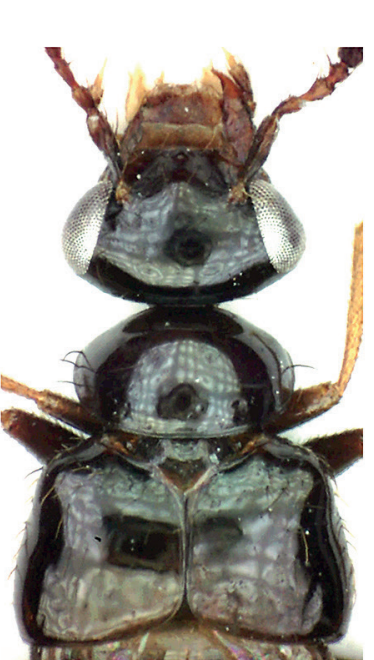

31

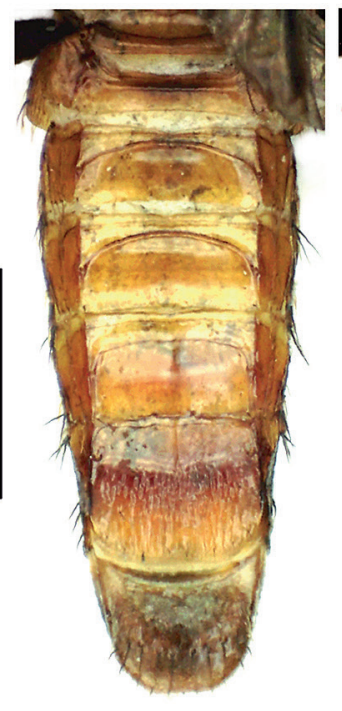

36

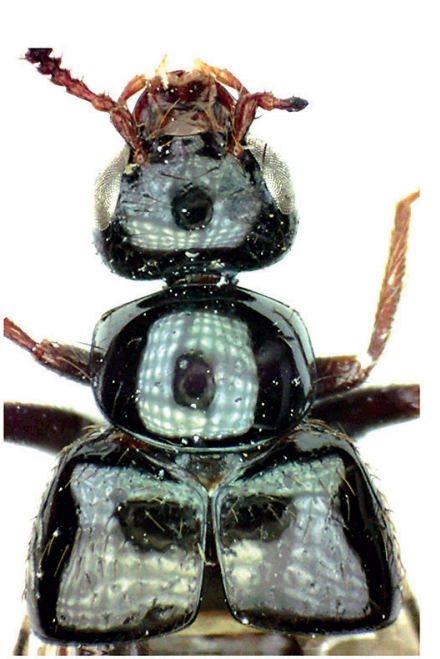

29

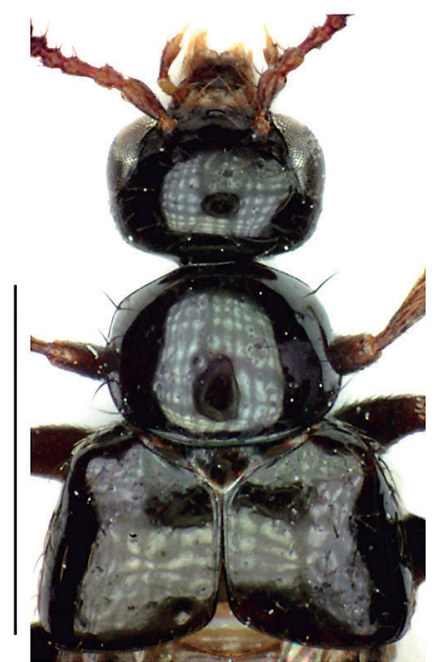

32

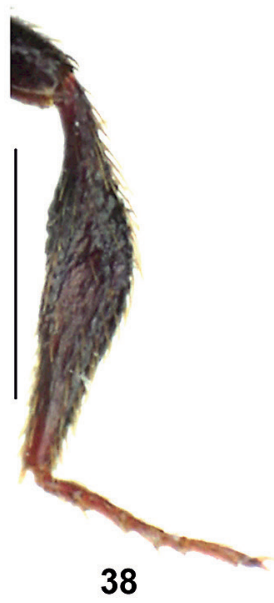

38

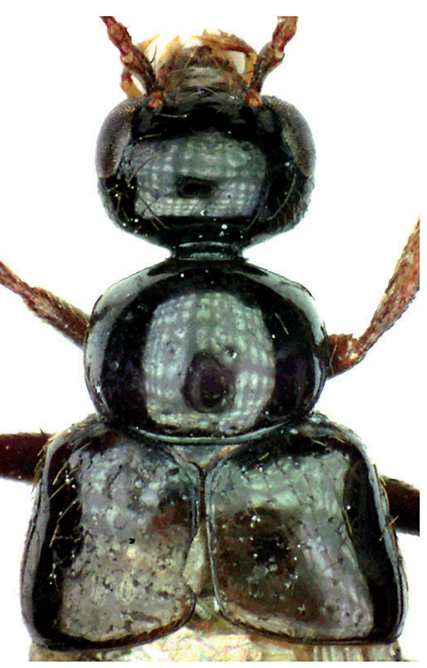

33
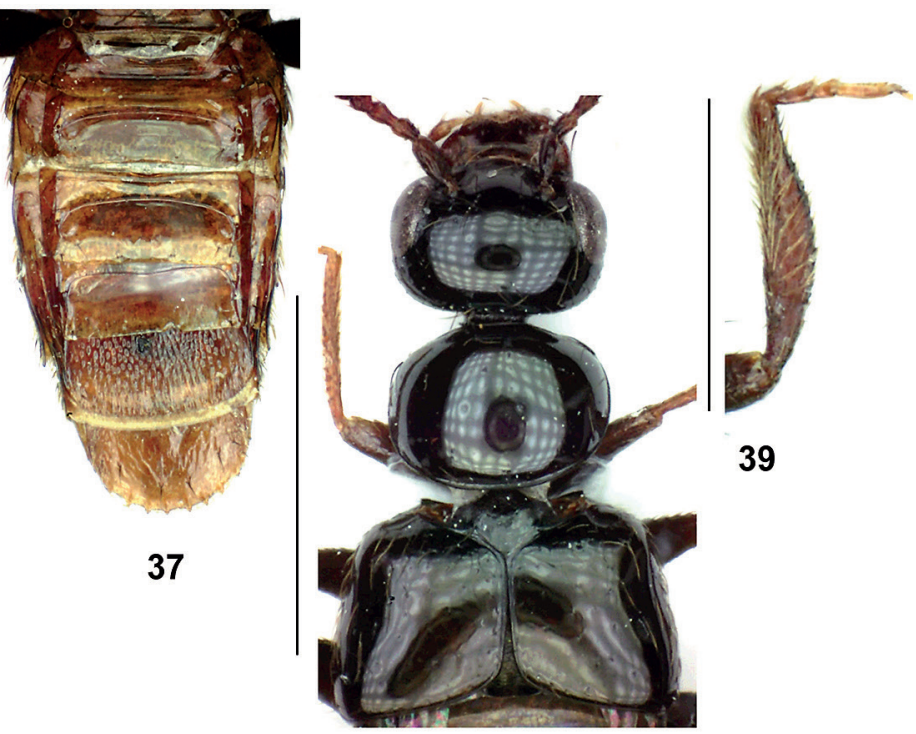

39

Figs 27-39. Forebody (27-34), abdomen (35-37), mesotibia (38), and protibia (39) of Orphnebius spp. of the O. hauseri group: fuscapicalis $(27,35)$, dilatatus $(28,36)$, latitibialis $(29,38)$, breviceps $(30)$, extensus $(31)$, serratus $(32,39)$, integer $(33,37)$, bicuspis, Laos (34). Scale bars: 27-37: $1.0 \mathrm{~mm}$; 38-49: $0.5 \mathrm{~mm}$. 


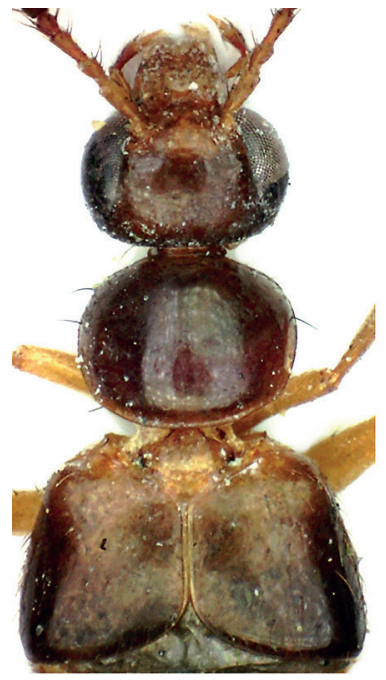

40

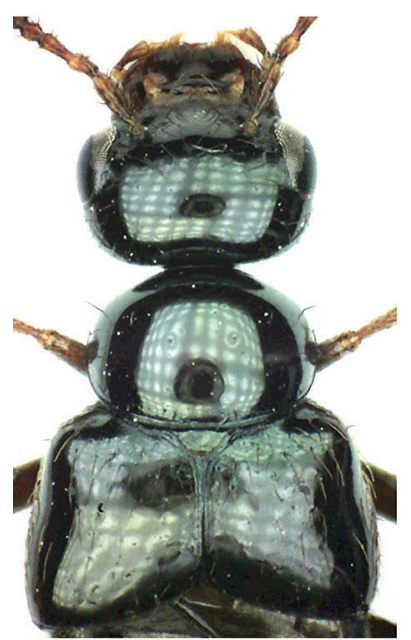

44

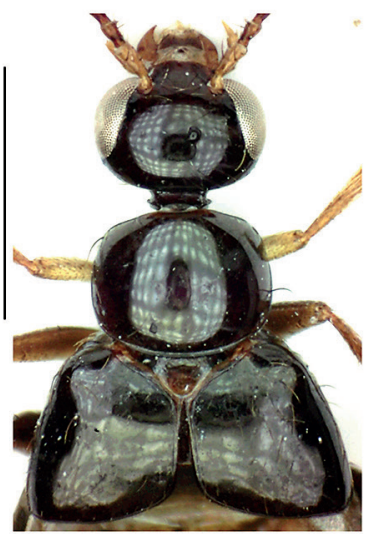

49

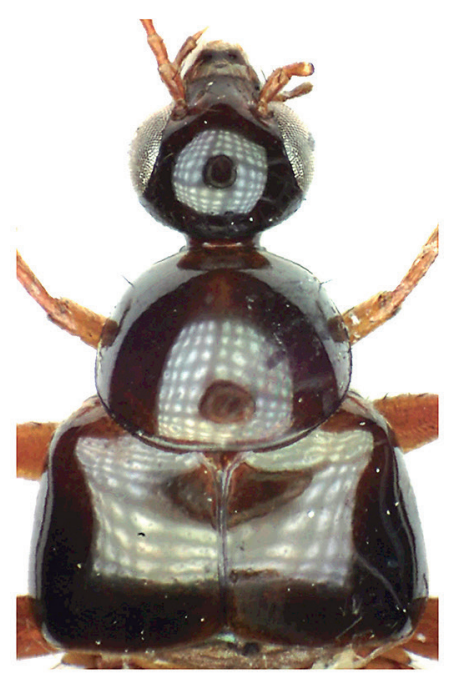

41

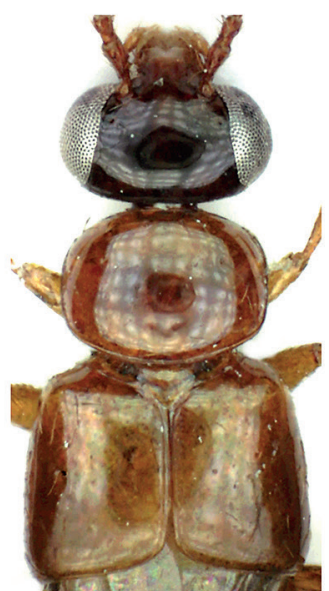

45

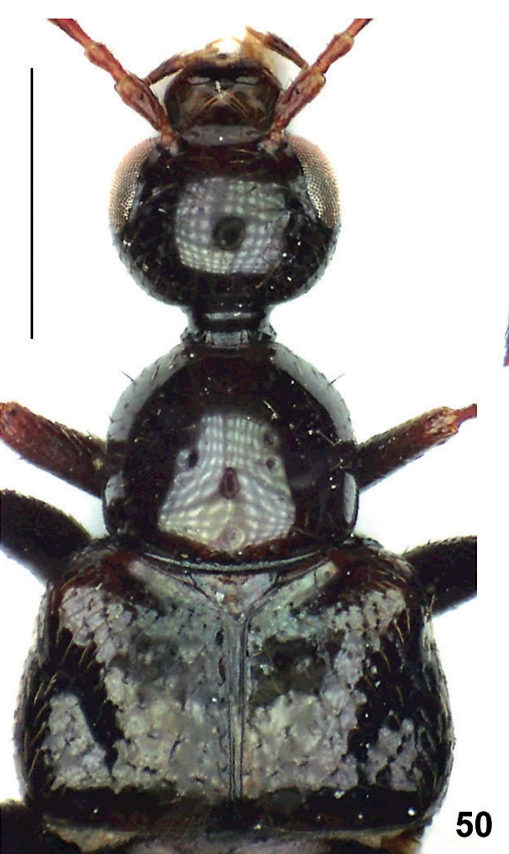

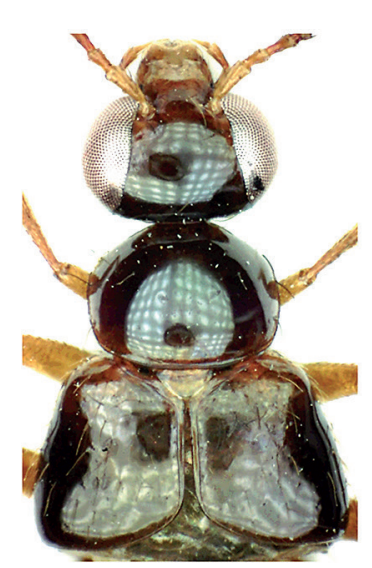

42

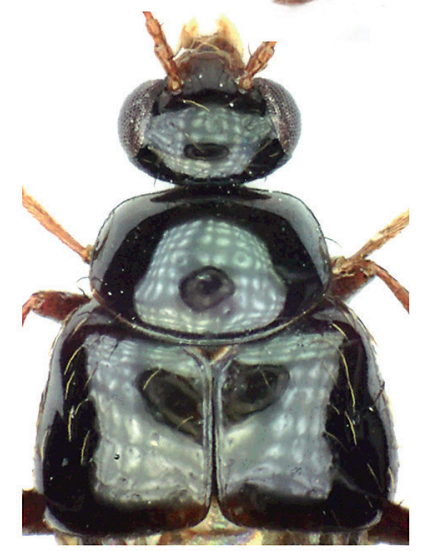

46

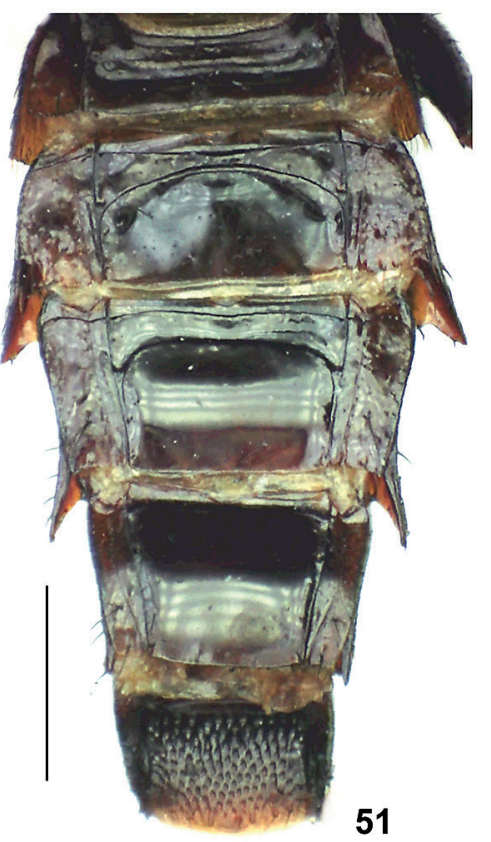

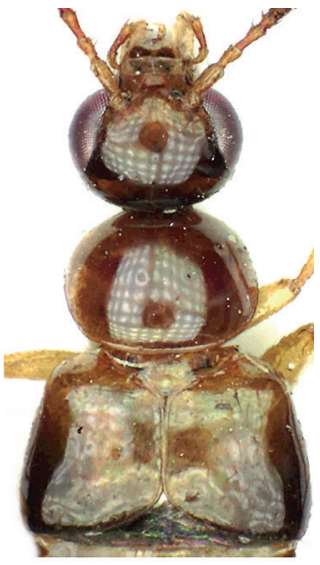

43

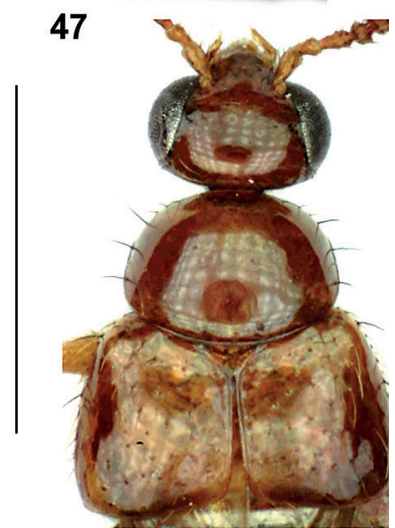

48

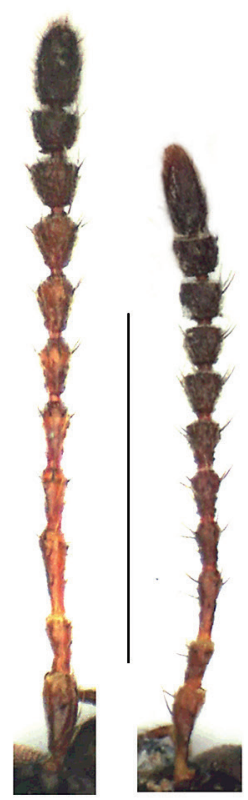

52

53

Figs 40-53. Forebody (40-50), abdomen (51), and antenna (52-53) of Orphnebius spp. of the O. hauseri group (40-49) and of the subgenus Deroleptus (50-53): opticus (40), effeminatus (41), biformis, male (42), biformis, female (43), bicuspis, NE India (44), retunsus (45), fusicollis (46-47), fodens (48), reductus (49), niger (50-52), siamensis (53). Scale bars: $1.0 \mathrm{~mm}$. 


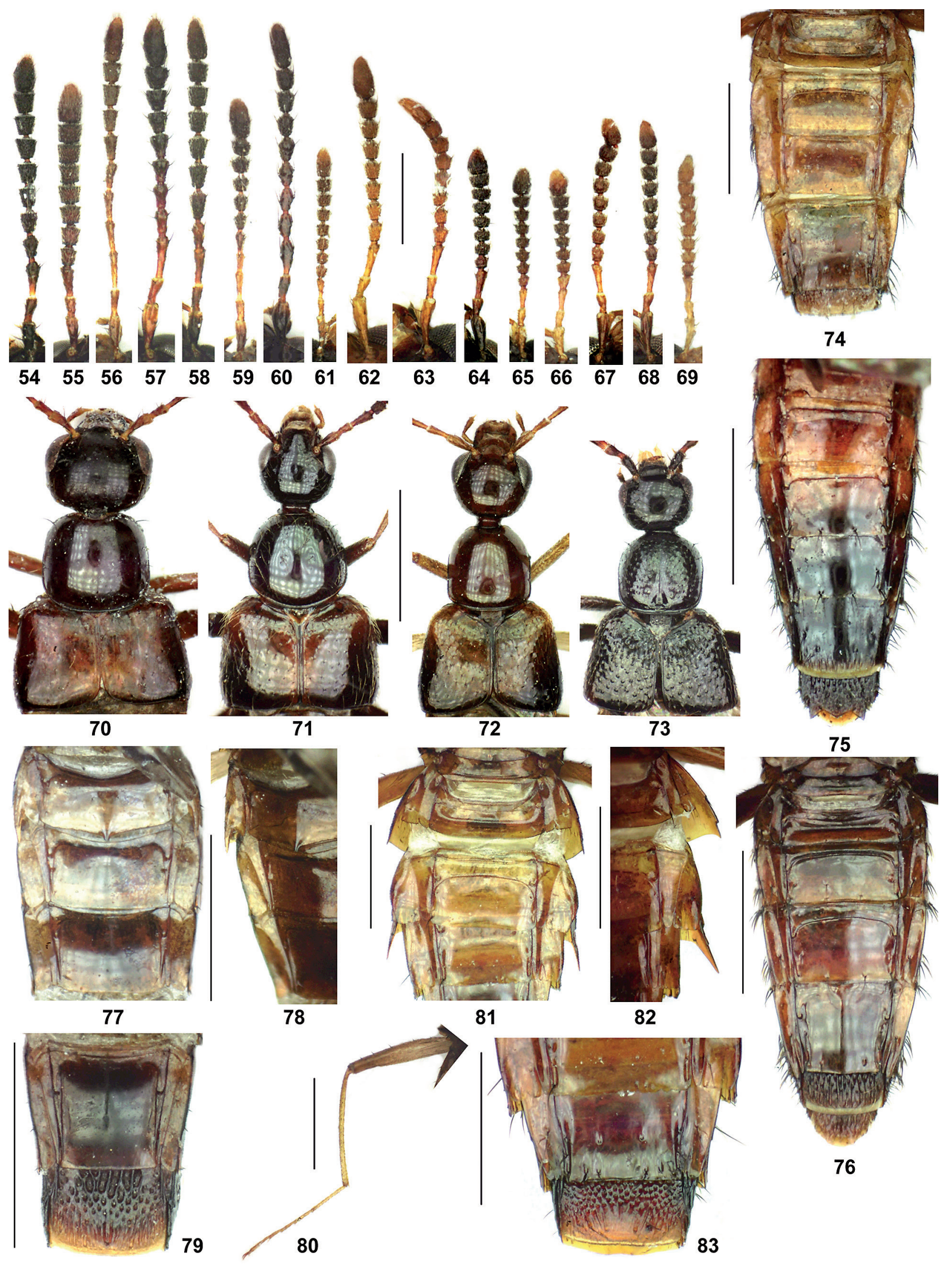

Figs 54-83. Antenna (54-69), forebody (70-73), abdomen (74-76), abdominal segments III-V (77, 81), lateral portion of abdominal segments III-V $(\mathbf{7 8}, \mathbf{8 2})$, tergites VI-VII $(79,83)$, and hind leg $(\mathbf{8 0})$ of Orphnebius spp. of the subgenus Deroleptus: discrepans $(54,73,75)$, triapicalis $(55,71,76)$, gracilior $(56,72,77-80)$, sexcarinatus $(57,81-83)$, spoliatus $(58)$, cultellatus (59), septemcuspis (60), vates (61), tortus (62), baccillatus (63), carinatus (64), dispar (65), laticeps (66), biimpressus (67), ulcerosus (68), falagrioides (69), siamensis (70, 74). Scale bars: 70-83: $1.0 \mathrm{~mm}$; 54-69: $0.5 \mathrm{~mm}$. 


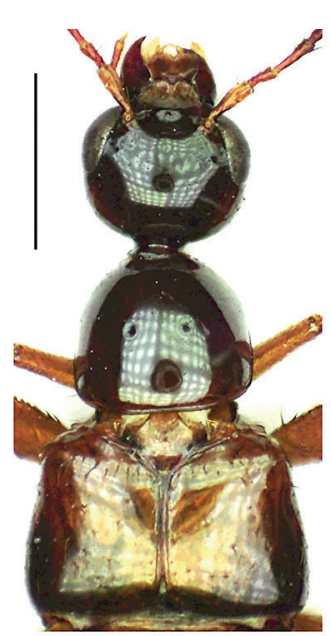

84

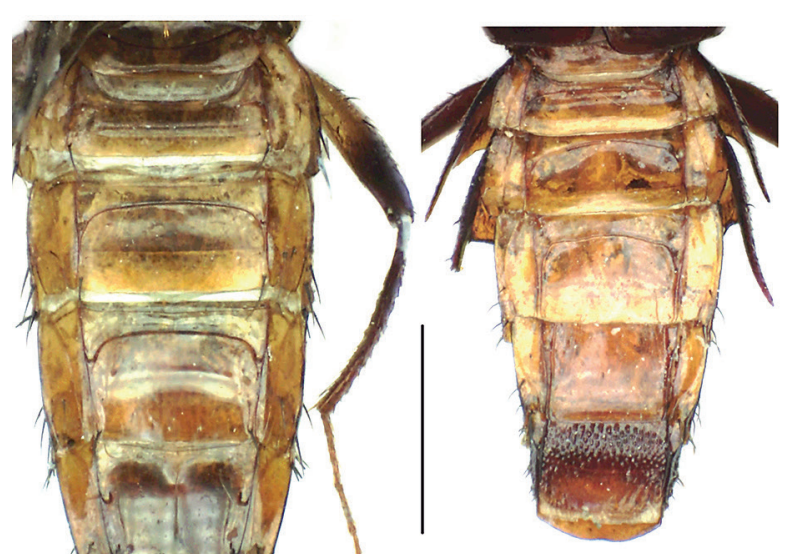

92

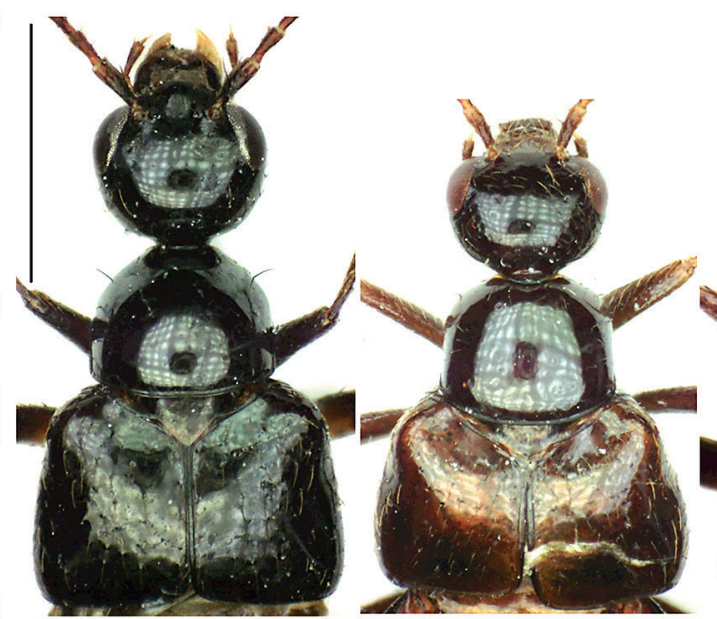

86

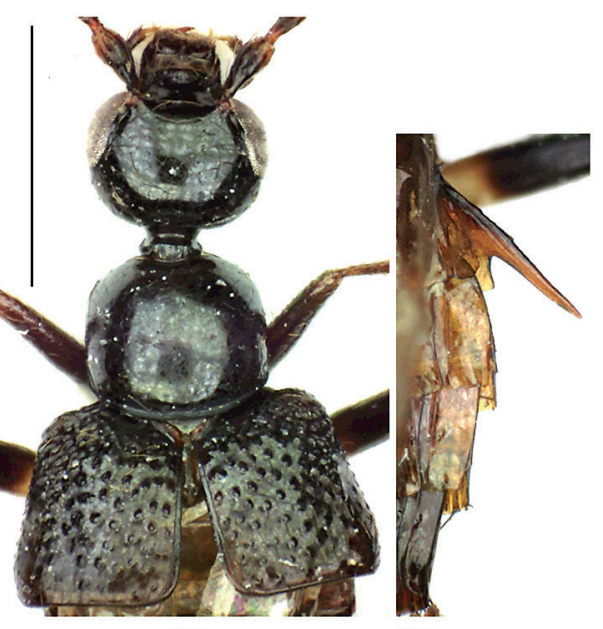

87

95
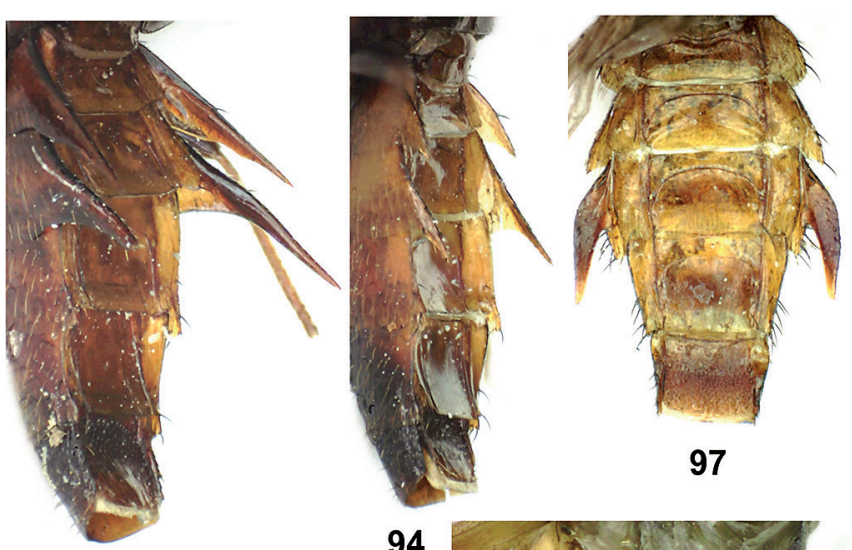

93

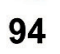

94 (. 91

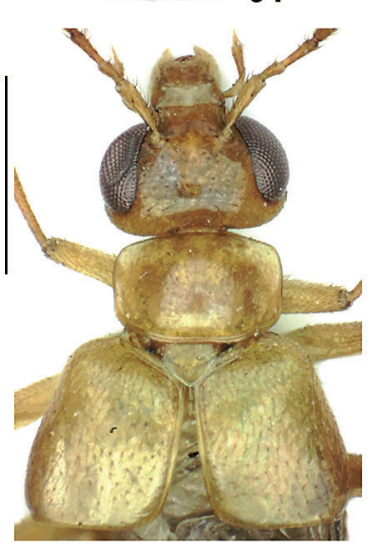

88

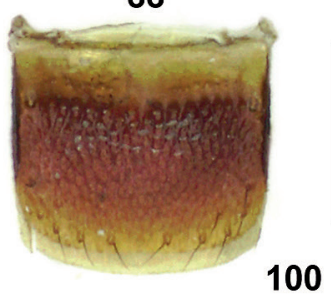

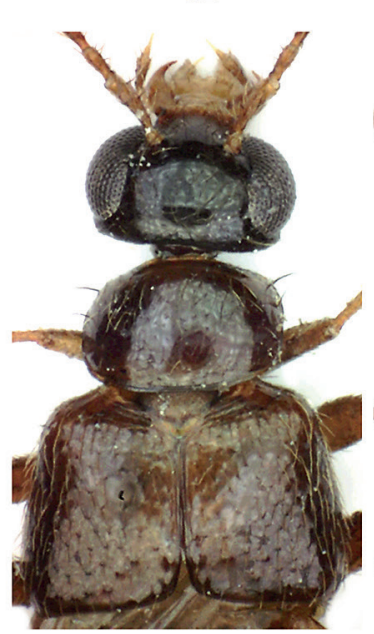

89

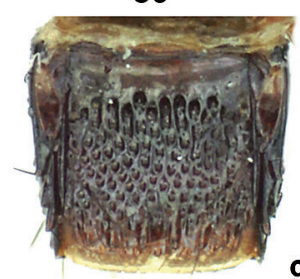

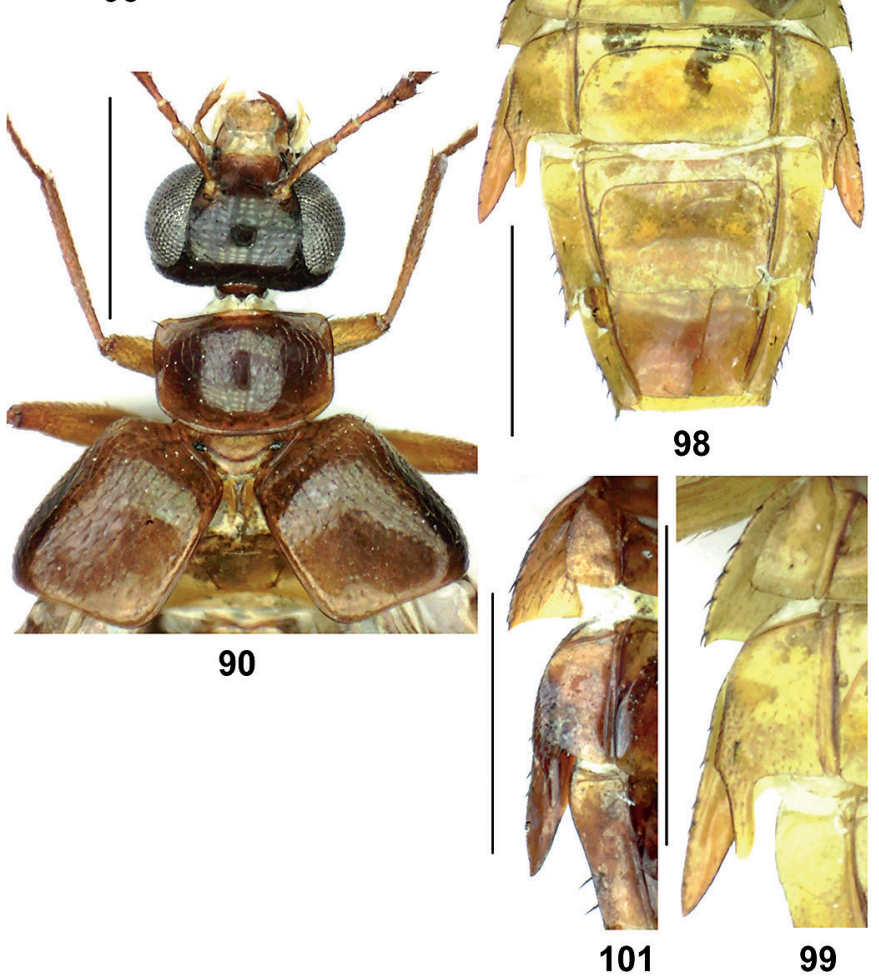

Figs 84-101. Forebody (84-90), abdomen (91-94, 97-98), lateral portion of abdominal segments III-V/VI (95, 99, 101), and tergite VII $(\mathbf{9 6}, 100)$ of Orphnebius spp. of the subgenus Deroleptus: sexcarinatus $(84)$, spoliatus $(85,91)$, cultellatus (86, 92-94), septemcuspis (87, 95-96), tortus (88, 98-100), vates $(89,97)$, baccillatus $(\mathbf{9 0}, \mathbf{1 0 1})$. Scale bars: 84-95, 97-99, 101: 1.0 mm; 96, 100: $0.5 \mathrm{~mm}$. 


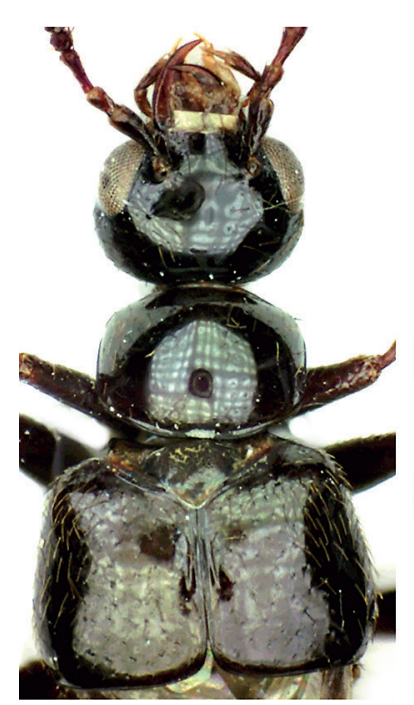

102

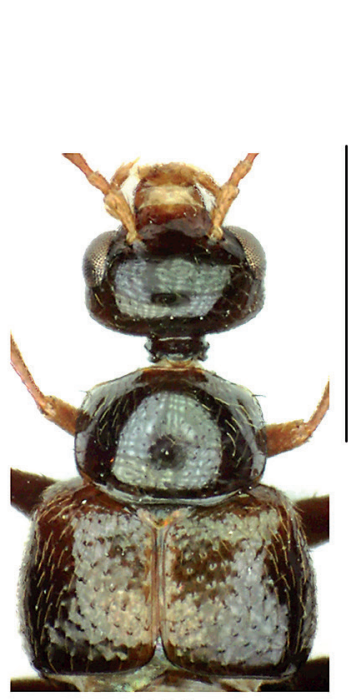

103

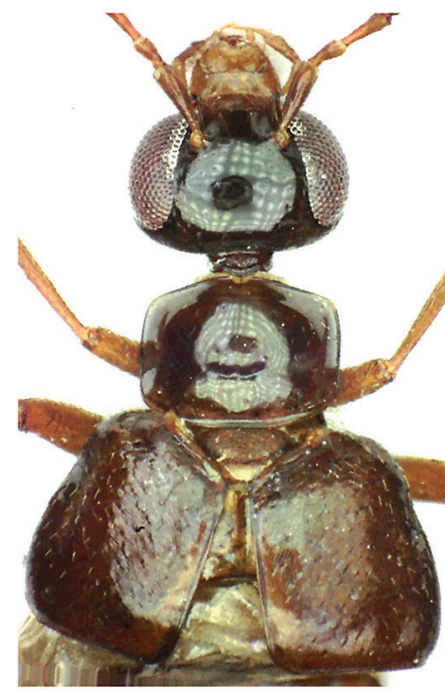

104

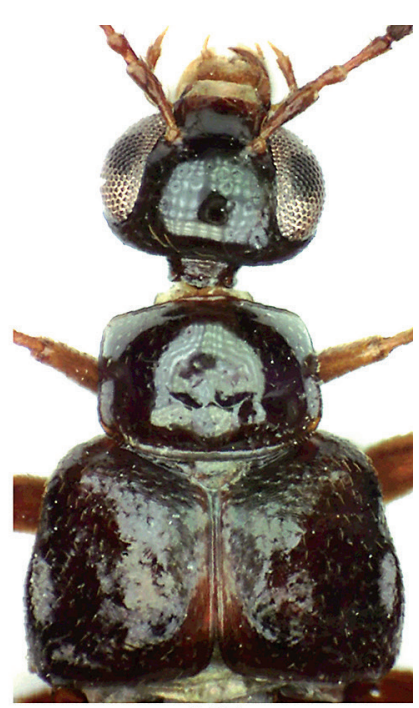

105

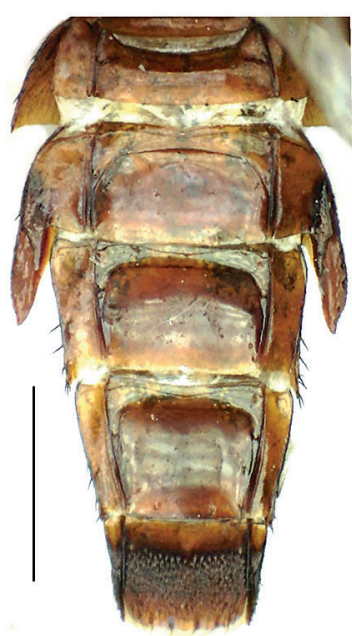

109

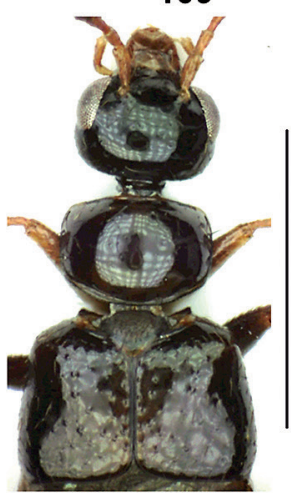

106

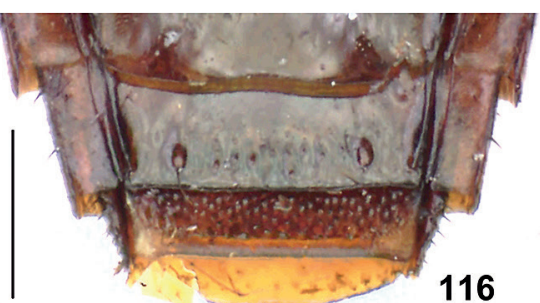

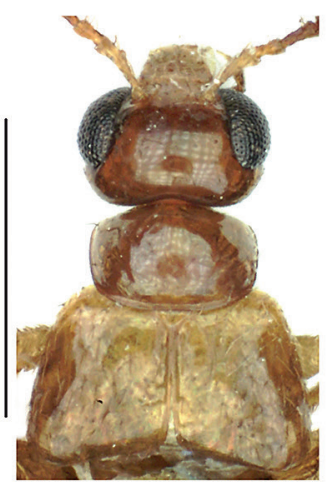

107

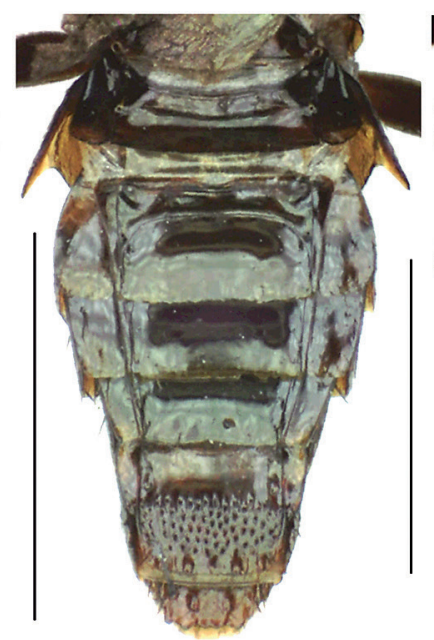

110

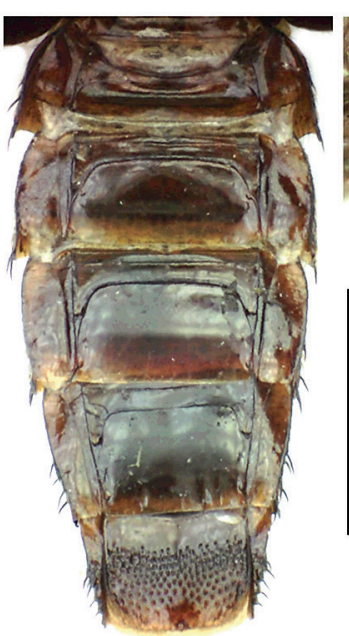

112

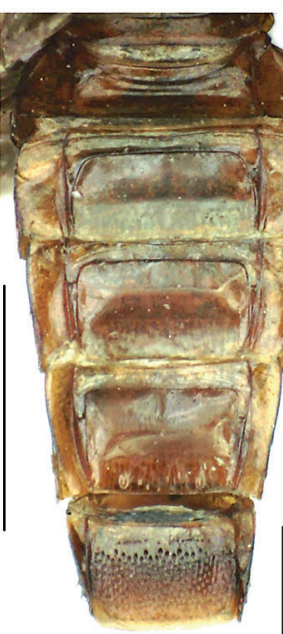

113

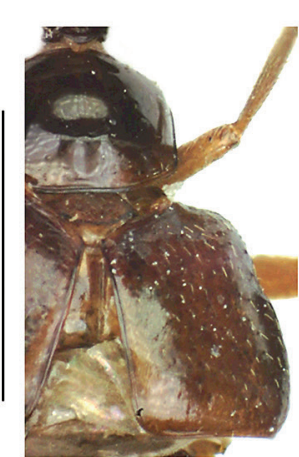

108

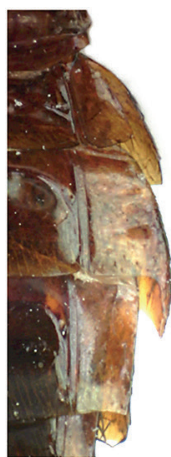

117

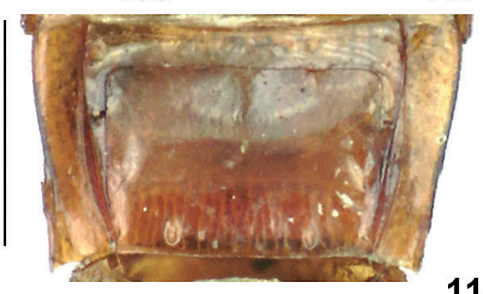

114

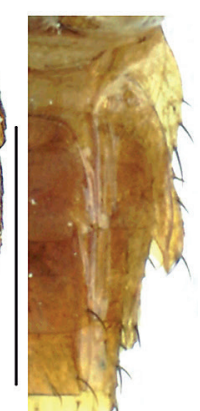

118

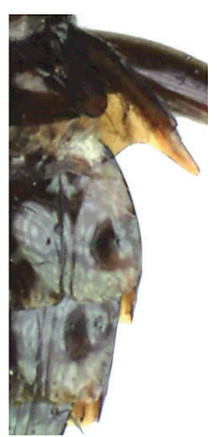

111
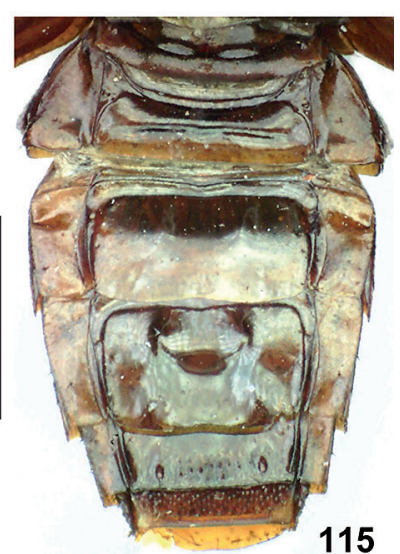

Figs 102-118. Forebody (102-108), abdomen (109-110, 112-113, 115), lateral portion of abdominal segments III-V/ VII $(111,117-118)$, and tergites VII(-VIII) $(114,116)$ of Orphnebius spp. of the subgenus Deroleptus: carinatus (102, 117), laticeps $(103,112)$, biimpressus $(104,108,113-114)$, ulcerosus $(105,115-116)$, dispar $(106,110-111)$, falagrioides $(107,118)$, baccillatus (109). Scale bars: 102-110, 112-113, 115, 117-118: $1.0 \mathrm{~mm} ; 111,114,116: 0.5 \mathrm{~mm}$. 


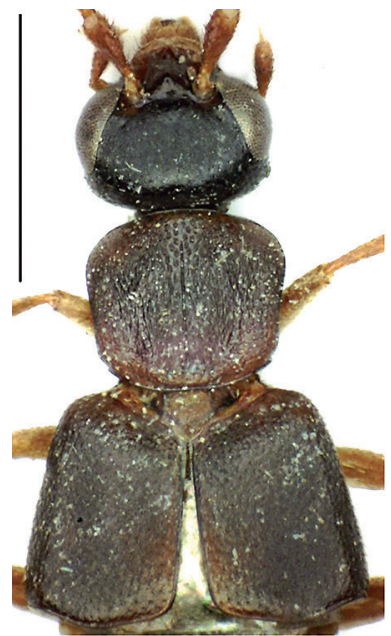

119

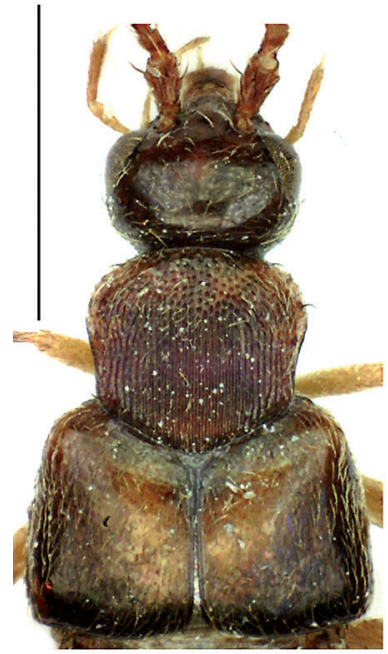

123

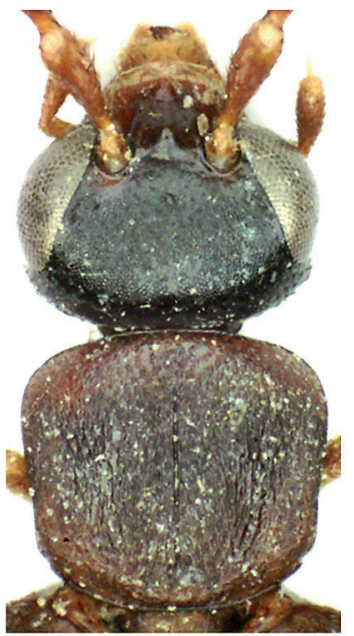

120

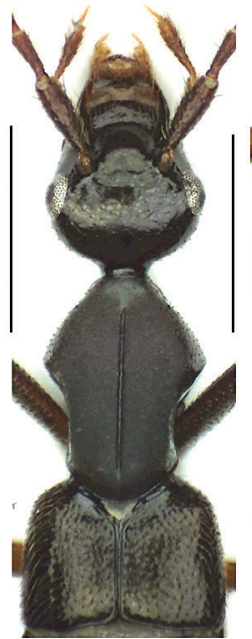

126

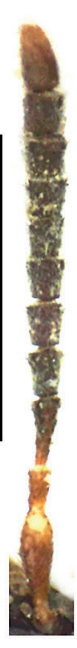

121

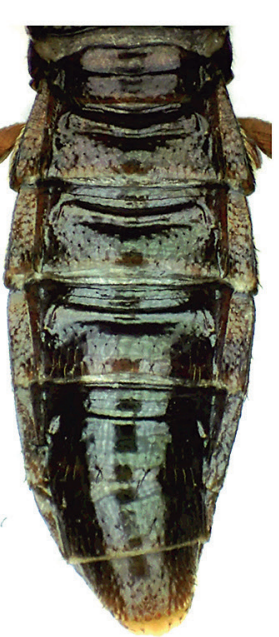

127

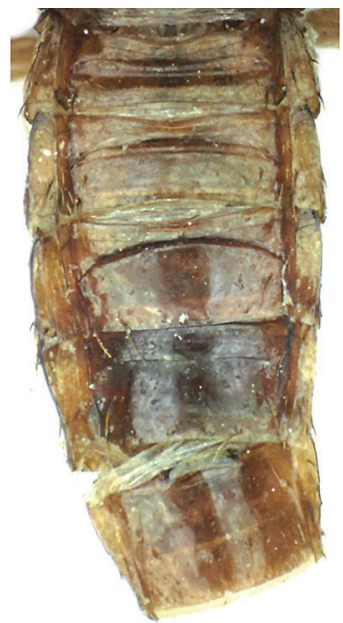

125

122

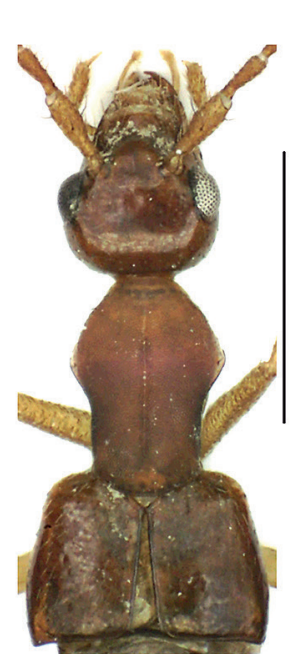

128

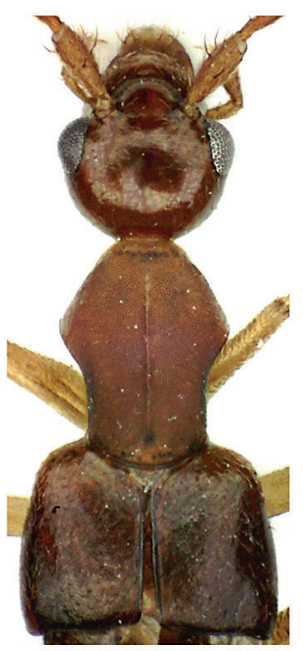

129
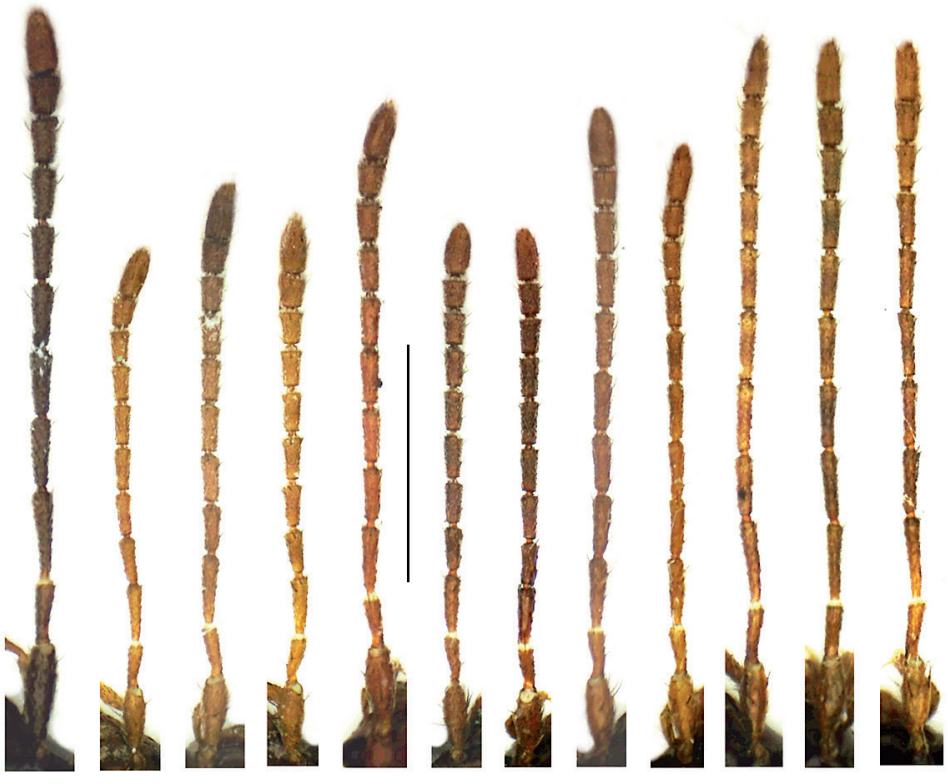

$\begin{array}{llllllllllll}132 & 133 & 134 & 135 & 136 & 137 & 138 & 139 & 140 & 141 & 142 & 143\end{array}$

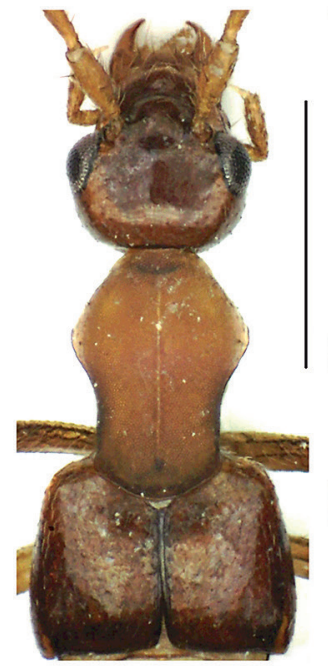

131

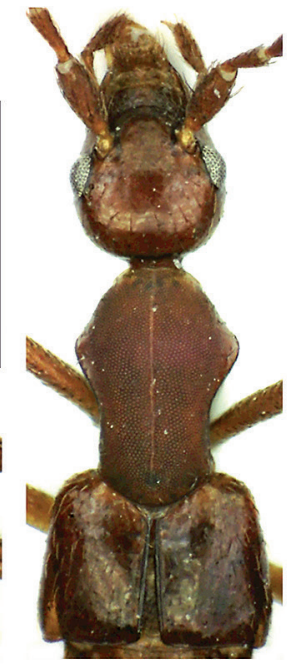

132

Figs 119-143. Drusilla bifida (119-122), Rabdotodrusilla pectinata (123-125), Amaurodera arunica (126-127, 132), A. gilvios $(128,133)$, A. reticulata $(129,134)$, A. dentata $(130,135)$, A. parvoculata (131, 136), A. thailandensis (137-138), A. fasciata (139), A. meorum (140), A. disparicollis (141), A. spinans (142), and A. varicollis (143): forebody (119, 123, 126, 128-131); head and pronotum (120); antenna $(121,124,132-143)$; abdomen $(122,125,127)$. Scale bars: $1.0 \mathrm{~mm}$. 


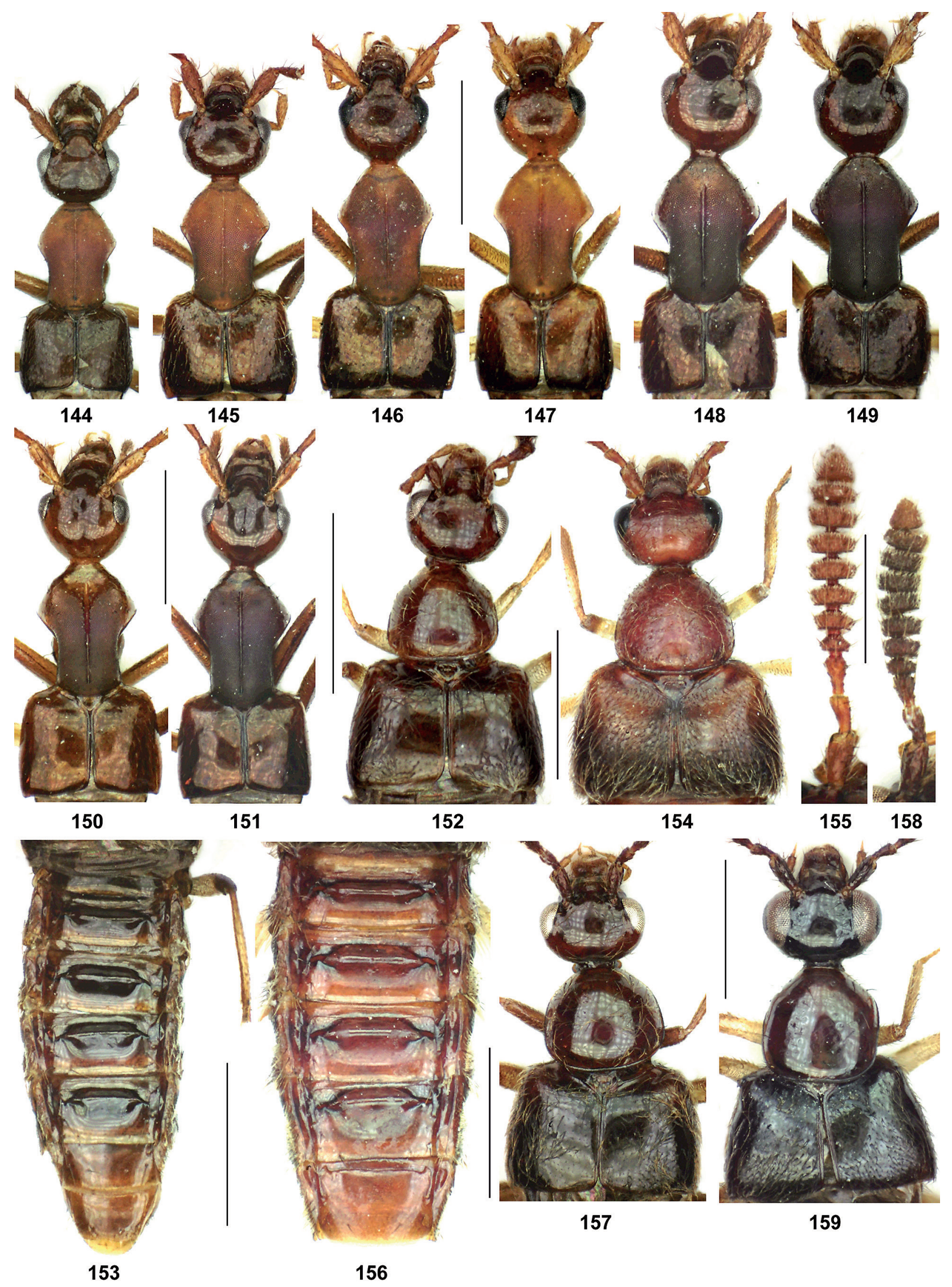

Figs 144-159. Amaurodera thailandensis (144-145), A. fasciata (146), A.meorum (147), A. spinans (148), A. varicollis (149), A. disparicollis, male (150), A. disparicollis, female (151), Tetrabothrus nilgiricus (152-153), T. pubescens, syntype (154-156), T. collucatus (157-158), and T. neoguineensis, holotype (159): forebody (144-152, 154, 157, 159); abdomen (153, 156); antenna $(155,158)$. Scale bars: $144-154,156-157,159: 1.0 \mathrm{~mm} ; 155,158: 0.5 \mathrm{~mm}$. 


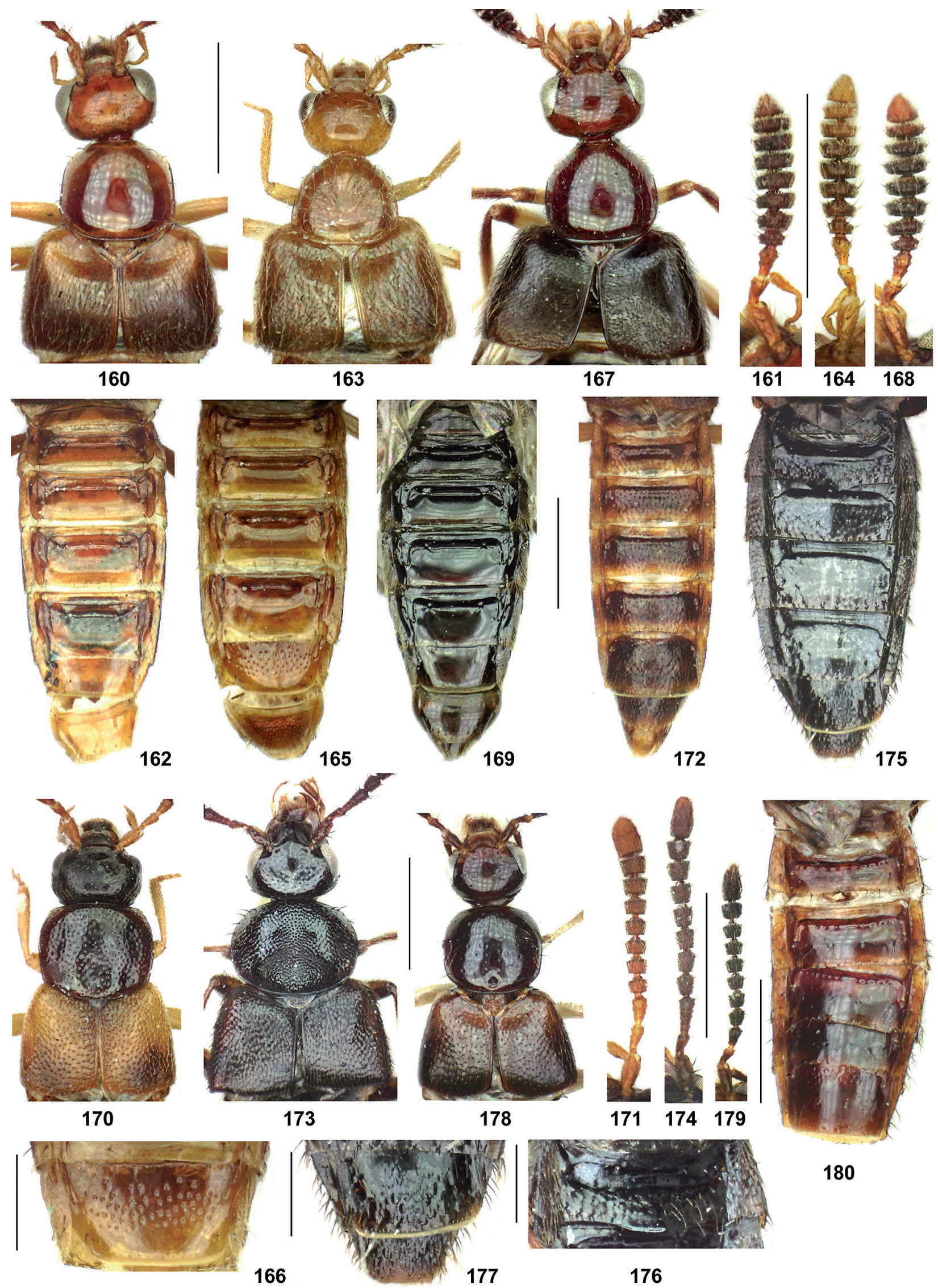

Figs 160-180. Tetrabothrus borneensis, holotype (160-162), T. punctiventris (163-166), T. sulawesicus (167-169), Zyras illecebrosus, paratype (170-172), Z. gibbus, holotype (173-177), and Z. quasar, holotype (178-180): forebody (160, 163, 167, 170, 173, 178); antenna $(161,164,168,171,174,179)$; abdomen $(162,165,169,172,175,180)$; tergite VIII (166); tergite III (176); tergites VIIVIII (177). Scale bars: 160-165, 167-175, 178-180: $1.0 \mathrm{~mm}$; 166, 176-177: $0.5 \mathrm{~mm}$. 


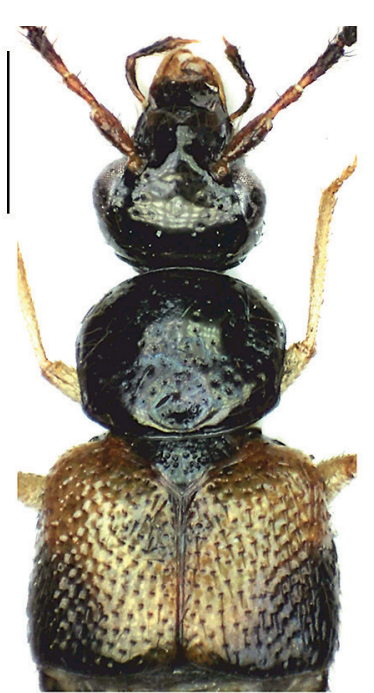

181

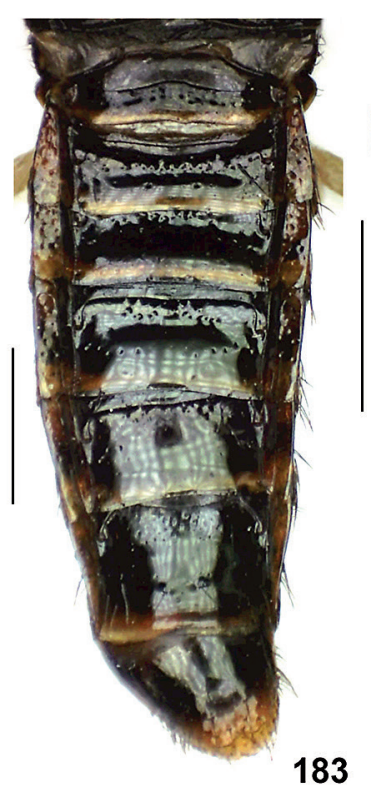

183

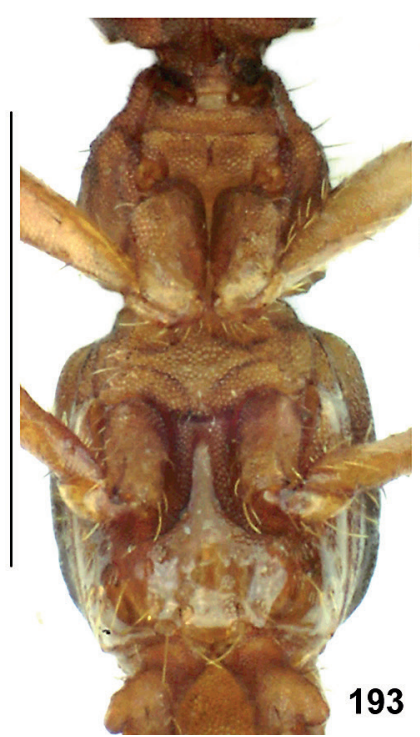

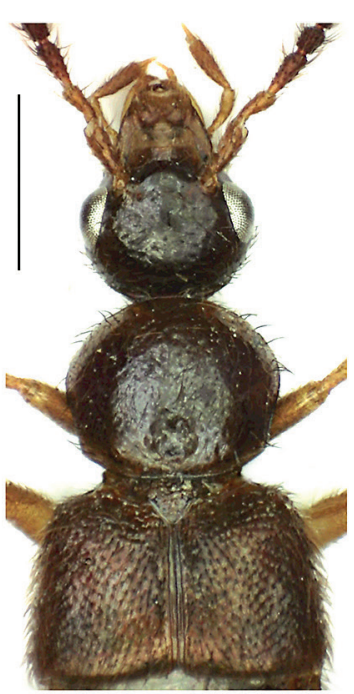

184

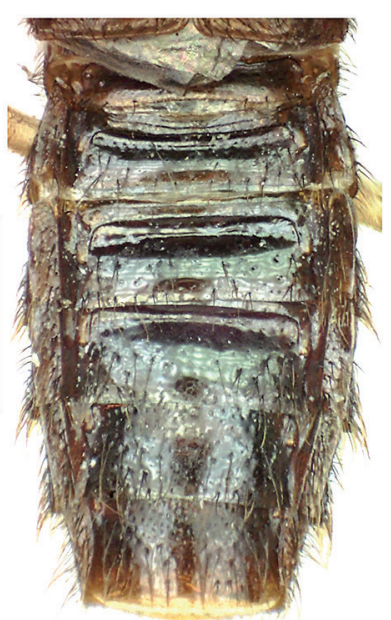

186

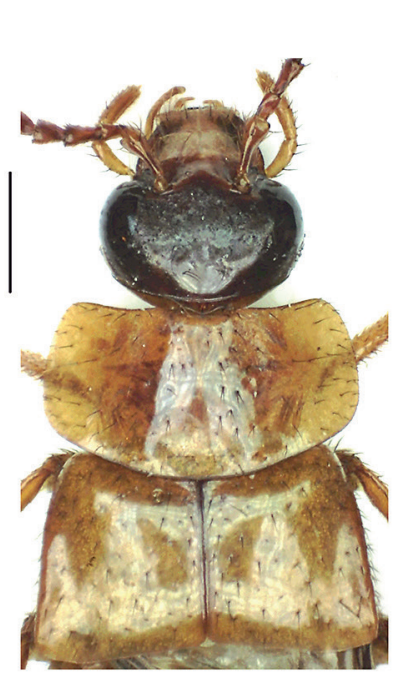

187

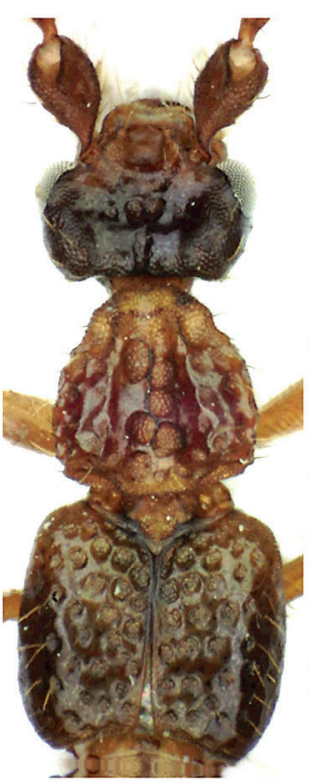

190

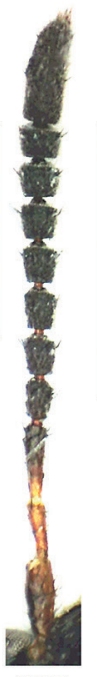

182

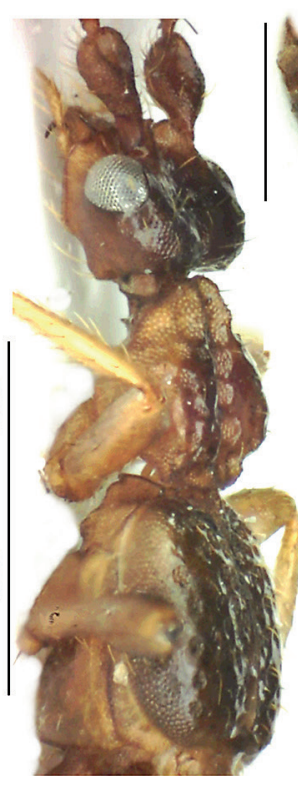

191
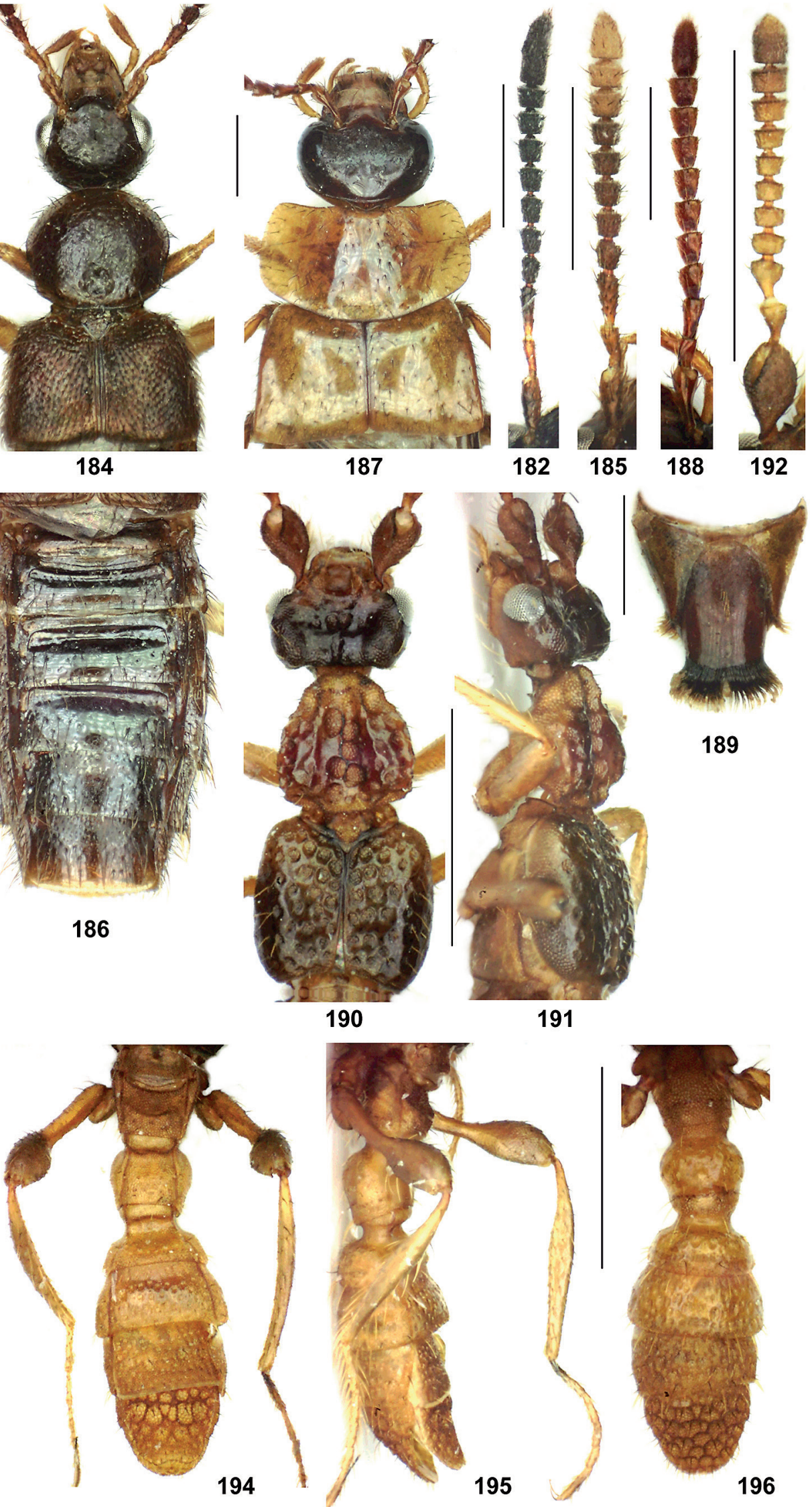

Figs 181-196. Zyras porrectus (181-183), Z. wunderlei (184-186), Pedinopleurus notabilis (187-189), and Aenictoides derivatus (190196): forebody $(181,184,187,190)$; antenna $(182,185,188,192)$; abdomen $(183,186,194)$; tergites IX-X (189); forebody in lateral view (191); thorax in ventral view (193); abdomen in lateral view (195); abdomen in ventral view (196). Scale bars: 181-188, 190-196: $1.0 \mathrm{~mm}$; 189: $0.5 \mathrm{~mm}$. 


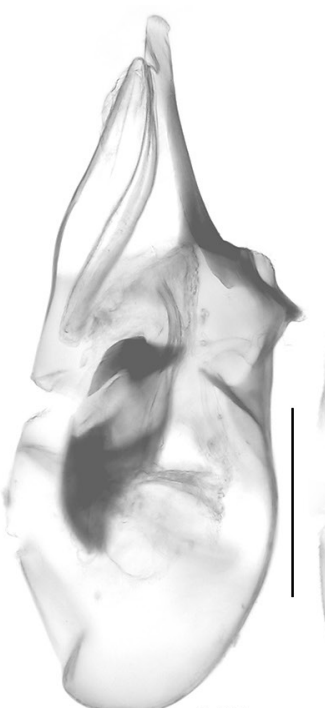

198

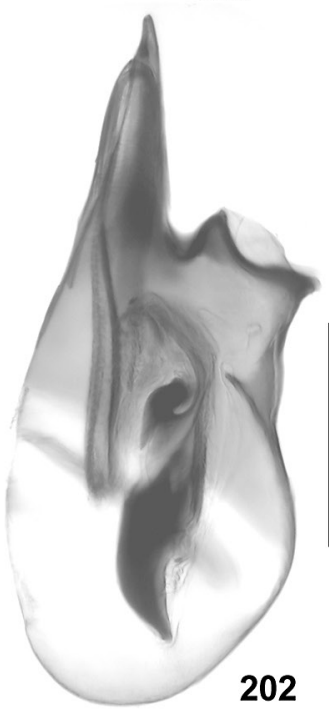

202

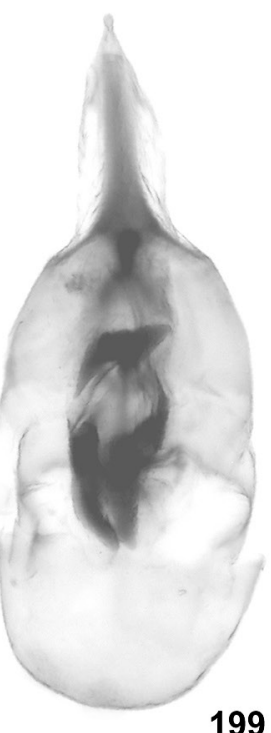

199

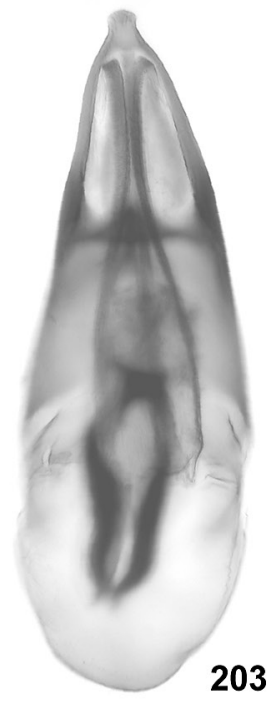

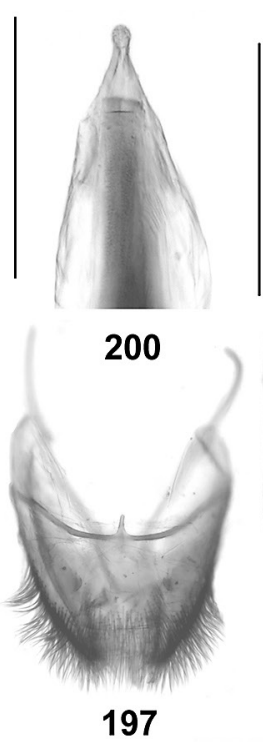

197
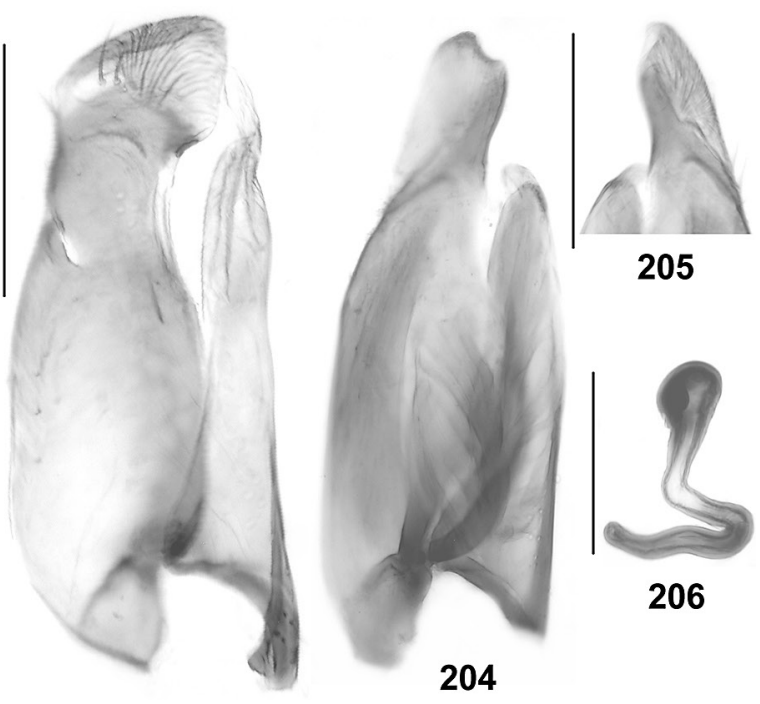

205

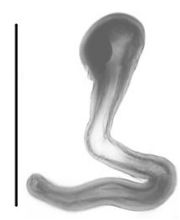

206

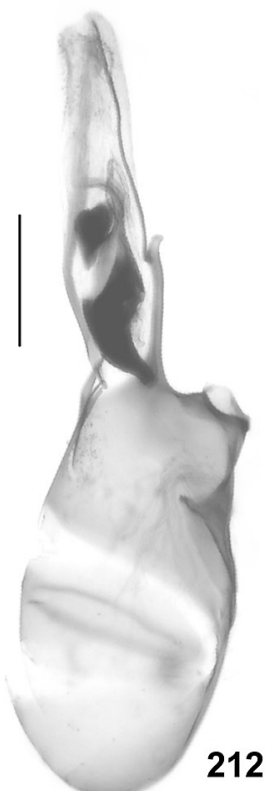

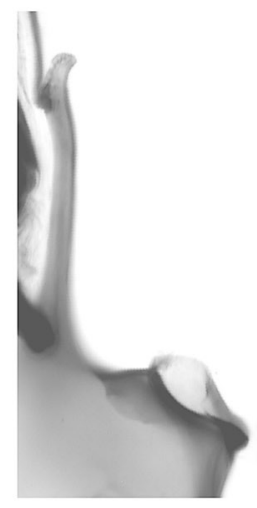

213

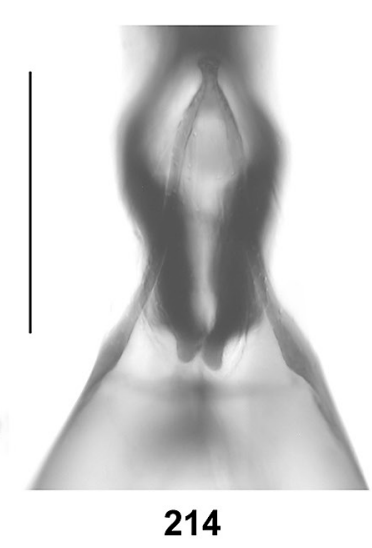

214

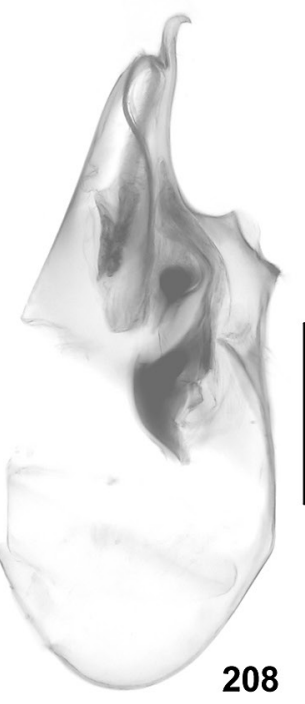

201

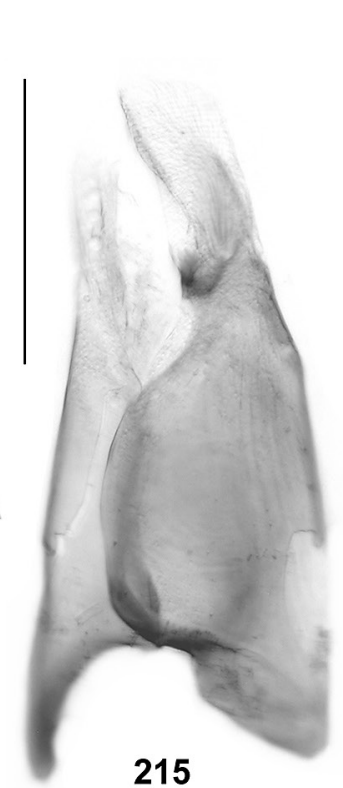

209
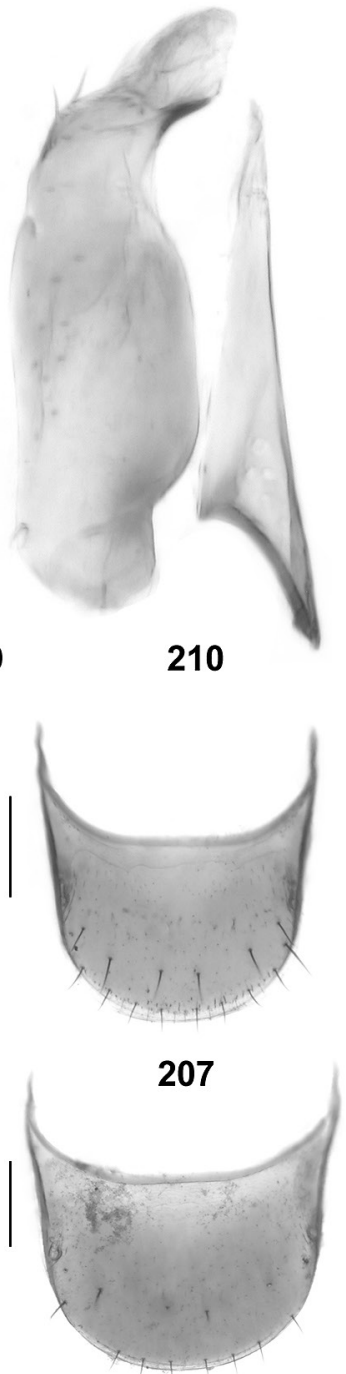

211

Figs 197-215. Orphnebius spinans (197-201), O.cernens (202-206), O. lunatus (207-210), and O.grandicollis (211-215): male segments IX-X (197); median lobe of aedeagus in lateral and in ventral view (198-199, 202-203, 208-209, 212); ventral process of aedeagus in ventral view $(200,214)$; paramere $(201,204,210,215)$; apex of paramere (205); spermatheca (206); tergite VIII (207, 211); ventral process of aedeagus in lateral view (213). Scale bars: $0.2 \mathrm{~mm}$. 

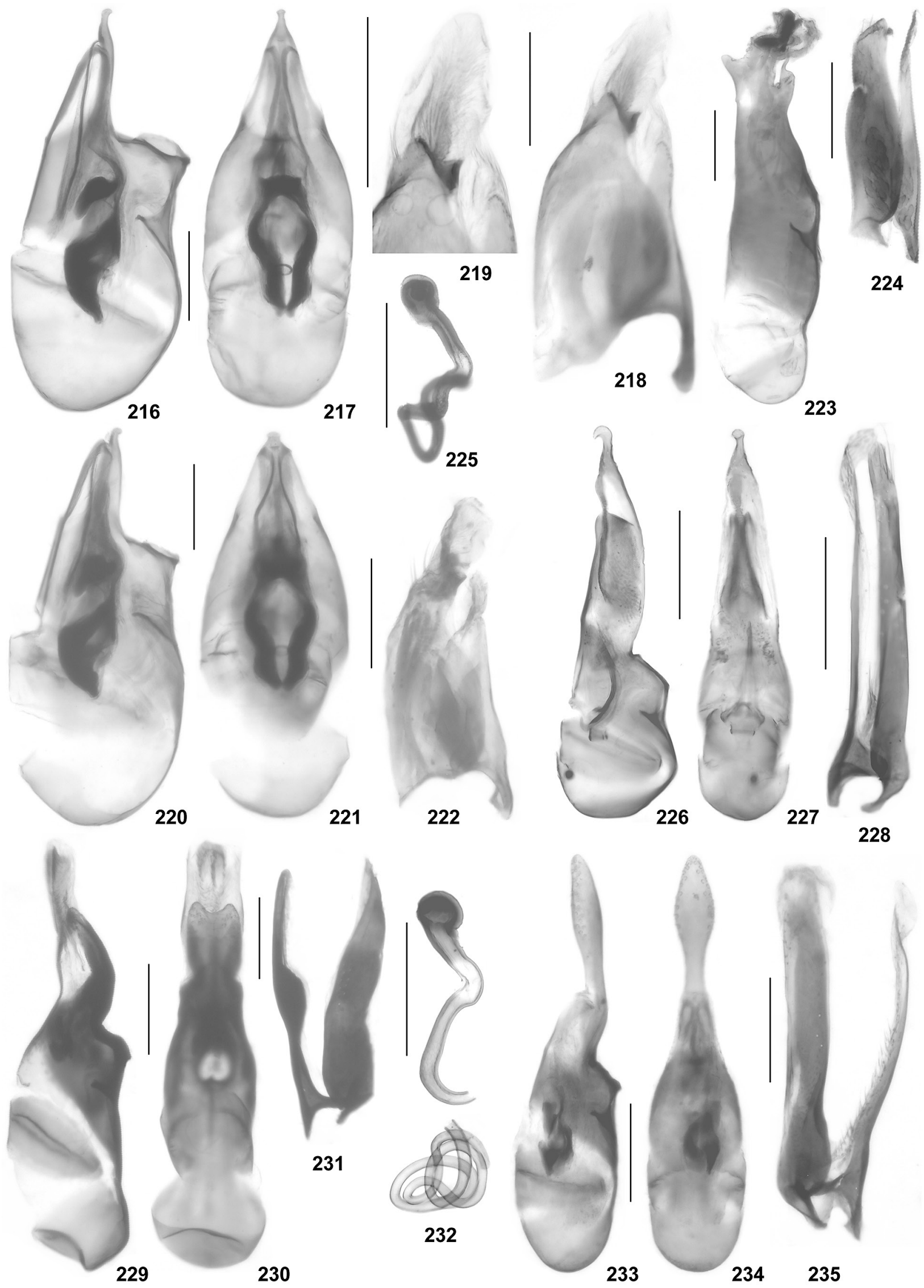

222

228

Figs 216-235. Orphnebius fuscapicalis (216-219), O. nigrapicalis (220-222), O. bakeri(223-225), O. breviceps (226-228), O. dilatatus (229-232), and O. extensus (233-235): median lobe of aedeagus in lateral and in ventral view (216-217, 220-221, 223, 226-227, 229-230, 233-234); paramere (218, 222, 224, 228, 231, 235); apex of paramere (219); spermatheca (225, 232). Scale bars: $0.2 \mathrm{~mm}$. 


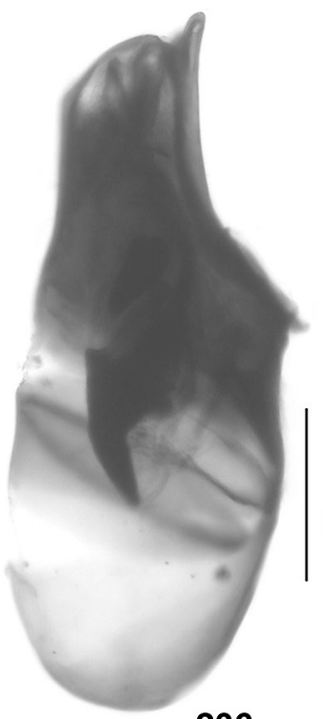

236

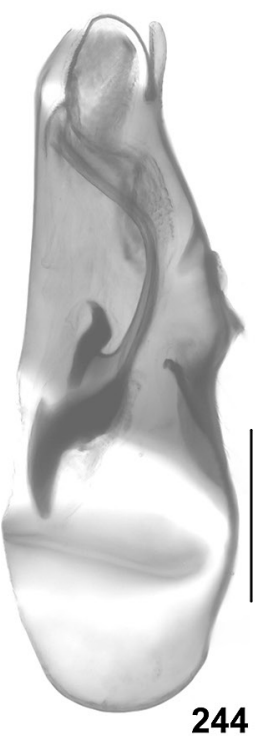

244

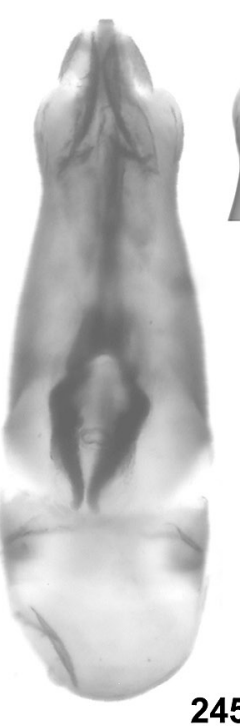

237

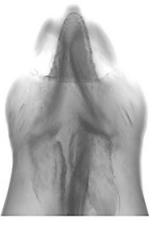

246

245
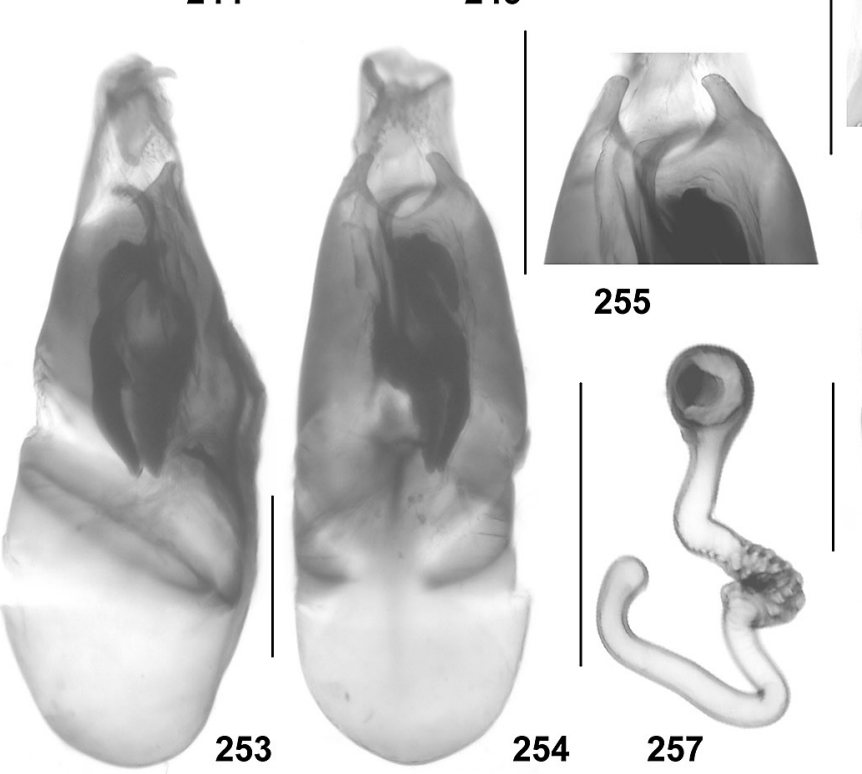

255

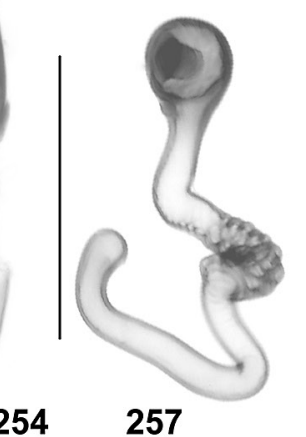

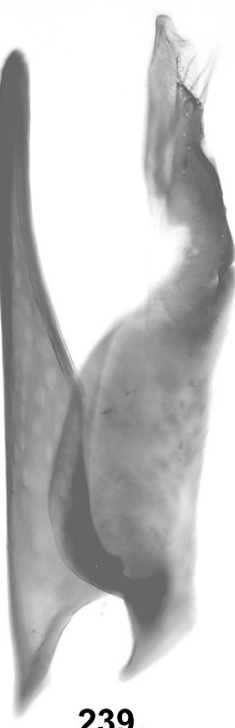
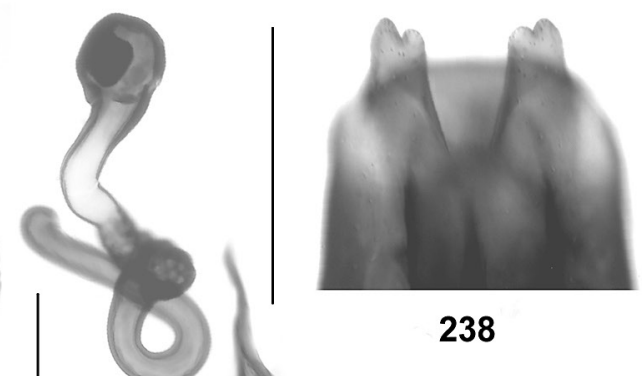

238

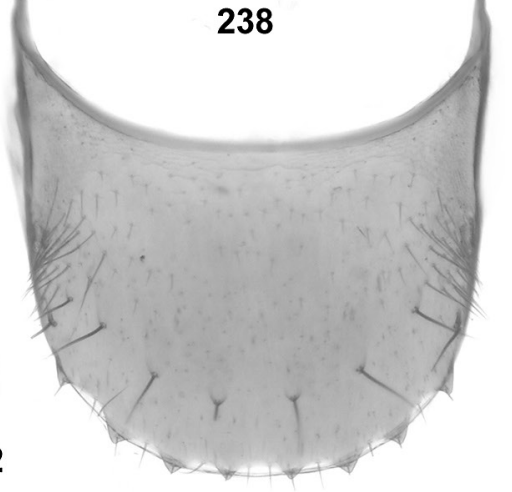

242
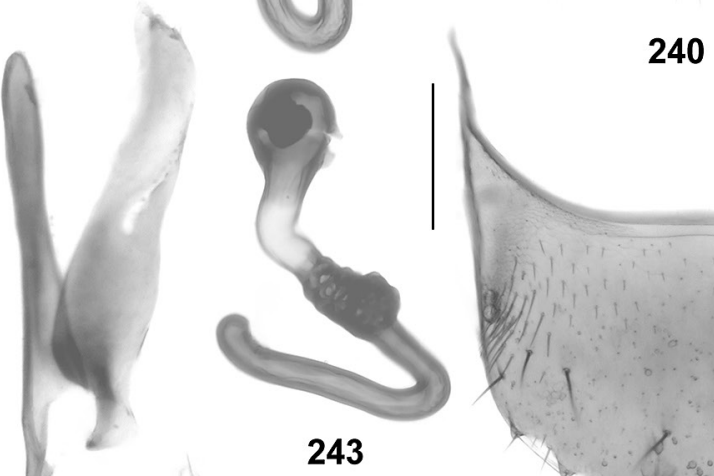

40
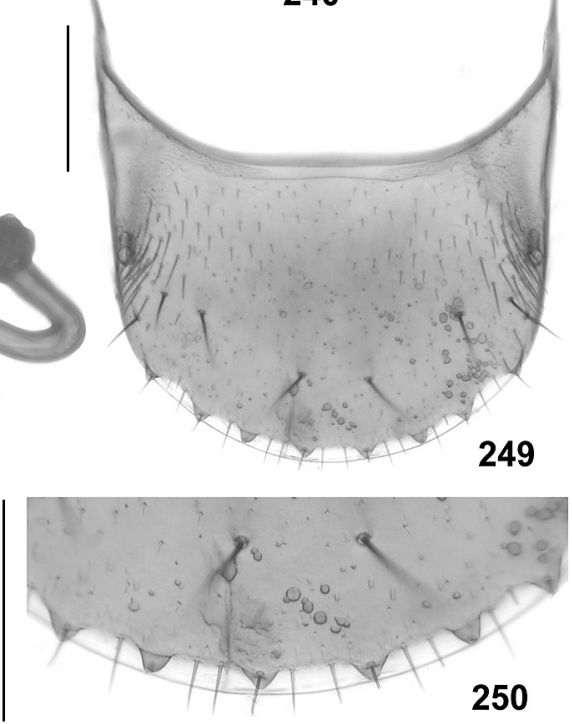

248
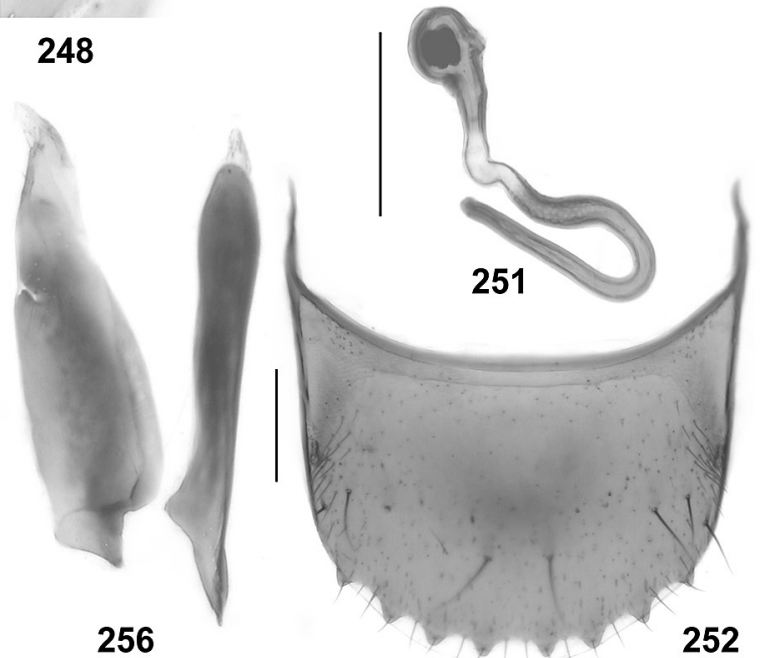

Figs 236-257. Orphnebius serratus (236-243), O. integer (244-250), O. latitibialis (251-252), and O. bicuspis from Laos (253257): median lobe of aedeagus in lateral and in ventral view (236-237, 244-245, 253-254); apex of median lobe in ventral view $(238,246,255)$; paramere $(239,247,256)$; tergite VIII $(240,249,252)$; spermatheca $(241-243,251,257)$; apex of paramerite (248); postero-median portion of tergite VIII (250). Scale bars: $0.2 \mathrm{~mm}$. 

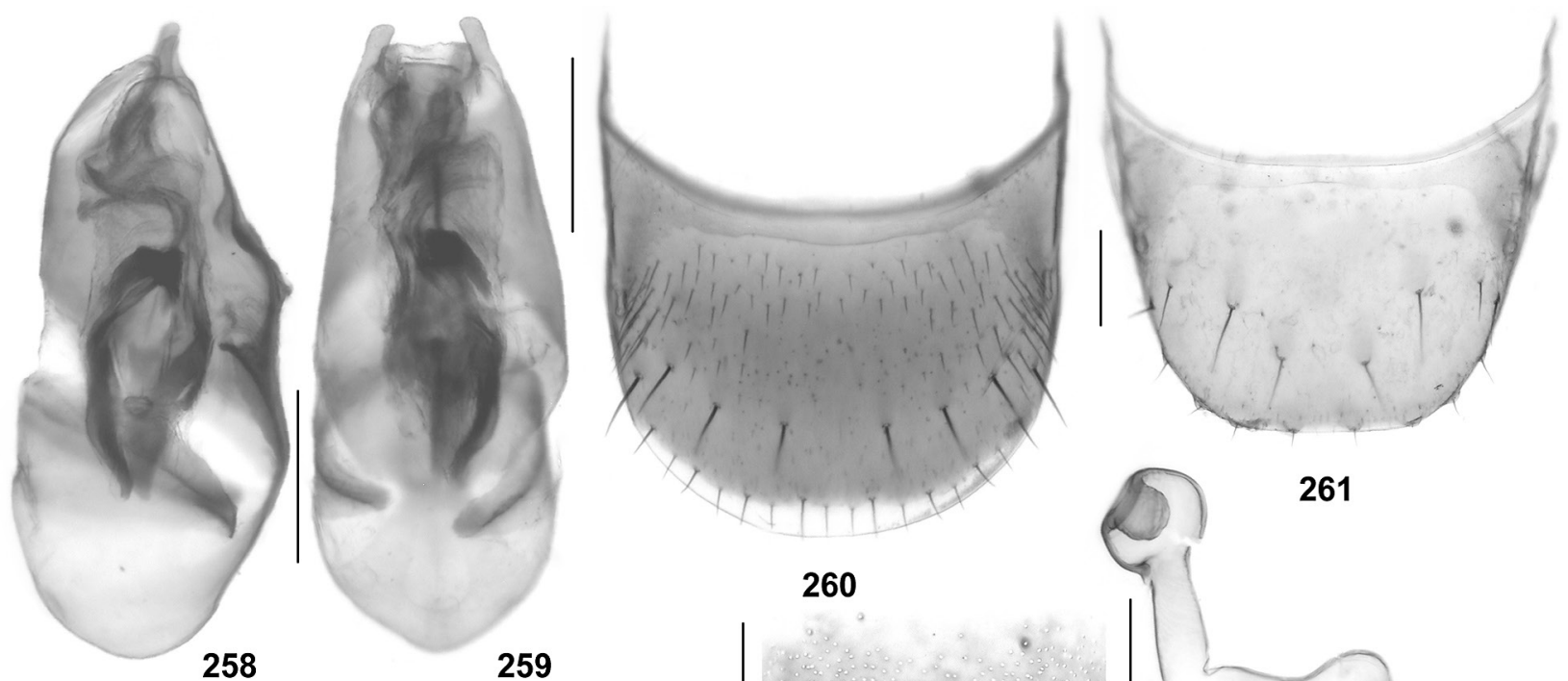

260

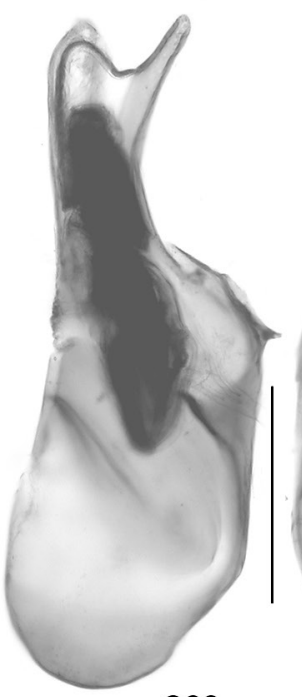

263

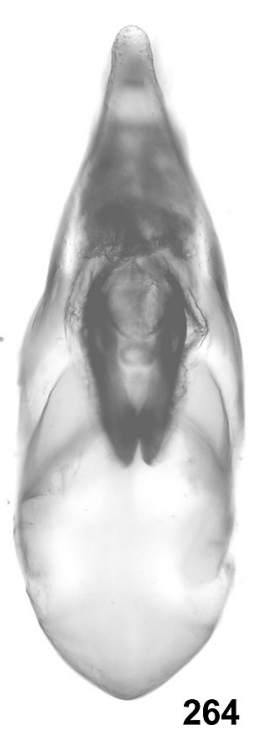

\section{9}
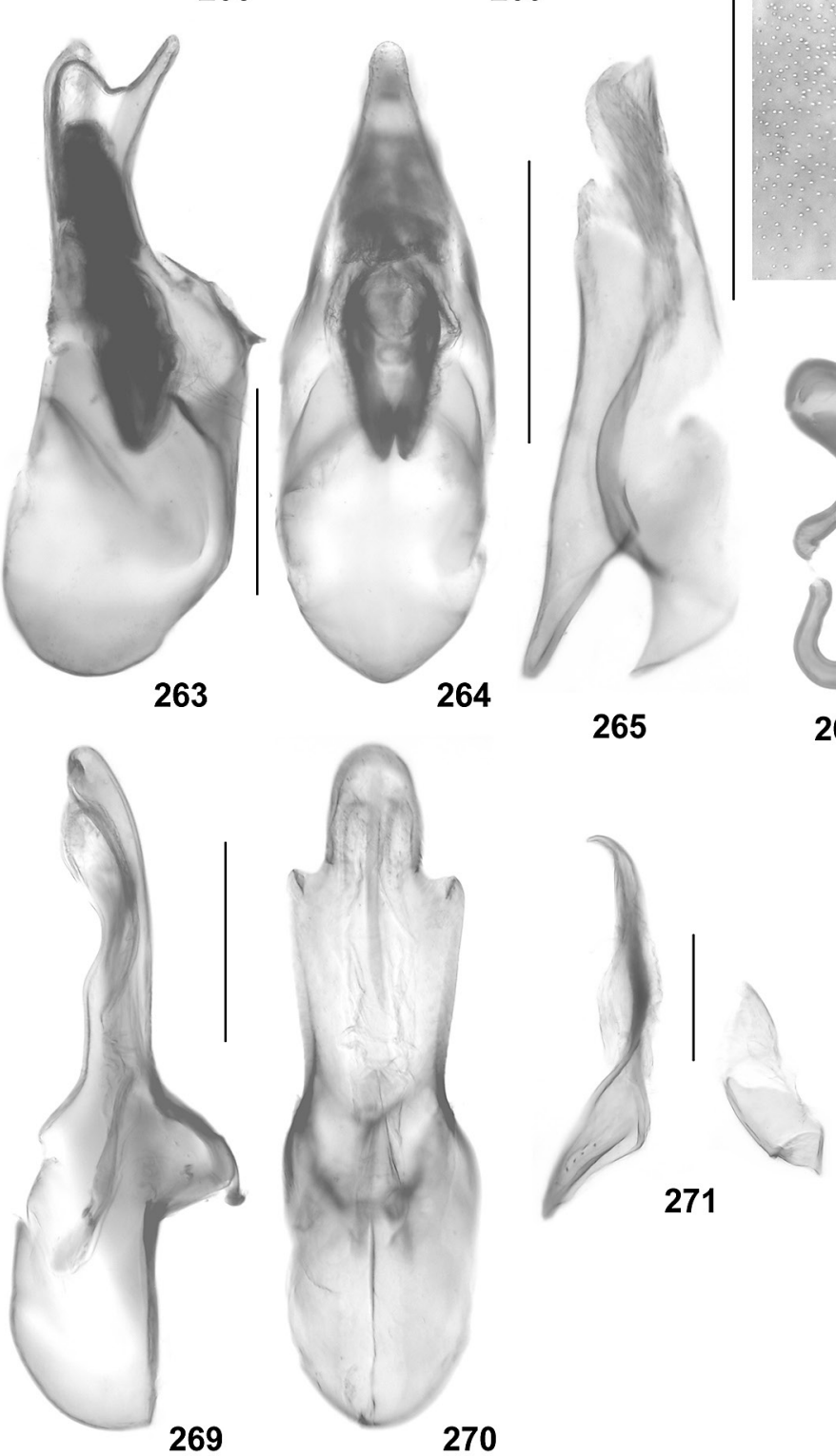

268
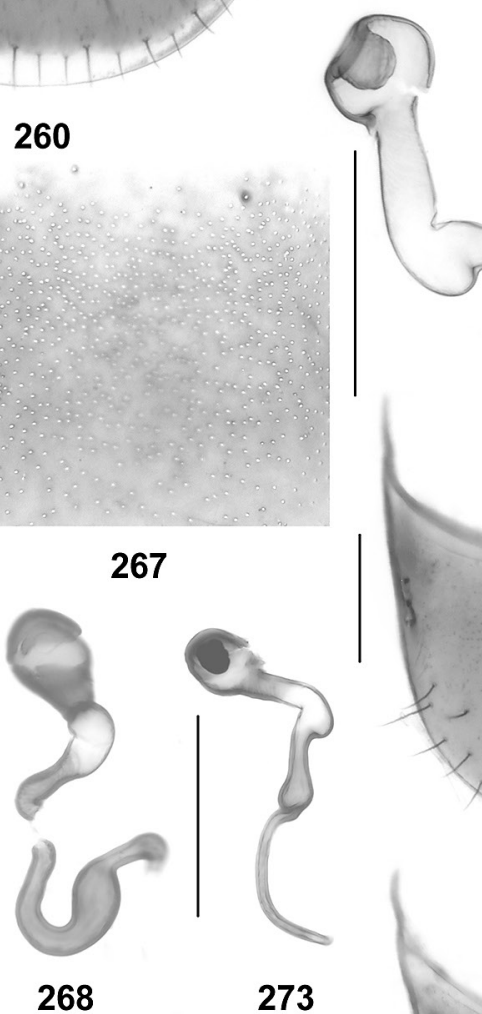

261
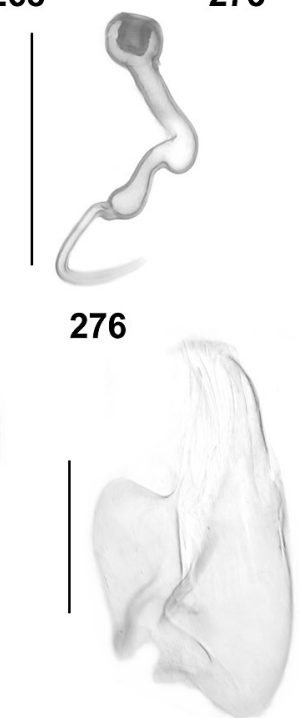

274

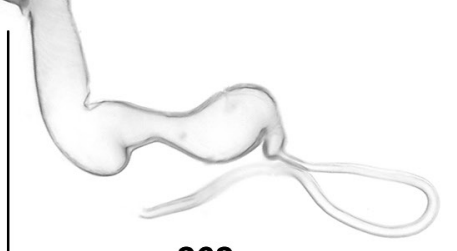

262
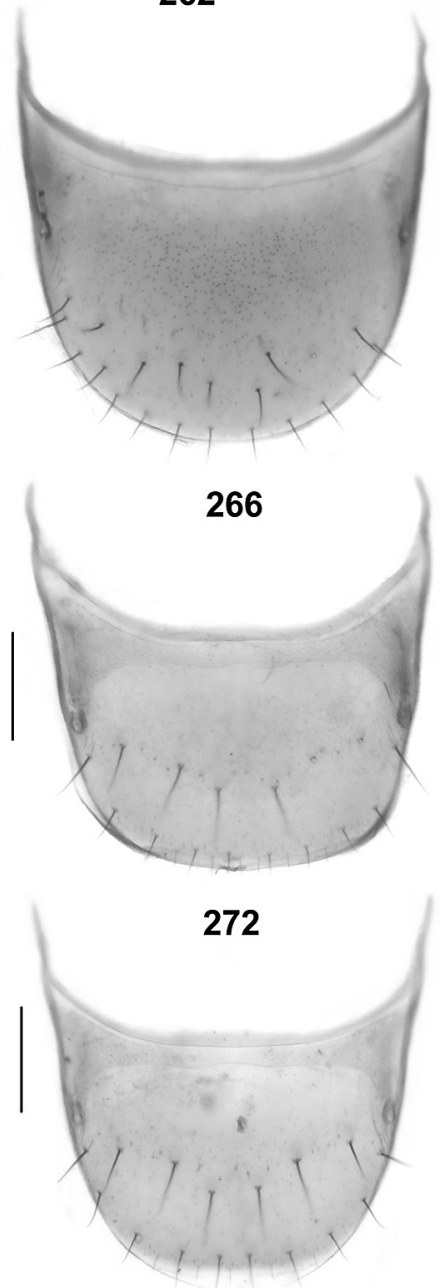

275

Figs 258-276. Orphnebius bicuspis (258-260; 258-259: India), O. opticus, syntype (261-262), O. fusicollis (263-268), O. reductus (269-273), and O. biformis (274-276): median lobe of aedeagus in lateral and in ventral view (258-259, 263-264, 269-270); tergite VIII $(260,261,266,272,275)$; spermatheca $(262,268,273,276)$; paramere $(265,271,274)$; anteromedian portion of sternite VIII (267). Scale bars: $0.2 \mathrm{~mm}$. 

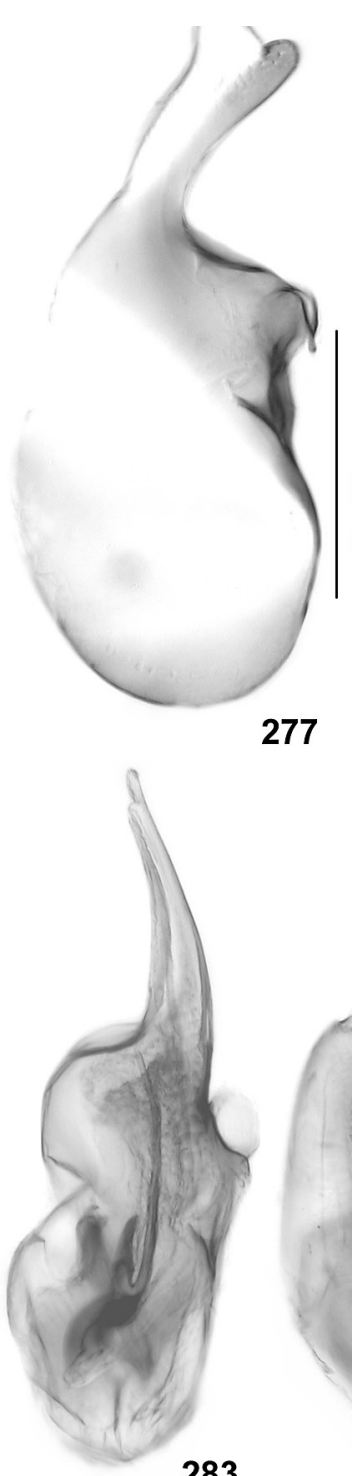

283

277
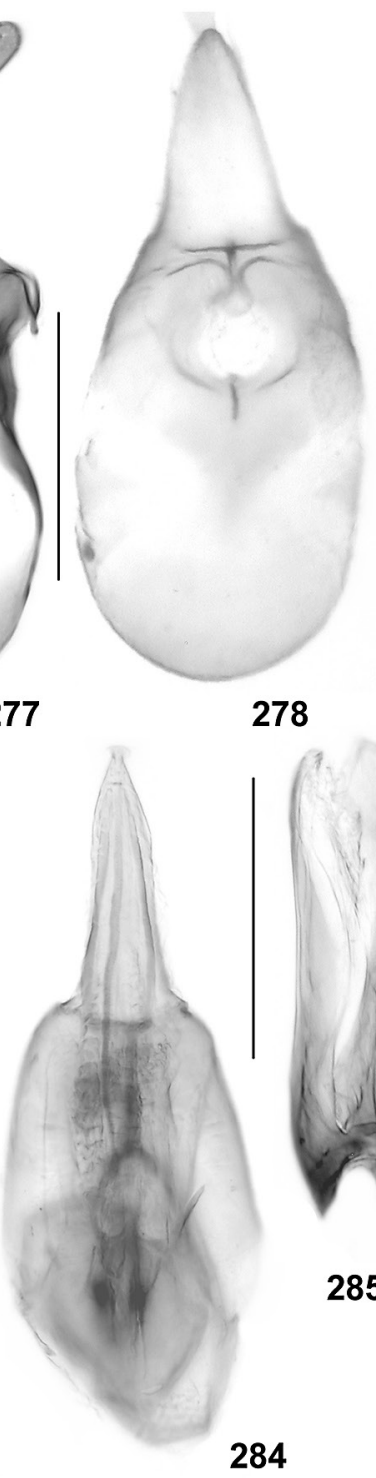

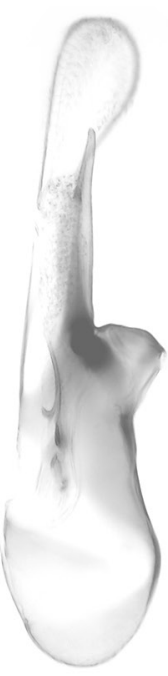

279

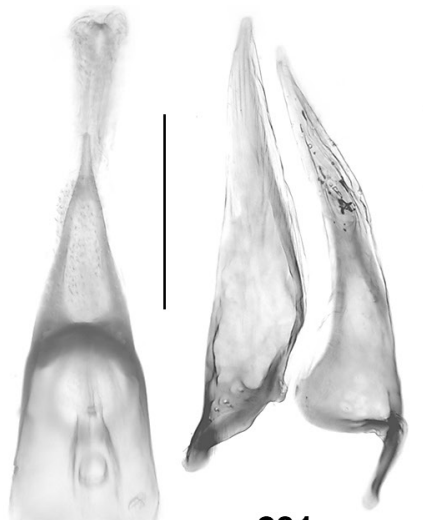

281

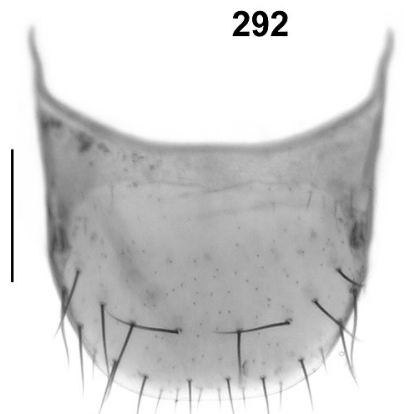

282

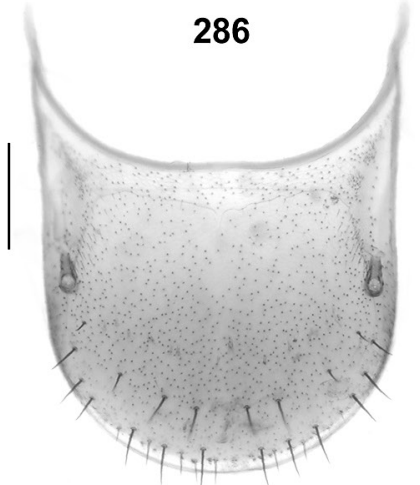

290
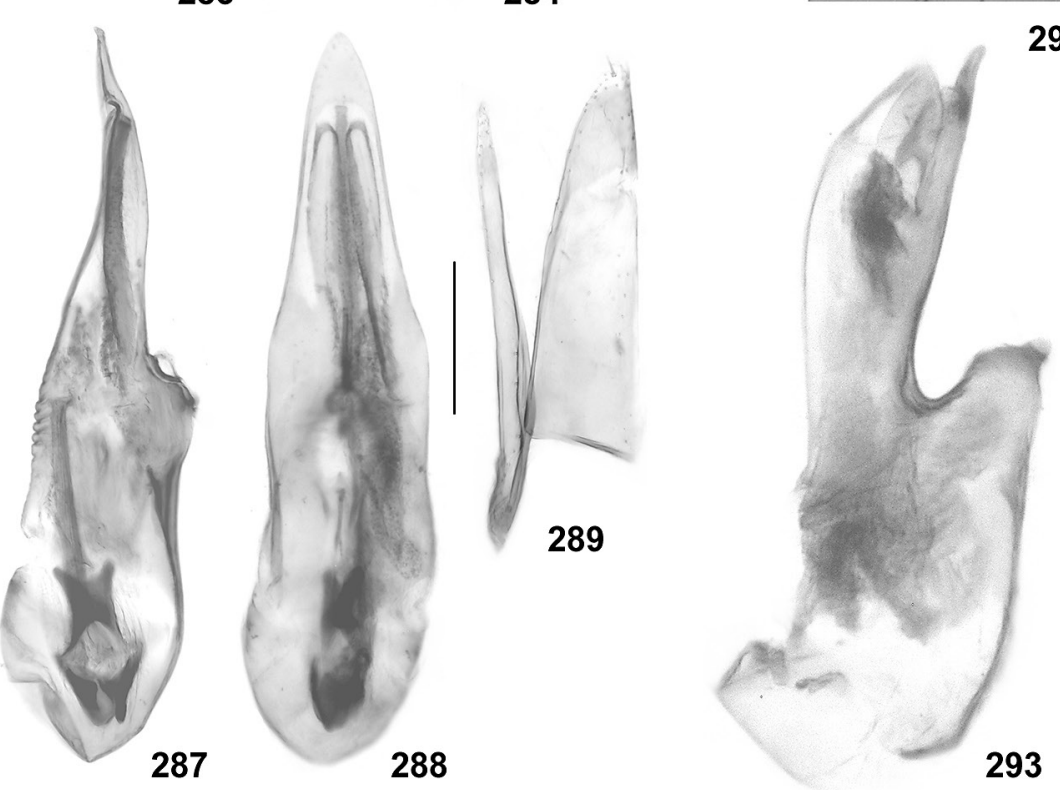

291
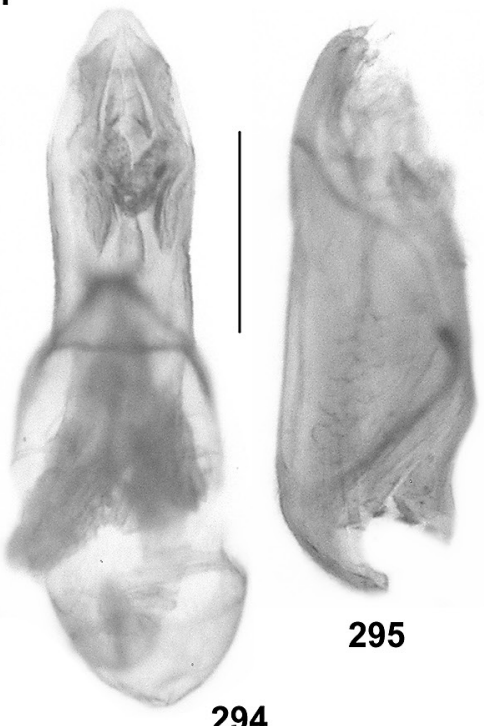

Figs 277-295. Orphnebius biformis (277-278), O. retunsus (279-282), O. fodens (283-286), O. effeminatus (287-292), and O. multimpressus (293-295): median lobe of aedeagus in lateral and in ventral view (277-280, 283-284, 287-288, 293-294); paramere $(281,285,289,295)$; tergite VIII $(282,286,290)$; median portion of tergite VIII (291); male tergites IX-X (292). Scale bars: $0.2 \mathrm{~mm}$. 


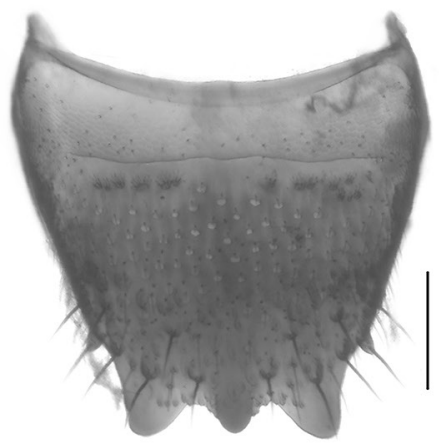

296

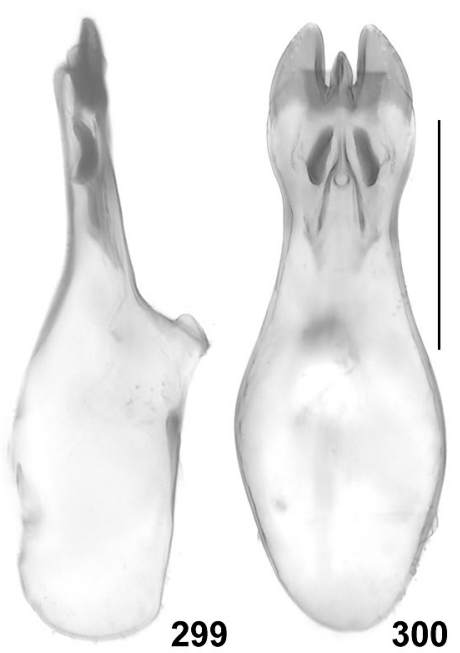

299

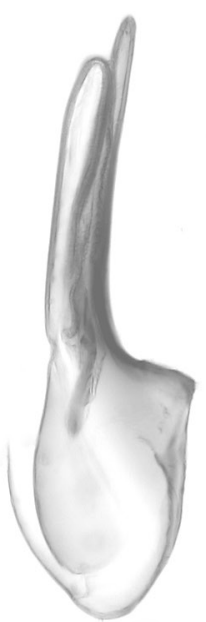

307

308

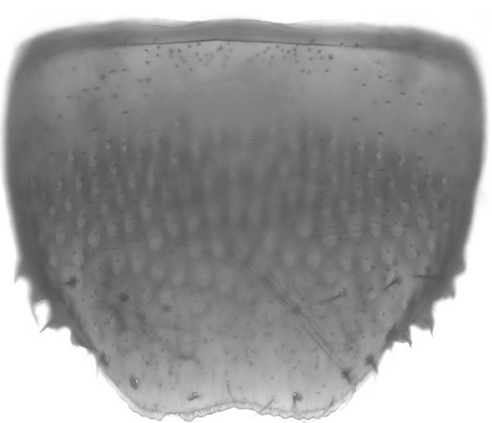

297

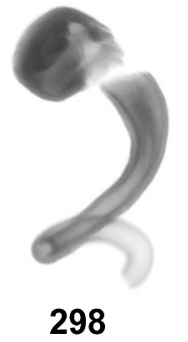

298

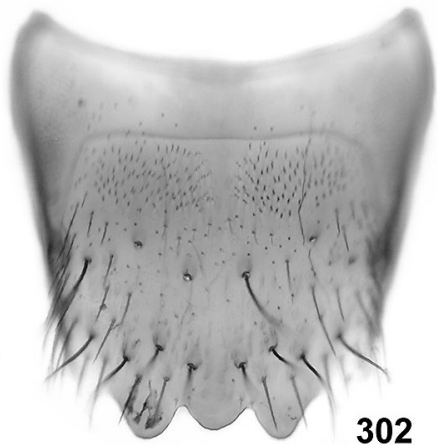

302

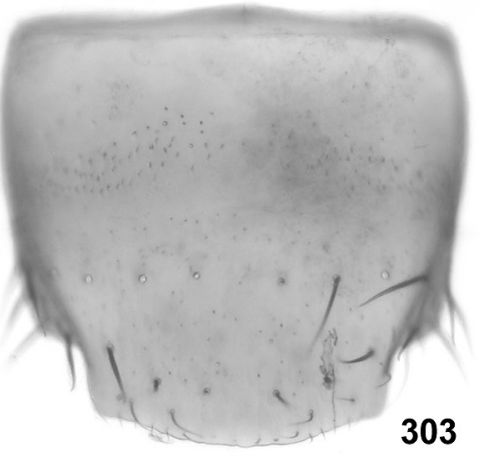

303

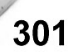

304

305

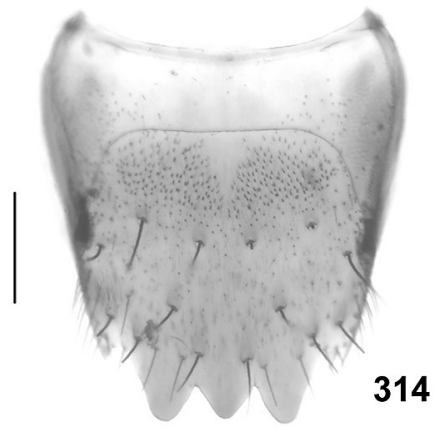

314

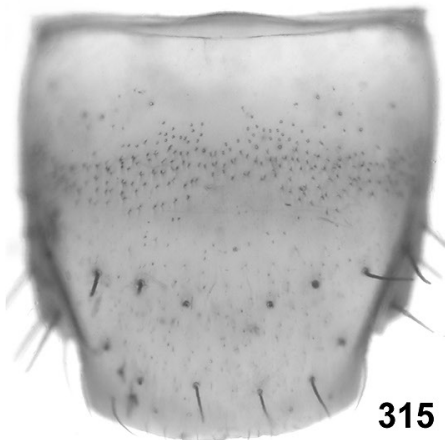

309
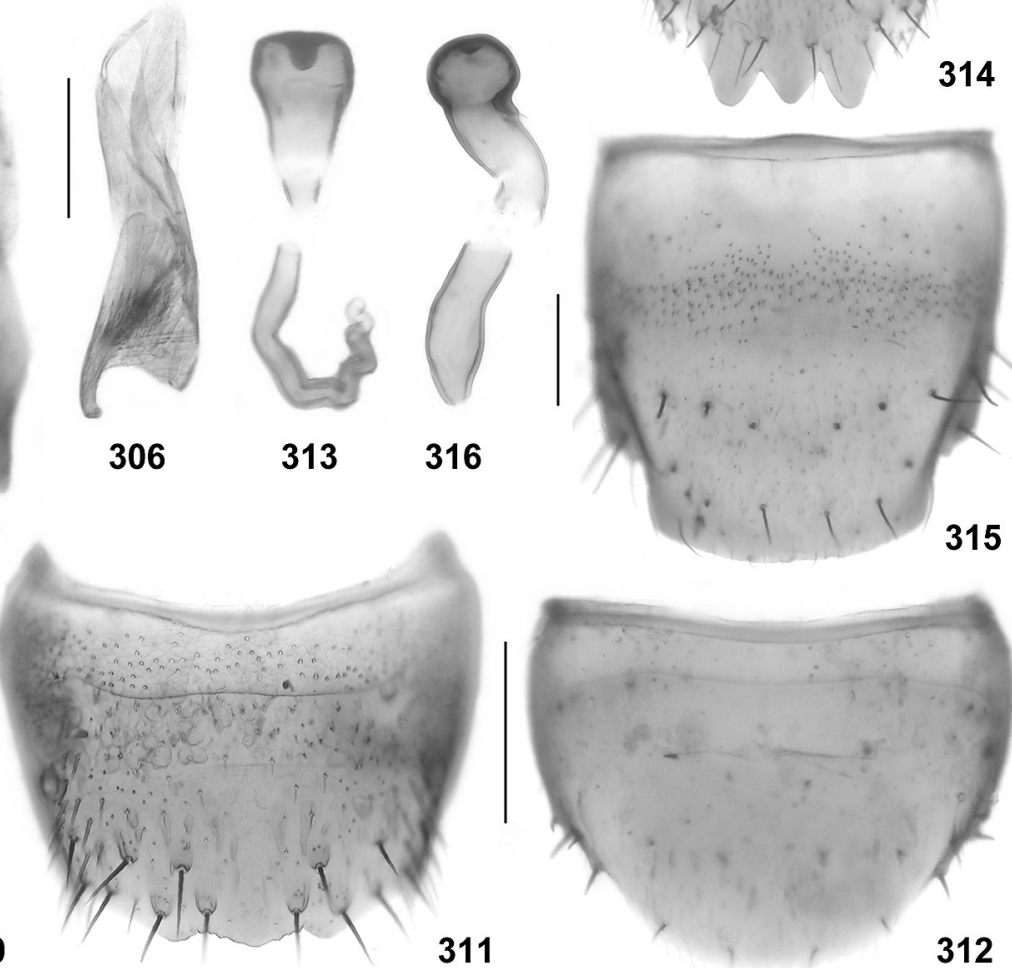

Figs 296-316. Orphnebius niger (296-298), O. siamensis (299-303), O. discrepans (304-306), O. triapicalis (307-310), O. gracilior (311-313), and O. sexcarinatus (314-316): tergite VIII (296, 302, 310, 311, 314); female sternite VIII $(297,312,315)$; spermatheca $(298,313,316)$; median lobe of aedeagus in lateral and in ventral view $(299-300,304-305,307-308)$; paramere $(301,306,309)$; male sternite VIII (303). Scale bars: $0.2 \mathrm{~mm}$. 

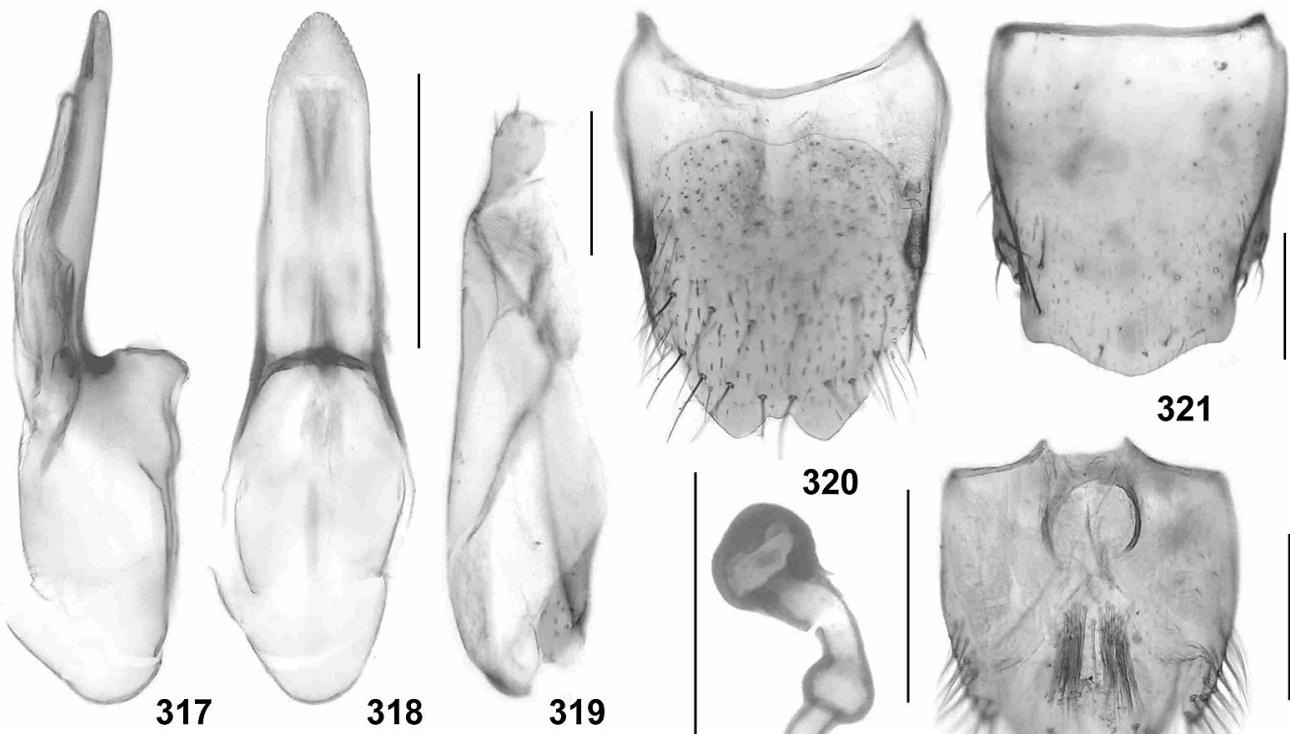

321

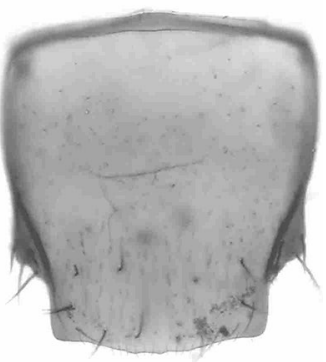

322
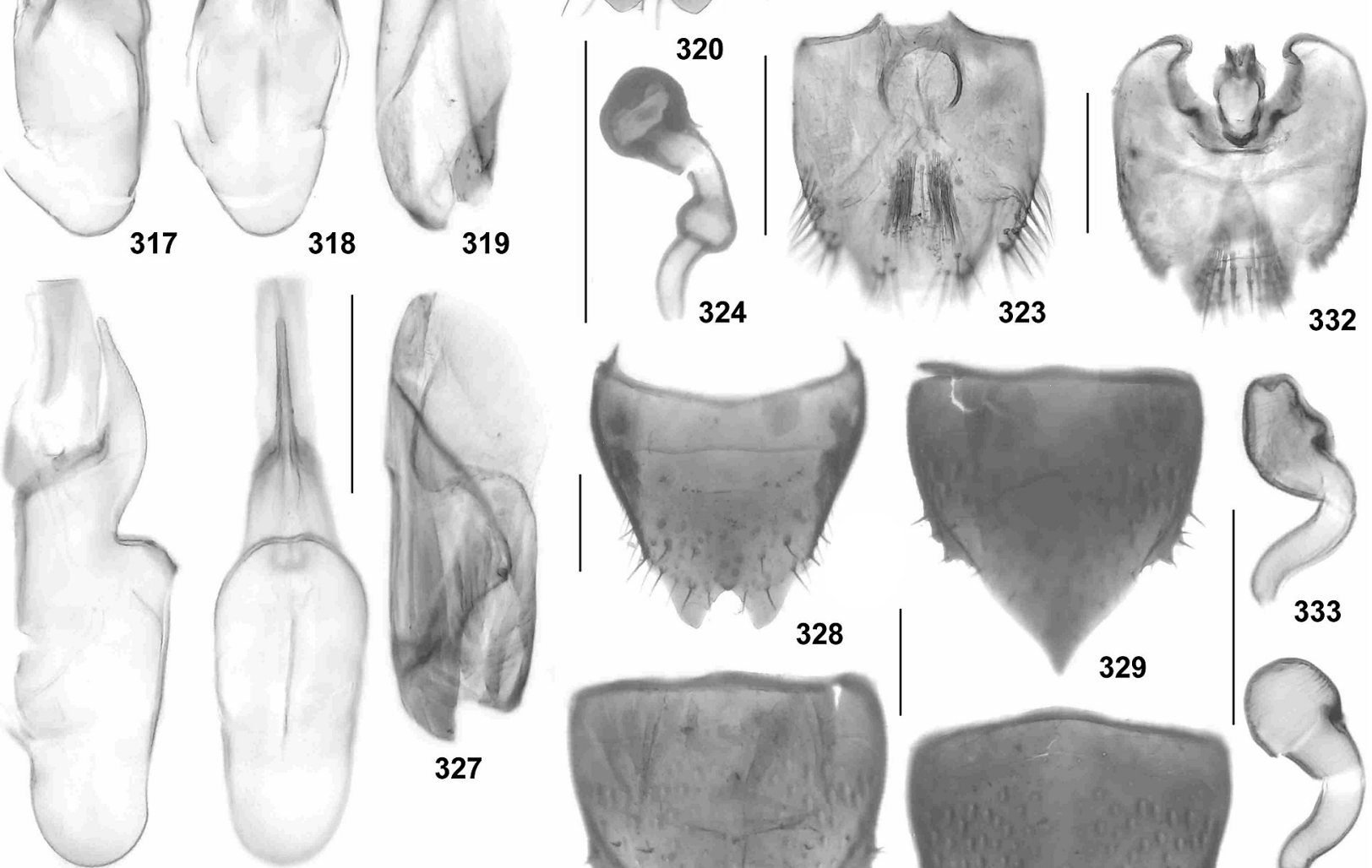

326
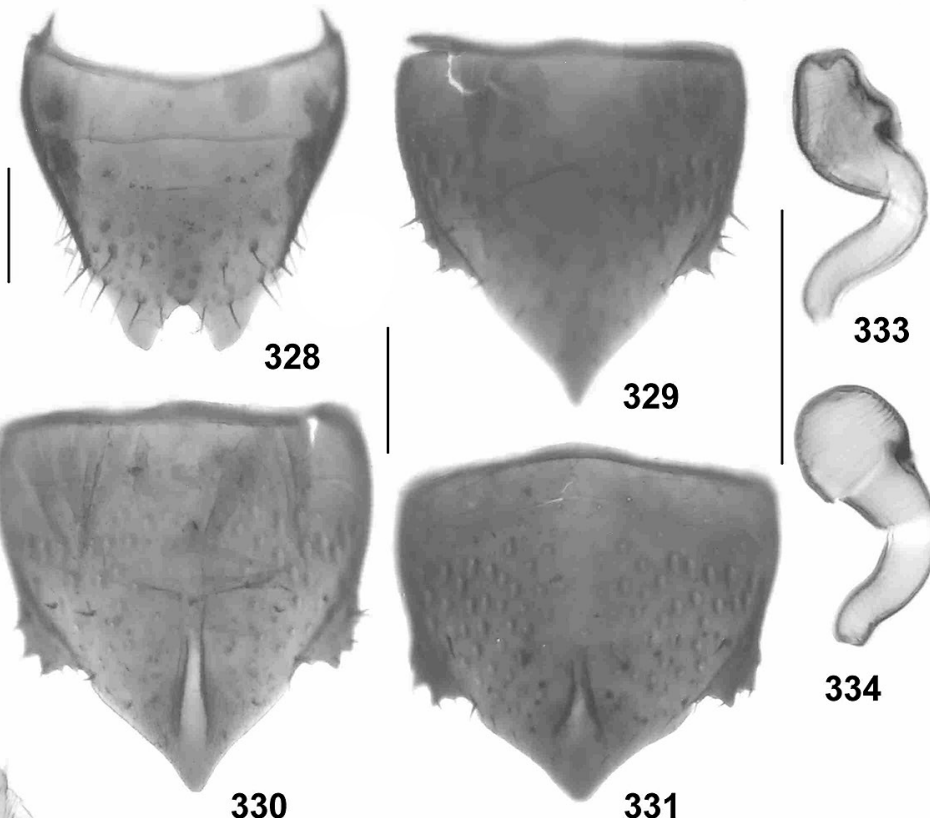

333
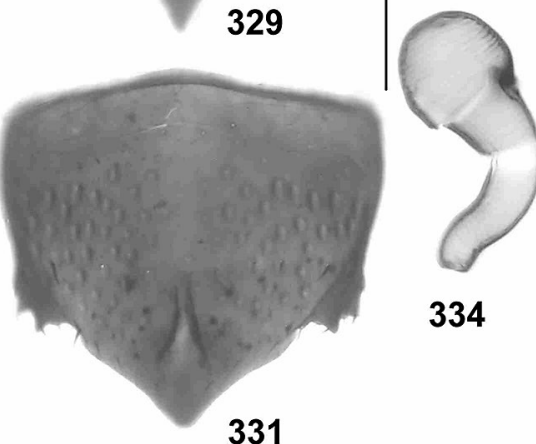

334

331
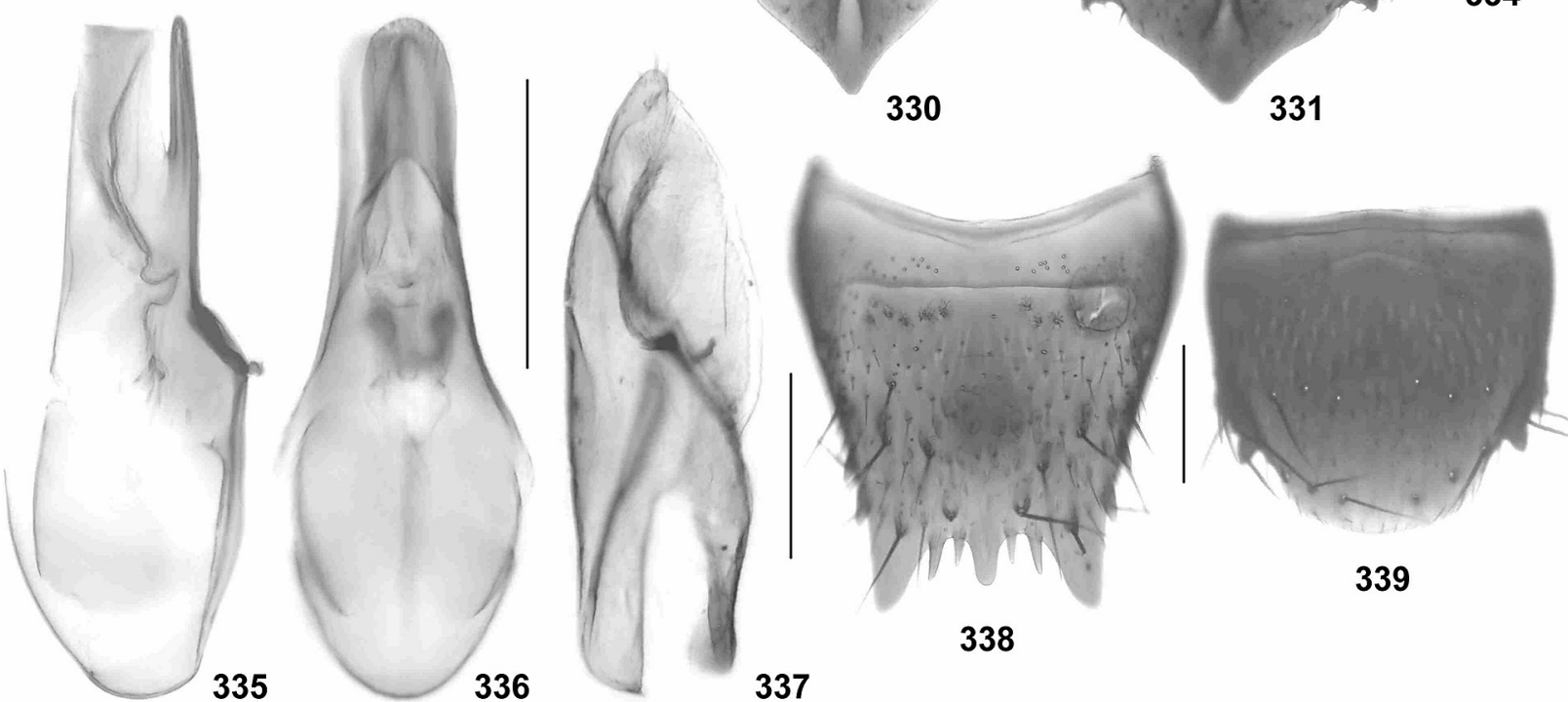

338

Figs 317-339. Orphnebius spoliatus (317-324), O. cultellatus (325-334: 331, 334: Laos), and O. septemcuspis (335-339): median lobe of aedeagus in lateral and in ventral view (317-318, 325-326, 335-336); paramere (319, 327, 337); tergite VIII $(320,328,338)$; male sternite VIII $(321,329,339)$; female sternite VIII $(322,330-331)$; female segments IX-X in ventral view (323, 332); spermatheca $(324,333-334)$. Scale bars: $0.2 \mathrm{~mm}$. 


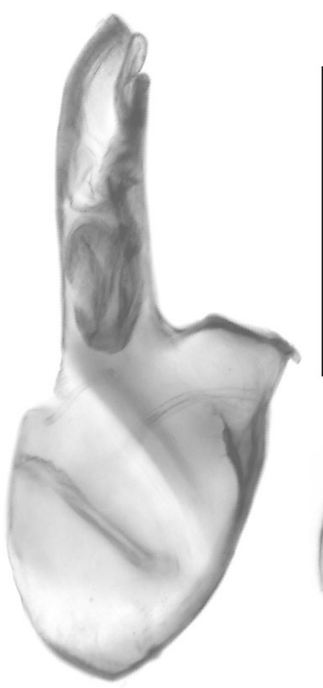

340
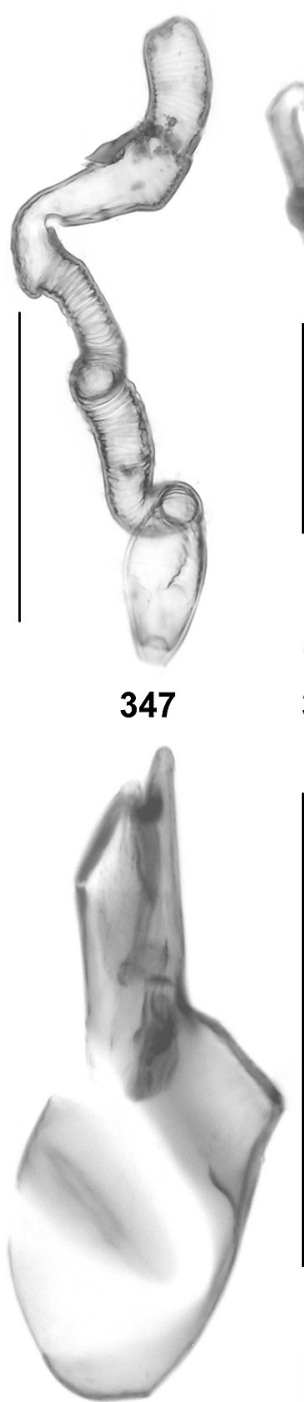

354

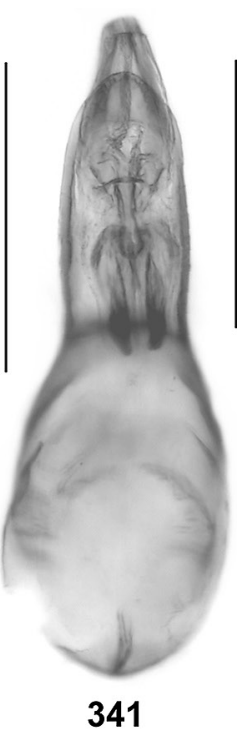

.

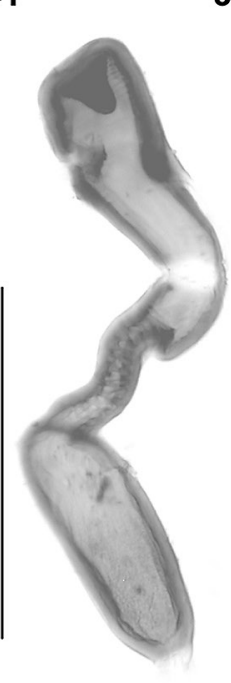

350

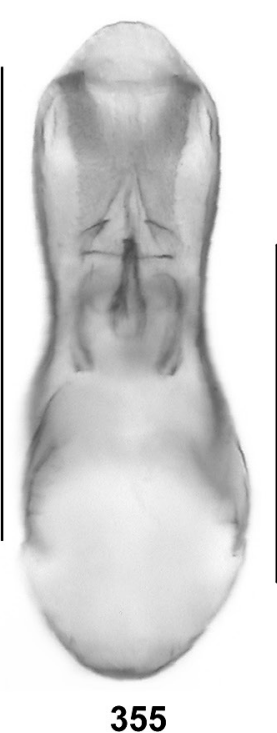

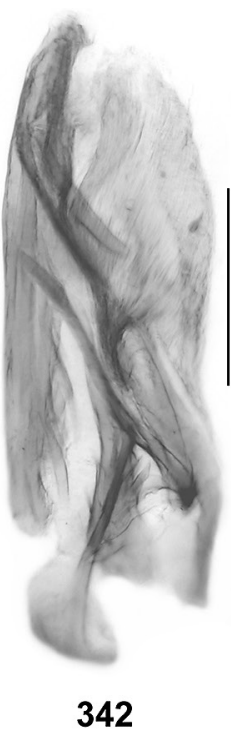

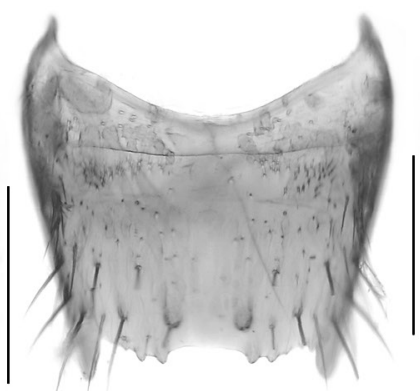

343

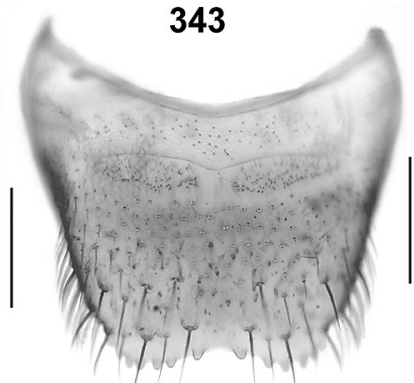

345
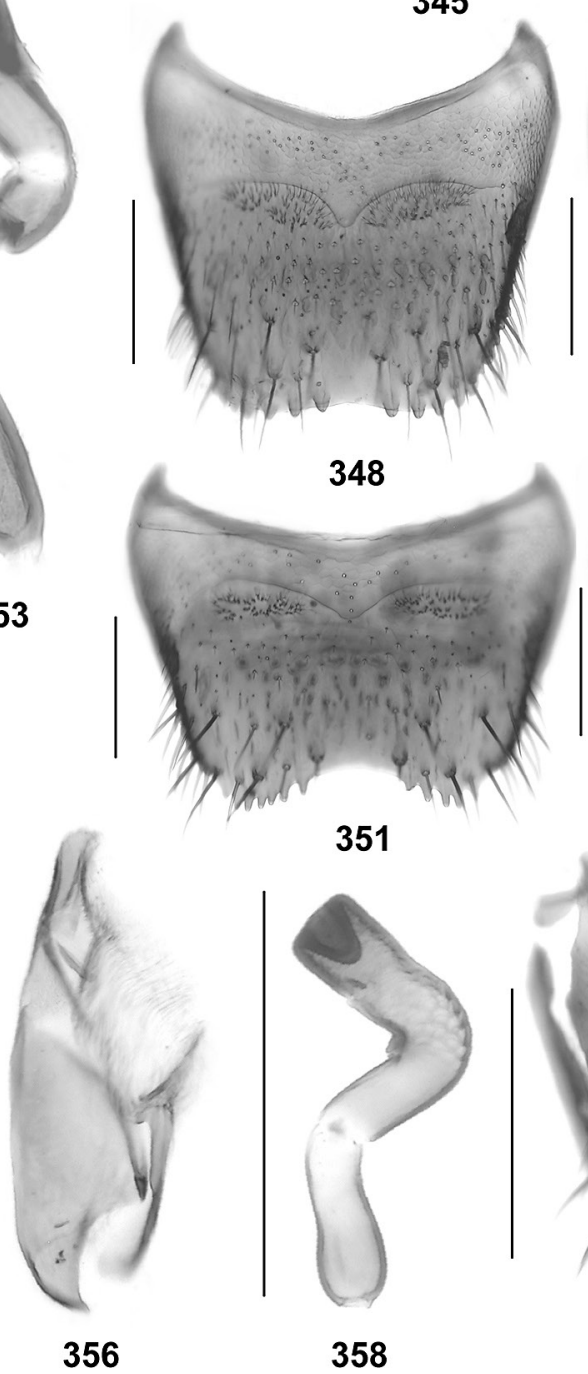

351
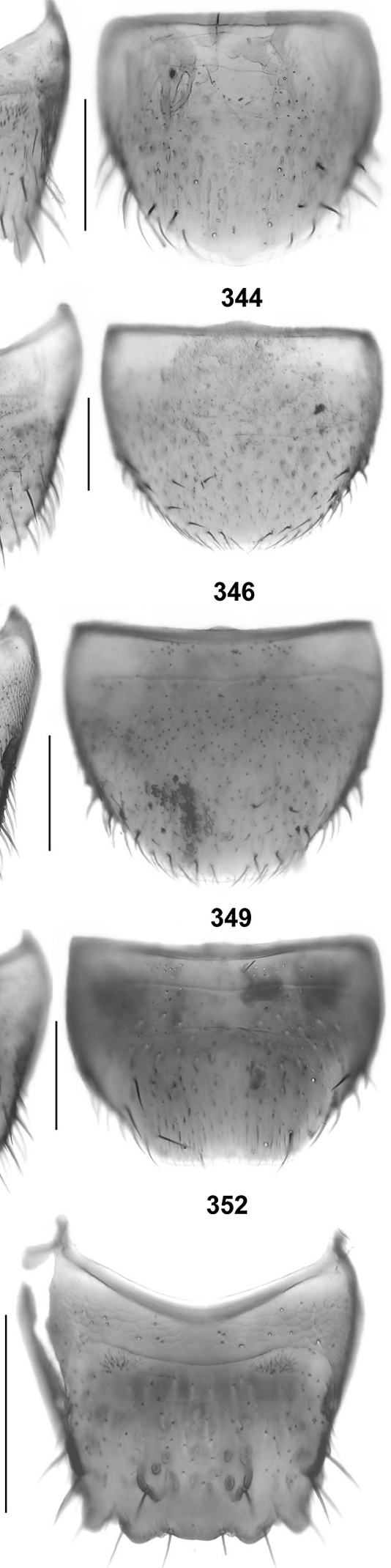

344

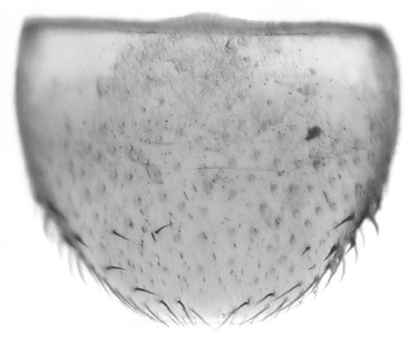

346

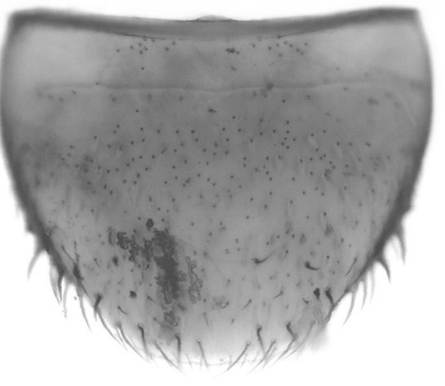

349

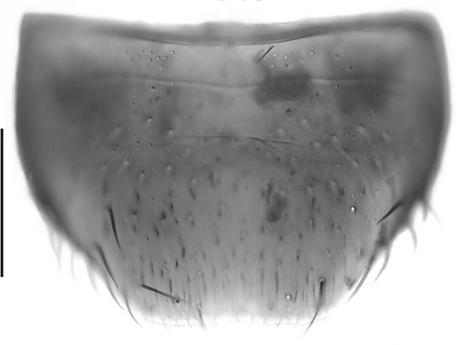

352
358

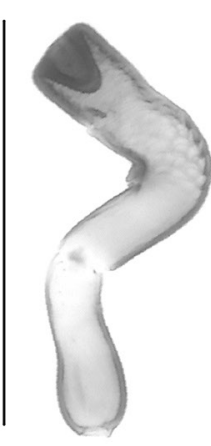

357

Figs 340-358. Orphnebius vates (340-344), O. tortus (345-347), O.baccillatus (348-350), O.carinatus (351-353), and O. dispar (354-358): median lobe of aedeagus in lateral and in ventral view (340-341, 354-355); paramere (342, 356); tergite VIII $(343,345,348,351,357)$; male sternite VIII (344); female sternite VIII $(346,349,352)$; spermatheca $(347,350,353,358)$. Scale bars: $0.2 \mathrm{~mm}$. 

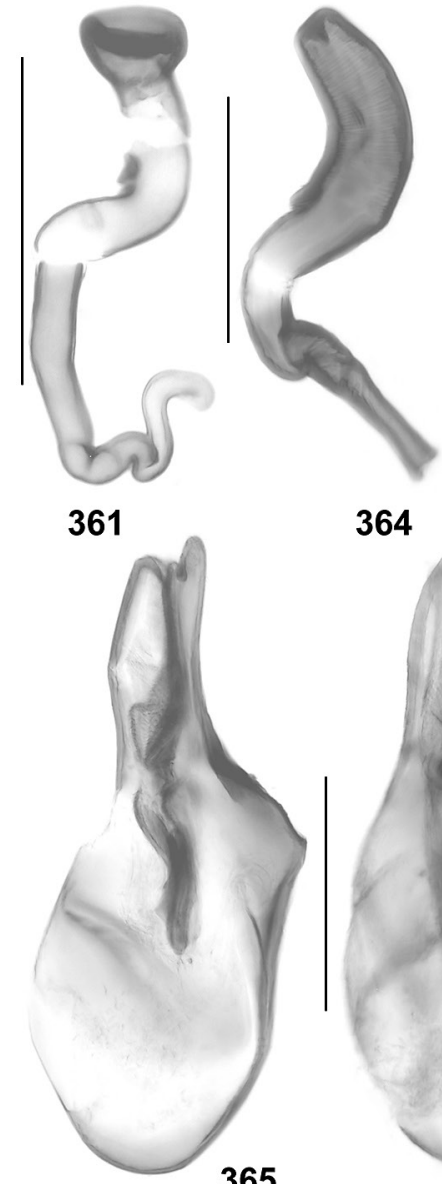

365

\begin{abstract}
364
\end{abstract}
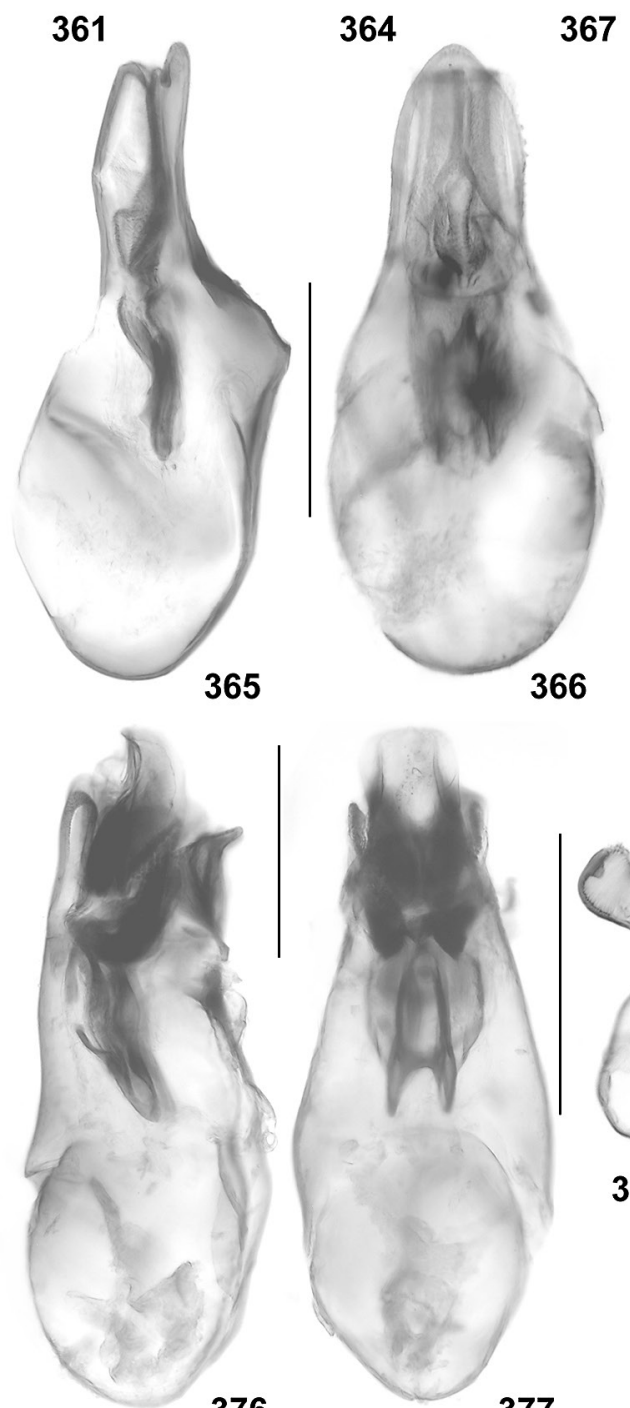

376

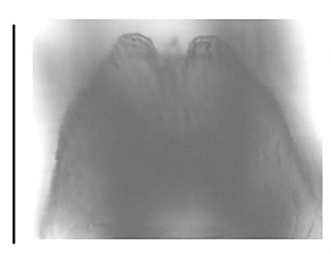

378

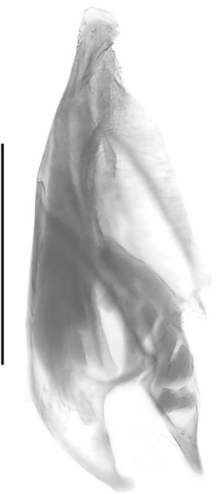

367

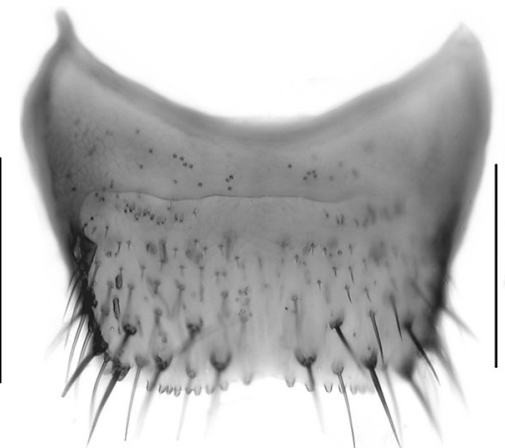

359

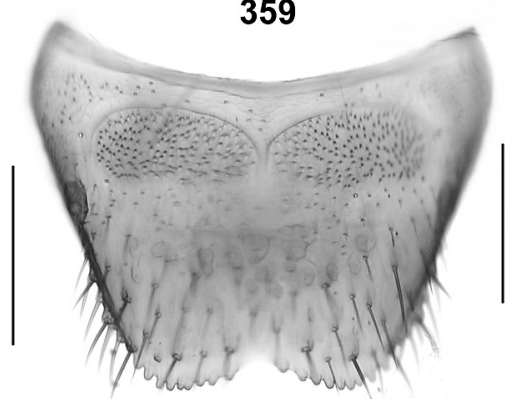

362
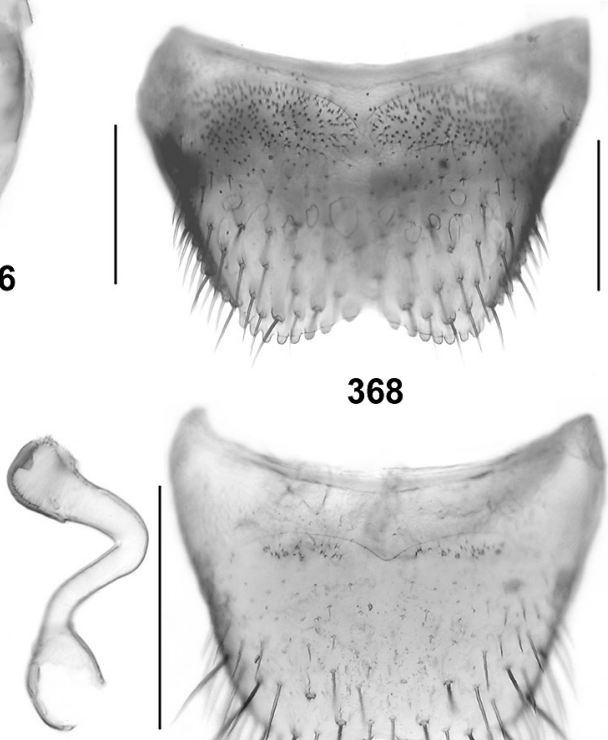

372
368

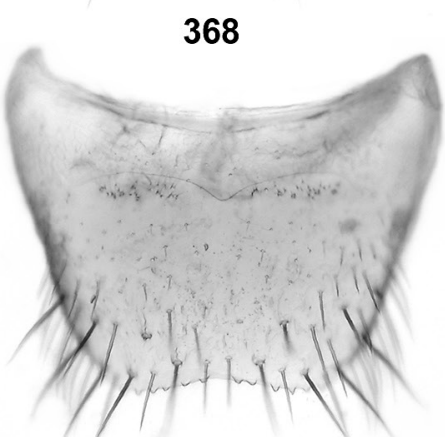

370

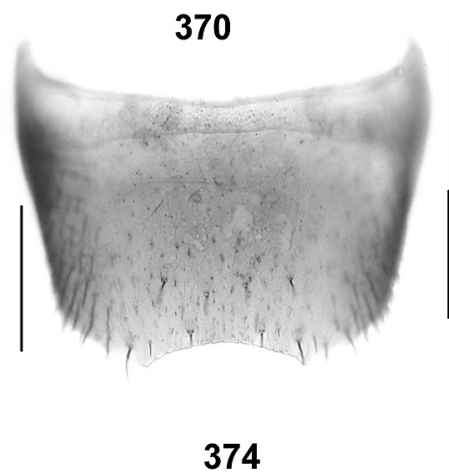

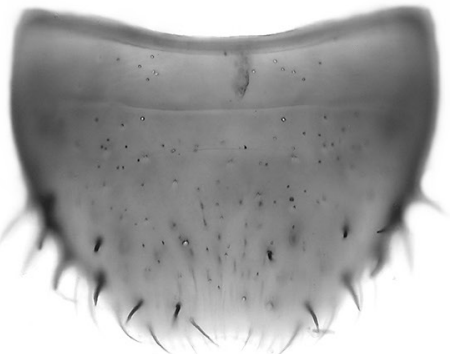

360

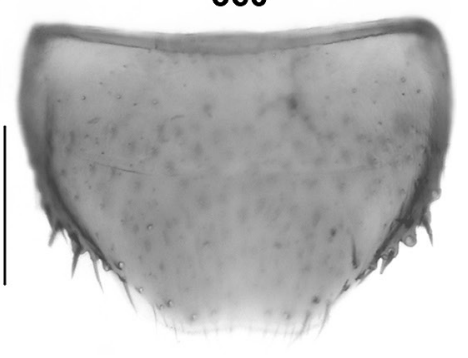

363

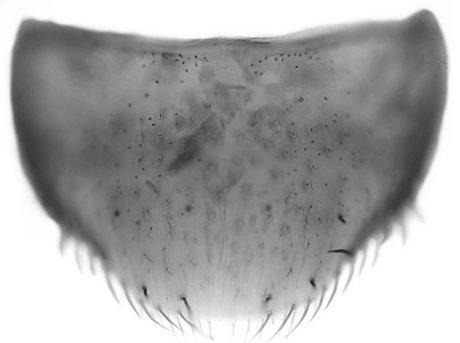

369

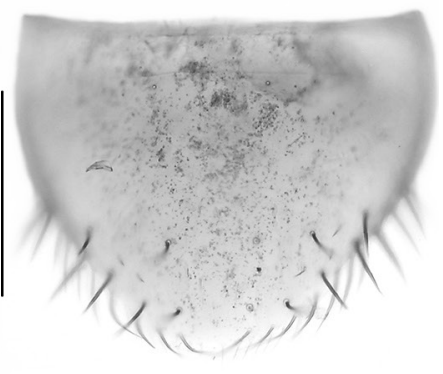

371

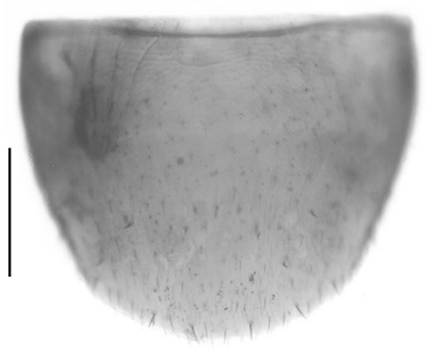

375

Figs 359-378. Orphnebius laticeps (359-361), O. biimpressus (362-364), O. ulcerosus (365-369), O. falagrioides (370-372), and Drusilla bifida (373-378): tergite VIII (359, 362, 368, 370, 374); female sternite VIII $(360,363,371)$; spermatheca $(361,364,372)$; median lobe of aedeagus in lateral and in ventral view (365-366, 376-377); paramere (367); male sternite VIII (369, 375); posteromedian portion or head (373); apex of ventral process of aedeagus (378). Scale bars: 359-372, 374-377: 0.2 mm; 373, $378: 0.1 \mathrm{~mm}$. 


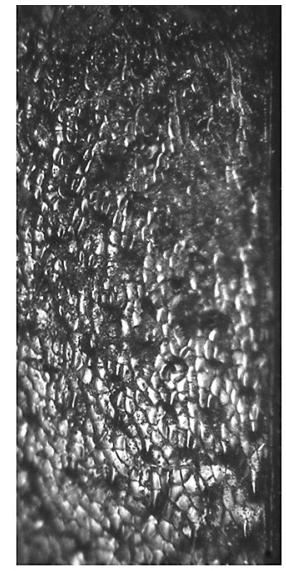

379

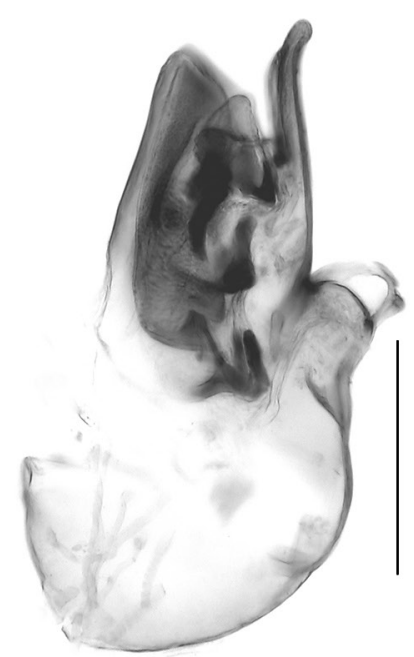

380

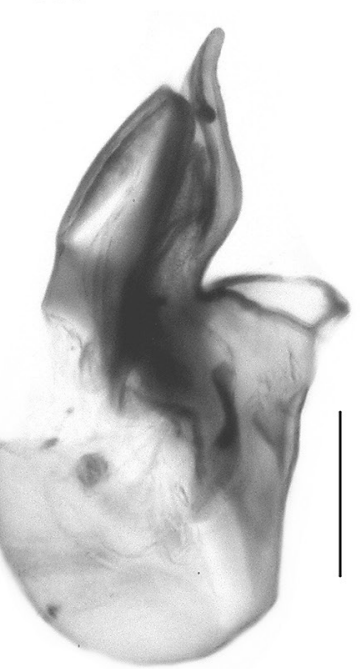

384

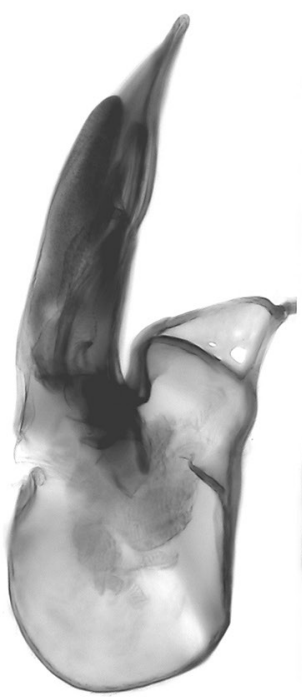

389
385

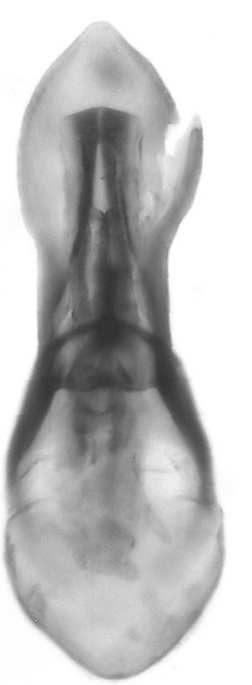

390
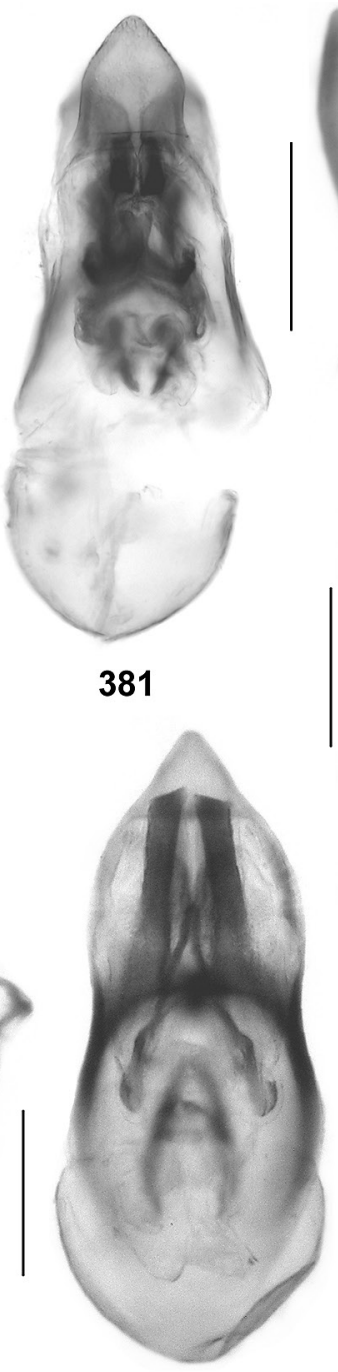

386

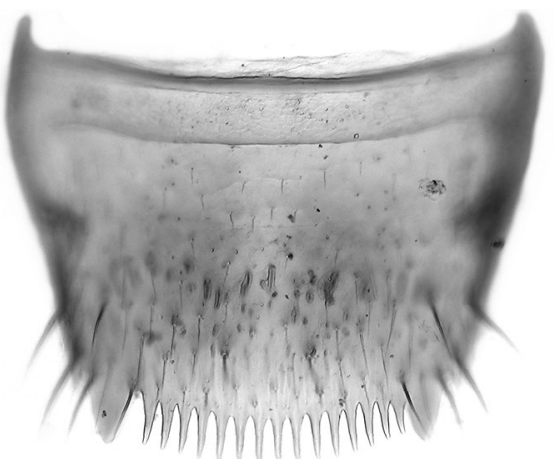

382

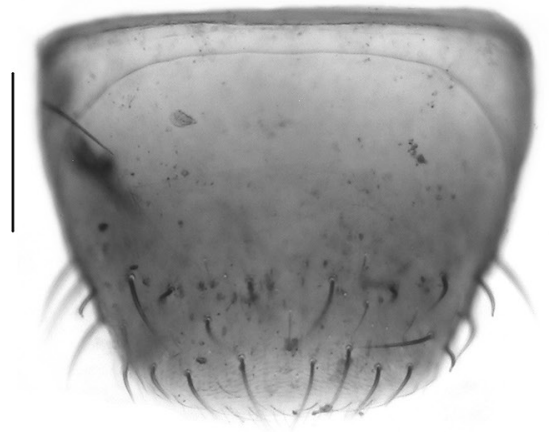

383

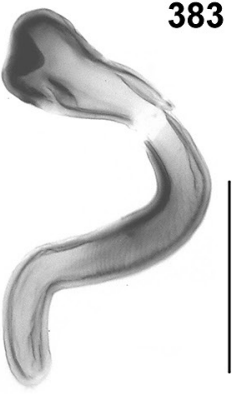

387

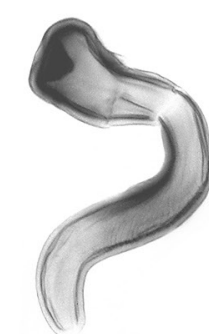

388

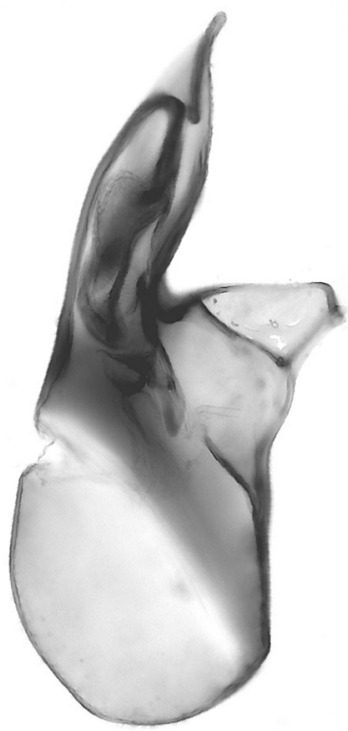

391

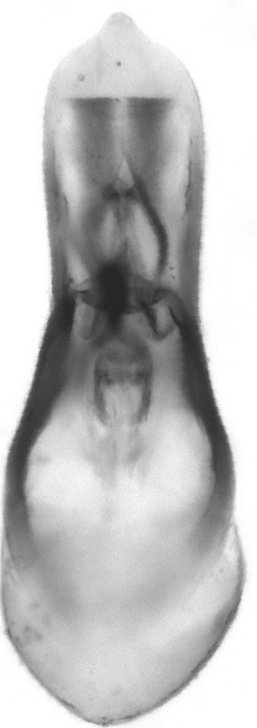

392

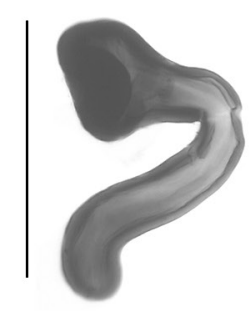

395

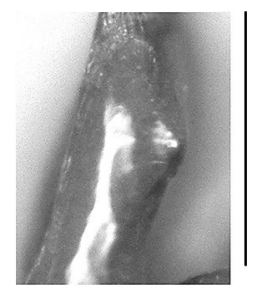

393

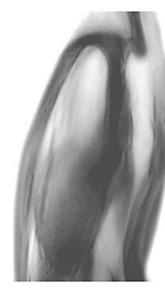

394

Figs 379-395. Drusilla bifida (379), Rabdotodrusilla pectinata (380-383), Amaurodera arunica (384-388), A. gilvios (389-390, 395), and A. reticulata (391-394): sutural portion of left elytron (379); median lobe of aedeagus in lateral and in ventral view (380381, 385-386, 389-392); male tergite VIII (382); male sternite VIII (383); male pronotum (384); spermatheca (387-388, 395); subapical portion of median lobe of aedeagus in dry preparation (393); subapical portion of median lobe of aedeagus in transparent light (394). Scale bars: 384: 0.5 mm; 379-383, 385-392, 395: 0.2 mm; 393-394: $0.1 \mathrm{~mm}$. 

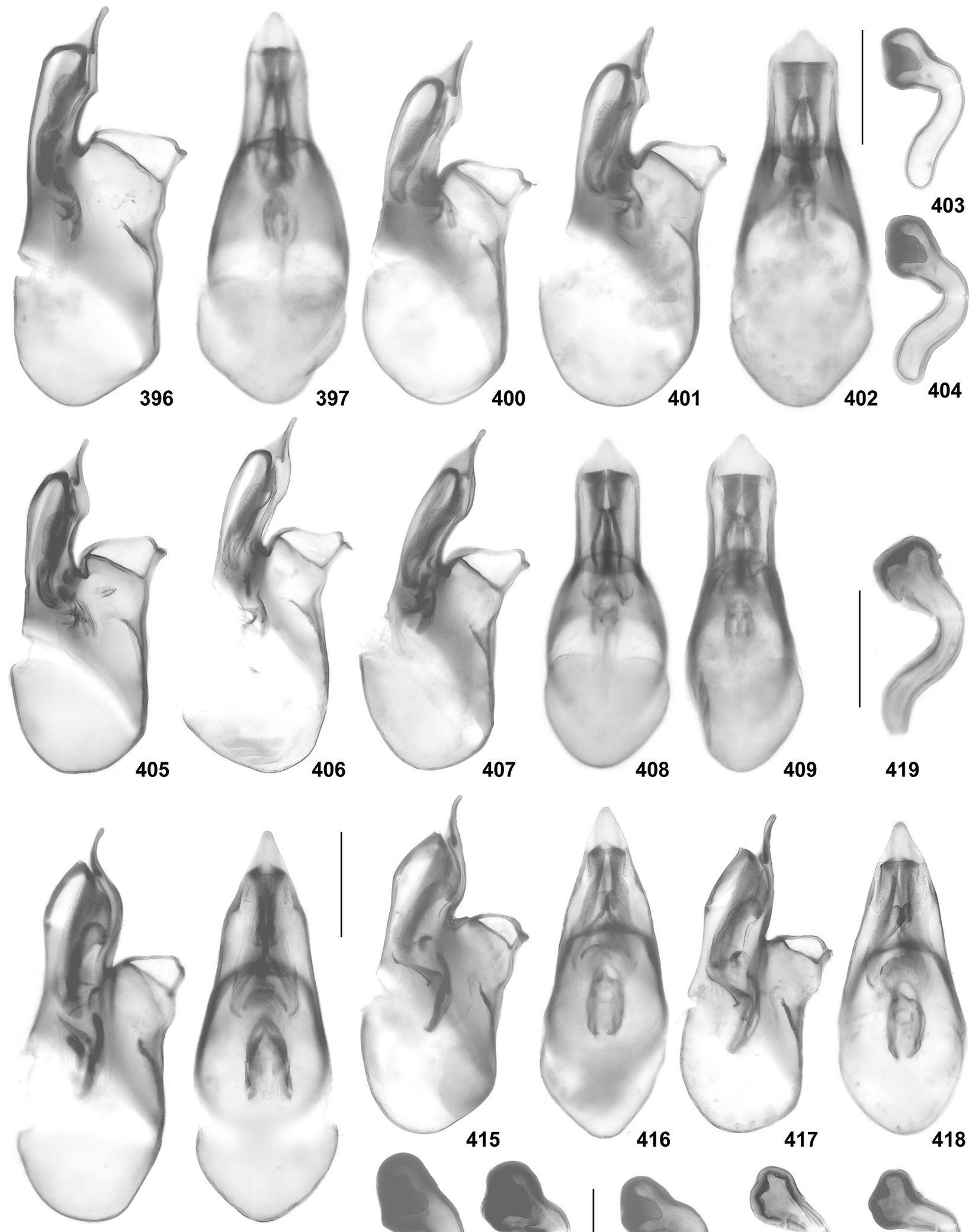

411
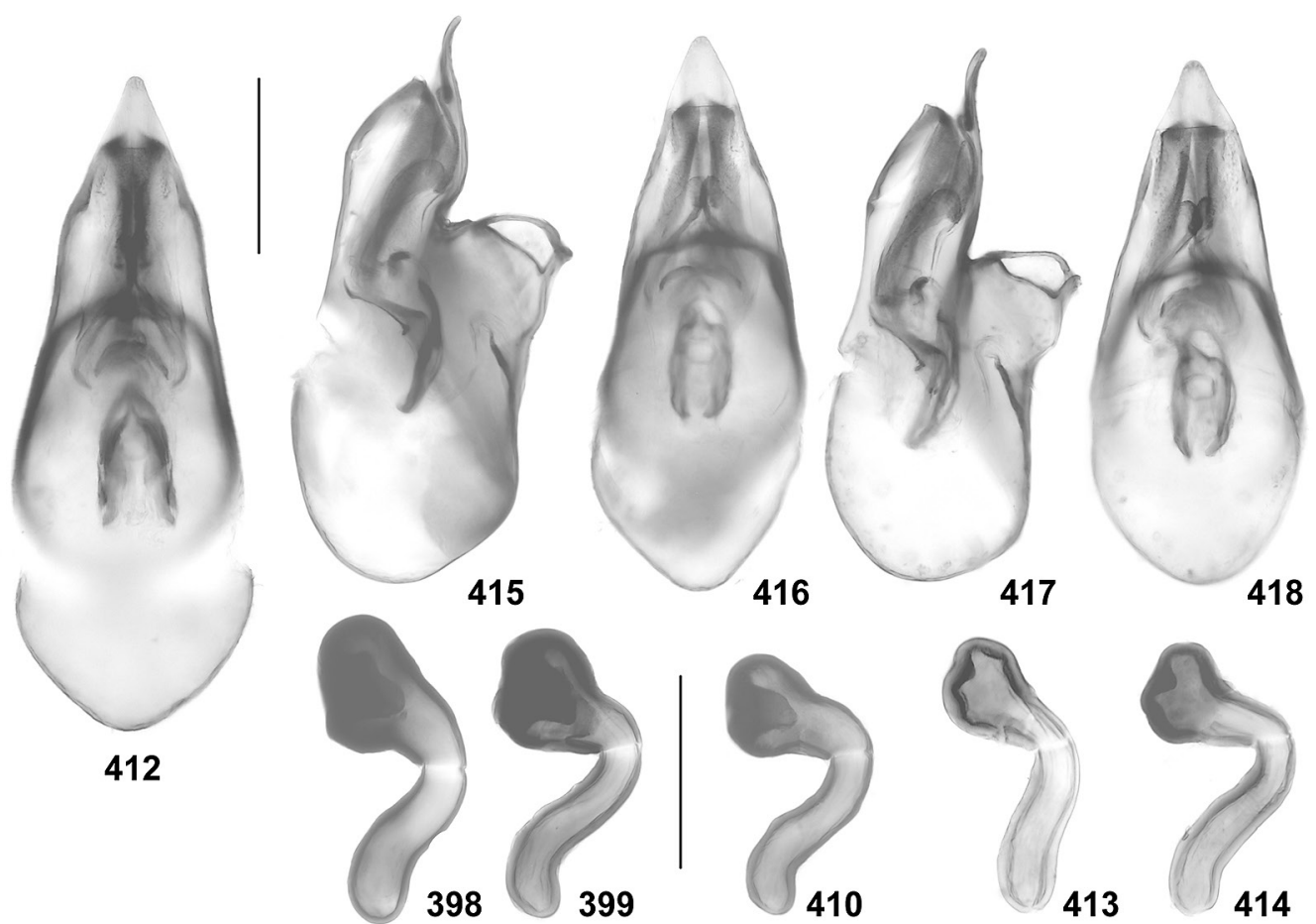

Figs 396-419. Amaurodera dentata (396-399), A. parvoculata (400-404), A. thailandensis (405-410), A. fasciata (411-414), and A. meorum (415-419: 415-416, 419: Khao Yai Nat. Park): median lobe of aedeagus in lateral and in ventral view (396-397, 400-402, 405-409, 411-412, 415-418); spermatheca (398-399, 403-404, 410, 413-414, 419). Scale bars: $0.2 \mathrm{~mm}$. 


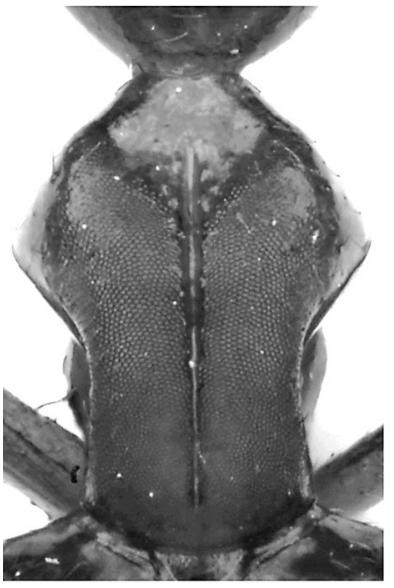

423

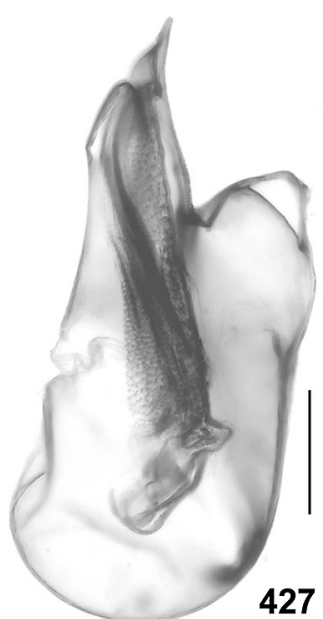

427
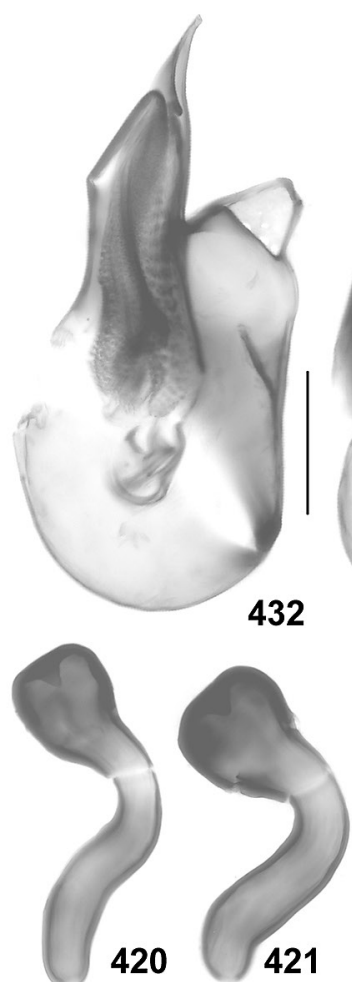

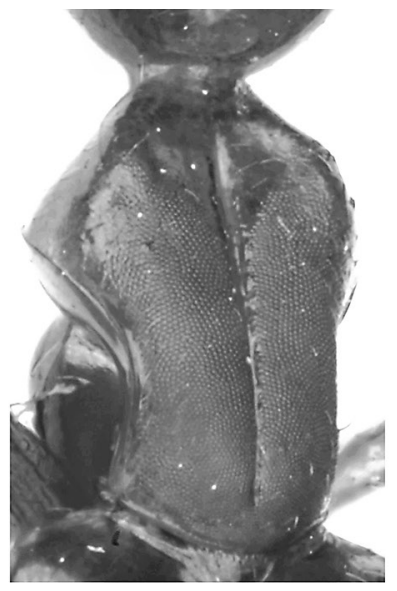

424

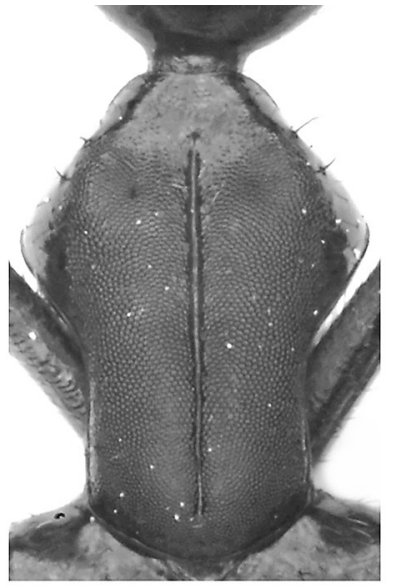

425

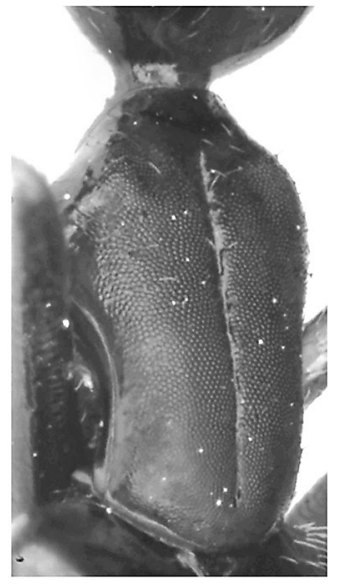

426
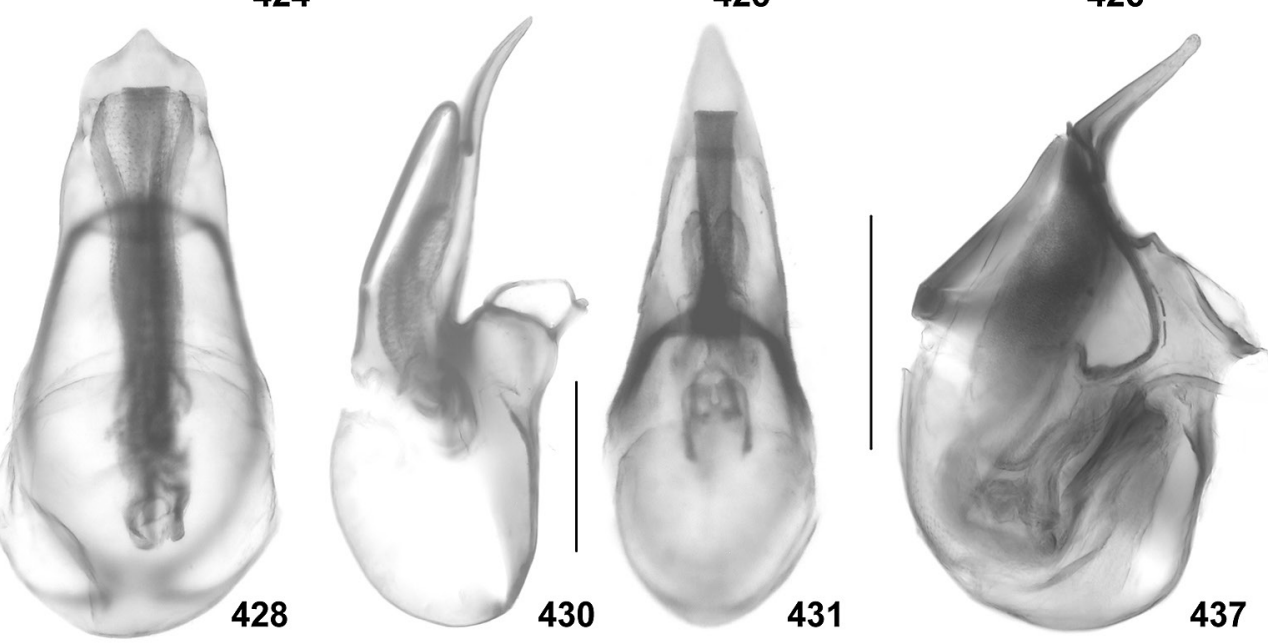

437
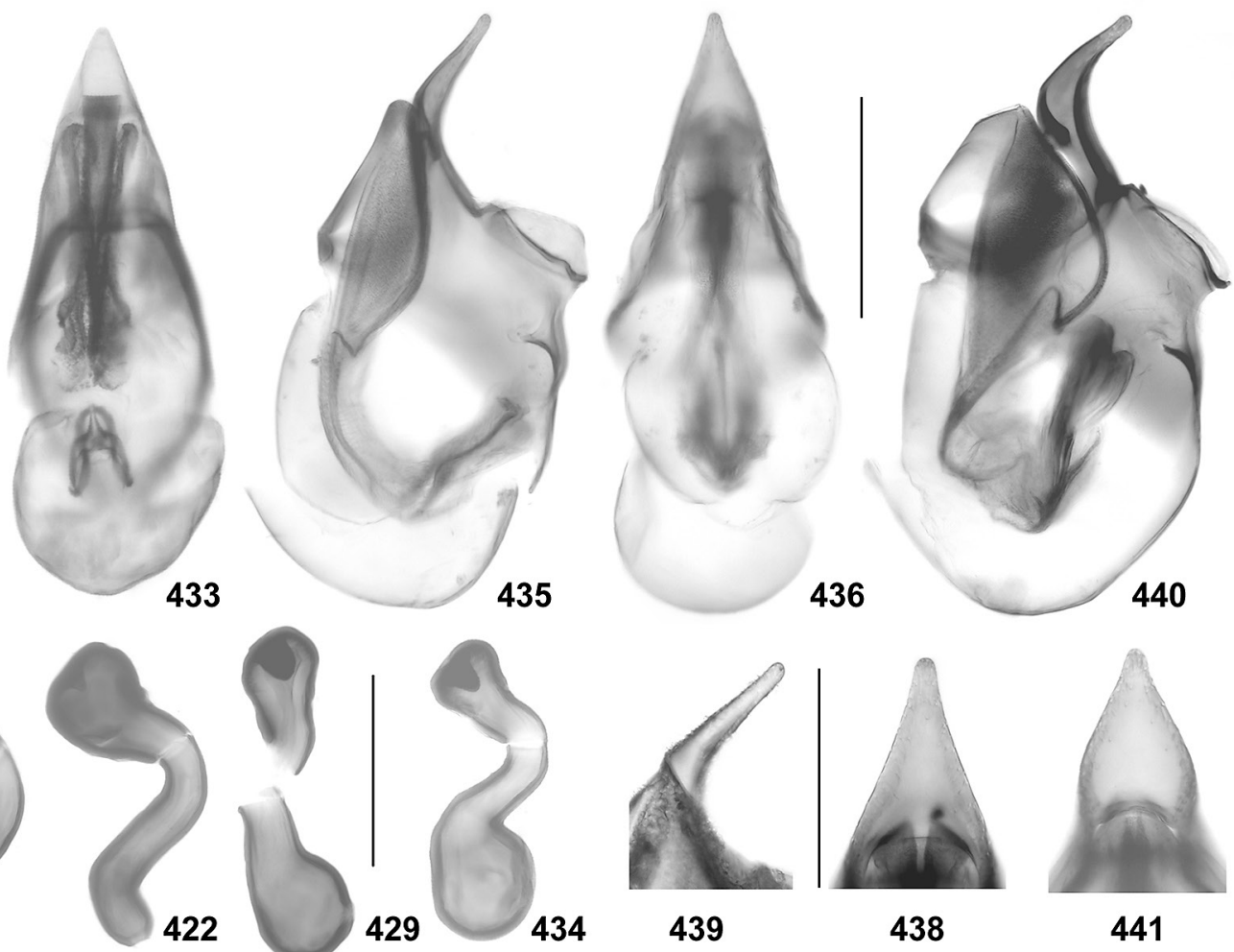

438

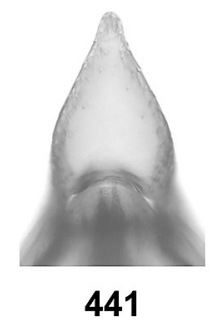

Figs 420-441. Amaurodera meorum (420-422), A. disparicollis (423-429), A. spinans (430-431), A. varicollis (432-434), Tetrabothrus nilgiricus (435-436), T. indicus (437-439; 439: lectotype), and T. inflexus from Laos (440-441): spermatheca (420-422, 429, 434); male pronotum (423-424); female pronotum (425-426); median lobe of aedeagus in lateral and in ventral view (427-428, $430-433,435-437,440)$; ventral process of aedeagus $(438-439,441)$. Scale bars: 423-426: $1.0 \mathrm{~mm}$; 420-422, 427-441: $0.2 \mathrm{~mm}$. 


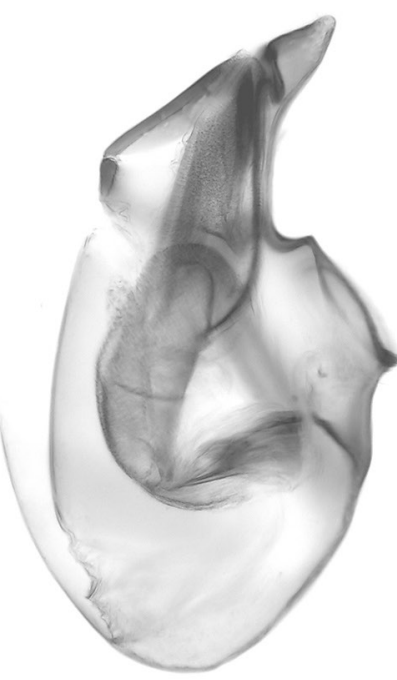

442

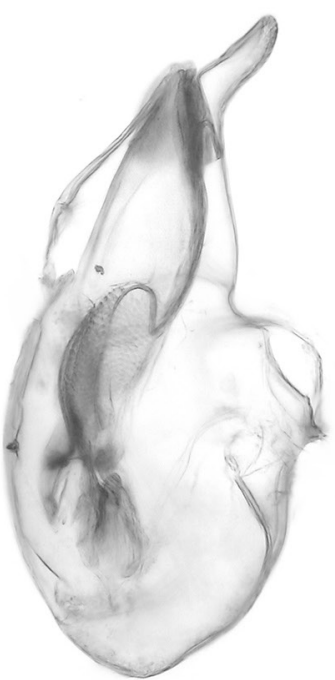

450

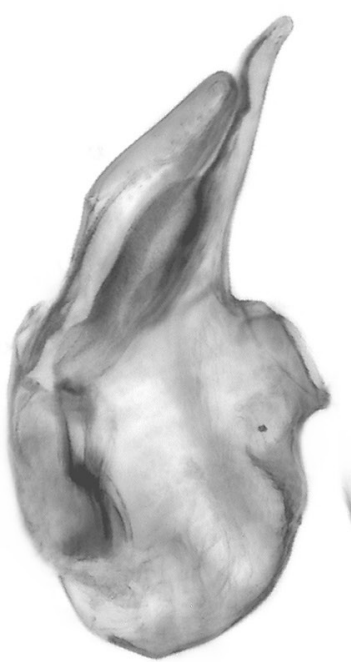

455

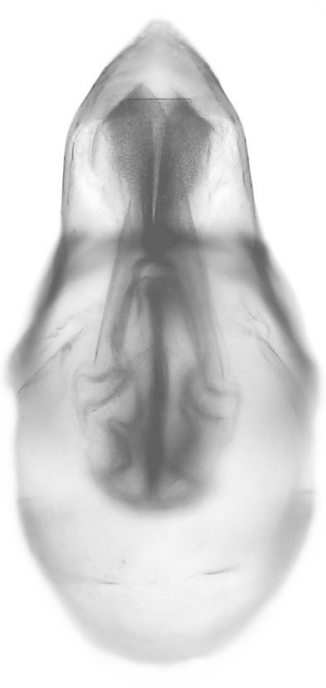

443

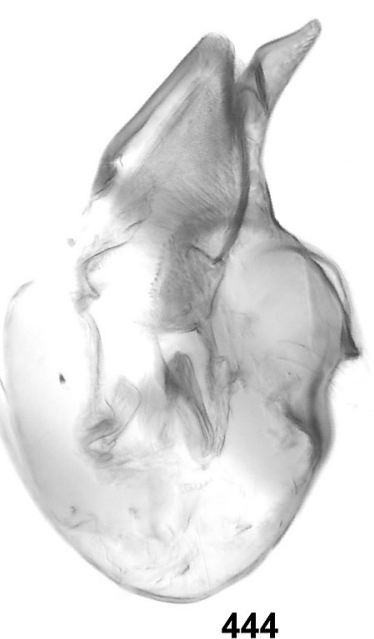

444

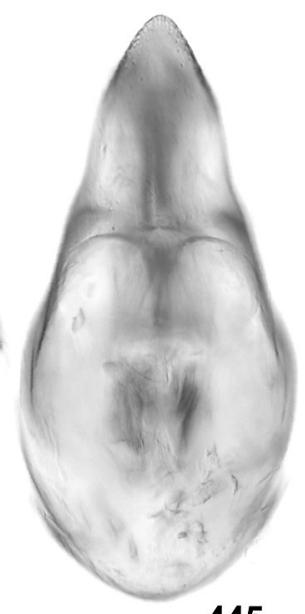

445
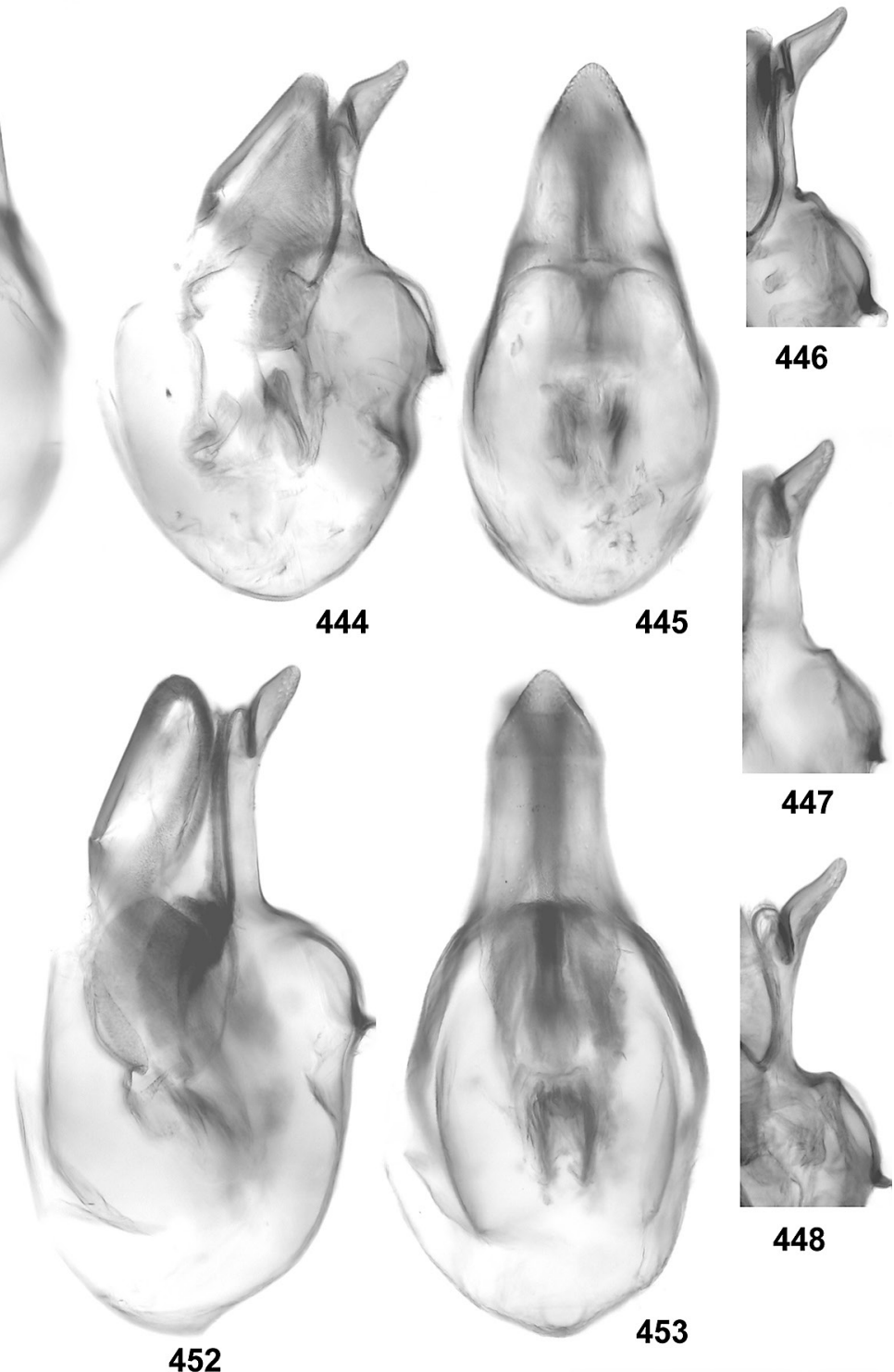

447

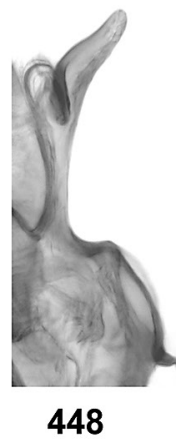

451

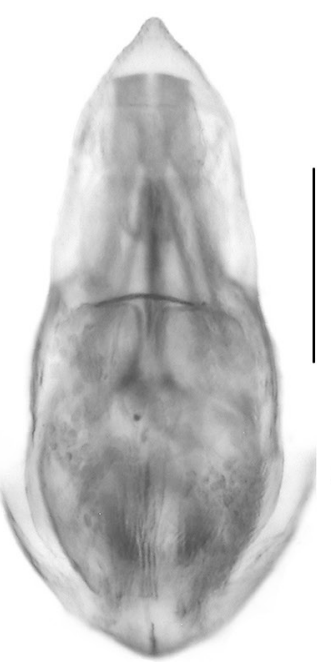

456

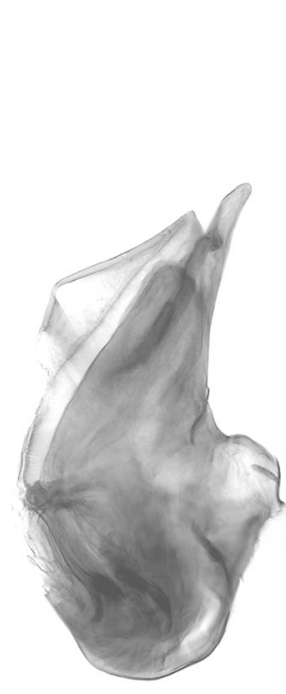

457

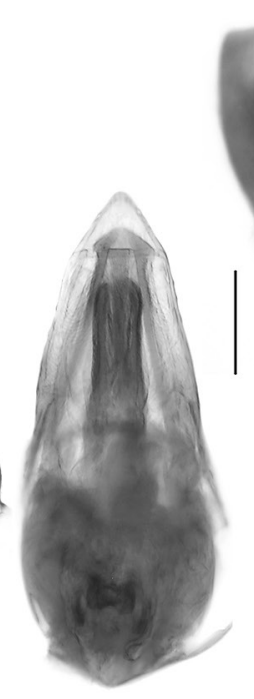

458
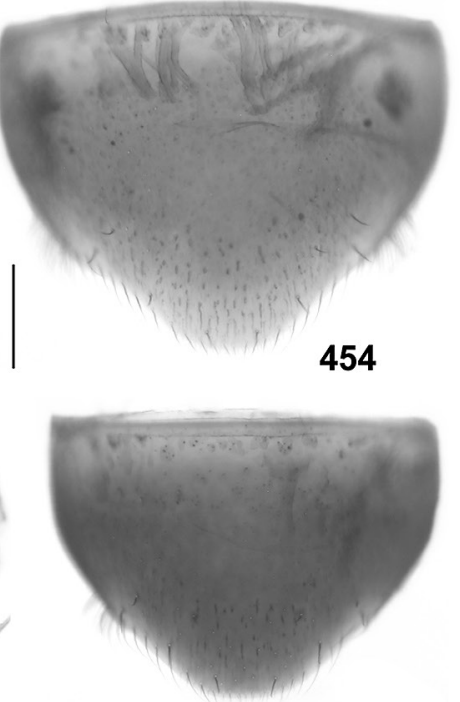

449

Figs 442-458. Tetrabothrus collucatus (442-443), T. borneensis (444-449), T. punctiventris (450-451), T. sulawesicus (452-454), Zyras illecebrosus, paratype (455-456), and Z. quasar, holotype (457-458): median lobe of aedeagus in lateral and in ventral view (442-445, 450-453, 455-458); apico-ventral portion of median lobe in lateral view (446-448); male sternite VIII (449, 454). Scale bars: $0.2 \mathrm{~mm}$. 

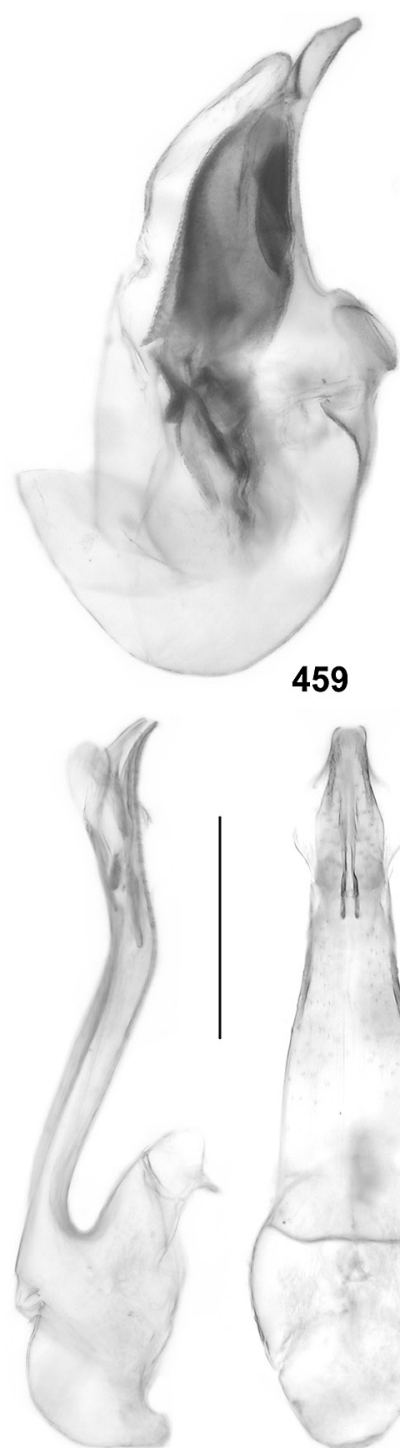

468

469
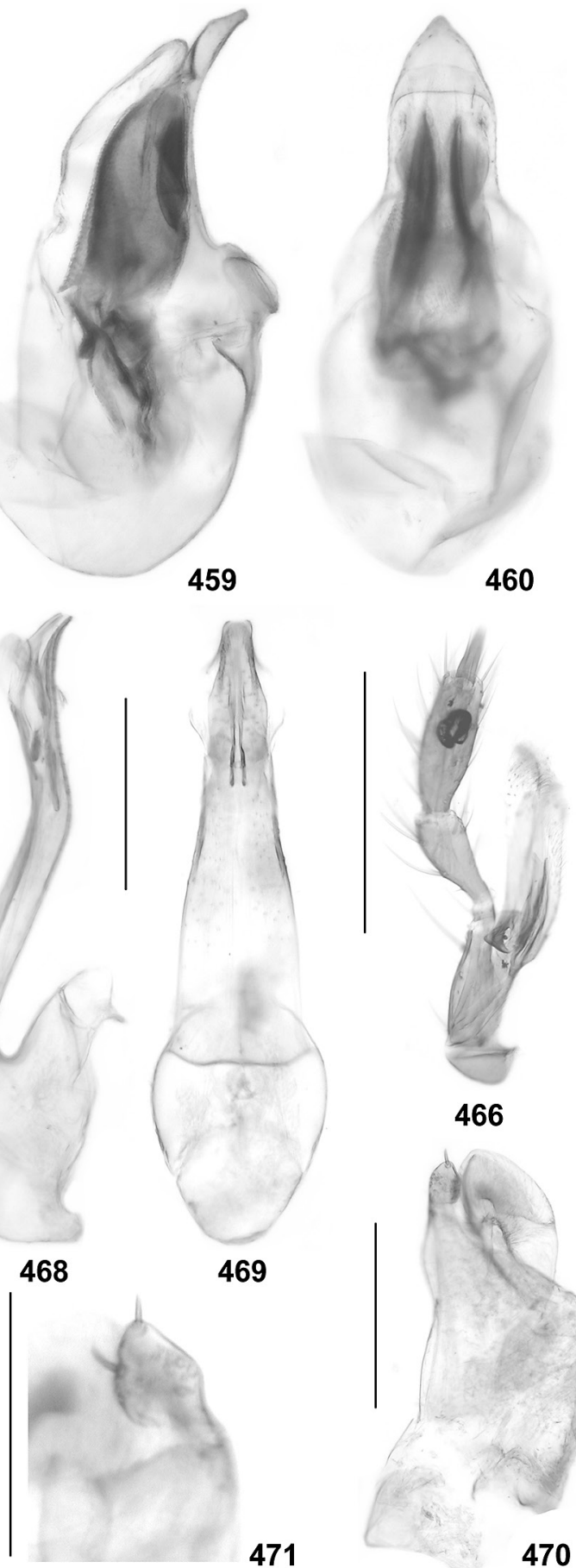

460

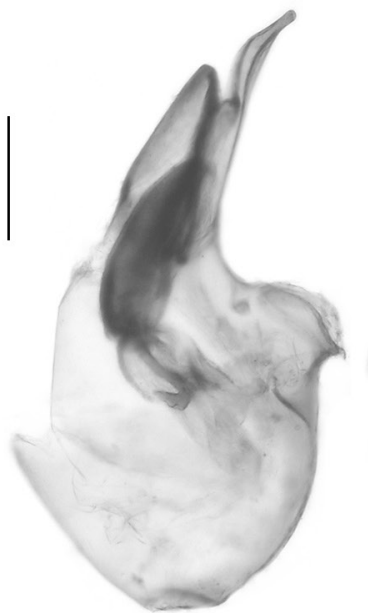

461

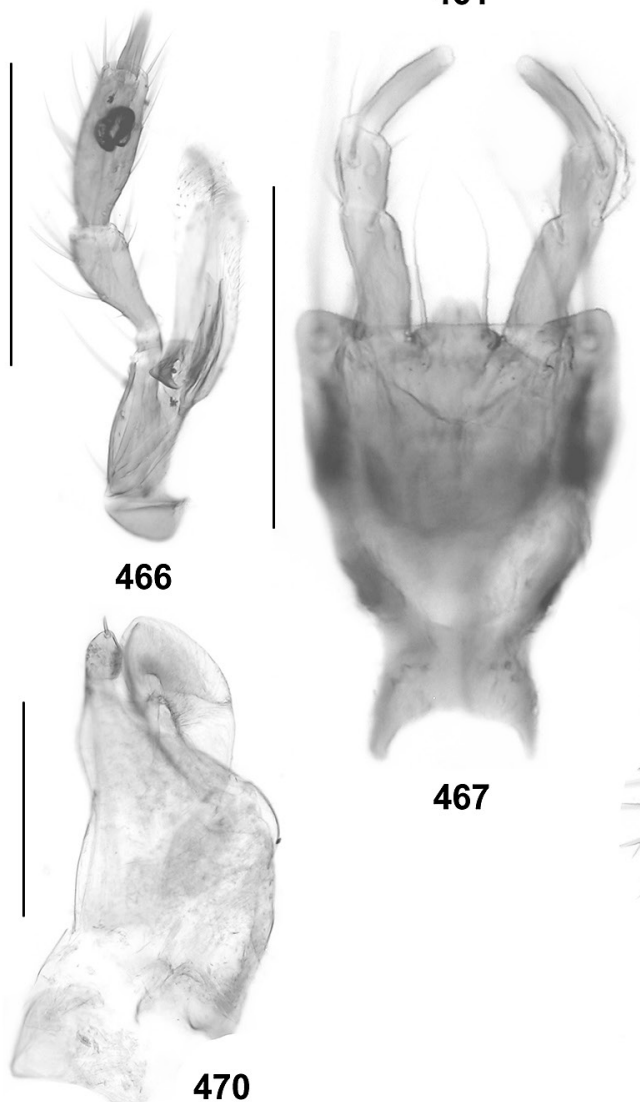

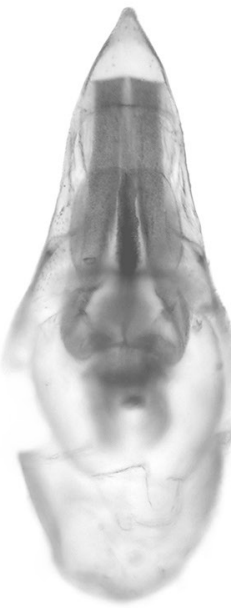

462

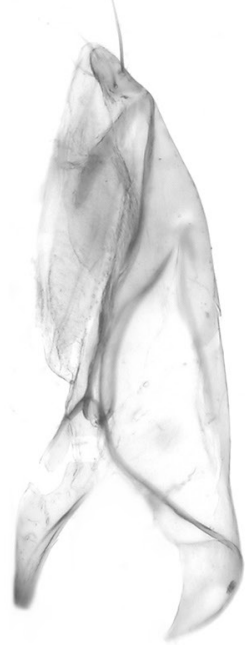

463
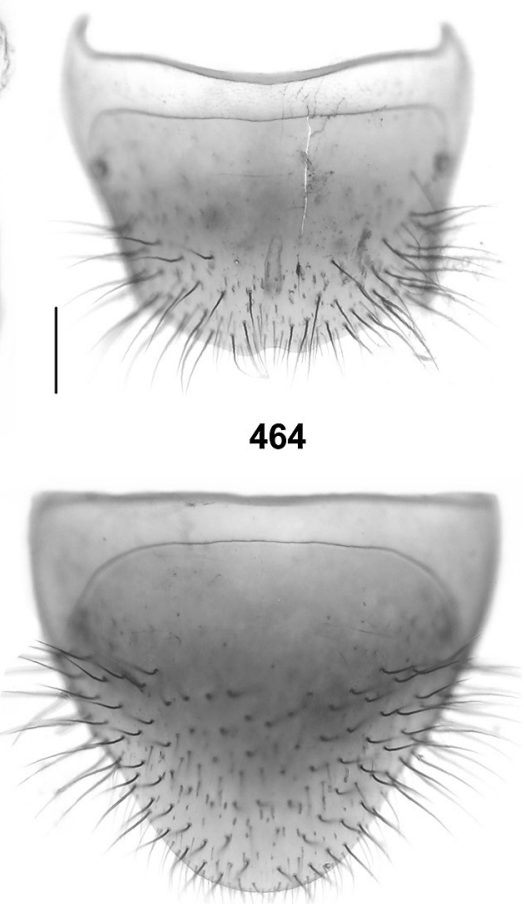

465

Figs 459-471. Zyras porrectus (459-460), Z. wunderlei (461-465), and Aenictoides derivata (466-471): median lobe of aedeagus in lateral and in ventral view (459-462, 468-469); paramere (463, 470); male tergite VIII (464); male sternite VIII (465); maxilla (466); labium (467); apical lobe of paramere (471). Scale bars: 459-466, 468-470: 0.2 mm; 467, 471: $0.1 \mathrm{~mm}$.

Comment: The above specimens represent the first records since the original description, which is based on a male from the Daba Shan at the border between Shaanxi and Chongqing and one from the Jiajin Shan in
West Sichuan (Assing 2006c). As was to be expected, the previously unknown female primary and secondary sexual characters are similar to those of other species of the $O$. hauseri subgroup. 


\section{Orphnebius spinans spec. nov.}

(Figs 1, 23, 197-201)

Type material: Holotype $0^{\star}:$ "NE India, Arunachal Pr., Etalin vicinity, $700 \mathrm{~m}, 28^{\circ} 36^{\prime} 56^{\prime \prime} \mathrm{N}, 95^{\circ} 53^{\prime} 21^{\prime \prime E}$, FIT (flight interception trap), L. Dembický leg., 12.-25.v.2012 / Holotypus ơ Orphnebius spinans sp. n., det. V. Assing 2015” (ZFMK).

Etymology: The specific epithet is the present participle of the Latin verb spinare (to sting) and alludes to the spine-shaped ventral process of the aedeagus (ventral view).

Description: Body length $3.3 \mathrm{~mm}$; length of forebody $1.5 \mathrm{~mm}$. Coloration: head black; pronotum and elytra blackish-brown, with the humeral and sutural portions of the elytra indistinctly paler; abdomen pale-reddish; legs with reddish-brown femora and reddish tibiae and tarsi; antennae blackish-brown with antennomeres I-III reddish-yellow and IV brown.

Head (Fig. 23) 1.17 times as broad as long and of subcircular shape; posterior angles completely obsolete; punctation extremely fine, barely visible, and very sparse; median and posterior dorsal portions extensively impunctate; interstices without microsculpture. Eyes very large, approximately as long as distance from posterior margin of eye to posterior constriction of head. Antenna (Fig. 1) $1.1 \mathrm{~mm}$ long, moderately incrassate, and weakly asymmetric; antennomere IV small and weakly transverse; antennomere $\mathrm{V}$ distinctly larger than IV and moderately transverse; antennomeres VI-X of gradually increasing width and increasingly transverse; X approximately 1.5 times as broad as long; XI strongly elongate, nearly as long as the combined length of VII-X.

Pronotum (Fig. 23) 1.26 times as broad as long and 1.20 times as broad as head, moderately convex in crosssection; posterior angles moderately marked; disc with a median pair of punctures, otherwise impunctate; margins with additional punctures.

Elytra (Fig. 23) 0.75 times as long as pronotum; suture distinctly gaping posteriorly; punctation sparse and fine. Hind wings fully developed. Metatarsomere I approximately as long as the combined length of II and III.

Abdomen broad, approximately as broad as combined width of elytra; tergites III-VI practically impunctate, except for fine setiferous punctures at posterior margins; tergite VII extensively with dense and coarse, oblong non-setiferous punctation leaving only a narrow transverse band at anterior margin glossy, posterior margin with distinct palisade fringe; tergite VIII with a marginal and a submarginal row of long setae, posterior margin broadly convex.

$\mathrm{o}^{\mathrm{x}}$ : hemi-tergites IX and tergite $\mathrm{X}$ with extremely dense and long pubescence (Fig. 197); median lobe of aedeagus (Figs 198-199) $0.78 \mathrm{~mm}$ long; ventral process spineshaped in ventral view (Fig. 200); paramere (Fig. 201)
$0.55 \mathrm{~mm}$ long, paramerite with four long setae subapically; condylite stout and much shorter than paramerite. o: unknown.

Comparative notes: Based on the modifications of the abdominal tergites IX and $\mathrm{X}$, the shapes and chaetotaxy of tergite and sternite VIII, the coloration pattern of the body, the morphology of the aedeagus (large and bulbous capsule; shapes of internal structures), and particularly the shape of the paramere, O. spinans belongs to the O.hauseri subgroup. The new species is distinguished from all the previously known representatives of this group particularly by the distinctive shapes of the ventral process of the aedeagus and of the parameres.

Distribution and natural history: The type locality is situated in Arunachal Pradesh, Northeast India. The circumstances of collection are identical to those of O. dispar.

\section{Orphnebius perpenetrans PACE, 2007}

Material examined: Malaysia: $10^{*}, 1$ ㅇ, Sabah (Borneo), Mt. Kinabalu, 1550-1650 m, 24.IV.1987, leg. Burckhard \& Löbl (MHNG, cAss).

Comment: The above specimens were collected together with some of the paratypes. This species belongs to the O. hauseri subgroup and is characterized particularly by the extremely derived shape of the paramere. Both the paramerite and the condylite are extremely slender, nearly spine-shaped.

\section{Orphnebius cernens spec. nov.}

(Figs 2, 24, 202-206)

Type material: Holotype $\sigma^{\star}:$ "Lao-NE, Hua Phan prov., $20^{\circ} 12^{\prime} \mathrm{N} 104^{\circ} 01^{\prime} \mathrm{E}$, Phu Phan Mt., $1750 \mathrm{~m}, 17 . v .-3 . v i$. 2008, Vít Kubáň leg. / Holotypus ơ Orphnebius cernens sp. n., det. V. Assing 2015” (NHMB).

Paratypes: $5 \sigma^{\star} o^{\star}, 1$ ㅇ, 3 sex?: same data as holotype (NHMB, cAss).

Etymology: The specific epithet is the present participle of the Latin verb cernere (to see) and alludes to the large eyes.

Description: Body length 3.6-4.2 mm; length of forebody 1.5-1.7 mm. Coloration: head black; pronotum and elytra blackish-brown to black; abdomen pale-reddish; legs with reddish to dark-brown femora and reddish tibiae and tarsi; antennae with antennomeres I-IV reddish and V-XI dark-brown to blackish-brown, $\mathrm{V}$ and $\mathrm{X}$ rarely paler; maxillary palpi brown to dark-brown with yellowish terminal palpomere. 
Head (Fig. 24) transverse, 1.3 times as broad as long; posterior angles completely obsolete; posterior margin of disc convex; punctation fine and sparse; median dorsal portion extensively impunctate; interstices without microsculpture. Eyes very large, reaching posterior margin of head. Antenna (Fig. 2) approximately $1.1 \mathrm{~mm}$ long, moderately incrassate, and moderately asymmetric; antennomere IV small and weakly transverse; antennomeres $\mathrm{V}-\mathrm{X}$ asymmetric, of gradually increasing width, and increasingly transverse; $\mathrm{X}$ nearly twice as broad as long; XI strongly elongate, slightly longer than the combined length of VIII-X.

Pronotum (Fig. 24) moderately transverse, 1.251.30 times as broad as long and 1.10-1.15 times as broad as head, moderately convex in cross-section; posterior angles weakly marked; disc with a median pair of punctures, otherwise nearly impunctate; margins with additional punctures; lateral margins each with three long, stout, and erect black setae.

Elytra (Fig. 24) approximately 0.85 times as long as pronotum; suture distinctly gaping posteriorly; punctation moderately sparse and fine; pubescence pale, fine, long, and sub-erect or depressed on disc. Hind wings fully developed. Metatarsomere I approximately as long as the combined length of II and III.

Abdomen: tergites III-VI with a lateral setiferous puncture on either side and with four setiferous punctures at posterior margin (individual punctures may be missing); tergite VII with oblong non-setiferous punctation across median portion, anterior and posterior portions without such punctation, with a transverse row of setiferous punctures near posterior margin, posterior margin with palisade fringe; tergite VIII with a marginal and a submarginal row of long setae, posterior margin broadly convex; sternite VIII with broadly convex posterior margin.

$\sigma^{*}$ : hemi-tergites IX and tergite $\mathrm{X}$ with extremely dense and long pubescence (O. hauseri type); median lobe of aedeagus (Figs 202-203) approximately $0.65 \mathrm{~mm}$ long; ventral process straight in lateral view and of subtriangular shape in ventral view; internal sac with large and strongly sclerotized structures; paramere (Figs 204-205) approximately $0.6 \mathrm{~mm}$ long, condylite distinctly shorter than paramerite, stout, curved, and with very short velum. o: spermatheca (Fig. 206) of similar shape as in other species of the O. hauseri subgroup.

Comparative notes: Among the species of the O. hauseri subgroup, O.cernens is most similar to O. dishamatus Assing, 2015 (China: Yunnan) both in external and in sexual characters. It is distinguished from that species by larger and more bulging eyes, a distinctly longer antennomere XI with parallel margins (O. dishamatus: with weakly convex margins), and by the morphology of the aedeagus (O. dishamatus: ventral process slightly shorter and with a less distinctly marked apex in ventral view; condylite of paramere straight). For illustrations of O. dishamatus see Assing (2015e).
Distribution and natural history: The type locality is situated in Hua Phan province, North Laos, at an altitude of approximately $1750 \mathrm{~m}$. Orphnebius lunatus, O. fuscapicalis, O.fusicollis, O. spoliatus, and an unnamed species were collected in the same locality.

\section{Orphnebius lunatus spec. nov.}

(Figs 3, 25, 207-210)

Type material: Holotype $o^{\star}$ : "Lao-NE, Hua Phan prov., $20^{\circ} 12^{\prime} \mathrm{N} 104^{\circ} 01^{\prime} \mathrm{E}$, Phu Phan Mt., $1750 \mathrm{~m}, 17 . v .-3 . v i$. 2008, Vít Kubáň leg. / Holotypus ơ Orphnebius lunatus sp. n., det. V. Assing 2015” (NHMB).

Paratype $\sigma^{\star}$ [left antenna, right antennomeres X-XI, and left hind leg missing]: "Laos, 1.-16.v.1999, Louangphrabang pr., $20^{\circ} 33-4^{\prime} \mathrm{N} 102^{\circ} 14^{\prime} \mathrm{E}$, Ban Song Cha (5 km W), 1200 m, Vít Kubáň leg." (cAss).

Etymology: The specific epithet is the past participle of the Latin verb lunare (to bend) and alludes to the distinctly bent apex of the ventral process of the aedeagus (lateral view).

Description: Body length 3.6-3.7 mm; length of forebody 1.5-1.7 mm. Coloration: head black; pronotum and elytra blackish-brown to black; abdomen pale-reddish; legs with brown femora and reddish tibiae and tarsi; antennae with antennomeres I-IV reddish and V-XI dark-brown to blackish; maxillary palpi brown to darkbrown with yellowish terminal palpomere.

Head (Fig. 25) transverse, 1.17-1.25 times as broad as long; posterior angles completely obsolete; posterior margin of disc convex; punctation fine and sparse; median dorsal portion extensively impunctate; interstices without microsculpture. Eyes large, somewhat longer than distance from posterior margin of eye to posterior constriction of head. Antenna (Fig. 3) $1.0 \mathrm{~mm}$ long, moderately incrassate, and weakly asymmetric; antennomere IV small and weakly transverse; antennomeres V-X of gradually increasing width and increasingly transverse; $\mathrm{X}$ twice as broad as long; XI elongate, approximately as long as the combined length of VIII-X.

Pronotum (Fig. 25) moderately transverse, 1.201.25 times as broad as long and 1.15-1.20 times as broad as head, moderately convex in cross-section; posterior angles weakly marked, nearly obsolete; disc with an indistinct median pair of punctures, otherwise nearly impunctate; margins with additional punctures; lateral margins each with three long and erect black setae.

Elytra (Fig. 25) approximately $0.80-0.85$ times as long as pronotum; suture distinctly gaping posteriorly; punctation moderately sparse and fine; pubescence pale, fine, long, and sub-erect or depressed on disc. Hind wings fully developed. Metatarsomere I approximately as long as the combined length of II and III.

Abdomen, including tergite VIII (Fig. 207), as in O. cernens. 
$\sigma^{*}$ : hemi-tergites IX and tergite $\mathrm{X}$ with extremely dense and long pubescence (O. hauseri type); median lobe of aedeagus (Figs 208-209) approximately $0.7 \mathrm{~mm}$ long; ventral process apically hooked in lateral view; internal sac with large and strongly sclerotized structures and with long flagellum; paramere (Fig. 210) small, approximately $0.4 \mathrm{~mm}$ long, condylite approximately as long as paramerite, straight, and apically acute.

o: unknown.

Comment: The somewhat damaged paratype differs from the holotype by slightly less transverse antennomeres VI-IX and by the different shapes of the apex of the ventral process and the crista apicalis of the aedeagus. In other respects, including the shape of the paramere, the two specimens are identical. The differences in the shape of the median lobe of the aedeagus most likely represent artefacts (apex of ventral process slightly deformed and portion between crista apicalis and ventral process apparently slightly damaged in the aedeagus of the holotype).

Comparative notes: Orphnebius lunatus is distinguished from the similar and syntopic O. cernens by a distinctly less transverse head, distinctly smaller eyes, shorter antennae with a shorter antennomere XI, as well as by the completely different shapes of the ventral process of the aedeagus and of the parameres. Based on the male sexual characters, O. lunatus is closely allied to O. scissus Assing, 2009 from Yunnan, from which it differs by the morphology of the aedeagus (ventral process much more strongly hooked apically and of different shape in ventral view; crista apicalis less pronounced; paramere with condylite of different shape and paramerite with less pronounced lateral incision). For illustrations of O. scissus see Assing (2009).

Distribution and natural history: The type material was found in two localities in Hua Phan and Louang Phrabang provinces at altitudes of 1200 and approximately $1750 \mathrm{~m}$. Orphnebius cernens, O. fuscapicalis, O. fusicollis, O. spoliatus, O. nigrapicalis, O. extensus, $O$. reductus, and an unnamed species were recorded from the same localities.

\section{Orphnebius grandicollis spec. nov.}

(Fig. 17, 22, 211-215)

Type material: Holotype $0^{\top}$ : "Lao, Phongsaly prov., 21 ${ }^{\circ} 41-2^{\prime} \mathrm{N} 102^{\circ} 06-8^{\prime} \mathrm{E}, 28 . v .-20 . v i .2003$, Phongsaly env., $\sim 1500$ m, Vít Kubáň leg. / Holotypus ơ Orphnebius grandicollis sp. n., det. V. Assing 2015” (NHMB).

Etymology: The specific epithet (Latin, adjective) alludes to the relatively large pronotum.
Description: Body length $4.8 \mathrm{~mm}$; length of forebody $2.1 \mathrm{~mm}$. Coloration: head black; pronotum and elytra blackish-brown; abdomen pale-reddish; legs with brown femora and reddish tibiae and tarsi; antennae with antennomeres I-V yellowish-red, VI dark-brown, and VII-XI blackish.

Head (Fig. 22) strongly transverse, nearly 1.4 times as broad as long (length measured from anterior margin of sclerotized portion of clypeus); posterior angles completely obsolete; punctation fine and very sparse; median and posterior dorsal portions extensively impunctate; interstices without microsculpture. Clypeus with anterior margin of sclerotized portion distinctly concave in the middle. Eyes very large, reaching posterior margin of head. Antenna (Fig. 17) $1.4 \mathrm{~mm}$ long, moderately incrassate, and weakly asymmetric; antennomere IV small and weakly transverse; antennomere V distinctly larger than IV and moderately transverse; antennomeres VI-X of gradually increasing width and increasingly transverse; $\mathrm{X}$ more than 1.5 times as broad as long; XI strongly elongate, approximately as long as the combined length of VIII-X.

Pronotum (Fig. 22) large and strongly transverse, 1.4 times as broad as long and 1.26 times as broad as head, moderately convex in cross-section; posterior angles moderately marked; disc with an indistinct median pair of punctures, otherwise nearly impunctate; margins with additional punctures; lateral margins and anterior angles with five long, stout, and erect black setae.

Elytra (Fig. 22) approximately 0.85 times as long as pronotum; suture distinctly gaping posteriorly; punctation moderately sparse and fine; pubescence pale, fine, long, and sub-erect to depressed on disc, stouter, denser, brown, and sub-erect at lateral margins. Hind wings fully developed. Metatarsomere I slightly shorter than the combined length of II and III.

Abdomen: tergites III-VI with two lateral setiferous punctures on either side; tergite VI with four additional setiferous punctures at posterior margin; tergite VII with dense striae of variable length in posterior twothirds and with a transverse row of eight setiferous punctures at posterior margin, posterior margin with palisade fringe; tergite VIII (Fig. 211) with a marginal and a submarginal row of long setae, posterior margin broadly convex; sternite VIII with broadly convex posterior margin.

$\sigma^{\top}$ : hemi-tergites IX and tergite $\mathrm{X}$ with extremely dense and long pubescence; median lobe of aedeagus (Figs 212-214) $0.85 \mathrm{~mm}$ long; ventral process short in relation to the conspicuously large basal portion, apically acute; internal sac with large and strongly sclerotized structures; paramere (Fig. 215) $0.5 \mathrm{~mm}$ long, paramerite longer than condylite.

o: unknown.

Comparative notes: Based on the modifications of the abdominal tergites IX and X, the shapes and chaetotaxy of tergite and sternite VIII, the coloration pattern 
of the body, the morphology of the aedeagus (large and bulbous capsule; shapes of internal structures), and particularly the shape of the paramere, O. grandicollis belongs to the O.hauseri subgroup. Among the species of this group, O. grandicollis is characterized by a large and strongly transverse pronotum, the antennal morphology, the median concavity of the anterior margin of the sclerotized portion of the clypeus, as well as the shapes of the median lobe and the parameres of the aedeagus.

Distribution and natural history: The holotype was collected in one locality in Phongsaly province, North Laos, at an altitude of approximately $1500 \mathrm{~m}$, together with $O$. serratus, O. reductus, and O. baccillatus.

\section{Orphnebius fuscapicalis spec. nov.}

(Figs 16, 27, 35, 216-219)

Type material: Holotype $0^{\star}:$ "Lao-NE, Hua Phan prov., $20^{\circ} 12^{\prime} \mathrm{N} 104^{\circ} 01^{\prime} \mathrm{E}$, Phu Phan Mt., $1750 \mathrm{~m}, 17 . v .-3 . v i$. 2008, Vít Kubáň leg. / Holotypus ơ Orphnebius fuscapicalis sp. n., det. V. Assing 2015” (NHMB).

Etymology: The specific epithet is an adjective composed of the Latin adjectives fuscus (dark, blackish-brown) and apicalis. It alludes to the infuscate abdominal segment VIII.

Description: Body length $5.7 \mathrm{~mm}$; length of forebody $2.3 \mathrm{~mm}$. Coloration: forebody black; abdomen palereddish with segment VIII blackish-brown (Fig. 35); legs with blackish-brown femora, brown to dark-brown tibiae, and reddish tarsi; antennae blackish, with antennomeres I-III reddish and IV dark-brown; maxillary palpi with palpomeres III dark-brown and IV yellowish. Head (Fig. 27) strongly transverse, nearly 1.4 times as broad as long; posterior angles completely obsolete; punctation fine and very sparse; median and posterior dorsal portions extensively impunctate; interstices without microsculpture. Eyes very large, reaching posterior margin of head, much longer than distance from posterior margin of eye to posterior constriction of head in dorsal view. Antenna (Fig. 26) $1.8 \mathrm{~mm}$ long, slender; antennomere IV distinctly oblong, approximately 1.5 times as long as broad; antennomeres V-VII weakly oblong, VIII approximately as broad as long, IX-X very weakly transverse, and XI conspicuously elongate, approximately four times as long as broad and nearly as long as combined length of VII-X.

Pronotum (Fig. 27) distinctly transverse, 1.25 times as broad as long and 1.14 times as broad as head, moderately convex in cross-section; posterior angles very obtusely marked; disc with an indistinct median pair of punctures, otherwise nearly impunctate; margins with additional punctures; lateral margins with three very long, stout, and erect black setae.
Elytra approximately 0.85 times as long as pronotum; suture distinctly gaping posteriorly; punctation sparse and very fine; pubescence pale, fine, long, and sub-erect to depressed. Hind wings fully developed. Metatarsomere I slightly longer than the combined length of II and III.

Abdomen (Fig. 35): tergites III-VI with two lateral setiferous punctures on either side; tergite VI with four additional setiferous punctures at posterior margin; tergite VII with very dense striae and with a transverse row of setiferous punctures at posterior margin, posterior margin with palisade fringe; tergite VIII with two transverse rows of long black setae, posterior margin broadly convex; sternite VIII with broadly convex posterior margin.

$\sigma^{*}$ : hemi-tergites IX and tergite $\mathrm{X}$ with extremely dense and long pubescence; median lobe of aedeagus (Fig. 216-217) $0.93 \mathrm{~mm}$ long; ventral process of moderate length and apically acute in ventral view; internal sac with large and strongly sclerotized structures; paramere (Fig. 218-219) $0.65 \mathrm{~mm}$ long, paramerite distinctly longer than condylite and subapically with short sclerotized process.

o: unknown.

Comparative notes: Based on the modifications of the abdominal tergites IX and X, the shapes and chaetotaxy of tergite and sternite VIII, the coloration pattern of the body, the morphology of the aedeagus (large and bulbous capsule; shapes of internal structures), and particularly the shape of the paramere, O. fuscapicalis belongs to the $O$. hauseri subgroup. Among the species of this group, O. fuscapicalis is characterized by conspicuously slender antennae, very large eyes, a distinctly infuscate abdominal tergite VIII, as well as by the shapes of the median lobe and the parameres of the aedeagus.

Distribution and natural history: The type locality is situated in Hua Phan province, North Laos, at an altitude of approximately $1750 \mathrm{~m}$. The holotype was collected together with O. cernens, O. lunatus, O. fusicollis, O. spoliatus, and an unnamed species.

Orphnebius nigrapicalis spec. nov. (Figs 220-222)

Type material: Holotype o": "Laos, 1.-16.v.1999, Louangphrabang pr., $20^{\circ} 33-4^{\prime} \mathrm{N} 102^{\circ} 14^{\prime} \mathrm{E}$, Ban Song Cha $(5 \mathrm{~km} \mathrm{~W}), 1200$ m, Vít Kubáň leg. / Holotypus ๙ Orphnebius nigrapicalis sp. n., det. V. Assing 2015” (NHMB).

Etymology: The specific epithet is an adjective composed of the Latin adjectives niger (black) and apicalis. It alludes to the infuscate abdominal segment VIII. 
Description: Size, coloration, and other external characters as in O. fuscapicalis, except as follows:

antennomeres I-IV blackish-brown; tibiae dark-brown to blackish-brown.

$\sigma^{\top}$ : median lobe of aedeagus (Figs 220-221) $0.93 \mathrm{~mm}$ long; ventral process short and broad, of subtriangular shape in ventral view; internal sac with large and strongly sclerotized structures; paramere $0.7 \mathrm{~mm}$ long, shaped as in Fig. 222.

i : unknown.

Comparative notes: Based on the similarly derived morphology of the antennae, the extremely similar remaining external character (including the infuscate abdominal segment VIII), and on the similar morphology of the aedeagus, this species is very closely related to O. fuscapicalis, from which it differs only by the coloration of the antennae and legs, as well as by the shorter, stouter, and in ventral view much broader ventral process of the aedeagus and by the shape of the paramere.

Distribution and natural history: The type locality is situated in Louang Phrabang province, North Laos, at an altitude of $1200 \mathrm{~m}$. The holotype was collected together with O. lunatus, O. extensus, and O. reductus.

\subsubsection{Orphnebius bakeri subgroup}

\section{Orphnebius bakeri BERNHAUER, 1929}

(Figs 4, 26, 223-225)

Material examined: Indonesia: $1 \sigma^{\star}, 1$ ㅇ, Borneo, Kalimantan Tengah, confluence of Busang and Rekut, $0^{\circ} 03^{\prime} \mathrm{S}$, $113^{\circ} 59^{\prime} \mathrm{E}$, flight interception trap, VIII.2001, leg. Brendell \& Mendel (BMNH).

Comment: Orphnebius bakeri is the type species of the subgeneric name Mesocephalobius BernHAUER, 1929, which was synonymized with Orphnebius by PACE (2007) and revalidated by HLAvÁč et al. (2011). The original description is based on type material from Singapore. PACE (2007) designated a lectotype and illustrated the median lobe of the aedeagus.

Redescription: Body length 4.0-4.2 mm; length of forebody $1.7 \mathrm{~mm}$. Coloration: head blackish; pronotum blackish-brown; elytra brown, with the postero-lateral portions slightly and diffusely darker; abdomen palereddish; legs dark-yellowish; antennae blackish, with antennomeres I-IV reddish; maxillary palpi yellowish. Head (Fig. 26) of transversely oval shape; posterior angles obsolete; dorsal surface with scattered very fine punctures laterally; median and posterior dorsal portions extensively impunctate; interstices without microsculpture. Eyes large, reaching posterior margin of head, much longer than distance from posterior margin of eye to posterior constriction of head in dorsal view. Antenna (Fig. 4)
1.1-1.2 mm long, distinctly incrassate and asymmetric; antennomere IV small and weakly transverse; antennomere $\mathrm{V}$ much larger than IV and asymmetric; V-X of gradually increasing width, increasingly transverse, and increasingly asymmetric; XI approximately as long as the combined length of VIII-X.

Pronotum (Fig. 26) 1.2 times as broad as long and 1.001.05 times as broad as head, broadest near anterior angles, strongly convex in cross-section; posterior angles weakly marked; disc with a median pair of punctures and some punctures near lateral margins, otherwise impunctate.

Elytra (Fig. 26) approximately 0.8 times as long as pronotum; punctation sparse and fine; pubescence long, pale, and sub-erect. Hind wings fully developed. Metatarsomere I slightly shorter than the combined length of II and III.

Abdomen: tergite VII with dense, oblong, non-setiferous punctation in posterior three-fourths, near posterior margin with six oblong tubercles, posterior margin with palisade fringe; tergite VIII and sternite VIII with convex posterior margins.

$\sigma^{*}$ : segments IX-X distinctly modified (of the O. hauseri type), with dense and long pubescence; median lobe of aedeagus (Fig. 223) conspicuously large and massive, approximately $1.0 \mathrm{~mm}$ long, with small ventral process of distinctive shape; internal sac with several small, strongly sclerotized structures; parameres (Fig. 224) much shorter than median lobe, approximately $0.55 \mathrm{~mm}$ long; condylite very slender and slightly longer than paramerite.

ㅇ: spermatheca (Fig. 225) strongly sclerotized and with long proximal portion.

Comparative notes: This species is characterized particularly by the distinctive male sexual characters.

Distribution: Orphnebius bakeri is currently known from Singapore and Borneo (Malaysia: Sabah; Brunei) (Bernhauer 1929, Pace 2007, and material examined).

\subsubsection{Orphnebius dilatatus subgroup}

\section{Orphnebius breviceps CAMERON, 1946}

(Figs 5, 30, 226-228)

Orphnebius (Megabocephalobius) breviceps CAMERon, 1946: $691 \mathrm{f}$.

Orphnebius vorax PACE, 2000: 71 ff.; syn. nov.

Type material: Holotype ơ: “62251 / Siam, Renong / Doherty / Orphnebius breviceps Cam. Type / Fry Coll. 1905.100. / Type / Holotypus o Orphnebius breviceps Cameron, rev. V. Assing 2015” (BMNH).

Comment: The original description of O. breviceps is based on a unique male from "Siam: Renong" (CAMERON 1946), that of O. vorax on an incomplete male and two females from “Thailand, River Kwae Ban Sai Yok" (PACE 
2000). The aedeagus of the holotype of O. breviceps is identical to that figured by PACE (2000) for O. vorax, which leads to the conclusion that both names refer to the same species. The below redescription is based on the holotype of $O$. breviceps.

Redescription: Small species; body length $2.7 \mathrm{~mm}$; length of forebody $1.3 \mathrm{~mm}$. Coloration: head and pronotum blackish-brown; elytra yellowish-brown, with the posterolateral portions extensively dark-brown; abdomen pale-reddish; legs reddish-brown; antennae dark-brown, with antennomeres II-V reddish and I reddish-brown; maxillary palpi brown with yellowish palpomere IV.

Head (Fig. 30) distinctly wedge-shaped and strongly transverse; punctation fine and very sparse; median and posterior dorsal portions extensively impunctate; interstices without microsculpture. Eyes large and strongly bulging, reaching posterior margin of head, much longer than distance from posterior margin of eye to posterior constriction of head in dorsal view. Antenna (Fig. 5) $1.0 \mathrm{~mm}$ long, distinctly incrassate; antennomere I approximately as long as the combined length of II-V; antennomere IV small and approximately as long as broad; antennomere $\mathrm{V}$ slightly less small than IV and moderately transverse; antennomere VI much larger, broader, and more transverse than V; antennomeres VI-X approximately twice as broad as long (or nearly so) and asymmetric; antennomere XI slightly longer than the combined length of IX and X.

Pronotum (Fig. 30) 1.59 times as broad as long and 0.95 times as broad as head, moderately convex in crosssection; lateral and posterior margins together nearly forming a semi-circle, posterior angles completely obsolete; disc with a median pair of punctures, otherwise impunctate.

Elytra (Fig. 30) approximately 0.9 times as long as pronotum; punctation sparse and fine; pubescence long, pale, and sub-erect to erect. Hind wings fully developed. Metatarsomere I approximately as long as the combined length of II and III.

Abdomen: tergite VII predominantly with dense longitudinal striae and additional oblong non-setiferous punctures, near posterior margin with some setiferous punctures, posterior margin with palisade fringe; tergite VIII with two transverse series of long black setae posteriorly, posterior margin convex, in the middle truncate; sternite VIII with broadly convex posterior margin.

$\mathrm{o}^{\top}$ : segments IX-X distinctly modified (of the O. hauseri type), with dense and long pubescence; median lobe of aedeagus (Figs 226-227) conspicuously slender, $0.7 \mathrm{~mm}$ long and of very distinctive shape; ventral process apically hook-shaped in lateral view; paramere (Fig. 228) of highly distinctive shape: paramerite and condylite very slender; paramerite distinctly notched approximately in the middle; condylite nearly as long as paramerite.

o: spermatheca with very long and coiled proximal portion (PACE 2000: figure 88).
Comparative notes: Orphnebius breviceps is distinguished from other revised representatives of the O. dilatatus subgroup by the morphology of the antennae, the coloration of the elytra, and especially by the male primary sexual characters.

Distribution: The currently known distribution is confined to two localities in Thailand.

Orphnebius dilatatus spec. nov.

(Figs 15, 28, 36, 229-232)

Type material: Holotype $0^{\star}$ : "Laos, Phongsaly prov., $21^{\circ} 21^{\prime} \mathrm{N} 102^{\circ} 03^{\prime} \mathrm{E}$, Ban Sano Mai, 19.-26.v.2004, 1150 m, Vít Kubáň leg. / Holotypus ơ Orphnebius dilatatus sp. n., det. V. Assing 2015" (NHMB).

Paratypes: $1 \sigma^{\star}, 1$ : : same data as holotype (NHMB, cAss); $2 \sigma^{*} \sigma^{*}$ : "Laos-N (Louangphrabang), 11-21.v.2002, $19^{\circ} 35^{\prime} \mathrm{N}, 101^{\circ} 58^{\prime} \mathrm{E}$, Thong Khan, 750 m, Vít Kubáň leg." (NHMB, cAss).

Etymology: The specific epithet (Latin, adjective) alludes to the medially distinctly dilated condylite of the paramere.

Description: Body size very variable; body length $3.3-5.0 \mathrm{~mm}$; length of forebody $1.3-2.0 \mathrm{~mm}$. Coloration: forebody black; abdomen red; legs with blackish-brown femora, brown tibiae, and reddish tarsi; antennae blackish with antennomeres II-IV at least partly dark-reddish; maxillary palpi brown to dark-brown with the apical palpomere yellowish.

Head (Fig. 28) conspicuously large, strongly wedgeshaped, broadest posteriorly, 1.5-1.6 times as broad as long; anterior margin of clypeus very broad and convexly produced in the middle; punctation extremely fine and sparse. Eyes moderately large and distinctly bulging, situated in posterior portion of head. Antenna (Fig. 15) 1.2-1.7 mm long; antennomere I conspicuously elongate, approximately as long as combined length of antennomeres II-IV; antennomeres III-IV distinctly, V-X weakly flattened; IV-X transverse and of gradually increasing width; X approximately 1.5 times as broad as long; XI nearly as long as combined length of VIII-X.

Pronotum (Fig. 28) 1.52-1.59 times as broad as long and $0.82-0.95$ times as broad as head, smaller and narrower in relation to head in larger than in smaller specimens, moderately convex in cross-section; lateral and posterior margins together nearly forming a semi-circle, posterior angles completely obsolete; disc with a median pair of punctures, otherwise impunctate; lateral margins anteriorly with three long, erect, stout black setae.

Elytra (Fig. 28) approximately 0.8 times as long as pronotum; punctation sparse and fine. Hind wings fully developed. Metatarsomere I approximately as long as the combined length of II and III. 
Abdomen (Fig. 36): tergites III-VI with a lateral setiferous puncture on either side, VI with four additional punctures at posterior margin; tergite VII primarily with dense longitudinal striae and additional oblong non-setiferous punctures in posterior two-thirds, near posterior margin with some setiferous punctures, posterior margin with palisade fringe; tergite VIII with two transverse series of long black setae posteriorly, posterior margin convex, in the middle truncate; sternite VIII with broadly convex posterior margin.

$\sigma^{*}$ : segments IX-X distinctly modified (of the O. hauseri type), with dense and long pubescence; median lobe of aedeagus (Figs 229-230) 0.60-0.83 mm long, strongly sclerotized, and of very distinctive shape; ventral process strongly curved in lateral view, apically concave in ventral view; paramere (Fig. 231) of highly distinctive shape: paramerite and condylite very slender, condylite strongly dilated in the middle.

o : segments IX-X distinctly modified (of the O. hauseri type), with dense and long pubescence; spermathecal capsule (Fig. 232) with long and slender distal portion and with coiled proximal portion.

Intraspecific variation: This species is subject to pronounced intraspecific variation of body size. Other variable characters (shape and relative size of the head, length of the antennae, size of the aedeagus, etc.) are related to body size.

Comparative notes: Based on the modifications of the abdominal segments IX-X and on the general morphology, O. dilatatus belongs to the O. hauseri group. As can be inferred from the similarly modified head and pronotum, it is closely allied to O. breviceps CAMERoN, 1940 (Thailand; body length $2.5-2.8 \mathrm{~mm}$ ), O. semivorax PACE, 2000 (Thailand; male unknown; $2.3 \mathrm{~mm}$ ), and O. incertus PACE, 2004 (Thailand; male unknown; $3.5 \mathrm{~mm}$ ). It is distinguished from all of them by larger body size and (except O. semivorax) different coloration of the forebody.

Distribution and natural history: The specimens were collected in two localities in Phongsaly and Louangphrabang provinces, North Laos, at altitudes of approximately 750 and $1500 \mathrm{~m}$. In the type locality they were found together with O.cultellatus and O. serratus, and in the locality in Louangphrabang together with O.extensus, O. serratus, O. latitibialis, O. bicuspis, O. retunsus, O. cultellatus, and O. carinatus.

\section{Orphnebius extensus spec. nov.}

(Figs 6, 31, 233-235)

Type material: Holotype ơ: "Laos, 1.-16.v.1999, Louangphrabang pr., $20^{\circ} 33-4^{\prime} \mathrm{N} 102^{\circ} 14^{\prime} \mathrm{E}$, Ban Song Cha $(5 \mathrm{~km} \mathrm{~W}), 1200$ m, Vít Kubáň leg. / Holotypus đ Orphnebius extensus sp. n., det. V. Assing 2015” (NHMB).
Paratypes: 10 exs.: same data as holotype (NHMB, cAss); 11 exs.: "Laos-N (Louangphrabang), 11-21.v.2002, $19^{\circ} 35^{\prime} \mathrm{N}, 101^{\circ} 58^{\prime} \mathrm{E}$, Thong Khan, 750 m, Vít Kubán leg." (NHMB, cAss); 3 exs.: "Laos-N (Oudomxai), 1-9.v.2002, $\sim 1100 \mathrm{~m}, 20^{\circ} 45^{\prime} \mathrm{N} 102^{\circ} 09^{\prime} \mathrm{E}$, Oudom Xai (17 km NEE), Vít Kubáň leg." (NHMB, cAss).

Etymology: The specific epithet (Latin, adjective: stretched) alludes to the long and slender parameres (especially the condylite) and median lobe of the aedeagus.

Description: Body size very variable; body length $3.2-4.3 \mathrm{~mm}$; length of forebody $1.4-1.7 \mathrm{~mm}$. Coloration: forebody black, with the elytra sometimes slightly paler anteriorly and in postero-median portion; abdomen red; legs with dark-brown femora and with reddish tibiae and tarsi; antennae blackish with antennomeres II-IV at least partly dark-reddish; maxillary palpi brown to darkbrown with the apical palpomere yellowish.

Head (Fig. 31) conspicuously wedge-shaped, broadest posteriorly, 1.56-1.88 times as broad as long, larger and more transverse in larger than in smaller specimens; posterior margin convex (small specimens) to truncate (large specimens); clypeus with broad and truncate anterior margin, near anterior margin with more or less pronounced elevation or tubercle (more pronounced in larger than in smaller specimens); dorsal surface nearly impunctate. Eyes strongly convex and asymmetrically wedge-shaped, situated in posterior angles of head (i.e., posterior margin of eye forming posterior margin of head postero-laterally). Antenna (Fig. 6) 1.0-1.4 mm long; antennomere I conspicuously elongate, approximately as long as combined length of antennomeres II-IV; antennomeres III-IV distinctly, V-X weakly flattened; IV-X transverse; V much larger and more transverse (approximately 1.5 times as broad as long) than IV; V-X asymmetric, of gradually increasing width, and distinctly transverse, VII-X nearly twice as broad as long; XI nearly as long as combined length of VIII-X.

Pronotum (Fig. 31) approximately 1.5 times as broad as long and 0.75-0.88 times as broad as head, smaller and narrower in relation to head in larger than in smaller specimens, moderately convex in cross-section; lateral and posterior margins together nearly forming a semicircle, posterior angles completely obsolete; disc with a median pair of punctures and sometimes few scattered additional punctures; lateral margins anteriorly with three long, erect, stout black setae.

Elytra (Fig. 31) 0.80-0.85 times as long as pronotum; punctation sparse and extremely fine; pubescence long, fine, and sub-erect. Hind wings fully developed. Metatarsomere I approximately as long as the combined length of II and III.

Abdomen: tergites III-VI with a lateral setiferous puncture on either side, VI with four additional punctures at posterior margin; tergite VII with dense longitudinal striae and oblong non-setiferous punctures in posterior two-thirds or three-fourths, near posterior margin with small and strongly oblong setiferous tubercles, poste- 
rior margin with palisade fringe; tergite VIII with two transverse series of long black setae posteriorly, posterior margin convex; sternite VIII with broadly convex posterior margin.

$0^{*}$ : segments IX-X distinctly modified (of the O. hauseri type), with dense and long pubescence; median lobe of aedeagus (Figs 233-234) 0.80-0.95 mm long, very slender; ventral process long and slender, apically shaped like a spear-head in ventral view; paramere (Fig. 235) $0.65-0.70 \mathrm{~mm}$ long, with slender paramerite and with conspicuously narrow (in apical half nearly filiform) condylite.

i : segments IX-X distinctly modified (modifications of the O.hauseri type), with dense and long pubescence; spermathecal capsule with long and coiled proximal portion.

Intraspecific variation: This species is subject to pronounced intraspecific variation of body size. Other variable characters (head shape and relative size, median tubercle on labrum, length of antennae, etc.) are related to body size, i.e., large specimens have a relatively larger and posteriorly more truncate head, a more pronounced median tubercle on the labrum, and longer antennae.

Comparative notes: As can be inferred from the similar external and sexual characters, particularly the derived morphology of the head and pronotum, the similar segments VII-X of the abdomen, and the derived morphology of the parameres, O. extensus is closely related to O. dilatatus, from which it differs by wedge-shaped and more bulging eyes in more posterior position, the shape of the labrum (with median tubercle and truncate anterior margin), the shape of the antennae (antennomeres $\mathrm{V}-\mathrm{X}$ more transverse and more distinctly asymmetric), reddish tibiae, the convex posterior margin of the abdominal tergite VIII, and by the primary sexual characters. According to their respective original descriptions, the species with a similar head shape described from Thailand (O. semivorax, O. incertus) do not have wedge-shaped eyes.

Distribution and natural history: The specimens were collected in three localities in Louangphrabang and Oudomxai provinces, North Laos, partly together with O.dilatatus, O. lunatus, O.nigrapicalis, O. reductus, O. serratus, O. latitibalis, O. bicuspis, O. retunsus, O. cultellatus, O. carinatus, O. integer, and/or O. septemcuspis. The altitudes range from 750 to $1200 \mathrm{~m}$.

\subsubsection{Orphnebius serratus subgroup}

Orphnebius serratus spec. nov.

(Figs 7, 32, 39, 236-243)

Type material: Holotype $\sigma^{\star}$ : "Laos-N (Louangphrabang), 11.-21.v.2002, $19^{\circ} 35^{\prime} \mathrm{N}, 101^{\circ} 58^{\prime} \mathrm{E}$, Thong Khan, $750 \mathrm{~m}$,
Vít Kubáň leg. / Holotypus ơ Orphnebius serratus sp. n., det. V. Assing 2015” (NHMB).

Paratypes: 19 exs. [2 teneral]: same data as holotype (NHMB, cAss); 1 \%: "Laos, Phongsaly prov., Phongsaly env., 6.-17.v.2004, 1500 $\mathrm{m}, 21^{\circ} 41^{\prime} \mathrm{N} 102^{\circ} 06-8^{\prime} \mathrm{E}$, V. Kubáň leg." (NHMB); 1 ㅇ: "Lao, Phongsaly prov., $21^{\circ} 41-2^{\prime \prime} \mathrm{N} \quad 102^{\circ} 06-8^{\prime} \mathrm{E}, 28 . v .-20 . v i .2003$, Phongsaly env., 1500 m, Vít Kubán leg.” (cAss); $10^{\star}$ [teneral]: "Laos, Phongsaly prov., $21^{\circ} 21^{\prime} \mathrm{N} 102^{\circ} 03^{\prime} \mathrm{E}$, Ban Sano Mai, 19.-26.v.2004, 1150 m, Vít Kubáň leg.” (NHMB) 1 o [teneral]: "Laos-N (Oudomxai), 1-9.v.2002, 1100 m, $20^{\circ} 45^{\prime} \mathrm{N} 102^{\circ} 09^{\prime} \mathrm{E}$, Oudom Xai (17 km NEE), Vít Kubáň leg." (NHMB).

Etymology: The specific epithet (Latin, adjective) alludes to the serrate posterior margin of the abdominal tergite VIII.

Description: Body length $3.0-5.0 \mathrm{~mm}$; length of forebody 1.5-2.1 mm. Coloration: forebody black; abdomen red; legs with the femora and tibiae blackish-brown, and with the tarsi reddish; antennae blackish with antennomeres II-IV at least partly dark-reddish; maxillary palpi brown with the apical palpomere yellowish.

Head (Fig. 32) of transversely rectangular shape, approximately 1.5 times as broad as long (length measured from sclerotized portion of clypeus); posterior angles nearly obsolete; posterior margin truncate or weakly convex; clypeus extensively membranous; dorsal surface nearly impunctate. Eyes large, more than twice as long as postocular region in dorsal view. Antenna (Fig. 7) $1.0-1.2 \mathrm{~mm}$ long; antennomere I very short, barely as long as the combined length of antennomeres II and III; antennomere IV weakly transverse and flattened; antennomere V much broader than antennomere IV; antennomeres V-X distinctly asymmetric, moderately flattened, and strongly transverse, more than twice as broad as long, and gradually increasing in width; XI short, only slightly longer than the combined length of IX and X.

Pronotum (Fig. 32) approximately 1.3 times as broad as long and 1.06-1.10 times as broad as head, moderately convex in cross-section; lateral and posterior margins together nearly forming a semi-circle, posterior angles completely obsolete; disc with a median pair of punctures, otherwise practically impunctate; lateral margins with three long, erect, stout black setae.

Elytra (Fig. 32) 0.75-0.80 times as long as pronotum; punctation sparse and fine; pubescence long, fine, pale, and sub-erect or depressed. Hind wings fully developed. Protibia moderately to distinctly dilated, more so in larger than in smaller specimens (Fig. 39). Metatarsomere I slightly shorter than the combined length of II and III.

Abdomen: tergites III-VI with a lateral setiferous puncture on either side, VI with four additional punctures at posterior margin; tergite VII with dense non-setiferous punctures in posterior two-thirds, posterior margin with palisade fringe; tergite VIII (Fig. 240) with a curved 
transverse series of eight setiferous tubercles bearing long black setae in posterior portion, with a lateral cluster of fine setae on either side, posterior margin convex and with eight short teeth; sternite VIII with broadly convex posterior margin.

$\mathrm{o}^{\star}$ : segments IX-X distinctly modified (O. hauseri type), with dense and long pubescence; median lobe of aedeagus (Figs 236-238) approximately $0.83 \mathrm{~mm}$ long; ventral process short, bifid, both apices incised in the middle; paramere (Fig. 239) approximately $0.7 \mathrm{~mm}$ long, with slender condylite; paramerite of distinctive shape, external margin notched at apical two-fifths.

ㅇ: segments IX-X distinctly modified (modifications of the O.hauseri type), with dense and long pubescence; proximal portion of spermathecal capsule simply curved, near distal portion distinctly dilated (Figs 241-243).

Comparative notes: Orphnebius serratus is distinguished from other species of the O. serratus subgroup by the dilated protibiae, by the distinctive shapes of the median lobe and the parameres of the aedeagus, and by the shape of the spermatheca.

Distribution and natural history: The specimens were collected in five localities in Louangphrabang, Phongsaly, and Oudomxai provinces, North Laos, at altitudes between 750 and $1500 \mathrm{~m}$, together with numerous other Orphnebius species.

\section{Orphnebius integer spec. nov.}

(Figs 8, 33, 37, 244-250)

Type material: Holotype $\sigma^{\star}$ : "Laos-N (Oudomxai), 1-9.v.2002, $\sim 1100 \mathrm{~m}, 20^{\circ} 45^{\prime} \mathrm{N} 102^{\circ} 09^{\prime} \mathrm{E}$, Oudom Xai (17 km NEE), Vít Kubáň leg. / Holotypus ơ Orphnebius integer sp. n., det. V. Assing 2015” (NHMB).

Paratype ơ: "Laos, Louangnamtha pr., $21^{\circ} 09^{\prime} \mathrm{N} 101^{\circ} 19^{\prime} \mathrm{E}$, Namtha $\rightarrow$ Muang Sing, 5-31.v.1997, 900-1200 m, Vít Kubáň leg." (cAss).

Etymology: The specific epithet (Latin, adjective: whole, undamaged) alludes to the apically undivided ventral process of the aedeagus.

Description: Body length 4.2-4.6 mm; length of forebody 1.7-1.9 mm. Coloration: forebody black; abdomen red; legs with blackish-brown femora, dark-brown tibiae, and reddish tarsi; antennae blackish with antennomeres II-IV at least partly dark-reddish; maxillary palpi brown to dark-brown with the apical palpomere yellowish.

Head (Fig. 33) of transversely rectangular shape, 1.45-1.48 times as broad as long (length measured from sclerotized portion of clypeus); posterior angles moderately marked; posterior margin truncate; clypeus extensively membranous; dorsal surface nearly impunctate. Eyes large, more than twice as long as postocular region in dorsal view. Antenna (Fig. 8) approximately $1.0 \mathrm{~mm}$ long; antennomere I very short, barely as long as the combined length of antennomeres II and III; antennomere IV weakly transverse and flattened; antennomere $\mathrm{V}$ much broader than antennomere IV; antennomeres V-X distinctly asymmetric, moderately flattened, and strongly transverse, more than twice as broad as long, and gradually increasing in width; XI nearly as long as the combined length of VIII-X.

Pronotum (Fig. 33) 1.33-1.42 times as broad as long and 1.07-1.13 times as broad as head, moderately convex in cross-section; lateral and posterior margins together nearly forming a semi-circle, posterior angles completely obsolete; disc with a median pair of punctures, otherwise practically impunctate; lateral margins with three long, erect, stout black setae.

Elytra (Fig. 33) approximately 0.75 times as long as pronotum; punctation sparse and fine; pubescence long, fine, pale, and sub-erect. Hind wings fully developed. Mesotibia moderately, smoothly dilated. Metatarsomere I slightly shorter than the combined length of II and III. Abdomen (Fig. 37): tergites III-VI with a lateral setiferous puncture on either side, VI with four additional punctures at posterior margin; tergite VII with dense nonsetiferous punctures in posterior two-thirds, posterior margin with palisade fringe; tergite VIII (Figs 249-250) with a postero-median pair of long black setae, with three lateral long black setae in posterior portion, and with a lateral cluster of fine setae on either side, posterior margin convex and with eight short teeth; sternite VIII with broadly convex posterior margin.

$\sigma^{7}$ : segments IX-X distinctly modified (O. hauseri type), with dense and long pubescence; median lobe of aedeagus (Figs 244-245) approximately $0.75 \mathrm{~mm}$ long; ventral process short, undivided, and apically acute (Fig. 246); paramere (Figs 247-248) approximately $0.6 \mathrm{~mm}$ long, with slender condylite.

o: : unknown.

Comparative notes: Orphnebius integer is distinguished from other species of the O. serratus subgroup by the moderately dilated mesotibiae and by the distinctive shapes of the median lobe and the parameres of the aedeagus.

Distribution and natural history: The type specimens were collected in two localities in Oudomxai and Louangnamtha provinces, North Laos, at altitudes between 900 and $1200 \mathrm{~m}$, in the type locality together with O. extensus, O. serratus, and O. septemcuspis.

\section{Orphnebius latitibialis spec. nov.} (Figs 29, 38, 251-252)

Type material: Holotype + [antennomere XI of left antenna and antennomeres IV-XI of right antenna missing]: “Laos-N (Louangphrabang), 11-21.v.2002, 19³ $35^{\prime} \mathrm{N}$, 
$101^{\circ} 58^{\prime} E$, Thong Khan, 750 m, Vít Kubáň leg. / Holotypus + Orphnebius latitibialis sp. n., det. V. Assing 2015” (NHMB).

Etymology: The specific epithet (Latin, adjective) alludes to the conspicuously dilated mesotibiae.

Description: Body length $4.3 \mathrm{~mm}$; length of forebody $2.0 \mathrm{~mm}$. Coloration: forebody black; abdomen red; legs with blackish-brown femora and mesotibiae, dark-brown pro- and metatibiae, and reddish tarsi; antennae blackish with antennomeres I-IV reddish-brown; maxillary palpi yellowish-red with the apical palpomere yellowish.

Head (Fig. 29) of transversely rectangular shape, 1.48 times as broad as long (length measured from sclerotized portion of clypeus); posterior angles moderately marked; posterior margin weakly concave in the middle; clypeus extensively membranous; dorsal surface nearly impunctate. Eyes large, more than twice as long as postocular region in dorsal view. Antennomere I approximately as long as the combined length of antennomeres II and III; antennomere IV moderately transverse and flattened; antennomere $\mathrm{V}$ much broader than antennomere IV; antennomeres $\mathrm{V}-\mathrm{X}$ distinctly asymmetric, moderately flattened, and strongly transverse, more than twice as broad as long, and gradually increasing in width.

Pronotum (Fig. 29) 1.3 times as broad as long and 1.06 times as broad as head, moderately convex in crosssection; lateral and posterior margins together nearly forming a semi-circle, posterior angles completely obsolete; disc with a median pair of punctures, otherwise practically impunctate; lateral margins with three long, erect, brown setae.

Elytra (Fig. 29) approximately 0.7 times as long as pronotum; punctation sparse and fine; pubescence long, fine, pale, and depressed to sub-erect. Hind wings fully developed. Mesotibia (Fig. 38) strongly dilated, covered with dense setiferous tubercles, posterior surface with large, long, and deep excavation without such tubercles. Metatarsomere I approximately as long as the combined length of II and III.

Abdomen: tergites III-VI with a lateral setiferous puncture on either side, III-IV with an additional pair of setiferous punctures at or near posterior margin, and V-VI with four additional punctures at posterior margin; tergite VII with dense slightly oblong non-setiferous punctures in posterior three-fourths, posterior margin with palisade fringe; tergite VIII (Fig. 252) with a postero-median pair of long black setae, with three lateral long black setae in posterior portion, and with a lateral cluster of fine setae on either side, posterior margin convex and with eight short teeth; sternite VIII with broadly convex posterior margin.

o: : unknown.

ㅇ: segments IX-X distinctly modified (of the O. hauseri type), with dense and long pubescence; spermathecal capsule with very long and thin proximal portion (Fig. 251).
Comparative notes and comment: Based on the external and sexual characters, O. latitibialis belongs to the $O$. serratus subgroup sensu strictu. The similar shape and chaetotaxy of tergite VIII, as well as the modified mesotibiae suggest that it is closely allied to O. integer. The species is readily distinguished from all its congeners by the conspicuously modified mesotibiae alone, so that a description based on a female seems justified.

Distribution and natural history: The type locality is situated in Louangphrabang province, North Laos, at an altitude of approximately $750 \mathrm{~m}$. Orphnebius dilatatus, O. extensus, O. serratus, O. bicuspis, O. retunsus, O. cultellatus, and O.carinatus were collected in the same locality.

\section{Orphnebius bicuspis spec. nov.}

(Figs $9-10,34,44,253-260$ )

Type material: Holotype $o^{\star}$ : "Laos-N (Louangphrabang), 11-21.v.2002, $19^{\circ} 35^{\prime} \mathrm{N}, 101^{\circ} 58^{\prime} \mathrm{E}$, Thong Khan, $750 \mathrm{~m}$, Vít Kubáň leg. / Holotypus ơ Orphnebius bicuspis sp. n., det. V. Assing 2015” (NHMB).

Paratypes: 12 exs. [3 teneral]: same data as holotype (NHMB, cAss); 2 ㅇ ㅇ: "Laos, 1.-16.v.1999, Louangphrabang pr., $20^{\circ} 33-4^{\prime} \mathrm{N} 102^{\circ} 14^{\prime} \mathrm{E}$, Ban Song Cha (5 km W), 1200 m, Vít Kubáň leg." (NHMB, cAss); $20^{\star} o^{\star}:$ "NE India, Arunachal Pr., Etalin vicinity, 700 m, 28 $36^{\prime} 56^{\prime \prime} \mathrm{N}$, 95 53'21"E, FIT (flight interception trap), L. Dembický leg., 12.-25.v.2012” (ZFMK, cAss).

Etymology: The specific epithet (Latin, adjective) alludes to the bifid ventral process of the aedeagus.

Description: Body length 2.7-4.1 mm; length of forebody 1.4-1.8 mm. Coloration: forebody black; abdomen red; legs with the femora blackish-brown, the tibae brown to dark-brown, and the tarsi reddish; antennae blackish with antennomeres II-III often, rarely also IV, slightly paler (brown to dark-brown); maxillary palpi pale-brown with the apical palpomere yellowish.

Head (Figs 34, 44) of transversely rectangular shape, approximately 1.4 times as broad as long; posterior angles nearly obsolete; posterior margin truncate or weakly convex; dorsal surface nearly impunctate. Eyes large, more than twice as long as postocular region in dorsal view. Antenna (Figs 9-10) approximately $1.0 \mathrm{~mm}$ long; antennomere I very short, approximately as long as the combined length of antennomeres II and III; antennomere IV distinctly transverse and flattened; antennomere $\mathrm{V}$ much broader than antennomere IV; antennomeres $\mathrm{V}-\mathrm{X}$ distinctly asymmetric, moderately flattened, and strongly transverse, more than twice as broad as long, and gradually increasing in width; $\mathrm{XI}$ approximately as long as the combined length of VIII-X. 
Pronotum (Figs 34, 44) approximately 1.4 times as broad as long and as broad as head, moderately convex in crosssection; lateral and posterior margins together nearly forming a semi-circle, posterior angles completely obsolete; disc with a median pair of punctures, otherwise practically impunctate; lateral margins with one long and stout, and with two moderately long and rather fine erect black setae.

Elytra (Figs 34, 44) 0.70-0.77 times as long as pronotum; punctation sparse and fine; pubescence long, fine, pale, and sub-erect or depressed. Hind wings fully developed. Tibiae unmodified. Metatarsomere I slightly shorter than the combined length of II and III.

Abdomen: tergites III-VI with a lateral setiferous puncture on either side, VI with four additional punctures at posterior margin; tergite VII with dense non-setiferous punctures in posterior two-thirds, posterior margin with palisade fringe; tergite VIII (Fig. 260) with a lateral cluster of fine setae on either side, posterior margin truncate in the middle and without teeth; sternite VIII with broadly convex posterior margin.

$\sigma^{\top}$ : segments IX-X distinctly modified (of the O. hauseri type), with dense and long pubescence; median lobe of aedeagus (Figs 253-255, 258-259) approximately $0.7 \mathrm{~mm}$ long; ventral process short and bifid; paramere (Fig. 256) approximately $0.6 \mathrm{~mm}$ long, with slender condylite; paramerite of distinctive shape, external margin notched at apical two-fifths.

ㅇ: segments IX-X distinctly modified (O. hauseri type), with dense and long pubescence; proximal portion of spermathecal capsule simply curved, near distal portion distinctly modified (Fig. 257).

Intraspecific variation: There are slight differences in the shape of the bifid apex of the ventral process of the aedeagus of the males from Arunachal Pradesh and from Laos. However, the external characters (Figs 9-10, $34,44)$ and the shape of the paramere are identical, so that the observed differences are attributed to intrarather than interspecific variation.

Comparative notes: Based on the shape of the head, the antennae, and the pronotum, the lateral clusters of setae on the abdominal tergite VIII, as well as on the bifid ventral process of the aedeagus and the morphology of the spermatheca, O. bicuspis belongs to the O. serratus subgroup. It is distinguished from O. serratus and other representatives of this subgroup by the non-dentate posterior margin of tergite VIII, as well as by the different shapes of the median lobe and the parameres of the aedeagus, from $O$. serratus additionally by smaller average body size, a narrower pronotum, and undilated protibiae. Regarding the bifid ventral process of the aedeagus, as well as the similar head shape, O. bicuspis is similar to O. incisus PACE, 2000, which was originally described from Thailand and subsequently reported also from Yunnan (PACE 2000, 2012b). Orphnebius bicuspis is distinguished from this species by slightly larger size (O. incisus: $3.4 \mathrm{~mm})$, the coloration of the antennae (O. incisus: antennomeres I-V brown, VI-XI black), the more transverse head, by the larger median lobe of the aedeagus (O. incisus: $<0.5 \mathrm{~mm}$, if the scale and the drawings are correct) and by the shorter and more broadly separated apices of the ventral process. For illustrations of $O$. incisus see PACE (2000).

Distribution and natural history: Orphnebius bicuspis is known from two localities in Louangphrabang province (Laos) and one in Arunachal Pradesh; the type locality is identical to that of O. serratus. The specimens were collected at altitudes between 700 and $1200 \mathrm{~m}$, in Laos together with O. dilatatus, O. extensus, O. serratus, O. latitibialis, O. lunatus, O. nigrapicalis, O. reductus, O. retunsus, O. cultellatus, and O. carinatus, and in Arunachal Pradesh together with O. spinans and O.dispar. At least the material from India was collected with a flight interception trap. Three of the type specimens from Laos are teneral.

\section{Orphnebius opticus CAMERON, 1946}

(Figs 14, 40, 261-262)

Orphnebius (Mesocephalobius) opticus CAMERon, 1946: 692.

Type material: Syntype o: “62249 / Siam, Renong / Doherty / Orphnebius opticus Cam. Type / Fry Coll. 1905.100. / Type / Syntypus ㅇ Orphnebius opticus Cameron, rev. V. Assing 2015” (BMNH).

Comment: The original description of O. opticus is based on an unspecified number of syntypes from "Siam: Renong" (CAMERON 1946). The sole syntype found in the collections at the $\mathrm{BMNH}$ is a female and consequently not designated as the lectotype.

Redescription: Body length $5.7 \mathrm{~mm}$; length of forebody $2.5 \mathrm{~mm}$. Coloration: head and pronotum brown, with the frons, the clypeus, and the mouthparts yellowishred, and the pronotal margins narrowly reddish; elytra dark-yellowish with the postero-lateral portions extensively brown; abdomen and legs dark-yellowish; antennae distinctly bicoloured, with antennomeres V-XI darkbrown and antennomeres I-IV reddish; maxillary palpi reddish with the apical palpomere yellowish.

Head (Fig. 40) strongly transverse, 1.3 times as broad as long; posterior angles obsolete; punctation extremely fine, barely visible, and very sparse; median and posterior dorsal portions extensively impunctate; interstices without microsculpture. Eyes very large, nearly reaching posterior margin, and more than twice as long as distance from posterior margin of eye to posterior constriction of head in dorsal view. Antenna (Fig. 14) $1.6 \mathrm{~mm}$ long, distinctly incrassate, and distinctly asymmetric; antennomere IV small and approximately as long as broad; antennomere $\mathrm{V}$ broader than IV and distinctly 
transverse; antennomeres VI-X strongly asymmetric, of gradually increasing width, and strongly transverse, approximately twice as broad as long; XI longer than the combined length of IX and X, but shorter than the combined length of VIII-X.

Pronotum (Fig. 40) 1.25 times as broad as long and 1.05 times as broad as head, moderately convex in crosssection; lateral and posterior margins together nearly forming a semi-circle, posterior angles completely obsolete; disc with a median pair of punctures, otherwise impunctate; margins with additional punctures; lateral margins with at least two long and erect black setae anteriorly.

Elytra (Fig. 40) approximately 0.8 times as long as pronotum; punctation sparse and fine; pubescence long, pale, and depressed to sub-erect. Hind wings fully developed. Metatarsomere I nearly as long as the combined length of II-IV.

Abdomen narrower than elytra; tergites III-VI each with two lateral punctures bearing black setae on either side; tergite VII with dense non-setiferous punctation in posterior two-thirds, at posterior margin with a transverse row of eight setiferous tubercles, posterior margin with distinct palisade fringe; tergite VIII (Fig. 261) weakly serrate, with eight setiferous tubercles at posterior margin, posterior margin broadly convex.

$0^{\pi}$ : unknown.

ㅇ: spermatheca as in Fig. 262.

Comparative notes: Among the revised species of the $O$. serratus subgroup with a serrate posterior margin of tergite VIII, this species is characterized by a less distincty quadrangular head, pale coloration, the antennal morphology, the pronotum being slightly broader than the head, the weakly serrate posterior margin of tergite VIII, and the shape of the spermatheca.

Distribution: The type locality, today Ranong, is situated in southern Thailand.

\subsubsection{Orphnebius conicornis subgroup}

\section{Orphnebius incrassatus Assing, 2015}

Material examined: China: 1 , , Yunnan, Gaoligong Shan, $27^{\circ} 47^{\prime} \mathrm{N}, 98^{\circ} 33^{\prime} \mathrm{E}, 2000-3000 \mathrm{~m}$, sifted, $12-15$. VI.2009, leg. Grebennikov (cAss).

Comment: The original description of this recently described species is based on a unique female from a locality in the Gaoligong Shan, to the southeast of Tengchong (Assing 2015a).

\section{Orphnebius fusicollis spec. nov.}

(Figs 11, 46-47, 263-268)

Type material: Holotype $0^{\star}$ : "Lao-NE, Hua Phan prov., $20^{\circ} 12^{\prime} \mathrm{N} 104^{\circ} 01^{\prime} \mathrm{E}$, Phu Phan Mt., $\sim 1750 \mathrm{~m}, 17 . v .-3 . v i$. 2008, Vít Kubáň leg. / Holotypus ơ Orphnebius fusicollis sp. n., det. V. Assing 2015” (NHMB).

Paratypes: $60^{\star} o^{\star}, 1$ : same data as holotype (NHMB, cAss).

Etymology: The specific epithet (Latin, adjective; from fusus: broad) alludes to the strongly transverse pronotum.

Description: Body length 3.4-4.2 mm; length of forebody $1.4-1.6 \mathrm{~mm}$. Coloration: forebody blackish; abdomen reddish, with the anterior half of tergite VII usually slightly darker; legs with dark-reddish to darkbrown femora and reddish tibiae and tarsi; antennae dark-brown with antennomeres I-III and the apex of XI reddish, and antennomere IV reddish-brown; maxillary palpi reddish with yellowish terminal palpomere.

Head (Fig. 46) strongly transverse, 1.35-1.40 times as broad as long, posteriorly distinctly angled in lateral view (Fig. 47), posterior margin of dorsal surface convex in dorsal view; punctation of lateral portions fine and very sparse; pubescence pale and long; median dorsal portion extensively impunctate; interstices without microsculpture. Eyes large, reaching posterior margin, and strongly bulging. Antenna (Fig. 11) 1.1-1.2 mm long, moderately incrassate, and symmetric; antennomeres III and IV flattened, $\mathrm{V}-\mathrm{X}$ of distinctly conical shape, IV-X weakly transverse, $\mathrm{X}$ distinctly longer than IX, and XI elongate, approximately as long as the combined length of VIII-X.

Pronotum (Fig. 46) large and strongly transverse, approximately 1.45 times as broad as long and 1.3 times as broad as head, moderately convex in cross-section; posterior angles very weakly marked, nearly obsolete; disc with an indistinct median pair of punctures, otherwise nearly impunctate; lateral margins each with three long and erect black setae.

Elytra (Fig. 46) nearly as long as pronotum; suture gaping posteriorly; punctation sparse and very fine; pubescence long and pale, depressed to sub-erect. Hind wings fully developed. Legs relatively short; metatarsomere I shorter than the combined length of II and III.

Abdomen: paratergites strongly elevated and sharply edged; tergites III-VI each with a lateral setiferous puncture on either side and with four setiferous punctures at posterior margin (individual punctures occasionally missing); tergite VII with non-setiferous punctation across middle, without such punctation in anterior and posterior portions, and with a transverse row of setiferous punctures near posterior margin, posterior margin with palisade fringe; tergite VIII (Fig. 266) with two transverse rows of black setae posteriorly and with strongly convex posterior margin; sternite VIII with strongly convex posterior margin; both tergite and ster- 
nite VIII with dense and fine gland openings on whole surface (Fig. 267).

$\sigma^{\star}$ : hemi-tergites IX and tergite $\mathrm{X}$ with extremely dense and long pubescence (O. hauseri type); median lobe of aedeagus (Figs 263-264) approximately $0.65 \mathrm{~mm}$ long; ventral process distinctly curved in lateral view; internal sac with large sclerotized structures; paramere (Fig. 267) approximately $0.45 \mathrm{~mm}$ long, with slender paramerite and stout, apically weakly convex condylite.

ㅇ: spermatheca (Fig. 268) of conspicuous shape, but not distinctive.

Comparative notes: As is suggested by the similar shape of the antennae and the similar general morphology of the aedeagus, $O$. fusicollis is closely allied to O. conicornis from China, from which it differs by distinctly darker coloration of the forebody, the legs, and the antennae, by the longer antennae with much less transverse antennomeres $\mathrm{V}-\mathrm{X}$ and a more elongate antennomere XI, a pronotum with at least weakly marked posterior angles and with three long black setae at the lateral margins (O. conicornis: posterior angles obsolete; lateral margins each with four brown setae), a smoothly curved ventral process of the aedeagus in lateral view (angled in O. conicornis), and by the shape of the paramere. For illustrations of O. conicornis see Assing (2006c).

Distribution and natural history: The type locality is situated in Hua Phan province, North Laos, at an altitude of approximately $1750 \mathrm{~m}$. Orphnebius cernens, O. lunatus, O. fuscapicalis, O. spoliatus, and an unnamed species were collected in the same locality.

\subsubsection{Orphnebius reductus subgroup}

\section{Orphnebius reductus spec. nov.}

(Figs 18, 49, 269-273)

Type material: Holotype $\sigma^{*}$ : "Laos, 1.-16.v.1999, Louangphrabang pr., $20^{\circ} 33-4^{\prime} \mathrm{N} 102^{\circ} 14^{\prime} \mathrm{E}$, Ban Song Cha (5 km W), 1200 m, Vít Kubáň leg. / Holotypus o Orphnebiusreductussp. n., det.V. Assing 2015”(NHMB). Paratypes: $15 \sigma^{\top} o^{\star}, 10$ 우 우 [3 teneral]: same data as holotype (NHMB, cAss); 1 \% : same data, but 24.iv.-16.v.1999 (NHMB); $10^{\top}$ : "Lao, Phongsaly prov., $21^{\circ} 41-2^{\prime} \mathrm{N} 102^{\circ} 06-$ 8'E, 28.v.-20.vi.2003, Phongsaly env., 1500 m, Vít Kubáň leg." (cAss).

Etymology: The specific epithet (Latin, adjective) alludes to the conspicuously reduced condylite of the paramere.

Description: Body length 3.8-4.6 mm; length of forebody 1.6-1.9 mm. Coloration: forebody blackish; abdomen pale-reddish; legs yellowish-red, with the profemora yellowish and the meso- and metafemora brown; antennae blackish, with the basal 1-3 antennomeres yellowish; maxillary palpi reddish-yellow with yellowish terminal palpomere.

Head (Fig. 49) strongly transverse, 1.30-1.35 times as broad as long; punctation of lateral portions extremely fine, barely visible, and very sparse; median and posterior dorsal portions extensively impunctate; interstices without microsculpture. Eyes enormous, nearly reaching posterior margin, and strongly bulging. Antenna (Fig. 18) sexually dimorphic, $1.3-1.4 \mathrm{~mm}$ long in male and 1.1-1.2 $\mathrm{mm}$ long in female, distinctly incrassate, and distinctly asymmetric; antennomere IV moderately transverse; antennomeres $\mathrm{V}-\mathrm{X}$ of gradually and distinctly increasing width, increasingly asymmetric, and increasingly transverse, more transverse in female than in male; $\mathrm{X}$ approximately twice as wide as long; XI elongate, longer (male) or shorter (female) than the combined length of VIII-X.

Pronotum (Fig. 49) moderately transverse, approximately 1.25 times as broad as long and 1.05-1.10 times as broad as head, moderately strongly convex in crosssection; posterior angles obsolete; disc with a median pair of punctures, otherwise practically impunctate; lateral margins each with (probably) four long and erect black setae.

Elytra (Fig. 49) approximately 0.7 times as long as pronotum; suture distinctly gaping posteriorly; punctation sparse and very fine; pubescence long and pale. Hind wings fully developed. Metatarsomere I approximately as long as the combined length of II and III.

Abdomen: paratergites strongly elevated and sharply edged; tergites III-VI each with two lateral setiferous punctures on either side, tergite VI additionally with four setiferous punctures at posterior margin; tergite VII with non-setiferous punctation in posterior two-thirds and with eight setiferous punctures near posterior margin, posterior margin with palisade fringe; tergite VIII (Fig. 272) with two transverse rows of black setae posteriorly and with broadly truncate posterior margin; sternite VIII with broadly, very weakly convex posterior margin.

$\sigma^{*}$ : hemi-tergites IX and tergite $\mathrm{X}$ with extremely dense and long pubescence; median lobe of aedeagus (Figs 269-270) 0.68-0.72 $\mathrm{mm}$ long and of distinctive shape; internal sac without strongly sclerotized structures; paramere (Fig. 271) approximately $0.55 \mathrm{~mm}$ long, with apically hooked paramerite of modified shape and with condylite of strongly reduced size.

o : abdominal segments IX-X of similar shape and chaetotaxy as in O. hauseri; spermatheca as in Fig. 273.

Comparative notes: Based on the modifications of the abdominal segments IX-X, the shape and chaetotaxy of tergite and sternite VIII, and on the morphology of the aedeagus, O. reductus belongs to the O. hauseri group. It is characterized especially by the enormous eyes, by the shape and pronounced sexual dimorphism of the antennae, the shape of the median lobe of the aedeagus, and the derived shape of the paramere. 
Distribution and natural history: This species is currently known from two localities in Phongsaly and Louang Phrabang provinces, North Laos. The specimens were collected at altitudes of 1200 and approximately $1500 \mathrm{~m}$, together with O. lunatus, O. nigrapicalis, O. grandicollis, O. extensus, O. serratus, O. bicuspis, O. vates, O. baccillatus, and two unnamed species.

\section{Orphnebius biformis spec. nov.}

(Figs 19-20, 42-43, 274-278)

Type material: Holotype $\sigma^{\star}$ : "Sumatra: Jambi pr.: Kerinci, Seblat N.P.: 7 km E Kayuaro: Mt. Tujuh, $1750 \pm 250$ m, $1^{\circ} 45^{\prime} \mathrm{S}, 101^{\circ} 25^{\prime} \mathrm{E}$, Dembický leg., 25.ii.-2.iii.2003 / Holotypus o Orphnebius biformis sp. n., det. V. Assing 2015” (NHMB).

Paratypes: 2 ㅇ 우 : same data as holotype (NHMB, cAss).

Etymology: The specific epithet (Latin, adjective) alludes to the hypothesized pronounced sexual dimorphism of the eyes and the antennae.

Description: Body length 4.3-4.8 mm; length of forebody 1.9-2.0 mm. Coloration: head dark-brown with the clypeus yellowish-red; pronotum dark-brown; elytra dark-brown with the anterior and sutural portions more or less extensively paler; abdomen reddish-yellow; legs yellowish; antennae dark-brown with antennomeres I-IV reddish-yellow; maxillary palpi reddish-yellow with yellowish terminal palpomere.

Head (Figs 42-43) sexually dimorphic, strongly transverse, approximately 1.3 (female) and 1.4 (male) times as broad as long, respectively; laterally with few scattered and very fine punctures; remainder of dorsal portion extensively impunctate; interstices without microsculpture. Eye size sexually dimorphic, in male enormous and strongly bulging, covering all of lateral margins, in female less large and less convex. Antenna (Figs 19-20) sexually dimorphic, approximately 1.6 and $1.3 \mathrm{~mm}$ long in male and in female respectively, distinctly incrassate, and distinctly asymmetric; antennomere IV small and moderately transverse; antennomere V moderately transverse and weakly transverse in female, strongly transverse and strongly asymmetric in male; antennomeres VI-X of gradually and distinctly increasing width, increasingly asymmetric, and increasingly transverse, more transverse in male than in female; $\mathrm{X}$ more than twice as wide as long; XI elongate, approximately three times as long as broad (male) or twice as long as broad (female).

Pronotum (Figs 42-43) moderately transverse, 1.211.26 times as broad as long and approximately 0.95 (male) or 1.1 times (female) as broad as head, moderately strongly convex in cross-section; posterior angles nearly obsolete; disc with a median pair of punctures, otherwise practically impunctate; lateral margins each with three long and erect black setae.
Elytra (Figs 42-43) approximately 0.7 times as long as pronotum; suture strongly gaping posteriorly; punctation sparse and very fine; pubescence long and pale. Hind wings fully developed. Metatarsomere I approximately as long as, or slightly longer than, the combined length of II and III.

Abdomen: paratergites moderately elevated and moderately sharply edged; tergites III-VI each with two lateral setiferous punctures on either side, tergite VI additionally with median pair of punctures at posterior margin; tergites IV-V with or without median pair of setiferous punctures at posterior margin; tergite VII with non-setiferous punctation in posterior two-thirds and with eight setiferous punctures near posterior margin, posterior margin with palisade fringe; tergite VIII (Fig. 275) with two transverse rows of black setae posteriorly and with broadly truncate posterior margin; sternite VIII with broadly and weakly convex posterior margin.

$\sigma^{*}$ : hemi-tergites IX and tergite $\mathrm{X}$ with extremely dense and long pubescence; median lobe of aedeagus (Figs 277-278) $0.51 \mathrm{~mm}$ long and of distinctive shape; internal sac without strongly sclerotized structures; paramere (Fig. 274) approximately $0.5 \mathrm{~mm}$ long, condylite very short and broad.

: abdominal segments IX-X of similar shape and chaetotaxy as in O. hauseri; spermatheca as in Fig. 276.

Comment: The holotype male is distinguished from the two female paratypes by the different shape of the antennae, the more transverse head (broader than the pronotum), and the distinctly larger and more convex eyes. These differences, however, are interpreted as sexual dimorphism, not only because the three specimens were collected in the same locality on the same date, but also because they are extremely similar in other respects and because a pronounced sexual dimorphism (of the antennae) was also observed in the closely related O. reductus.

Comparative notes: Based on the modifications of the abdominal segments IX-X, the shape and chaetotaxy of tergite and sternite VIII, the pronounced sexual dimorphism of the antennae, the absence of strongly sclerotized structures in the internal sac of the aedeagus, and particularly on the very similar morphology of the spermatheca, this species is closely allied to O. reductus, from which it differs by different coloration, a pronounced sexual dimorphism of the head (including the eyes), by the shape of the male and female antennae, the coloration, and the primary sexual characters, particularly the completely different shape of the median lobe and the parameres of the aedeagus.

None of the three Orphnebius species previously recorded from Sumatra (O. laticeps CAmeron, 1925, O. ophthalmicus Cameron, 1936, O. harpagonum PACE, 2010) is similar to O. biformis. 
Distribution and natural history: The type locality is situated in Sumatera Barat, Sumatra, Indonesia, at an altitude of approximately $1750 \mathrm{~m}$.

\section{Orphnebius krypticola PACE, 2007}

Material examined: Brunei: $1 \sigma$, Temburung District, ridge NE of Kuala Belalong, 300 m, light trap, X.1992, leg. Martin (BMNH).

Comment: The original description is based on a unique male from Brunei. The specific epithet is evidently a misspelling: in the heading of the description PACE (2007) writes "kripticola", whereas in other parts of the article (abstract, résumé, keys, figure caption) he uses the - etymologically correct - epithet "krypticola" five times. HLAváč et al. (2011) list the species as Orphnebius kripticola.

The fact that PACE (2007) uses the epithet "krypticola" five times, as opposed to one occurrence of "kripticola", is evidence that he meant to use the etymologically correct noun and that the spelling "kripticola" represents an inadvertant error in the sense of Article 32.5.1 of the Code (ICZN 1999). According to Article 24.2.3 of the Code, HLAváč et al. (2011) cannot be regarded as First Revisers, since they do not cite both spellings together. Thus, the epithet "krypticola" is here designated as the correct original spelling.

Based on the shapes of tergite and sternite VIII, as well as on the male sexual characters (ventral process massive; paramerite slender and curved), O. krypticola belongs to the $O$. reductus subgroup.

\subsubsection{Orphnebius retunsus subgroup}

\section{Orphnebius retunsus spec. nov.}

(Figs 12, 45, 279-282)

Type material: Holotype $0^{\star}:$ "Laos-N (Louangphrabang), 11-21.v.2002, $19^{\circ} 35^{\prime} \mathrm{N}, 101^{\circ} 58^{\prime} \mathrm{E}$, Thong Khan, $750 \mathrm{~m}$, Vít Kubáň leg. / Holotypus ơ Orphnebius retunsus sp. n., det. V. Assing 2015” (NHMB).

Etymology: The specific epithet (Latin, adjective: blunt) alludes to the dorsally flattened paratergites.

Description: Body length $3.3 \mathrm{~mm}$; length of forebody $1.6 \mathrm{~mm}$. Coloration: head blackish-brown (except for the reddish clypeus and the mouthparts), remainder of body reddish; legs and maxillary palpi yellowish; antennae reddish.

Head (Fig. 45) strongly transverse, 1.4 times as broad as long; posterior angles completely obsolete; punctation of lateral portions extremely fine, barely visible, and very sparse; median and posterior dorsal portions extensively impunctate; interstices without microsculpture. Eyes extremely large, occupying all of lateral margins of head, and strongly bulging. Antenna (Fig. 12) $1.0 \mathrm{~mm}$ long, strongly incrassate; antennomere IV strongly transverse, approximately twice as broad as long; antennomeres $\mathrm{V}-\mathrm{X}$ even more transverse, nearly three times as broad as long (disc-shaped) and gradually increasing in width; XI nearly as long as the combined length of VIII-X.

Pronotum (Fig. 45) strongly transverse, approximately 1.4 times as broad as long and as broad as head, moderately convex in cross-section; posterior angles moderately marked; disc with a median pair of punctures, otherwise practically impunctate.

Elytra (Fig. 45) nearly as long as pronotum; suture distinctly gaping posteriorly; punctation moderately sparse and very fine; pubescence very fine and pale, barely visible. Hind wings fully developed. Metatarsomere I approximately as long as the combined length of II and III.

Abdomen: segments III-VI with relatively broad (with distinct dorsal surface) and weakly elevated paratergites; tergites III-VI each with a lateral setiferous puncture on either side; tergite VI additionally with four setiferous punctures at posterior margin; tergite VII anteriorly with dense and coarse striae, posteriorly with oblong non-setiferous punctation, and with a transverse row of indistinct oblong setiferous tubercles near posterior margin, posterior margin with palisade fringe; posterior margin of tergite VIII (Fig. 282) broadly convex, in the middle truncate; sternite VIII with convex posterior margin.

$\sigma^{*}$ : hemi-tergites IX and tergite $\mathrm{X}$ with extremely dense and long pubescence; median lobe of aedeagus (Figs 279-280) $0.53 \mathrm{~mm}$ long; ventral process long and apically acute in ventral view; internal sac without strongly sclerotized structures; paramere (Fig. 281) nearly as long as median lobe; paramerite and condylite of subequal length, somewhat wedge-shaped, and apically acute.

+ : unknown.

Comparative notes: Based on the modifications of the abdominal tergites IX and X, as well as the shapes and chaetotaxy of tergite and sternite VIII, O. retunsus belongs to the O. hauseri group. It is distinguished from the species of the $O$. hauseri subgroup by the different coloration, enormous eyes, strongly transverse antennomeres IV-X, the broad (not sharp) and less strongly elevated paramerites of the abdominal segments III-VI, and by the absence of strongly sclerotized structures in the internal sac of the aedeagus. Since the species does not belong to the $O$. dilatatus and $O$. serratus subgroups either, it probably represents a subgroup of its own.

Distribution and natural history: The type locality and the circumstances of collection are identical to those of O. bicuspis. 


\section{Orphnebius fodens spec. nov.}

(Figs 13, 48, 283-286)

Type material: Holotype $\sigma^{\star}$ [antennomeres XI of both antennae missing]: "Malaysia, Sabah, Sandakan, S. Lokan (LF), Sept. 96 AYC Chung / FIT 3/2/2 / BMNH $\{$ E $\}$ 2002-113, A. Y. C. Chung, LF = Logged Forest / Holotypus o Orphnebius fodens sp. n., det. V. Assing 2016" (BMNH).

Etymology: The specific epithet is the present participle of the Latin verb fodere (to sting) and alludes to the conspicuously acute ventral process of the aedeagus.

Description: Body length $3.2 \mathrm{~mm}$; length of forebody $1.4 \mathrm{~mm}$. Coloration: head and pronotum brown; elytra and abdomen pale-reddish; legs reddish-yellow; antennae reddish; maxillary palpi yellowish.

Head (Fig. 48) strongly transverse, 1.3 times as broad as long, and of transversely oval shape; posterior angles completely obsolete; dorsal surface practically impunctate, except for some fine punctures in lateral portions. Eyes large and bulging, approximately twice as long as distance from posterior margin of eye to posterior constriction of head. Antenna (Fig. 13) strongly incrassate and not distinctly asymmetric; antennomeres IV-X strongly transverse, of increasing width, and increasingly transverse, $\mathrm{X}$ nearly three times as broad as long.

Pronotum (Fig. 48) strongly transverse, 1.35 times as broad as long and 1.17 times as broad as head; lateral and posterior margins nearly forming a semi-circle, posterior angles practically obsolete; disc with a median pair of punctures, otherwise impunctate; lateral margins each with three very long and erect black setae.

Elytra (Fig. 48) approximately 0.85 times as long as pronotum; disc with moderately sparse and moderately fine punctation; pubescence fine, pale, and sub-erect. Hind wings fully developed. Tarsi relatively short; metatarsomere I approximately as long as the combined length of II and III.

Abdomen: tergites IV-VI each with 5-6 setiferous tubercles at posterior margins, these tubercles bearing long dark setae; tergite VII with pronounced, dense and long striae, posterior margin with palisade fringe; tergite VIII (Fig. 286) anteriorly with short pubescence, in posterior half with two transverse rows of eight long black setae, posterior margin broadly truncate; posterior margin of sternite VIII weakly convex in the middle.

$\sigma^{\top}:$ hemi-tergites IX of moderate length; hemi-tergites IX and tergite $\mathrm{X}$ with dense and long pubescence; median lobe of aedeagus (Figs 283-284) $0.5 \mathrm{~mm}$ long, with very slender and acute ventral process; internal structures small and moderately sclerotized; paramere (Fig. 285) barely $0.35 \mathrm{~mm}$ long, paramerite and condylite basally broad and apically tapering, of subequal length. o : unknown.
Comparative notes: Based on the similar sculpture of tergite VII, similarly small size, similar head shape and large eyes, and particularly on the similar morphology of the median lobe of the aedeagus, $O$. fodens is closely allied to $O$. retunsus, from which it differs by a less transverse head, a broader pronotum (in relation to head), shorter elytra, the sculpture of tergite VII (striae longer, posteriorly without non-setiferous punctation), as well as by the different male primary sexual characters.

Distribution and natural history: The type locality is situated near Sandakan in Sabah, Borneo. The holotype was collected with a flight interception trap.

\subsubsection{Orphnebius effeminatus subgroup}

\section{Orphnebius effeminatus spec. nov.}

(Figs 21, 41, 287-292)

Type material: Holotype ơ: "Malaysia, Pahang, 2003, Cameron Highlands; Tanah Rata, 1500-1700 m, P. Pacholátko leg., 24.-31.i. / Holotypus ơ Orphnebius effeminatus sp. n., det. V. Assing 2015” (NHMB).

Etymology: The specific epithet alludes to the long male hemi-tergites IX, which resemble the condition found in females of other revised representatives of the O. hauseri group.

Description: Body length $5.6 \mathrm{~mm}$; length of forebody $2.2 \mathrm{~mm}$. Coloration: head blackish; pronotum and elytra blackish-brown; abdomen yellowish-red, with the middle of tergite VII slightly darker; legs pale-brown; antennae distinctly bicoloured, with antennomeres I-V yellowishred and VI-XI black; maxillary palpi yellowish, with palpomere III slightly darker.

Head (Fig. 41) moderately transverse, 1.15 times as broad as long; posterior angles completely obsolete; dorsal surface practically impunctate, except for some fine punctures at dorsal margins of eyes. Eyes large and bulging, nearly twice as long as distance from posterior margin of eye to posterior constriction of head. Antenna (Fig. 21) $1.4 \mathrm{~mm}$ long, weakly incrassate, and not distinctly asymmetric; antennomeres IV-V small, of equal size, and weakly oblong, VI much larger than V and approximately as long as broad, VII-IX gradually and weakly increasingly in width and weakly transverse, $\mathrm{X}$ approximately as long as broad, and XI strongly elongate, longer than the combined length of VIII-X.

Pronotum (Fig. 41) large in relation to head, 1.15 times as broad as long and 1.3 times as broad as head; lateral and posterior margins nearly forming a semi-circle, posterior angles completely obsolete; disc impunctate; anterior angles each with a long, stout, and erect seta.

Elytra (Fig. 41) 0.73 times as long as pronotum; disc with sparse and extremely fine and shallow punctation, seemingly impunctate at lower magnification. Hind wings 
fully developed. Metatarsomere I slightly shorter than the combined length of II and III.

Abdomen: sternites and paratergites III-VI strongly developed and together forming sharp edges; tergites III-VI seemingly impunctate, only with minute lateral punctures; tergite VII smooth in anterior third, with non-setiferous punctation in median third, and with longitudinal striae in posterior third, near posterior margin with a transverse row of setiferous punctures, posterior margin with palisade fringe; posterior margin of tergite VIII (Fig. 290) broadly convex; sternite VIII with convex posterior margin; both tergite and sternite VIII with conspicuously dense fine gland openings (Fig. 291).

$\sigma^{\star}$ : hemi-tergites IX (Fig. 292) conspicuously long (of similar condition as the female hemi-tergites IX of other revised species of the O. hauseri group); hemitergites IX and tergite $\mathrm{X}$ with very dense and long pubescence; median lobe of aedeagus (Figs 287-288) elongate and slender, $0.95 \mathrm{~mm}$ long; crista apicalis very small; internal sac with two sclerotized basal structures of distinctive shapes; paramere (Fig. 289) $0.65 \mathrm{~mm}$ long, condylite slender and somewhat longer than the flattened paramerite.

o: unknown.

Comparative notes: Based on the modifications of the abdominal tergites IX and X, on the morphology of the median lobe of the aedeagus and of the parameres, as well as the shapes and chaetotaxy of tergite and sternite VIII, O. effeminatus belongs to the O.hauseri group. It is distinguished from all the revised species of this group particularly by the coloration of the antennae, the practically impunctate disc of the pronotum, much longer male hemi-tergites IX, the shape and internal structures of the median lobe of the aedeagus, and the shape of the parameres. In addition, it is characterized by large eyes, the nearly impunctate dorsal surface of the head, a large pronotum (in relation to the head), and the strongly developed and sharply edged sternites and paratergites III-VI. This species represents a subgroup of its own within the O. hauseri group. The similar shape and internal structures of the median lobe of the aedeagus suggests that O. effeminatus may be closely allied to O. biapicalis PACE, 2007 from Borneo, a species described from a single male without head. However, the short original description of this species fails to mention important other characters that would confirm this hypothesis.

Distribution and natural history: The type locality is situated in Peninsular Malaysia at an altitude of $1500-1700 \mathrm{~m}$

\subsubsection{Unnamed species of the Orphnebius hauseri group}

The following species of the O. hauseri group are represented exclusively by females. Since, with few exceptions, a reliable identification of representatives of this group is possible only based on the male primary sexual characters, they remain unnamed.

\section{Orphnebius spec. 1 (0. hauseri subgroup)}

Material examined: Thailand: 1 , Meghalaya, Khasi Hills, S Cherrapunjee, 1200 m, 26.X.1978, leg. Besuchet \& Löbl (MHNG).

\section{Orphnebius spec. 2 (0. hauseri subgroup)}

Material examined: Thailand: 1 , Chiang Mai, Doi Inthanon, 1650 m, 7.XI.1985, leg. Burckhard \& Löbl (MHNG); 1 \%, Chiang Mai, Doi Suthep, 1550 m, 4.XI. 1985, leg. Burckhard \& Löbl (MHNG).

\section{Orphnebius spec. 3 (0. hauseri subgroup)}

Material examined: Laos: 1 , Phongsaly prov., Phongsaly env., $21^{\circ} 41^{\prime} \mathrm{N}, 102^{\circ} 06^{\prime} \mathrm{E}, \sim 1500 \mathrm{~m}, 6 .-17 . V .2004$, leg. Kubáň (NHMB).

\section{Orphnebius spec. 4 (0. hauseri subgroup)}

Material examined: Laos: 1 , , Hua Phan prov., $20^{\circ} 12^{\prime} \mathrm{N}$ $104^{\circ} 01^{\prime}$ E, Phu Phan Mt., 1750 m, 17.V.-3.VI.2008, leg. Kubán (NHMB).

\section{Orphnebius spec. 5 (0. dilatatus subgroup)}

Material examined: Thailand: 1 , , Phetchaburi, Kraeng Krachan National Park, 450 m, 19.XI.1985, leg. Burckhard \& Löbl (MHNG).

\section{Orphnebius spec. 6 (0. serratus subgroup)}

Material examined: Laos: 1 , , Phongsaly prov., Phongsaly env., $21^{\circ} 41^{\prime} \mathrm{N}, 102^{\circ} 06^{\prime} \mathrm{E}, \sim 1500 \mathrm{~m}, 6 .-17 . V .2004$, leg. Kubán̆ (NHMB).

\section{Orphnebius spec. 7 (0. conicornis subgroup)}

Material examined: Laos: 1 , Phongsaly prov., Ban Sano Mai, $21^{\circ} 21^{\prime} \mathrm{N}, 102^{\circ} 03^{\prime} \mathrm{E}, \sim 1150 \mathrm{~m}, 19 .-26 . V .2004$, leg. Kubáň (NHMB). 


\section{Orphnebius spec. 8}

Material examined: Thailand: 1 , Chanthaburi, Khao Sabap National Park, 150-300 m, 23.-24.XI.1985, leg. Burckhard \& Löbl (MHNG).

\section{Orphnebius spec. 9 (0. reductus subgroup)}

Material examined: Brunei: 1 으, Kuala Belalong FSC, $4^{\circ} 34^{\prime} \mathrm{N}, 115^{\circ} 07^{\prime} \mathrm{E}, 270 \mathrm{~m}$, Dipterocarp forest, flight interception trap, 24.V.1991, leg. Mawdsley (BMNH).

\section{Orphnebius spec. 10}

Material examined: Malaysia: 1 오 Sarawak (Borneo), Semengoh Forest, $11 \mathrm{mi}$ SW Kuching, V.1968, leg. Taylor (MHNG).

\subsubsection{Subgenus Deroleptus Bernhauer, 1915}

Deroleptus Bernhauer, 1915a: 150.

Megalocephalobius Bernhauer, 1929: 146; syn. nov.

Comment: An examination of the type material of Orphnebius falagrioides BERNHAUER, 1929, the type species of the subgenus Megalocephalobius BERNHAUER, 1929, revealed that O. falagrioides is allied to the species assigned to Deroleptus below. For details see the section on $O$. falagrioides. In consequence, Megalocephalobius is placed in synonymy with the senior name Deroleptus.

\subsubsection{Orphnebius draco group}

Orphnebius (Deroleptus) multimpressus Assing, 2015 (Figs 293-295)

Material examined: China: $10^{\star}$, Xishuangbanna, $23 \mathrm{~km}$ NW Jinghong, $\mathrm{Na}$ Ban env., $22^{\circ} 09^{\prime} \mathrm{N}, 100^{\circ} 40^{\prime} \mathrm{E}, 730 \mathrm{~m}$, 23.V.2008, leg. Weigel (NME); $10^{\star}$, Xishuangbanna, $37 \mathrm{~km}$ NW Jinghong, Guo Men Shan, $22^{\circ} 14^{\prime} \mathrm{N}, 100^{\circ} 36^{\prime} \mathrm{E}$, 1080 m, open land, Malaise trap, 8.VII.2008, leg. Meng (cAss).

Comment: The original description of this species is based on a unique female from Xishuangbanna (Assing 2015a). The previously unknown male sexual characters are illustrated in Figs 293-295.

\subsubsection{Orphnebius niger group}

Orphnebius (Deroleptus) niger (CAMERON, 1939)

(Figs 50-52, 296-298)

Deroleptus niger CAMERON, 1939a: $492 \mathrm{f}$.

Orphnebius turensis PACE, 2012b: 289; syn. nov.

Type material examined: O. niger: Lectotype $\circ$, present designation: "Assam, Patkai Mts. / Doherty / Deroleptus niger Cam. Type / Fry Coll. 1905.100. / Type / Lectotypus + Deroleptus niger Cameron, desig. V. Assing 2015” $(\mathrm{BMNH})$

O. turensis: Holotype +: "NE India, Meghalaya, 2002, $1 \mathrm{~km} \mathrm{E}$ of Tura, $500-600 \mathrm{~m}, 25^{\circ} 30^{\prime} \mathrm{N}, 90^{\circ} 14^{\prime} \mathrm{E}, 2 .-5$.v., M. Trýzna \& P. Benda lgt. / Holotypus Orphnebius turensis mihi, det. R. Pace 2010 / Orphnebius turensis n. sp., det. R. Pace 2010 / Orphnebius niger (Cameron), det. V. Assing 2016" (cSch).

Additional material examined: India: $1 \%$, Meghalaya, Tura peak, $25^{\circ} 30^{\prime} \mathrm{N}, 90^{\circ} 14^{\prime} \mathrm{E}, 600-1000 \mathrm{~m}, 12 .-22$. VI.2007, leg. Dembický (NHMB).

Comment: Orphnebius niger was described from an unspecified number of syntypes from "Assam: Sudiya; Patkai Mountains" (CAMERon 1939a). The sole syntype located in the collections at the BMNH, a female, is designated as the lectotype. In the original description of O.turensis, which is based on two females from " $\mathrm{N}$ India, Maghalaya [sic], $1 \mathrm{~km}$ E Tura 500-600 m, 25 $30^{\circ} \mathrm{N}$ $90^{\circ} 14^{\prime} \mathrm{E}$ ", PACE (2012b) compared the species with O. bryanti CAMERON, 1920 rather than with O. niger, probably because the latter was originally described in the genus Deroleptus. A comparison of the lectotype of $O$. niger with the holotype of $O$. turensis revealed that they are conspecific. Consequently, O. turensis is placed in synonymy with $O$. niger. The external and sexual characters of O. niger are illustrated in Figs 50-52, 296-298.

Orphnebius (Deroleptus) siamensis CAMERon, 1946 (Figs 53, 70, 74, 299-303)

Orphnebius (Mesocephalobius) siamensis CAMERon, 1946: 693.

Type material examined: Holotype o": "62250 / Siam, Renong / Doherty / Orphnebius siamensis Cam. Type / Fry Coll. 1905.100. / Type / Holotypus ơ Orphnebius siamensis Cameron, rev. V. Assing 2015” (BMNH).

Comment: The original description is based on a unique male from "Siam: Renong" (CAMERon 1946).

Redescription: Body length $5.4 \mathrm{~mm}$; length of forebody $2.3 \mathrm{~mm}$. Coloration: head and pronotum blackishbrown; elytra pale-brown, with the postero-lateral portions extensively dark-brown; abdomen reddish, 
with segments VI-VII slightly darker; legs: pro- and mesofemora brown, metafemora bicoloured with the basal half yellowish and the apical half brown, tibiae and tarsi pale-reddish; antennae blackish-brown with antennomeres I-II, the base of III, and the apex of XI reddish; maxillary palpi reddish.

Head (Fig. 70) 1.33 times as broad as long; posterior angles weakly marked; lateral dorsal portions with moderately scattered fine punctation; median dorsal portion extensively impunctate; interstices without microsculpture. Eyes large, approximately as long as the distance from posterior margin of eye to posterior constriction of head in dorsal view. Antenna (Fig. 53) $1.9 \mathrm{~mm}$ long and slender; antennomeres IV-VI distinctly oblong, VII approximately as long as broad, VIII-X weakly transverse, and XI approximately as long as the combined length of IX and X.

Pronotum (Fig. 70) 1.15 times as broad as long and approximately as broad as head, strongly convex in crosssection; anterior margin strongly concave in the middle; lateral margins nearly straight and subparallel in dorsal view; disc with a median pair of punctures, otherwise practically impunctate; near lateral margins with three long and erect black setae anteriorly.

Elytra (Fig. 70) approximately 0.85 times as long as pronotum; punctation fine and sparse; pubescence long, pale, and depressed to sub-erect. Hind wings present. Metatarsomere I approximately as long as the combined length of II-IV.

Abdomen (Fig. 74) approximately as broad as elytra; tergite VI at posterior margin with a tubercle on either side of the middle, laterally with a long carina on either side; tergite VII with coarse sculpture, at posterior margin with some setiferous punctures; tergite VIII (Fig. 302) with coarsely granulose setiferous punctation, with a transverse band of numerous gland openings in anterior half, and with a distinctly tridentate posterior margin; sternite VIII (Fig. 303) with a transverse band of gland openings in anterior half, with convexly produced posterior margin, and laterally with a cluster of stout black setae on either side.

$\sigma^{\star}$ : median lobe of aedeagus (Figs 299-300) $0.55 \mathrm{~mm}$ long and slender; ventral process dorso-ventrally depressed and apically tricuspidate in ventral view; paramere (Fig. 301) $0.5 \mathrm{~mm}$ long and of distinctive shape.

क: unknown.

Comparative notes: Among the species of the O. niger group, O. siamensis is characterized by the slender antennae and particularly by the shapes of the median lobe and the parameres of the aedeagus.

Distribution and natural history: The type locality is situated in the vicinity of Ranong, South Thailand. Additional data are not available.

\section{Orphnebius (Deroleptus) ceylonicus (CAMERon, 1939)}

Material examined: Sri Lanka: 2 exs., S Talatuoya, $1000 \mathrm{~m}$, 28.I.1970, leg. Mussard, Besuchet \& Löbl (MHNG, cAss).

Comment: The above specimens are in agreement with the details indicated in the original description, particularly the conspicuous granules on the elytra.

\section{Orphnebius (Deroleptus) discrepans spec. nov. (Figs 54, 73, 75, 304-306)}

Type material: Holotype $0^{\star}:$ "China: S-Yunnan (Xishuangbanna), EKL, $23 \mathrm{~km}$ NW Jinghong, vic. Na Ban (NNNR) / N2209.49, E100³9.92, 28.VI.2008, 730 m, forest, leg. A. Weigel / Holotypus ơ Orphnebius discrepans sp. n., det. V. Assing 2015” (NME).

Etymology: The specific epithet is the present participle of the Latin verb discrepare (to deviate, to disagree) and alludes the number and extent of differences between this species and other previously examined representatives of Deroleptus.

Description: Body length $4.7 \mathrm{~mm}$; length of forebody $2.0 \mathrm{~mm}$. Coloration: forebody black; abdomen bicoloured with segments III-V bright reddish and VI-VIII blackish; legs: pro- and mesofemora blackish, metafemora blackish with narrowly yellowish base, tibiae dark-brown with reddish bases, tarsi reddish; antennae blackish-brown with the bases of antennomeres II and III reddish-yellow; maxillary palpi blackish-brown with the apical palpomere yellowish.

Head (Fig. 73) strongly transverse, 1.18 times as broad as long, posteriorly noticeably tapering behind eyes; lateral dorsal portions with sparse and very fine punctation; median dorsal portion extensively impunctate; dorsal surface without microsculpture. Eyes large and bulging, more than twice as long than postocular region and distinctly longer than the distance from posterior margin of eye to posterior constriction in dorsal view. Antenna (Fig. 54) $1.8 \mathrm{~mm}$ long; antennomere IV weakly oblong; antennomeres V-X of conical shape, V and VI approximately a broad as long, VII-X weakly transverse, XI shorter than the combined length of IX and X.

Pronotum (Fig. 73) approximately as broad as long and 1.1 times as broad as head; lateral margins straight and subparallel in dorsal view; punctation moderately dense, defined, and somewhat granulose; interstices without microsculpture; in posterior median portion with a pronounced impression, this impression extending into a long, fine, and distinct median furrow nearly reaching anterior margin of pronotum.

Elytra (Fig. 73) as long as pronotum; punctation coarser than that of pronotum, defined, granulose, dense anteriorly and somewhat less dense posteriorly; interstices 
without microsculpture. Hind wings fully developed. Legs long and slender; metatibia $1.0 \mathrm{~mm}$ long; metatarsus nearly 0.9 times as long as metatibia; metatarsomere I approximately as long as the combined length of II-IV. Abdomen (Fig. 75) narrower than elytra; sternites and paratergites without postero-lateral processes; tergites III and IV impunctate, except for a lateral puncture bearing a long dark seta on either side; tergite $\mathrm{V}$ with four punctures bearing long dark setae posteriorly, otherwise impunctate; tergite VI with a lateral puncture on either side and with four punctures posteriorly, each of these punctures bearing a long dark seta; tergite VII with a lateral puncture bearing a long dark seta on either side, in posterior fourth with longitudinal striae, posterior margin with palisade fringe; tergite VIII with coarse and dense puncture-like sculpture, with four long dark setae at posterior margin, posterior margin with a median and four lateral processes of triangular shape.

$\sigma^{*}$ : sternite VIII slightly longer than tergite VIII, its posterior margin convex; median lobe of aedeagus (Figs 304-305) $0.68 \mathrm{~mm}$ long (total length, including apical structures), of conspicuous shape, with very slender and basally strongly bent ventral process; paramere (Fig. 306) $0.65 \mathrm{~mm}$ long and slender.

Comparative notes: This distinctive species differs from other geographically close Deroleptus species by the completely different external (habitus; coloration; punctation of the pronotum and elytra; shape of the pronotum; punctation and sculpture of the abdomen; absence of postero-lateral processes of the abdominal paratergites and sternites) and male sexual characters.

Distribution and natural history: The type locality is situated in southwestern Yunnan, Southwest China. The holotype was collected on the wing.

\section{Orphnebius (Deroleptus) triapicalis spec. nov.} (Figs 55, 71, 76, 307-310)

Type material: Holotype o : "P.R. China, Sichuan, Emei Shan, N29³3'56", E10321'24", 26.V.2011, 1829 m, sift06, V. Grebennikov / Holotypus o Orphnebius triapicalis sp. n., det. V. Assing 2015” (CAS).

Etymology: The specific epithet (adjective) alludes to the tricuspidate posterior margin of the abdominal tergite VIII.

Description: Body length $5.0 \mathrm{~mm}$; length of forebody $2.2 \mathrm{~mm}$. Coloration: head and pronotum blackishbrown; elytra blackish-brown, with the sutural and anterior portion diffusely paler brown; abdomen with tergites III-VI reddish with the antero-median portions indistinctly darker, tergites VII-VIII dark-brown; legs dark brown (femora slightly darker than tibiae) with dark-reddish tarsi; antennae brown with reddish-brown antennomeres I and II; maxillary palpi reddish with the apical palpomere yellowish.

Head (Fig. 71) approximately as long as broad, tapering posteriorly behind eyes; lateral dorsal portions with moderately dense and fine punctation; median dorsal portion only with scattered fine punctures; interstices without microsculpture. Eyes large, slightly shorter than the distance from posterior margin of eye to posterior constriction in dorsal view. Antenna (Fig. 55) $1.6 \mathrm{~mm}$ long and rather massive; antennomere IV weakly oblong; antennomeres $\mathrm{V}-\mathrm{X}$ of conical shape, weakly transverse, and of gradually, but weakly increasing width; $\mathrm{X}$ less than 1.5 times as broad as long; XI nearly as long as the combined length of IX and X.

Pronotum (Fig. 71) 1.04 times as broad as long and 1.27 times as broad as head, strongly convex in crosssection; lateral margins nearly straight and subparallel in dorsal view; midline and posterior portion extensively impunctate, on either side of the impunctate median band with a series of denser punctures; lateral and anterior portions with very fine and sparse punctation.

Elytra (Fig. 71) 0.83 times as long and 1.6 times as broad as pronotum; punctation fine and sparse. Hind wings present. Metatarsomere I slightly shorter than the combined length of II-IV.

Abdomen (Fig. 76) narrower than elytra; tergites III-V each with a lateral setiferous puncture on either side and with four setiferous punctures at posterior margin; tergite VI with 2-3 seriate lateral punctures on either side and with four punctures near posterior margin; tergite VII with coarse sculpture mostly composed of dense longitudinal rugae, posterior margin with pronounced palisade fringe; tergite VIII (Fig. 310) with coarsely granulose setiferous punctation and with tricuspidate posterior margin.

$\sigma^{*}$ : sternite VIII slightly longer than tergite VIII, its posterior margin convex; median lobe of aedeagus (Figs 307-308) $0.5 \mathrm{~mm}$ long and slender; paramere $0.5 \mathrm{~mm}$ long, slender, shaped as in Fig. 309.

Comparative notes: Based on the similar external (habitus, punctation, tricuspidate posterior margin of tergite VIII) and male sexual characters (shapes of median lobe of aedeagus and of paramere), this species is undoubtedly closely allied to O. tricuspis Assing, 2009 (male unknown), O. tridentatus Assing, 2015, both from Yunnan, and O. nanlingensis PACE, 2004 (Fujian, Guangdong). It is distinguished from them as follows:

- from O. tricuspis by paler coloration and bicoloured elytra (O. tricuspis: forebody uniformly black; femora blackish-brown), a more robust body (O. tricuspis: width of pronotum $0.65 \mathrm{~mm}$, width of elytra $1.0 \mathrm{~mm}$; O. triapicalis: width of pronotum $0.75 \mathrm{~mm}$, width of elytra $1.25 \mathrm{~mm}$ ), nearly straight metatibiae (O. tricuspis: metatibiae distinctly curved), the absence of sublateral keels in the posterior portion of tergite VI, and the coarser and denser granules on tergite VIII; 
- from O. tridentatus by the coloration (O. tridentatus: forebody and legs paler; tergite VI blackish-brown, except for the yellowish anterior margin), distinctly more massive antennae, a more convex (cross-section) and less transverse pronotum (O. tridentatus: pronotum 1.12 times as broad as long), the sculpture of tergite VII (O. tridentatus: predominantly composed of oblong puncture-like impressions), the longer median projection at the posterior margin of tergite VIII, and the much larger aedeagus (O. tridentatus: median lobe of aedeagus $0.38 \mathrm{~mm}$ long);

- from O. nanlingensis by larger body size, reddish tergites III-VI (O. nanlingensis: abdomen nearly uniformly dark-brown), much less transverse antennomeres VI-X, less transverse head and pronotum, the longer median process at the posterior margin of tergite VIII, and a much larger and more slender median lobe of the aedeagus (O. nanlingensis: median lobe of aedeagus $0.38 \mathrm{~mm}$ long).

For illustrations of O.tricuspis, O. tridentatus, and O. nanlingensis see Assing (2006c, 2009, 2015a).

Distribution and natural history: The type locality is situated in southwestern Yunnan, Southwest China. The holotype was collected on the wing.

\section{Orphnebius (Deroleptus) gracilior spec. nov.}

(Figs 56, 72, 77-80, 311-313)

Type material: Holotype $9:$ "NE India, Arunachal Pr., Etalin vicinity, 700 m, 28³6'56"N, 9553'21"E, FIT (flight interception trap), L. Dembický leg., 12.-25.v.2012 / Holotypus ㅇ Orphnebius gracilior sp. n., det. V. Assing 2015” (ZFMK).

Paratype : same data as holotype (cAss).

Etymology: The specific epithet is the comparative of the Latin adjective gracilis (slender) and alludes to the conspicuously slender body, legs, and antennae.

Description: Body length 5.0-5.7 mm; length of forebody $2.1-2.2 \mathrm{~mm}$. Coloration: head and pronotum dark-brown; elytra pale-brown with the postero-lateral portions extensively dark-brown; abdomen with tergites III-V and VIII-X dark-reddish to brown and tergites VI-VII dark-brown to blackish-brown with reddish posterior margins; legs yellowish with the apical portions of the femora weakly infuscate; antennae with antennomeres IV-XI brown and I-III partly reddish; maxillary palpi brown to dark-brown with the apical palpomere yellowish.

Head (Fig. 72) weakly transverse, 1.02-1.05 times as broad as long, tapering behind eyes, posterior angles obsolete; lateral dorsal portions with moderately sparse and extremely fine punctation; median dorsal portion extensively without punctation; interstices without microsculpture. Eyes large, as long as, or slightly longer than the distance from posterior margin of eye to posterior constriction in dorsal view. Antenna (Fig. 56) $2.1 \mathrm{~mm}$ long and conspicuously slender; antennomere IV strongly oblong, more than three times as long as broad; $\mathrm{V}$ approximately three times as long as broad; VI approximately 2.5 times as long as broad; VII twice as long as broad; VIII-X of decreasing length and decreasingly oblong; X weakly oblong; XI slightly longer than the combined length of IX and X.

Pronotum (Fig. 72) slender, 1.05 times as long as broad and as broad as, or slightly broader than head, strongly convex in cross-section; lateral margins in posterior half slightly sinuate in dorsal view; anterior margin strongly concave in the middle; disc with a median pair of punctures, otherwise practically impunctate.

Elytra approximately 0.85 times as long as, and much broader than pronotum; punctation distinct and moderately dense, denser anteriorly than posteriorly. Hind wings fully developed. Legs conspicuously long and slender; mesotibia weakly, metatibia distinctly curved in apical half; metatibia $1.3 \mathrm{~mm}$, mesotarsus $1.1 \mathrm{~mm}$ long; metatarsomere I nearly as long as the combined length of II-IV (Fig. 80).

Abdomen (Figs 77-79) long and slender, narrower than elytra, gradually tapering posteriad; paratergites III each with acute, horizontal, and moderately long posterolateral process; posterior margin of tergite III with a more or less pronounced median spine; tergites III-VI each with two lateral setiferous punctures on either side; tergite VI with a long lateral keel on either side; tergite VII anteriorly with six pronounced oblong impressions separated by narrow carinae, in median third with conspicuously coarse non-setiferous punctation, in posterior third with longitudinal striae, in the middle of posterior portion with a pronounced median keel, on either side of this keel with a setiferous tubercle, posterior margin with a palisade fringe; tergite VIII (Fig. 311) transverse, weakly tridentate posteriorly, anteriorly with numerous gland openings, in median portion with very short and fine setae, and in posterior portion with approximately ten setiferous tubercles.

0 : unknown.

o : sternite VIII (Fig. 312) transverse, laterally with a few stout setae inserting in blunt processes, posterior margin convex; spermatheca (Fig. 313) small in relation to body size, approximately $0.23 \mathrm{~mm}$ long and with proximal portion of distinctive shape.

Comparative notes: Based on the similar external characters (habitus, punctation, tricuspidate posterior margin of tergite VIII; chaetotaxy of sternite VIII), this species belongs to the $O$. niger group. Among the species of this group it somewhat resembles O. tricuspis in size and body shape, but differs from this species by much longer and more slender legs and antennae, distinctly paler coloration (particularly of the legs), larger eyes, a more slender pronotum with sinuate lateral margins, and different modifications of the abdominal segments III, 
VI, VII, and VIII, and by the completely different shape of the spermatheca.

Distribution and natural history: The type locality is situated in Arunachal Pradesh, northeastern India, and identical to that $O$. spinans and $O$. dispar. The specimens were collected with a flight interception trap at an altitude of $700 \mathrm{~m}$.

\section{Orphnebius (Deroleptus) sexcarinatus spec. nov.} (Figs 57, 81-84, 314-316)

Type material: Holotype + : "Sumatra: Aceh \#25b, Mt Leuser NP, 300-500 m, Ketambe, 23-30.XI.1989, Löbl, Agosti, Burckhard / Holotypus o Orphnebius sexcarinatus sp. n., det. V. Assing 2015” (MHNG).

Etymology: The specific epithet (adjective) alludes to the six oblong setiferous tubercles at the posterior margin of the abdominal tergite VI.

Description: Body length $7.2 \mathrm{~mm}$; length of forebody $3.3 \mathrm{~mm}$. Coloration: head blackish-brown; pronotum dark-brown; elytra dark-yellowish with the posterolateral portions infuscate; abdomen reddish with segment VI slightly and segment VII distinctly darker; legs pale-reddish; antennae blackish-brown with antennomeres I-IV and the apex of antennomere XI reddish; maxillary palpi reddish with the apical palpomere yellowish.

Head (Fig. 84) transverse, 1.25 times as broad as long (length measured from sclerotized portion of clypeus), lateral and posterior margins behind eyes broadly rounded; dorsal surface with a distinct lateral puncture on either side and with few scattered smaller punctures at or near dorsal margin of eyes, otherwise impunctate; interstices without microsculpture; sclerotized portion of clypeus very short. Eyes large, approximately as long as the distance from posterior margin of eye to posterior constriction in dorsal view. Antenna (Fig. 57) $2.15 \mathrm{~mm}$ long and slender; antennomere IV strongly oblong, approximately twice as long as broad; V nearly twice as long as broad; VI approximately 1.5 times as long as broad; VII weakly oblong; VIII approximately as long as broad; IX and X weakly transverse; XI slightly longer than the combined length of IX and X.

Pronotum (Fig. 84) weakly transverse, 1.07 times as broad as long and approximately as broad as head, strongly convex in cross-section; lateral margins subparallel and straight in dorsal view; anterior margin strongly concave in the middle; disc with a median pair of punctures, otherwise practically impunctate.

Elytra (Fig. 84) approximately 0.8 times as long as, and much broader than pronotum; punctation fine and sparse, less sparse anteriorly than posteriorly, postero-sutural angles practically impunctate. Hind wings fully developed. Legs long and slender; mesofemur conspicuously modified: postero-ventral surface distinctly flattened, even slightly concave in cross-section; metatibia weakly curved in apical half; metatibia $1.55 \mathrm{~mm}$, mesotarsus $1.3 \mathrm{~mm}$ long; metatarsomere I very long, nearly as long as the combined length of II-IV.

Abdomen (Figs 81-83) broader than elytra; lateral margin of sternite III broadly, triangularly developed, with a short and acute spine-shaped apex; sternite IV with a pronounced long and spine-shaped postero-lateral process; paratergites III and IV very broad; tergites IIIVI each with two lateral setiferous punctures on either side; tergite $\mathrm{V}$ additionally with a median pair of punctures slightly behind middle and with a pair of median punctures at posterior margin; tergite VI additionally with a median pair of setiferous tubercles slightly behind middle and with six oblong setiferous tubercles at posterior margin, the lateral tubercle anteriorly extending into a long carina; tergite VII with dense non-setiferous punctation anteriorly and with dense longitudinal striae in posterior third, near posterior margin with a transverse row of approximately six long black setae, posterior margin with palisade fringe; tergite VIII (Fig. 314) oblong, flattened, with three pronounced tooth-like projections at posterior margin, and in anterior portion with two extensive clusters of numerous gland openings; sternite VIII (Fig. 315) with a transverse band of gland openings at anterior third, posterior margin broadly produced and weakly convex.

$o^{\top}$ : unknown.

․ spermatheca (Fig. 316) with short distal and proximal portions.

Comparative notes: This species differs from O. gracilior, with which it shares a similar habitus, by much larger body size, much less slender antennomeres IV-X, the coloration of the legs, less slender head and pronotum, modified mesofemora, the modifications of the abdominal sternites III-IV, the modifications of tergite VI, a much broader abdomen, the presence of a median pair of punctures on tergites V and VII, an oblong tergite VIII with much more pronounced posterior teeth, and by the shape of the spermatheca. Orphnebius sexcarinatus is readily distinguished from the three Orphnebius species previously recorded from Sumatra by much larger size and completely different coloration alone.

Distribution and natural history: The type locality is situated in Aceh, North Sumatra, Indonesia, at an altitude between 300 and $500 \mathrm{~m}$.

\section{Orphnebius (Deroleptus) spoliatus spec. nov.}

(Figs 58, 85, 91, 317-324)

Type material: Holotype $0^{\star}:$ "Lao-NE, Hua Phan prov., $20^{\circ} 12^{\prime} \mathrm{N} 104^{\circ} 01^{\prime} \mathrm{E}$, Phu Phan Mt., $\sim 1750 \mathrm{~m}, 17 . v$.-3.vi. 2008, Vít Kubáň leg. / Holotypus ơ Orphnebius spoliatus sp. n., det. V. Assing 2015” (NHMB). 
Paratypes: 15 exs. [ 1 o $^{*}$ teneral]: same data as holotype (NHMB, cAss).

Etymology: The specific epithet is the past participle of the Latin verb spoliare (to rob) and alludes to the absence of distinct processes of the abdominal paratergites and sternites III-V.

Description: Body length 5.0-6.6 mm; length of forebody 2.1-2.7 mm. Coloration: forebody black; abdomen palereddish with segment VII dark-brown to blackish-brown; legs with the pro- and mesofemora and the apical half of the metafemora blackish-brown to blackish, the basal half of the metafemora yellow, the tibiae dark-brown, and the tarsi reddish; antennae blackish with (parts of) antennomeres II and III often reddish; maxillary palpi reddish to dark-brown with the terminal palpomere yellowish.

Head (Fig. 85) 1.11-1.17 times as broad as long, posterior angles practically obsolete; dorsal surface with fine and very sparse punctation and with depressed pubescence; interstices without microsculpture. Eyes large, approximately as long as distance from posterior margin of eye to posterior constriction of head. Antenna (Fig. 58) slender and weakly incrassate, 1.9-2.2 mm long; antennomeres III and IV slightly flattened; antennomeres IV-VII distinctly oblong, VIII approximately as long as broad, IX-X weakly transverse, XI longer than the combined length of IX and X.

Pronotum (Fig. 85) approximately 1.15 times as broad as long and 1.01-1.05 times as broad as head, strongly convex in cross-section; lateral margins nearly straight and subparallel in dorsal view; disc with scattered macropunctures; antero-lateral portions with two long, black and erect setae on either side.

Elytra (Fig. 85) approximately as long as pronotum; punctation sparse, weakly granulose in posterior portion; pubescence pale, long, and depressed or sub-erect. Hind wings present. Legs long and slender; metatibia $1.15-1.25 \mathrm{~mm}$ long; metatarsus $0.82-0.88$ times as long as metatibia; metatarsomere I nearly as long as the combined length of II-IV.

Abdomen (Fig. 91): sternites and paratergites III-V without postero-lateral processes; tergites III-IV with a lateral setiferous puncture, otherwise impunctate; tergites V-VI with two lateral punctures on either side and with a median pair of small punctures near posterior margin; tergite VI with a tubercle in the middle of lateral margin and with a short keel near posterior portion of lateral margin on either side; tergite VII, except for anterior margin, with conspicuously coarse and dense, partly confluent non-setiferous punctation, posterior margin with palisade fringe; tergite VIII (Fig. 320) oblong, with two transverse series of black setae posteriorly, posterior margin with a pair of tooth-like projections, with a $\mathrm{V}$-shaped excision between these projections, and with a small median tooth in the middle of this excision; sternite VIII (Figs 321-322) oblong, posterior margin convex in the middle, lateral margins with two blunt setiferous projections in posterior portion; tergite $\mathrm{X}$ with a pair of brush-like clusters of setae anteriorly (Fig. 323).

$\sigma^{*}$ : posterior margin of sternite VIII (Fig. 321) distinctly convex; median lobe of aedeagus (Figs 317-318) approximately $0.5 \mathrm{~mm}$ long and of simple shape; ventral process long, straight in lateral view, and apically strongly convex in ventral view; paramere (Fig. 319) approximately $0.45 \mathrm{~mm}$ long and slender, apical lobe apically convex.

\%: posterior margin of sternite VIII weakly convex (Fig. 322); spermatheca (Fig. 324) approximately $0.18 \mathrm{~mm}$ long, proximal portion of duct distinctly dilated in the middle.

Comparative notes: This species somewhat resembles O. tridentatus of the O. niger group in habitus, proportions, the shapes of the abdominal tergite and sternite VIII, and the shape of the paramere, but differs from it by larger body size, the coloration (O. tridentatus: posterior portion of tergite VIII blackish-brown; legs dark-brown, metafemora not bicoloured), a relatively larger head, larger eyes, much longer and more slender antennae, and a much longer and differently shaped median lobe of the aedeagus. For illustrations of O. tridentatus see Assing (2015a).

Distribution and natural history: The type locality is situated in Hua Phan province in northeastern Laos. The holotype was collected at an altitude of approximately $1750 \mathrm{~m}$, together with O.cernens, O. lunatus, O. fuscapicalis, O. fusicollis, and an unnamed species. One of the paratypes is teneral.

\section{Orphnebius (Deroleptus) cultellatus spec. nov. (Figs 59, 86, 92-94, 325-334)}

Type material: Holotype $\sigma^{\star}$ : “Thailand - Chiang Mai, Doi Suthep 890 m, Barber F. III.86. P. Schwendinger / Holotypus ơ Orphnebius cultellatus sp. n., det. V. Assing 2015” (MHNG).

Paratypes: $1 \sigma^{\star}, 2$ ㅇ ㅇ: same data as holotype (MHNG, cAss); $10^{\star}$ : same data as holotype, but "950 m IV.86" (MHNG); 1 ㅇ: "Thailand: Chiang Mai, Rd to Wab Pang An, 50 km NE Chiang Mai, 900 m, Burckhardt-Löbl, 3.XI.85" (MHNG); 1 ơ, 1 \%: "Laos-N (Louangphrabang), 11-21.v.2002, $19^{\circ} 35^{\prime} \mathrm{N}, 101^{\circ} 58^{\prime} \mathrm{E}$, Thong Khan, $750 \mathrm{~m}$, Vít Kubáň leg. / Collection Naturhistorisches Museum Basel” (NHMB); 1 : "Laos, Phongsaly prov., $21^{\circ} 21^{\prime} \mathrm{N}$, $102^{\circ} 03^{\prime} \mathrm{E}$, Ban Sano Mai, 19.-26.v.2004, 1150 m, Vít Kubáň leg." (cAss).

Etymology: The specific epithet is an adjective derived from the Latin noun cultellus (small knife) and alludes to the knife-shaped ventral process of the aedeagus.

Description: Body length 4.3-5.3 mm; length of forebody 1.7-2.1 mm. Coloration: forebody blackish-brown to black, with the humeral and sutural portions of the 
elytra usually reddish to reddish-brown; abdomen bicoloured with segments III-VI bright-reddish and VII-X blackish-brown to blackish; legs: femora dark-brown to blackish-brown, tibiae mostly reddish, meso- and metatibiae rarely dark-brown to blackish-brown, tarsi reddish to dark-reddish; antennae blackish-brown to black, with the basal four antennomeres usually more or less extensively reddish to brown; maxillary palpi dark-brown to blackish with the apical palpomere yellowish.

Head (Fig. 86) 1.15-1.19 times as broad as long; lateral dorsal portions with sparse and fine punctation; median dorsal portion extensively impunctate; dorsal surface without microsculpture. Eyes large and bulging, slightly to distinctly longer than the distance from posterior margin of eye to posterior constriction in dorsal view. Antenna (Fig. 59) 1.3-1.5 mm long; antennomere IV oblong and flattened; antennomere $\mathrm{V}$ weakly oblong and somewhat flattened; antennomeres VI-X of gradually increasing width and increasingly transverse, $\mathrm{X}$ slightly less than 1.5 times as broad as long, and XI slightly shorter than the combined length of VIII-X.

Pronotum (Fig. 86) 1.10-1.15 times as broad as long and slightly broader than head, strongly convex in crosssection; lateral margins straight and subparallel in dorsal view; disc with few scattered macropunctures and with sparse setiferous micropunctation.

Elytra (Fig. 86) approximately as long as pronotum; punctation fine and sparse; pubescence long, depressed to sub-erect; interstices without microsculpture. Hind wings fully developed. Legs long and slender; metatibia 0.85-1.05 mm long; metatarsomere I of variable length, as long as the combined length of II-III, or as long as the combined length of II-IV, or of intermediate length.

Abdomen (Figs 92-94) approximately as broad as (small specimens) or broader than elytra (large specimens); sternites III and IV with distinct postero-lateral processes of highly variable length, width, and shape; tergites IIIVI with a lateral puncture on either side and with sparse fine punctures at posterior margins; tergite VII with dense, coarse, and circular non-setiferous punctures in anterior half and with irregular striae in posterior half, postero-median portion smooth, posterior margin with pronounced palisade fringe; tergite VIII (Fig. 328) with dense and coarse non-setiferous punctation, except for a narrow smooth impunctate median band, posteriorly with a pronounced excision and anterior to this excision with a more or less pronounced median tubercle; sternite VIII (Figs 329-331) sharply produced posteriorly, laterally with a comb of 3-4 setiferous tooth-shaped projections; tergite X (Fig. 332) with dense and long pubescence.

$\sigma^{\star}$ : sternite VIII (Fig. 329) without oblong folds; median lobe of aedeagus (Figs 325-326) approximately $0.55 \mathrm{~mm}$ long; ventral process laterally compressed, somewhat knife-shaped, and sharply edged ventrally; paramere (Fig. 327) $0.45 \mathrm{~mm}$ long, condylite with a large velum. ㅇ: sternite VIII (Figs 330-331) in postero-median portion with a pair of oblong folds; segment IX (Fig. 332) with sclerotized ventral structure of characteristic shape; spermatheca (Figs 333-334) small $(0.2 \mathrm{~mm})$ and of simple shape.

Intraspecific variation: The specimens from Laos differ slightly from those from Thailand by the shapes of the female sternite VIII and of the spermatheca (Figs 330-334), but otherwise no evidence was found suggesting that they should represent distinct species.

Comparative notes: Orphnebius cultellatus is characterized not only by the distinctive primary sexual characters, but also by the conspicuous modifications of tergite and sternite VIII.

Distribution and natural history: The species was found in two localities in North Thailand (Doi Suthep and a locality to the northeast of Chiang Mai) and two in Laos. The specimens from the type locality were collected with pitfall traps. The altitudes range from 750 to $1150 \mathrm{~m}$.

\subsubsection{Orphnebius siwalikensis group}

Orphnebius (Deroleptus) septemcuspis spec. nov. (Figs 60, 87, 95-96, 335-339)

Type material: Holotype $\sigma^{\star}$ : "Laos-N (Oudomxai), 1.-9.v.2002, $\sim 1100 \mathrm{~m}, 20^{\circ} 45^{\prime} \mathrm{N} 102^{\circ} 09^{\prime} \mathrm{E}$, Oudom Xai (17 km NEE), Vít Kubáň leg. / Collection Naturhistorisches Museum Basel / Holotypus o Orphnebius septemcuspis sp. n., det. V. Assing 2015” (NHMB).

Etymology: The specific epithet (Latin, adjective: with seven apices) alludes to the conspicuous shape of the posterior margin of the abdominal tergite VIII.

Description: Body length $5.0 \mathrm{~mm}$; length of forebody $2.1 \mathrm{~mm}$. Coloration: body black, with the abdominal segments III-V reddish; legs blackish, with the narrow base of the mesofemora and the basal third of the metafemora yellow and with the tarsi reddish; antennae black; maxillary palpi blackish with the terminal palpomere yellow.

Head (Fig. 87) 1.18 times as broad as long; posterior angles practically obsolete; punctation extremely fine and sparse; median dorsal portion impunctate; interstices without microsculpture. Eyes large, longer than distance from posterior margin of eye to posterior constriction of head. Antenna (Fig. 60) slender, $2.05 \mathrm{~mm}$ long, and of distinctive morphology; antennomere I conspicuously club-shaped, apically distinctly dilated; antennomeres III-V distinctly flattened, IV-VI distinctly oblong, VII-IX weakly oblong, X approximately as long as broad, and XI distinctly longer than the combined length of IX and X. 
Pronotum (Fig. 87) 1.12 times as broad as long and approximately as broad as head, strongly convex in crosssection; lateral margins parallel and straight in dorsal view; disc with few scattered macropunctures, otherwise impunctate, near antero-lateral angles with a long black seta.

Elytra (Fig. 87) approximately as long as pronotum; punctation moderately sparse and coarsely granulose. Hind wings present. Legs long and slender; metatibia $1.2 \mathrm{~mm}$ long; metatarsus 0.9 times as long as metatibia; metatarsomere I longer than the combined length of II and III.

Abdomen (Figs 95-96): sternite III with a long and apically acute postero-lateral process; tergite III impunctate; tergites IV-V with several setiferous punctures at posterior margin, otherwise impunctate; tergite VI with a long lateral keel and a lateral setiferous puncture on either side, and with several punctures at posterior margin, between these punctures with some microstriae; tergite VII, except for anterior margin, with coarse and very dense non-setiferous punctation, near posterior margin with a transverse row of oblong setiferous tubercles, posterior margin with palisade fringe; tergite VIII (Fig. 338) of very distinctive shape, with seven pronounced teeth at posterior margin (a long median, two long lateral, four shorter sublateral teeth) and two additional tooth-like processes in posterior portion of lateral margin on either side; sternite VIII (Fig. 339), too, of distinctive shape, posterior margin convex, sublaterally with a short comb of three stout setiferous tooth-shaped processes on either side.

$\mathrm{o}^{\star}$ : median lobe of aedeagus (Figs 335-336) $0.47 \mathrm{~mm}$ long and of simple shape; ventral process straight in lateral view and apically convex in ventral view; paramere (Fig. 337) $0.42 \mathrm{~mm}$ long, with a moderately long apical lobe.

Comparative notes: Among other geographically close Deroleptus species, O. septemcuspis is characterized by numerous distinctive characters, particularly the coloration, the morphology of the antennae (especially the conspicuously club-shaped antennomere I), coarsely granulose punctation of the elytra, an abdominal tergite VII with extensively non-setiferous punctation and with additional setiferous tubercles, a tergite and sternite VIII of very distinctive shapes, and by the morphology of the aedeagus.

Distribution and natural history: The type locality is situated near Oudom Xai in North Laos. The holotype was collected at an altitude of approximately $1100 \mathrm{~m}$, together with O. extensus, O. serratus, and O. integer.

\section{Orphnebius (Deroleptus) vates spec. nov.}

(Figs 61, 89, 97, 340-344)

Type material: Holotype $\sigma^{\star}$ : "Lao, Phongsaly prov., $21^{\circ} 41^{\prime} \mathrm{N} 102^{\circ} 6^{\prime} \mathrm{E}$, Phongsaly env., 6.-17.v.2004, $1500 \mathrm{~m}$, Vít Kubáň leg. / Holotypus ơ Orphnebius vates sp. n., det. V. Assing 2015” (NHMB).

Etymology: The specific epithet (Latin, noun: seer) alludes to the conspicuously large eyes.

Description: Body length $3.8 \mathrm{~mm}$; length of forebody $1.6 \mathrm{~mm}$. Coloration: head black with pale-brown mouthparts; pronotum and elytra dark-brown, with the humeral and sutural portions of the elytra indistinctly and diffusely paler; abdomen dark-yellowish with brown tergite VII; legs with brown femora and pale-brown tibiae and tarsi; antennae dark-brown with antennomeres I-III reddish.

Head (Fig. 89) strongly transverse and with marked posterior angles; dorsal surface with fine and moderately sparse punctation and with depressed pubescence; interstices without microsculpture. Eyes extremely large, extending along whole lateral margins of head nearly to posterior margin. Antenna (Fig. 61) $1.2 \mathrm{~mm}$ long and very weakly incrassate; antennomere IV approximately as long as broad; antennomeres $\mathrm{V}-\mathrm{X}$ weakly and gradually increasing in width and increasingly transverse; $\mathrm{X}$ weakly transverse, distinctly less than 1.5 times as broad as long; XI slightly longer than the combined length of IX and X. Pronotum (Fig. 89) small and strongly transverse, 1.46 times as broad as long and 0.95 times as broad as head, moderately convex in cross-section; lateral margins weakly convex in dorsal view; punctation very fine and rather sparse; pubescence sub-erect, long, and pale; lateral margins each with two long black setae anteriorly.

Elytra (Fig. 89) 1.15 times as long as pronotum; at postero-sutural angle with a small smooth elevation; punctation moderately sparse, somewhat granulose in posterior portion; pubescence pale, long, and depressed. Hind wings present. Legs long and slender; metatibia $0.7 \mathrm{~mm}$ long; metatarsus 0.9 times as long as metatibia; metatarsomere I slightly longer than the combined length of II and III.

Abdomen (Fig. 97): sternites III and IV with short and broad lateral extensions; sternite $\mathrm{V}$ with pronounced postero-lateral processes; tergites III-IV with very fine punctures at posterior margin, otherwise impunctate; tergites V-VI with a lateral puncture on either side and with very fine punctures at posterior margin; tergite VII with very dense non-setiferous punctation in posterior two-thirds, posterior margin with palisade fringe; tergite VIII (Fig. 343) with two transverse series of setiferous punctures bearing black setae, in posterior portion with a median pair of setiferous granules, posterior margin of distinctive shape, with a rather long lateral process and with two short sub-lateral teeth on either 
side; sternite VIII (Fig. 344) with strongly convex posterior margin.

$\sigma^{7}$ : median lobe of aedeagus (Figs 340-341) $0.4 \mathrm{~mm}$ long and of simple shape; ventral process straight in lateral view and apically strongly convex in ventral view; paramere (Fig. 342) $0.5 \mathrm{~mm}$ long, without conspicuous modifications.

Comparative notes: Orphnebius vates is distinguished from other geographically close Deroleptus species by numerous characters, particularly its small body size, conspicuously large eyes, the morphology of the antennae, a small and strongly transverse pronotum, the punctation of the elytra, the modifications of the abdominal sternites III-V, the shape of tergite VIII, and the morphology of the aedeagus.

Distribution and natural history: The type locality is situated near Phongsaly in North Laos. The holotype was collected at an altitude of approximately $1500 \mathrm{~m}$, together with O. grandicollis, O. serratus, O. reductus, O. baccillatus, and two unnamed species.

\section{Orphnebius (Deroleptus) tortus spec. nov.}

(Figs 62, 88, 98-100, 345-347)

Type material: Holotype : : "India Meghalaya, Khasi Hills 1000 m, Mawsynram-Balat 27.X.78, Besuchet-Löbl / Holotypus ㅇ Orphnebius tortus sp.n., det. V. Assing 2015” (MHNG).

Etymology: The specific epithet is the past participle of the Latin verb torquere (to twist) and alludes to the twisted proximal portion of the spermatheca.

Description: Body length $5.4 \mathrm{~mm}$; length of forebody $2.3 \mathrm{~mm}$. Coloration: head yellowish-brown; pronotum dark-yellowish; elytra yellowish; abdomen with segments III-IV and VIII yellowish, V-VI yellowish-brown, and VII somewhat infuscate; legs yellowish; antennae reddish-brown with the basal 4-5 antennomeres reddish; maxillary palpi pale-reddish, with the terminal palpomere yellowish.

Head (Fig. 88) flattened, strongly transverse, 1.5 times as broad as long, and with moderately marked posterior angles; posterior margin concave in the middle; dorsal surface with fine, shallow, and moderately sparse punctation, median dorsal portion impunctate; interstices without microsculpture. Eyes extremely large, extending along almost all of lateral margins of head nearly to posterior margin. Antenna (Fig. 62) $1.8 \mathrm{~mm}$ long, not incrassate; antennomeres IV-VII oblong, VIII approximately as long as broad, IX-X weakly transverse, and XI slightly longer than the combined length of IX and X.

Pronotum (Fig. 88) small and strongly transverse, broadest near anterior angles, 1.5 times as broad as long, and 0.9 times as broad as head, moderately convex in cross-section; lateral margins straight, weakly converging posteriad in dorsal view; punctation very fine and moderately dense; pubescence suberect, short, and pale; near anterior angles probably with a long seta on either side (puncture visible, but setae broken off in the holotype).

Elytra (Fig. 88) approximately 1.25 times as long as pronotum; along anterior half of suture with narrow and indistinct elevation; punctation moderately dense and fine, but much more distinct than that of pronotum, weakly granulose in posterior portion; pubescence pale, moderately short, and depressed. Hind wings present. Legs long and slender; metatibia $1.3 \mathrm{~mm}$ long; metatarsus approximately 0.9 times as long as metatibia; metatarsomere I approximately as long as the combined length of II and III.

Abdomen (Figs 98-100) broader than elytra; sternite III with a large, but not very long lateral extension of triangular shape; sternite IV with long, slender but somewhat massive, dorso-ventrally flattened, weakly erect, and apically acute postero-lateral extension; paratergite IV with a smaller, spine-shaped, and apically convex posterior extension; posterior extensions of paratergites and sternite IV contiguous; tergites III-VI each with one or two lateral setiferous punctures on either side, tergite VI additionally with median pair of setiferous punctures at posterior margin; tergites III each with a small tubercle on either side; tergite VII in posterior three-fourths with very dense and coarse non-setiferous punctation, near posterior margin with twelve setiferous granules, posterior margin with palisade fringe; tergite VIII (Fig. 345) with numerous setiferous granules in posterior portion, with dense short pubescence anteriorly, with a transverse series of non-setiferous teeth near posterior margin, with numerous small gland openings near anterior margin, and with a pair of extensive clusters of gland openings anteriorly, posterior margin concave; sternite VIII (Fig. 346) transverse and with smoothly convex posterior margin, laterally with a cluster of stout black setae on either side.

+ : spermatheca (Fig. 347) of distinctive shape, proximal portion of capsule of conspicuous shape, twisted.

Comparative notes: As can be inferred from the similar external characters, particularly the shared morphology of the head, the similar modifications of the head and the abdominal segment IV, O. tortus is undoubtedly closely allied to O. baccillatus (see the following section), from which it differs particularly by paler coloration, more slender antennae, the slightly different shapes of the posterior processes of sternite and paratergites IV, the deeper posterior excision of tergite VIII, and the shape of the spermatheca.

Distribution and natural history: The type locality is situated in the Khasi Hills, Meghalaya, Northeast India. The slightly teneral holotype was collected at an altitude of $1000 \mathrm{~m}$. 


\section{Orphnebius (Deroleptus) baccillatus spec. nov.}

(Figs 63, 90, 101, 109, 348-350)

Type material: Holotype + : "Lao, Phongsaly prov., $21^{\circ} 41-2^{\prime} \mathrm{N} 102^{\circ} 06-8^{\prime} \mathrm{E}, 28 . v .-20 . v i .2003$, Phongsaly env., $\sim 1500$ m, Vít Kubáň leg. / Holotypus + Orphnebius baccillatus sp. n., det. V. Assing 2015” (NHMB).

Etymology: The specific epithet is an adjective derived from the Latin noun baccillum (walking stick, cane) and alludes to the conspicuous shape of the spermatheca.

Description: Body length $6.2 \mathrm{~mm}$; length of forebody $2.5 \mathrm{~mm}$. Coloration: head blackish-brown; pronotum brown with broadly pale-brown margins; elytra brown; abdomen pale reddish-brown with the posterior twothirds of tergite VII dark-brown; legs pale-reddish; antennae reddish; maxillary palpi pale-reddish, with the terminal palpomere yellowish.

Head (Fig. 90) dorso-ventrally flattened, strongly transverse, 1.5 times as broad as long, and with marked posterior angles; dorsal surface with fine and sparse punctation, median dorsal portion impunctate; interstices without microsculpture. Eyes extremely large, extending along almost all of lateral margins of head nearly to posterior margin. Antenna (Fig. 63) $1.7 \mathrm{~mm}$ long, not incrassate; antennomeres IV-V approximately as long as broad, VI-X very weakly transverse and of subequal width; XI slightly longer than the combined length of IX and $\mathrm{X}$.

Pronotum (Fig. 90) small and strongly transverse, broadest across anterior angles, 1.42 times as broad as long, and 0.90 times as broad as head, moderately convex in cross-section; lateral margins straight, weakly converging posteriad in dorsal view; punctation very fine and moderately sparse; pubescence depressed, short, and pale; near anterior angles with a stout, erect, black seta on either side.

Elytra (Fig. 90) 1.37 times as long as pronotum; punctation moderately dense and fine; pubescence pale, short, and depressed. Hind wings present. Legs long and slender; metatibia $1.2 \mathrm{~mm}$ long; metatarsus approximately 0.9 times as long as metatibia; metatarsomere I approximately as long as the combined length of II and III.

Abdomen (Figs 101, 109): sternite III with a large, but not very long lateral extension of triangular shape; sternite IV with long, slender but somewhat massive, weakly erect, and apically acute postero-lateral extension; paratergite IV with a smaller spine-shaped posterior extension; posterior extensions of paratergites and sternite IV contiguous; tergites III-VI each with a lateral puncture bearing a dark seta on either side, tergite VI additionally with four setiferous punctures at posterior margin; tergite VII in posterior two-thirds with very dense and coarse non-setiferous punctation, near posterior margin with a transverse row of eight setiferous granules, posterior margin with palisade fringe; tergite VIII (Fig. 348) with numerous setiferous granules in posterior portion, with dense short pubescence anteriorly, with a transverse series of non-setiferous teeth near posterior margin, with numerous small gland openings near anterior margin, and with a pair of clusters of gland openings anteriorly, posterior margin weakly concave; sternite VIII (Fig. 349) transverse and with smoothly convex posterior margin. o : spermatheca (Fig. 350) of distinctive shape, very long $(0.6 \mathrm{~mm})$, distal portion shaped like a walking stick, in transitional portion between distal and proximal portion somewhat coiled.

Comparative notes and comment: Orphnebius baccillatus differs from its consubgeners by distinctive external and sexual characters (large eyes, shape of pronotum, shapes of postero-lateral extensions of abdominal sternites III-IV and paratergite IV, the conspicuous shape and sculpture of tergite VIII, shape of the spermatheca). The species is additionally distinguished from O. vates, the only other large-eyed Deroleptus species known from Laos, by much larger size.

Distribution and natural history: The type locality is situated near Phongsaly in North Laos and nearly identical to that of $O$. vates. The holotype was collected at an altitude of approximately $1500 \mathrm{~m}$.

\section{Orphnebius (Deroleptus) carinatus spec. nov. \\ (Figs 64, 102, 117, 351-353)}

Type material: Holotype + : "Laos-N (Louangphrabang), 11-21.v.2002, $19^{\circ} 35^{\prime} \mathrm{N} 101^{\circ} 58^{\prime} \mathrm{E}$, Tong Khan, 750 m, Vit Kubán leg. / Holotypus + Orphnebius carinatus sp. n., det. V. Assing 2015” (NHMB).

Etymology: The specific epithet (Latin, adjective: keeled) alludes to the short carina near the suture of each elytron.

Description: Body length $4.2 \mathrm{~mm}$; length of forebody $2.0 \mathrm{~mm}$. Coloration: forebody black; abdomen dark-reddish; legs with the femora blackish-brown and the tibiae and tarsi dark-brown; antennae black, with antennomeres II and III dark-brown; maxillary palpi dark-brown with the apical palpomere yellowish.

Head (Fig. 102) distinctly transverse, 1.3 times and broad as long; posterior angles broadly convex, weakly marked; punctation in lateral portions sparse and fine; median dorsal portion extensively impunctate; interstices without microsculpture. Eyes large, approximately as long as the distance from posterior margin of eye to posterior constriction in dorsal view. Antenna (Fig. 64) $1.2 \mathrm{~mm}$ long and distinctly incrassate; antennomere IV moderately transverse; antennomeres $\mathrm{V}-\mathrm{X}$ strongly transverse and of gradually increasing width; $\mathrm{X}$ twice as broad as long; XI approximately as long as the combined length of IX and X. 
Pronotum (Fig. 102) 1.3 times as broad as long and nearly as broad as head, strongly convex in cross-section; lateral margins weakly convex in dorsal view; posterior angles very weakly marked, nearly obsolete; midline broadly impunctate, lateral portions of disc with extremely fine, barely visible and sparse punctation; pubescence short, fine, and pale.

Elytra (Fig. 102) slightly longer and much broader than pronotum; in anterior portion with a pair of distinct sutural carinae; punctation fine and moderately sparse; pubescence longer than that of pronotum. Hind wings present. Legs of moderate length and moderately slender; metatibia $0.9 \mathrm{~mm}$ long; metatarsus 0.9 times as long as metatibia; metatarsomere I slightly longer than the combined length of II and III.

Abdomen (Fig. 117): sternite III with very short, sternite IV with slightly longer, broad and apically acute postero-lateral processes; sternite III with a lateral setiferous puncture on either side; sternites IV-VI with two lateral setiferous punctures on either side; tergite VII with dense non-setiferous punctation and with a transverse row of oblong setiferous tubercles near posterior margin, posterior margin with palisade fringe; tergite VIII (Fig. 351) strongly transverse, posterior margin strongly and broadly concave, laterally with a series of 5-7 sharp teeth on either side.

$\sigma^{\top}$ : unknown.

ㅇ: sternite VIII (Fig. 352) strongly transverse, posterior margin truncate in the middle; spermatheca (Fig. 353) $0.35 \mathrm{~mm}$ long and of distinctive shape.

Comparative notes and comment: Orphnebius carinatus is characterized by the presence of sutural carinae on the elytra, the transverse head, the antennal morphology, the shape of tergite VIII, and the shape of the spermatheca. It differs from O. tuberipennis (South India), with which it shares the presence of sutural carinae and a similar shape of the abdominal tergite VIII, by distinctly darker coloration, much smaller eyes, much more transverse antennomeres IV-X, much more sparsely and finely punctate elytra, and the absence of a pronounced pair of setiferous tubercles on tergite VII.

Distribution and natural history: The type locality is identical to that of O. retunsus and several other newly described species.

\section{Orphnebius (Deroleptus) dispar spec. nov. (Figs 65, 106, 110-111, 354-358)}

Type material: Holotype $0^{\top}:$ "NE India, Arunachal Pr., Etalin vicinity, 700 m, 28 $36^{\prime} 56^{\prime \prime} \mathrm{N}, 95^{\circ} 53^{\prime} 21^{\prime \prime E}$, FIT (flight interception trap), L. Dembický leg., 12.-25.v.2012 / Holotypus o Orphnebius dispar sp. n., det. V. Assing 2015” (ZFMK).

Paratypes: 5 우 $q$ same data as holotype (ZFMK, cAss); 1 ơ: "NE-India, Meghalaya, Tura Peak, 600-1000 m, $25^{\circ} 30^{\prime} \mathrm{N} 90^{\circ} 14^{\prime} \mathrm{E}, \quad$ L. Dembický leg., 12.-22.vi.2007” (NHMB)

Etymology: The specific epithet (Latin, adjective: disparate, dissimilar) alludes to the pronounced sexual dimorphism of the abdominal sternite III.

Description: Body length $3.0-3.5 \mathrm{~mm}$; length of forebody $1.2-1.5 \mathrm{~mm}$. Coloration: body black; legs brown with dark-brown femora; antennae blackish-brown with antennomeres I-III yellowish-red; maxillary palpi reddish-yellow with the apical palpomere yellowish.

Head (Fig. 106) strongly transverse, approximately 1.4 times as broad as long; posterior angles moderately marked; punctation very fine and sparse; median dorsal portion impunctate; interstices without microsculpture. Eyes very large, approximately three times as long as postocular region from posterior margin of eye to posterior angle. Antenna (Fig. 65) 0.9-1.0 mm long and slender; antennomere IV weakly transverse; antennomeres $\mathrm{V}-\mathrm{X}$ of gradually increasing width and increasingly transverse; $\mathrm{X}$ slightly more than 1.5 times as broad as long; XI approximately as long as the combined length of IX and X.

Pronotum (Fig. 106) approximately 1.4 times as broad as long and as broad as head, moderately convex in crosssection; lateral margins each with three long and black erect setae; disc with fine and sparse punctation.

Elytra (Fig. 106) 1.10-1.15 times as long as, and much broader than pronotum; punctation sparse and distinct, partly somewhat granulose. Hind wings fully developed. Metatarsomere I approximately as long as the combined length of II-IV.

Abdomen (Figs 110-111) narrower than elytra; sternite III with pronounced sexual dimorphism; tergites III-VI practically impunctate; tergite VII with dense non-setiferous punctation in posterior three-fifths, near anterior margin with a transverse row of four to six granules, posterior margin with distinct palisade fringe; tergite VIII (Fig. 357) with a pair of median and approximately six setiferous granules at posterior margin, posterior margin with four blunt tooth-like processes.

$\sigma^{*}$ : sternite III postero-laterally with pronounced spineshaped process; median lobe of aedeagus (Figs 354-355) small, $0.28 \mathrm{~mm}$ long and of simple shape; paramere (Fig. 356) nearly $0.3 \mathrm{~mm}$ long, with long paramerite and very short spine-shaped condylite.

o : sternite III postero-laterally slightly produced, but not spine-shaped; spermatheca (Fig. 358) small and of simple, but distinctive morphology.

Comparative notes: Among congeners of similarly small size and dark coloration, this species is characterized particularly by the sparse and partly somewhat granulose punctation, the sexual dimorphism of sternite III, the modifications of the tergites VII and VIII, and by the shapes of the aedeagus and the spermatheca. Species with similar external and sexual characters are unknown to me. 
Distribution and natural history: Orphnebius dispar is currently known from two localities in Arunachal Pradesh and Meghalaya, northeastern India. The specimens from the type locality were collected with a flight interception trap at an altitude of $700 \mathrm{~m}$, together with O. spinans and an unnamed Orphnebius species. The paratype from Meghalaya was found at an altitude between 600 and $1000 \mathrm{~m}$, together with O. niger.

\section{Orphnebius (Deroleptus) laticeps CAMERon, 1925} (Figs 66, 103, 112, 359-361)

Material examined: Indonesia: 1 \% , Sumatra, Gn Merapi, $5 \mathrm{~km}$ E Kotobaru, 1600 m, 18.-25.V.2001, leg. Bolm (NHMB).

Comment: The above female is in agreement with the original description of O. laticeps, which is based on an unspecified number of syntypes from "Sumatra; Si Rambé” (Cameron 1925). In particular, CAMERON (1925) states that the male tergite VII has a "tubercle just in front of the middle of the posterior border", a character shared by the examined female. In Deroleptus species, the abdominal tergites VII and VIII are generally not subject to a sexual dimorphism, so that it can be assumed that both males and females possess such a posterior tubercle on tergite VII. The external and sexual characters of the above female are illustrated in Figs 66, 103, 112, 359-361.

\section{Orphnebius (Deroleptus) biimpressus spec. nov.} (Figs 67, 104, 108, 113-114, 362-364)

Type material: Holotype + : "Sumatra (Aceh), Ketambe, Leuser Nat. Park, 450 m, 26.II.-1.III.1991, Bocák \& Bocáková lgt. / Holotypus † Orphnebius biimpressus sp. n., det. V. Assing 2015" (NHMB).

Etymology: The specific epithet (Latin, adjective) alludes to the lateral impression on each elytron.

Description: Body length $4.8 \mathrm{~mm}$; length of forebody $2.1 \mathrm{~mm}$. Coloration: head blackish-brown; pronotum and elytra dark-brown; abdomen reddish-brown with segment VII dark-brown; legs reddish; antennae brown with antennomeres II-III and the apex of antennomere XI reddish; maxillary palpi reddish with the apical palpomere yellowish.

Head (Fig. 104) strongly transverse, 1.4 times as broad as long; punctation in lateral portions sparse and fine; median and posterior dorsal portions extensively impunctate; interstices without microsculpture. Eyes enormous and strongly bulging, nearly reaching posterior margin of head. Antenna (Fig. 67) $1.5 \mathrm{~mm}$ long and not distinctly incrassate; antennomere IV approximately as long as broad; antennomeres $\mathrm{V}-\mathrm{X}$ weakly transverse, gradually and very weakly increasing in width; $\mathrm{X}$ much less than 1.5 times as broad as long; XI barely as long as the combined length of IX and X.

Pronotum (Fig. 104) 1.26 times as broad as long and 0.9 times as broad as head, moderately convex in crosssection, of inversely trapezoid shape; maximal width across anterior angles; lateral margins nearly straight in dorsal view; posterior angles moderately marked; in posterior portion with a transverse median impression; disc with scattered and very indistinct punctation, nearly impunctate. Elytra (Figs 104, 108) approximately 1.25 times as long as, and much broader than pronotum; laterally with an oblong impression, this impression externally delimited by an oblong elevation; punctation moderately dense and rather fine; interstices with distinct microreticulation; pubescence short, pale, and depressed. Hind wings present. Legs of moderate length and moderately slender; metatibia $1.0 \mathrm{~mm}$ long; metatarsus little more than 0.8 times as long as metatibia; metatarsomere I much longer than the combined length of II and III.

Abdomen (Figs 113-114): sternites III-V not distinctly modified; tergites IV-VI each with a lateral tubercle on either side; tergites III-VI with shallow microsculpture anteriorly and each with two lateral setiferous punctures on either side; tergite VI with a pair of small tubercles at posterior margin; tergite VII with dense non-setiferous punctation, except along anterior margin; tergite VIII (Fig. 362) transverse, anteriorly with a pair of extensive clusters of numerous gland openings; posterior margin distinctly serrate and broadly excised; sternite VIII (Fig. 363) strongly transverse, laterally with a cluster of several very stout setae inserting in sclerotized projections, posterior margin nearly truncate in the middle.

$\sigma^{*}$ : unknown.

: spermathecal capsule (Fig. 364) rather large and slender, $0.39 \mathrm{~mm}$ long, and of distinctive shape.

Comparative notes and comment: Orphnebius biimpressus is characterized by the slender, weakly incrassate antennae, enormous eyes, the transverse impression on the pronotum, the presence of microreticulation on the elytra, the lateral impressions and elevations of the elytra, unmodified abdominal sternites III-V, the presence of a pair of tubercles at the posterior margin of tergite VI, the anterior pair of extensive clusters of gland openings on tergite VIII, and by the distinctive shape of the spermatheca. It additionally differs from O. laticeps, the only other representative of Deroleptus known from Sumatra, by larger body size (O. laticeps: length of forebody $1.7 \mathrm{~mm}$ ), the darker antennomere I (O. laticeps: antennomere I pale-reddish), the relatively smaller and inversely trapezoid pronotum, much finer and sparser punctation of the elytra, much paler coloration of the abdomen and the legs, and the deeper posterior excision of tergite VIII.

Distribution and natural history: The type locality is situated in the Gunung Leuser National Park in Aceh province, North Sumatra, Indonesia. The holotype was collected at an altitude of $450 \mathrm{~m}$. 
Orphnebius (Deroleptus) ulcerosus spec. nov.

(Figs 68, 105, 115-116, 365-369)

Type material: Holotype $0^{\top}$ : "Borneo, Sabah, Tibow, $45 \mathrm{~km}$ NE of Sapulut, 600-900 m, 7-15 Apr 2000, Bolm lgt. / Holotypus ơ Orphnebius ulcerosus sp. n., det. V. Assing 2015" (NHMB).

Etymology: The specific epithet (Latin, adjective: with ulcers) alludes to the tubercles and other elevations on the elytra.

Description: Body length $5.2 \mathrm{~mm}$; length of forebody $2.2 \mathrm{~mm}$. Coloration: head blackish; pronotum and elytra blackish-brown, with the elytral suture dark-reddish; abdomen reddish-brown with the antero-median portions of tergites III-VI dark-brown; legs pale-brown; antennae dark-brown with antennomeres II-III and apex of XI reddish and antennomere I brown; maxillary palpi reddish with the apical palpomere yellowish.

Head (Fig. 105) strongly transverse, 1.37 times as broad as long; punctation in lateral portions sparse, shallow, and fine; median and posterior dorsal portions extensively impunctate; interstices without microsculpture. Eyes enormous and bulging, nearly reaching posterior margin of head. Antenna (Fig. 68) $1.4 \mathrm{~mm}$ long and weakly incrassate; antennomere IV approximately as long as broad; antennomeres $\mathrm{V}-\mathrm{X}$ weakly transverse, gradually and very weakly increasing in width; $X$ less than 1.5 times as broad as long; XI barely as long as the combined length of IX and X.

Pronotum (Fig. 105) 1.3 times as broad as long and as broad as head, moderately convex in cross-section, of subrectangular shape; lateral margins straight in dorsal view; posterior angles moderately marked; behind middle with two circular impressions separated by a narrow carina; disc with scattered punctation.

Elytra (Fig. 106) 1.13 times as long as, and much broader than pronotum; each elytron with a small median tubercle, with an oblique elevation near postero-sutural angle, and with an extensive, moderately deep impression externally limited by an oblong elevation in posterior half; punctation fine and sparse; interstices with pronounced microsculpture composed of obliquely transverse meshes; pubescence short and indistinct. Hind wings present. Legs of moderate length and moderately slender; metatibia $1.15 \mathrm{~mm}$ long and distinctly curved; metatarsus little more than 0.8 times as long as metatibia; metatarsomere I nearly as long as the combined length of II-IV.

Abdomen broad, much broader than elytra; sternites III-V not distinctly modified, only lateral portion of sternite weakly elevated; paratergites IV each with an anterior tubercle; setiferous punctation of tergites IIIVII as in O. biimpressus; anterior and lateral portions of tergites III-VI with distinct microreticulation; tergite $\mathrm{V}$ with a pronounced and extensive median impression; tergite VI with a pair of distinct lateral tubercles at posterior margin and with additional smaller granules between these tubercles; tergite VII with non-setiferous punctation, posterior margin with palisade fringe; tergite VIII (Fig. 368) transverse, anteriorly with a pair of extensive clusters of numerous gland openings, posterior margin distinctly serrate and broadly excised; sternite VIII (Fig. 369) strongly transverse, laterally with a cluster of several very stout setae inserting in sclerotized projections, posterior margin nearly truncate in the middle.

$\sigma^{\top}$ : median lobe of aedeagus (Figs 365-366) $0.55 \mathrm{~mm}$ long; paramere as in Fig. 367.

†: unknown.

Comparative notes and comment: Based on the similar morphology of the antennae and the head, the shared median impression(s) on the pronotum, the similarly shaped pronotum, the shared presence of microsculpture and of a lateral elevation on the elytra, the shared presence of microsculpture in the anterior portions of tergites III-VI, the shared presence of a pair of tubercles at the posterior margin of tergite VI, the similar shapes of tergite and sternite VIII, as well as the presence of a distinct anterior pair of clusters of numerous gland openings on tergite VIII, O. ulcerosus is very closely allied to O. biimpressus, from which it differs by larger body size, the pair of impressions on the pronotum, the modifications and more pronounced microsculpture of the elytra, a much broader abdomen, the presence of an anterior tubercle on paratergites IV, the absence of lateral tubercles on tergites IV-VI, the more widely separated lateral tubercles and the additional smaller tubercles at the posterior margin of tergite VI, the weakly concave posterior margins of tergites IV and $\mathrm{V}$, and the deep median impression of tergite $\mathrm{V}$.

Distribution and natural history: The type locality is situated in Sabah, North Borneo, Malaysia, at an altitude between 600 and $900 \mathrm{~m}$.

\section{Orphnebius falagrioides BeRnHAUER, 1929}

(Figs 69, 107, 118, 370-372)

Orphnebius (Megalocephalobius) falagrioides BERNHAUER, 1929: 142.

Type material examined: Lectotype $\circ$, present designation: "Mt. Makiling, Luzon, Baker / Orphnebius falagrioides Brnh., Typ. un. / Chicago NHMus, M. Bernhauer Collection / FMNHINS 3048063, Field Museum, Pinned / Lectotypus o Orphnebius falagrioides Bernhauer, desig. V. Assing 2016 / Orphnebius falagrioides Bernhauer, det. V. Assing 2016” (FMNH).

Comment: Orphnebius falagrioides was made available in key and a footnote without a proper description, without explicitly marking it as a new name, without providing data of actual type specimens, and without stating a type 
locality (BERNHAUER 1929). BLACKWELDER (1952) designated $O$. falagrioides as the type species of the subgenus Megalocephalobius Bernhauer, 1929. One specimen with Bernhauer's original type label attached to it was located in the Bernhauer collection at the FMNH. As can be inferred from the type label ("Typ. un."), it is a unique syntype. Nevertheless, it is designated as the lectotype.

Redescription: Body length $3.0 \mathrm{~mm}$; length of forebody $1.5 \mathrm{~mm}$. Coloration: head and pronotum brown; elytra yellowish; abdomen pale yellowish-brown; legs yellowish; antennae pale-reddish with yellowish antennomeres I-II. Head (Fig. 107) strongly transverse, broadest across eyes, not wedge-shaped; dorsal surface with barely noticeable, extremely fine and sparse punctation and pubescence. Eyes enormous and strongly bulging, approximately four times as long as postocular region in dorsal view. Antennae (Fig. 69) $1.15 \mathrm{~mm}$ long and slender; antennomeres IV-X moderately transverse and XI barely as long as the combined length of IX and X.

Pronotum (Fig. 107) small in relation to head and strongly transverse, 1.55 times as broad as long and approximately 0.9 times as broad as head, broadest near anterior angles; posterior angles broadly rounded, nearly obsolete; disc with a median pair of punctures and with some punctures laterally.

Elytra (Fig. 107) much broader than pronotum, with moderately fine and sparse punctation; on either side of anterior half of suture with an indistinct oblong elevation. Hind wings fully developed. Legs long and slender; metatarsus nearly as long as metatibia; metatarsomere I approximately as long as the combined length of metatarsomeres II and III.

Abdomen (Fig. 118): sternite and paratergites IV with an oblique process directed posteriad; tergites III-VI practically impunctate; tergite VII with dense non-setiferous punctation in posterior three-fourths, with a transverse row of setiferous punctures near posterior margin, and with a pronounced palisade fringe at posterior margin; tergite VIII (Fig. 370) transverse and with weakly concave, finely serrate posterior margin; sternite VIII (Fig. 371) transverse and with convex posterior margin. o: spermatheca as in Fig. 372.

Comparative notes: Orphnebius falagrioides belongs to the O. siwalikensis group, as can be inferred from the external and sexual characters. Among the species of the O. siwalikensis group, it is characterized by small body size, a large and strongly transverse head, a relatively small and strongly transverse pronotum, the presence of an oblong elevation on either side of the anterior half of the elytral suture, the modifications of sternite and paratergites IV, and by the shape of the spermatheca.

Distribution and natural history: The type locality is situated in Luzon, Philippines. Additional data are not available.

\subsubsection{Unnamed species of the subgenus Deroleptus}

The following species is represented only by a single, non-distinctive female and remains unnamed.

\section{Orphnebius (Deroleptus) spec.}

Material examined: Indonesia: 1 ㅇ, Sumatra, Aceh, Mt. Leuser National Park, Ketambe, 500 m, 23.-30.XI.1989, leg. Agosti et al. (MHNG).

\subsubsection{Subgenus Strabocephalium BERNHAUER, 1911}

\section{Orphnebius (Strabocephalium) mirabile (BERNHAUER, 1911)}

Material examined: Malaysia: 1 , Sabah (Borneo), Crocker Mt., Gunong Emas, 500-1900 m, V.1995, leg. Jeniš (MHNG).

Comment: This species has been recorded only from Borneo. The proximal portion of the spermathecal capsule of the above female is of slightly different shape than that illustrated by PACE (2014), but the abdominal tergite VIII is identical (see PACE 2014: figure 124).

\section{Orphnebius (Strabocephalium) borneorum PACE, 2014}

Material examined: Malaysia: $1 \sigma^{\star}$, Sabah (Borneo), Bajnaran Maitland, Sapulut, 22.-24.V.1995, leg. Jeniš (MHNG).

Comment: The original description is based on nine type specimens from Danum Valley, Sabah (PACE 2014). It does not seem unlikely that either this species or O. mirabilis is conspecific with O. borneanus PACE, 2007. The genitalia are quite similar (see figures in PACE 2007, 2014).

\section{Orphnebius (Strabocephalium) spec. 1}

Material examined: India: 1 ㅇ, Madras, Anaimalai Hills, 18 km N Valparai, 1250 m, 18.XI.1972, leg. Besuchet et al. (MHNG).

Comment: The above female most likely represents an undescribed species.

\section{Orphnebius (Strabocephalium) spec. 2}

Material examined: India: 1 ㅇ, Meghalaya, Khasi Hills, Mawsynram-Balat, 1000 m, 27.X.1978, leg. Besuchet \& Löbl (MHNG). 
Comment: The above female, too, most likely represents an undescribed species distinguished from the preceding one by paler coloration, a much smaller head, and pronounced postero-lateral processes of the abdominal sternites III and IV.

\subsection{Genus Drusilla LEACH, 1819}

\section{Drusilla (Drusilla) canaliculata (FABRICIUs, 1787)}

Myrmedonia polyporina GISTEL, 1857: 17; syn. nov.

Comment: Huaváč et al. (2011) list Drusilla polyporina (GISTEL, 1857) as a nomen dubium. The original description, which is based on an unspecified number of syntypes from "Styriae", is practically devoid of relevant information. All that is specified is the coloration ("nigerrima; antennis thorace elytris et pedibus fuscis"), the size, and that it is close to D. canaliculata. The type material is presumably lost (Assing 2008). However, it can be inferred that the type material of $D$. polyporina is conspecific with $D$. canaliculata, the only representative of the genus distributed in what used to be "Styria" (Assing 2005b). In order to dispose of the doubtful D. polyporina, it is placed in synonymy with the senior synonym D. canaliculata.

\section{Drusilla (Drusilla) erichsoni (PeYRon, 1857)}

Myrmedonia erichsoni Peyron, 1857: $635 \mathrm{f}$. Myrmedonia aptera Peyron, 1858: 417; syn. nov.

Comment: Huaváč et al. (2011) list Drusilla erichsoni (Peyron, 1857) as a species incertae sedis and D. aptera (PEyron, 1858) as a "nomen dubium?". As can be inferred from an earlier revision of the West Palaearctic species of Drusilla, D. erichsoni undoubtedly belongs to the nominal subgenus (Assing 2005b).

Drusilla erichsoni was originally described based on material from the environs of Montpellier; the species is endemic to southeastern France (Assing 2005b). In the original description of D. aptera, PEYRON (1858) states that the species is "assez commune" in the environs of "Tarsous" (southern Anatolia) and that he also saw one male from "Montpellier, Près de port Juvénal". Thus, there is no doubt that the description of D. aptera refers to at least two species. The whereabouts of Peyron's type material is unknown (Assing 2005b). In order to dispose of the doubtful name D. aptera, the male from the environs of Montpellier, where D. erichsoni is the only species matching the original description, is designated as the lectotype and D. aptera is placed in synonymy with D. erichsoni.

\section{Drusilla (Drusilla) yunnanensis PACE, 1993}

Material examined: China: 8 exs., Sichuan, Moxi env., Hailuogou valley, Mulinsen vill., $29^{\circ} 37^{\prime} \mathrm{N}, 102^{\circ} 07^{\prime} \mathrm{E}$, $1680 \mathrm{~m}$, pig carrion in advanced decay, 19.VI.2014, leg. Hájek \& Růžička (NMP, cAss).

Comment: The previously known distribution was confined to three localities Yunnan; for a map see Assing $(2015 \mathrm{c})$. The above material represents the first record from Sichuan. The external and sexual characters are illustrated in Assing (2015c). Remarkably, all eight specimens were collected from pig carrion.

\section{Drusilla flagellata Assing, 2015}

Material examined: Laos: 1 ex., Louang Phrabang province, $5 \mathrm{~km} \mathrm{~W} \mathrm{Ban} \mathrm{Song} \mathrm{Cha,} 1200 \mathrm{~m}, 12 .-16 . V .1999$, Kubán (NHMB); 1 ex., Phongsaly prov., Phongsaly env., $21^{\circ} 41^{\prime} \mathrm{N}, \quad 102^{\circ} 07^{\prime} \mathrm{E}, \quad 1500 \mathrm{~m}, 28$. V.-20.VI.2003, leg. Kubáň (cAss).

Comment: This recently described species was previously known only from the Chinese province Yunnan (Assing 2015c).

\section{Drusilla khamhengi PACE, 1986}

Material examined: Thailand: 1 , , Doi Inthanon, PongNoi, $18^{\circ} 38^{\prime} \mathrm{N}, 98^{\circ} 33^{\prime} \mathrm{E}, 930 \mathrm{~m}$, along stream, 13.I.2014, leg. $\mathrm{Ob}$ (cAss); 1 우, Doi Inthanon, Sob Aeb village, $18^{\circ} 32^{\prime} \mathrm{N}$, 98³7'E, $590 \mathrm{~m}$, along stream, sifted, 17.II.2014, leg. Ob (cAss).

Comment: This species has been recorded only from Thailand.

\section{Drusilla zyrasoides DvoŘÁk, 1988}

Drusilla zyrasoides Dvořak, 1988: $4 \mathrm{f}$. Drusilla truncatella PACE, 2004: 286; syn. nov.

Type material examined: see Assing (2015d).

Comment: Drusilla zyrasoides was described from Vietnam; the type material was studied and illustrated earlier (Assing 2015d). The original description of D. truncatella is based on a single female from "W Malaysia, Pahang, Cameron Highlands, Tanah Rata" (PACE 2004). According to the drawings of the female primary and secondary sexual characters (PACE 2004: figures 133-134), the holotype of $D$. truncatella is undoubtedly conspecific with D. zyrasoides; for comparison see figures 43, 49 in Assing (2015d). Hence the synonymy proposed above. 
Drusilla bifida spec. nov.

(Figs 119-122, 373-379)

Type material: Holotype $0^{*}$ : "Thailand [47] - Doi Pha Hom Pok, Bhoo Muan waterf., $20^{\circ} 02^{\prime} \mathrm{N}, 99^{\circ} 14^{\prime} \mathrm{E}, 800 \mathrm{~m}$, litter, 25.I.2014, leg. Ob / Holotypus ơ Drusilla bifida sp. n., det. V. Assing 2015" (cAss).

Etymology: The specific epithet (Latin, adjective) alludes to the bifid ventral process of the aedeagus.

Description: Body length $4.7 \mathrm{~mm}$; length of forebody $2.2 \mathrm{~mm}$. Coloration: head blackish; pronotum and elytra dark-brown; scutellum paler brown; abdomen darkbrown, with segments III and VIII-X reddish-brown; legs dark-yellowish; antenna dark-brown with antennomeres I-II and the base of III reddish; maxillary palpi brown with the apical palpomere yellowish.

Head (Figs 119-120) transverse, 1.21 times as broad as long; posterior angles weakly marked, nearly obsolete; frons and sclerotized portion of clypeus each with a distinct smooth elevation; punctation fine, practically invisible in the pronounced microreticulation (Fig. 373); dorsal surface nearly matt. Eyes large and strongly bulging, nearly twice as long as distance from posterior margin of eye to posterior constriction in dorsal view. Antenna (Fig. 121) $1.9 \mathrm{~mm}$ long and rather massive; antennomere III somewhat flattened, distinctly dilated apically, approximately twice as long as broad, and much longer than antennomere II; antennomeres IV distinctly and V-VI weakly oblong, VII aproximately as long as broad, VIII-X indistinctly transverse, and XI small, narrower than the preceding antennomeres and shorter than the combined length of IX and X.

Pronotum (Figs 119-120) 1.08 times as broad as long and as broad as head, very weakly convex in cross-section, broadest at anterior angles; disc coarsely and longitudinally rugosely sculptured, matt, only in antero-median portion less matt and with defined punctation; midline with very narrow sulcus reaching neither anterior nor posterior margins; disc with an indistinct elevation and a lateral oblong impression on either side.

Elytra (Fig. 119) 1.07 times as long as pronotum; punctation dense and moderately fine; interstices with pronounced microreticulation (Fig. 379). Hind wings present. Metatarsomere I slightly longer than the combined length of II and III.

Abdomen (Fig. 121) slightly narrower than elytra; sternites III-VI anteriorly with dense and posteriorly with sparser fine punctation; tergite VII with very fine and very sparse punctation; posterior margin of tergite VII with palisade fringe.

$0^{\top}$ : tergite VIII (Fig. 374) transverse, posterior margin with distinct and broad concavity in the middle; sternite VIII (Fig. 375) transverse and with convex posterior margin; median lobe of aedeagus (Figs 376-377) $0.53 \mathrm{~mm}$ long; ventral process apically bifid (Fig. 378); internal structures of distinctive shapes; paramere $0.47 \mathrm{~mm}$ long.
†: unknown.

Comparative notes and comment: Drusilla bifida is distinguished from other species recorded from Thailand and neighbouring regions by the bifid ventral process of the aedeagus, the characteristic sculpture of the pronotum, and the smooth elevations on the frons and the clypeus, from most species also by the coloration, the massive antennae, and the pronounced microsculpture on the head and elytra. The median lobe of the aedeagus slightly resembles that of the much larger D. umranicola PACE, 2005 from India (Meghalaya) and that of D. thaifuscicollis PACE, 2012 (Thailand), from which D. bifida additionally differs by the nearly obsolete posterior angles of the head, much larger eyes, and darker and distinctly more massive antennae with a relatively shorter antennomere XI.

Distribution and natural history: The type locality is situated in the extreme north of Thailand, close to the border with Myanmar. The holotype was sifted from leaf litter near a waterfall at an altitude of $800 \mathrm{~m}$.

\subsection{Genus Episkiodrusilla PACE, 2013}

This recently described genus currently includes five species, the type species E. rubricollis (CAMERON, 1939), originally described from North India (CAMERon 1939) and subsequently reported also from South India (PACE 2001), E. franzi (PACE, 1992) from Nepal, E. neocoenonicacollis (PACE, 2008) from Borneo, E. malayrubricollis PACE, 2013 from Peninsular Malaysia, and E. veluticollis PACE, 2013 from Taiwan (PACE 2013). Based on external characters, particularly the morphology of the pronotum and the dense non-setiferous punctation on tergite VII, this species is unlikely to be closely allied to Drusilla as suggested by PACE (2013). According to CAMERon (1939), the sculpture of tergite VII resembles that of Pheidologitonetes CAMERon, 1939.

\section{Episkiodrusilla spec. nov.}

Material examined: India: 19 , Meghalaya, Khasi Hills, Mawsynram-Balat, 1000 m, 27.X.1978, leg. Besuchet \& Löbl (MHNG).

The above female is in agreement with the original descriptions of neither of the two geographically closest species E. rubricollis and E. franzi, and its spermatheca is different from those of E. neocoenonicacollis and E. veluticollis. Nevertheless, this evidently new species is not described for want of males. The abdominal tergite and sternite VIII of the above female are covered by dense and coarse non-setiferous punctation, suggesting that the same is true also of other Episkiodrusilla species, although this is not mentioned in their respective original descriptions. 


\subsection{Genus Rabdotodrusilla PACE, 2013}

Rabdotodrusilla was described in the same article as Episkiodrusilla. The genus previously included only one species, R. malaysiensis PACE, 2013 from Malaysia, a species described based on a single female. According to PACE (2013), this genus is characterized and distinguished from Drusilla by a pronotum "with long strong sulci, without a deep median sulcus". Additional characters are neither indicated nor described. The new species described below is tentatively attributed to Rabdotodrusilla, as it shares with R. malaysiensis the modified sculpture of the pronotum. However, the status of this genus requires revision. The morphology of the aedeagus and other characters suggest that these species belong to Drusilla and that Rabdotodrusilla is a synonym of that genus.

\section{Rabdotodrusilla pectinata spec. nov.} (Figs 123-125, 380-383)

Type material: Holotype $\sigma^{\star}$ : "Thailand - Chiang Mai, Doi Suthep 1120 m. Barber F. I.86, P. Schwendinger / Holotypus o Rabdotodrusilla pectinata sp. n., det. V. Assing 2015" (MHNG).

Paratype $\sigma^{\star}$ [damaged]: same data as holotype (cAss).

Etymology: The specific epithet is an adjective derived from the Latin noun pecten (comb) and alludes to the shape of the posterior margin of tergite VIII.

Description: Body length $4.2 \mathrm{~mm}$; length of forebody $1.8 \mathrm{~mm}$. Coloration: head and pronotum dark-brown; elytra pale-brown with the postero-lateral portions extensively dark-brown; abdomen pale reddish-brown with segment VI infuscate; legs yellowish, with the tibiae infuscate; antennae brown with antennomeres I-II and the apex of XI paler; maxillary palpi yellowish-red with yellowish palpomere IV.

Head (Fig. 123) transverse, approximately 1.17 times as broad as long; punctation rather sparse and fine; pubesence long, pale, and depressed to sub-erect. Eyes large, longer than distance from posterior margin of eye to posterior constriction of head. Antenna (Fig. 124) rather massive, $1.5 \mathrm{~mm}$ long; antennomere I stout, barely twice as long as broad; II short, distinctly less than twice as long as broad; III nearly twice as long as II and more than twice as long as broad; IV very weakly transverse; $\mathrm{V}-\mathrm{X}$ gradually increasing in width and increasingly transverse; IX-X more than 1.5 times as broad as long; XI nearly as long as the combined length of VIII-X.

Pronotum (Fig. 123) approximately 1.07 times as broad as long and 1.1 times as broad as head; posterior margin obtusely produced in the middle; disc matt and with dense, long, and straight longitudinal striae in posterior three-fourths, anteriorly and in antero-lateral portions more glossy and with granulose punctation.
Elytra (Fig. 123) approximately 0.8 times as long as pronotum; punctation very fine and dense. Hind wings present. Metatarsomere I approximately as long as the combined length of II-III.

Abdomen (Fig. 125) narrower than elytra; tergites IIIVII each with a row of setiferous punctures at posterior margin, otherwise nearly impunctate, without microsculpture; posterior margin with palisade fringe.

$\sigma^{*}$ : tergite VIII (Fig. 382) transverse, posterior margin with a pronounced lateral tooth-like projection on either side, between these projections with 15 conspicuous spine-shaped processes (somewhat resembling a comb); sternite VIII (Fig. 383) transverse and with weakly convex posterior margin; median lobe of aedeagus (Figs 380-381) approximately $0.55 \mathrm{~mm}$ long, with internal structures of distinctive shapes.

o: unknown.

Comparative notes: This species is readily distinguished from $R$. malaysiensis by several external characters alone, particularly its larger body size ( $R$. malaysiensis: $2.7 \mathrm{~mm}$ ), much more massive antennae with transverse antennomeres IV-X (R. malaysiensis: antennomeres IV-IX oblong), the different coloration of the femora ( $R$. malaysiensis: bicoloured, brown with yellow bases), and the absence of microsculpture on the elytra and the abdomen. For illustrations of R. malaysiensis see PACE (2013).

Distribution and natural history: The type locality is situated in Doi Suthep, North Thailand. The specimens were collected with pitfall traps at an altitude of $1120 \mathrm{~m}$.

\subsection{Genus Pella StepHens, 1833}

\section{Pella cinctipennis (EPPELSHeIM, 1884)}

Material examined: Lebanon: 2 우 [det. Feldmann], Jbail district, Ehmej, ca. 1100 m, pitfall trap, IV.2015, leg. Reuter (cFel).

Comment: This rare species was previously known from scattered localities in Middle Asia (Tajikistan, Uzbekistan), the Caucasus region (Azerbaijan), and southwestern Turkey (MAruyama 2006). The above females represent the first record from Lebanon and the Middle East.

\subsection{Genus Peltodonia Bernhauer, 1936}

\section{Peltodonia bodemeyeri (Bernhauer, 1936)}

Material examined: Lebanon: 1 ㅇ [det. Feldmann], Rachaya, Tannoura, $33^{\circ} 29^{\prime} \mathrm{N}, 35^{\circ} 48^{\prime} \mathrm{E}, 900 \mathrm{~m}$, oak forest, pitfall trap, V.2015, leg. Reuter (cFel). 
Comment: Peltodonia bodemeyeri had been recorded only from Turkey and Israel (Assing 2009, 2014). The above female represents the first record from Lebanon.

\subsection{Genus Myrmoecia Mulsant \& ReY, 1873}

\section{Myrmoecia libanensis (PIC, 1901)}

Material examined: Turkey: 1 ex. [det. Feldmann], Hatay, $15 \mathrm{~km}$ WSW Antakya, Batıayaz, Musa Dağ1, 500 m, pitfall trap, 6.-23.IV.2014, leg. Reuter (cFel).

Comment: Myrmoecia libanensis was originally described from Lebanon and subsequently recorded also from one locality in Turkey and one in Israel (Assing 2006e, 2014).

\subsection{Genus Amaurodera FAuveL, 1905}

\subsubsection{General remarks}

Including the new species described below and the newly established synonymies, Amaurodera currently includes 46 species (see section 3.8.2). The distribution of the genus is essentially Oriental, with some species (groups) occurring also in the south of the East Palaearctic region; it ranges from the Himalaya to the Philippines. Some species, particularly most of those recorded from the Himalaya, have very restricted distributions, whereas others are remarkably widespread. The latter particularly applies to A. kraepelini, whose distribution ranges from the Himalaya to Java.

Since most of the new species are described from Thailand, a key to the species recorded from this country is provided in section 3.8.3.

\subsubsection{Checklist}

\begin{tabular}{|c|c|}
\hline Species & Distribution \\
\hline amabilis PACE, 2008 & Malaysia: Borneo: Sabah \\
\hline angularis Assing, 2015 & North India: West Bengal \\
\hline arunica spec. nov. & East Nepal \\
\hline birmana PACE, 1986 & Burma \\
\hline bomfordi (EPPELSHEIM, 1890) & North India; Nepal \\
\hline bulbosa PACE, 2008 & Malaysia: Borneo: Sabah \\
\hline cameroni Assing, 2003 & Northeast India; Nepal \\
\hline coriacea Assing, 2003 & Central Nepal \\
\hline darenae YAN \& LI, 2015 & China: Guangxi \\
\hline dentata spec. nov. & Thailand \\
\hline discoidea PACE, 2008 & Brunei (Borneo) \\
\hline disparicollis spec. nov. & Indonesia: Sumatra \\
\hline elegans CAMERon, 1939 & North India \\
\hline fasciata spec. nov. & Thailand \\
\hline frondium PACE, 2008 & Malaysia: Borneo: Sabah \\
\hline fulgens Assing, 2003 & Central Nepal \\
\hline gilvios spec. nov. & Thailand \\
\hline granata Assing, 2003 & East Nepal \\
\hline ilamica Assing, 2005 & East Nepal; North India: West Bengal \\
\hline incisa PACE, 2008 & Malaysia: Borneo: Sabah \\
\hline intermedia CAMERoN, 1943 & Malaysia: Borneo: Sarawak \\
\hline kinabaluensis PACE, 1989 & Malaysia: Borneo: Sabah \\
\hline kleebergi Assing, 2006 & East Nepal \\
\hline $\begin{array}{l}\text { kraepelini FAUVEL, } 1905 \\
=\text { rougemonti PACE, 1987; syn. nov. } \\
=\text { smetanai } \text { PACE, 1992; syn. nov. } \\
=\text { yaoana } \text { PACE, 1992; syn. nov. }\end{array}$ & Nepal; China: Yunnan, Hainan; Thailand; Indonesia: Java, Bali \\
\hline
\end{tabular}




\begin{tabular}{|c|c|}
\hline Species & Distribution \\
\hline martensi CoIfFAIT, 1982 & Nepal \\
\hline meorum PACE, 1992 & Thailand \\
\hline nigra CAMERon, 1925 & Indonesia: Java, Sumatra \\
\hline orousseti PACE, 1990 & Philippines \\
\hline pahangensis PACE, 2003 & Malaysia: Pahang \\
\hline parvoculata spec. nov. & Thailand \\
\hline philippina CAMERON, 1941 & Philippines \\
\hline plena PACE, 2003 & Malaysia \\
\hline projecta Assing, 2015 & Vietnam \\
\hline reticulata spec. nov. & Thailand \\
\hline schawalleri Assing, 2005 & East Nepal \\
\hline schuelkei Assing, 2009 & China: Yunnan \\
\hline $\begin{array}{l}\text { silvana } \mathrm{PACE}, 1992 \\
=\text { loebli } \mathrm{PACE}, 1992\end{array}$ & Central Nepal \\
\hline similis CAMERON, 1928 & Malaysia: Borneo: Sarawak \\
\hline soror CAMERON, 1939 & North India; Nepal \\
\hline spathulifera Assing, 2005 & Central Nepal \\
\hline spinans spec. nov. & Indonesia: Sumatra \\
\hline thailandensis PACE, 1986 & Thailand \\
\hline veluticollis MotsCHULSKY, 1858 & Burma; East Nepal \\
\hline verrucosa Assing, 2003 & East Nepal \\
\hline varicollis spec. nov. & Indonesia: Sumatra \\
\hline yunnanensis PACE, 1998 & China: Yunnan; Thailand \\
\hline
\end{tabular}

\subsubsection{Key to the named Amaurodera species of Thailand}

1. Body usually of dark coloration: forebody black; abdomen usually blackish, sometimes with tergite III slightly paler, rarely with reddish tergites III-IV; antennae with at least antennomeres III-VI usually blackish-brown to blackish, rarely paler. Head and pronotum without sexual dimorphism. $\varsigma^{\top}$ : median lobe of aedeagus as in Assing (2003: figures 14-15). + : proximal portion of spermathecal capsule conspicuously dilated (AssiNG 2003: figure 16). Very variable and widespread species. kraepelini FAUVEL

- Body usually of paler coloration: forebody mostly reddish to reddish-brown; abdomen with at least tergite III (sometimes except for the infuscate posterior margins) pale-reddish; antennae yellowish to brown. Head with or without sexual dimorphism. $\sigma^{*}$ : median lobe of aedeagus of different shape. +9 : proximal portion of spermathecal capsule not strongly dilated.

2. Pronotum with numerous moderately long and more or less erect setae in antero-lateral portion. $\sigma^{*}$ : median lobe of aedeagus with very broad (ventral view) and strongly sinuate (lateral view) ventral process (YAN \& LI 2015: figures $5 \mathrm{~B}-\mathrm{C}$ ); apical lobe of paramere conspicuously long, more than half as long as basal portion of paramere. \%: spermathecal capsula somewhat truncate proximally. yunnanensis PACE

- Pronotum only with few long and erect setae anteriorly. Primary sexual characters different; apical lobe of paramere shorter than basal portion of paramere.

3. Head with sexual dimorphism, in male rather extensively impressed in median portion (e.g., Fig. 145), without such an impression in female. Mostly smaller species; pronotum only in one species $>0.88 \mathrm{~mm}$ long. Abdominal tergites III and IV usually pale-reddish (rarely darker), usually not infuscate at posterior margins. Ventral process of aedeagus slender, more or less parallel-sided or subapically even dilated in ventral view. Spermatheca with distinctly delated distal portion and with large apical cuticular invagination. 
- Head without sexual dimorphism, impressed neither in male nor in female. Larger species; pronotum at least $0.88 \mathrm{~mm}$ long. Abdominal tergites III and IV mostly with more or less distinctly infuscate posterior margins. Ventral process of aedeagus basally broad, lateral margins converging apicad in ventral view. Spermatheca with weakly dilated distal portion and with small apical cuticular invagination.

4. Elytra with distinct microreticulation visible at a magnification of 40-50 x (Fig. 129). Ventral process of aedeagus ventro-medially with a pair of lateral angular projections (Figs 391, 393-394). reticulata spec. nov.

- Elytra with indistinct traces of microreticulation visible only at high magnification $(100 \mathrm{x})$. Ventral process of aedeagus of different shape.

5. Smaller species, pronotum $0.70-0.80 \mathrm{~mm}$ long.

- Larger species, pronotum $0.81-0.94 \mathrm{~mm}$ long.

6. Legs uniformly yellowish. Median lobe of aedeagus smaller, < $0.6 \mathrm{~mm}$ long (Figs 389-390). Spermatheca as in Fig. 395. gilvios spec. nov.

- At least meso- and metafemora usually more or less distinctly infuscate apically. Median lobe of aedeagus larger, $>0.7 \mathrm{~mm}$ long, ventral process distinctly angled in the middle in lateral view (Figs 396-397). Spermatheca as in Figs 398-399. dentata spec. nov.

7. Smaller species; length of pronotum $0.81-0.87 \mathrm{~mm}$. Eyes usually larger, approximately 0.7 times as long as distance from posterior margin of eye to posterior constriction of head (Fig. 144). Ventral process of aedeagus smoothly sinuate in lateral view (Figs 405-409). Spermatheca as in Fig. 410. thailandensis PACE

- Larger species; length of pronotum 0.88-0.94 mm. Eyes smaller, approximately half as long as distance from posterior margin of eye to posterior constriction of head. Ventral process of aedeagus more or less distinctly angular in lateral view (Figs 400-402). Spermatheca as in Figs 403-404. parvoculata spec. nov.

8. Ventral process of aedeagus strongly bulging in lateral view; crista apicalis larger (Figs 411-412). Spermatheca smaller and with shorter proximal portion (Figs 413-414. fasciata spec. nov.

- Ventral process of aedeagus weakly to moderately bulging in lateral view; crista apicalis smaller (Figs 415-418). Spermatheca larger and with longer proximal portion (Fig. 419). meorum PACE

\subsubsection{Descriptions and additional records}

\section{Amaurodera cameroni Assing, 2003}

Material examined: India: 2 exs., Arunachal Pradesh, Etalin env., $28^{\circ} 37^{\prime} \mathrm{N}, 95^{\circ} 53^{\prime} \mathrm{E}, 700 \mathrm{~m}$, sifted, 12.-15.V.2012, leg. Dembický (ZMFK, cAss).

Comment: The previously known distribution included Nepal and North India eastwards to Assam. The above specimens represent the first record from Arunachal Pradesh (Assing 2003, 2005a, 2009, 2015c).

YAN \& Li (2015a) suggest that A. cameroni may be conspecific with A. yunnanensis PACE, 1998. In the latter, however, the ventral process of the aedeagus is much more convex subapically (lateral view), the crista apicalis of the aedeagus is longer, and the spermatheca differs by a shorter distal portion and a longer and terminally convex proximal portion of the capsule (A. cameroni: proximal portion distinctly truncate). For illustrations of the intraspecific variation of the genitalia of A. cameroni see Assing (2003), for figures of A. yunnanensis see YAN \& LI (2015a) and PACE (1998).

\section{Amaurodera arunica spec. nov.} (Figs 126-127, 132, 384-388)

Type material: Holotype o $\sigma^{*}$ "E-NEPAL, Arun Valley, env. Tashigaon, 2200-2400 m, 12.+28.-29.V.2014, 27³7'N, $87^{\circ} 14^{\prime} \mathrm{E}$, leg. Schmidt / Holotypus ơ Amaurodera arunica sp. n., det. V. Assing 2015” (NME).

Paratypes: 19 exs.: same data as holotype (NME, cAss).

Etymology: The specific epithet is an adjective derived from Arun, the name of the valley where the type locality is situated.

Description: Body length 5.8-6.8 mm; length of forebody 2.8-3.1 mm. Coloration: body black, with tergites III-IV and the anterior portions of the anterior paratergites often slightly paler; legs: profemora blackish-brown to blackish, meso- and metafemora blackish-brown to blackish with dark-yellowish bases, tibiae brown, tarsi yellowish-brown; antennae blackish-brown to blackish, with antennomere IX reddish to brown, the basal 1-3 antennomeres brown to dark-brown, and often (the bases of) antennomeres II and III dark-reddish to reddish-brown; maxillary palpi brown with yellowish palpomere IV.

Head (Fig. 126) weakly oblong, broadest across eyes, without sexual dimorphism; punctation sparse and extremely 
fine; interstices with very shallow, nearly obsolete microreticulation. Eyes 0.5-0.6 times as long as the distance from posterior margin of eye to posterior constriction of head. Antenna (Fig. 132) approximately 3.1-3.4 mm long and very slender.

Pronotum (Figs 126, 384) 1.15-1.25 mm long, nearly 1.5 times as long as broad, and slightly broader than head; dorsal surface matt; dorsal and lateral surface meeting at an angle posteriorly; microreticulation reaching lateral carinae only in posterior portion; narrow median furrow long, but reaching neither anterior nor posterior margins.

Elytra (Fig. 126) short, approximately 0.45 times as long as pronotum; punctation dense, distinct, and somewhat granulose; pubescence short and depressed. Hind wings reduced. Metatarsomere I approximately as long as the combined length of II-IV.

Abdomen (Fig. 127) approximately 1.15 times as broad as elytra; tergites III-V with fine (but distinct) and moderately sparse punctation; tergite VI with extremely fine and very sparse punctation; tergite VII with sparse and fine punctation only in posterior portion, anterior portion practically impunctate; tergite VIII with somewhat granulose punctation in posterior third, anterior two-thirds impunctate; microsculpture extremely shallow, nearly obsolete, distinct only on tergite VIII; posterior margin of tergite VII with palisade fringe; posterior margin of tergite VIII distinctly serrate.

$0^{*}$ : sternite VIII noticeably longer than tergite VIII, posterior margin distinctly convex; median lobe of aedeagus (Figs 385-386) $0.72-0.77 \mathrm{~mm}$ long and of compact shape; ventral process strongly sinuate in lateral view, basally broad in ventral view; paramere approximately $0.75 \mathrm{~mm}$ long.

: sternite VIII approximately as long as tergite VIII, posterior margin broadly convex; spermatheca as in Figs 387-388.

Comparative notes: Based on the external and the sexual characters, $A$. arunica belongs to the $A$. silvana group (see Assing 2003). The male and female primary sexual characters are most similar to those of A. silvana PACE, 1992 (Central Nepal: Annapurna and Dhaulagiri ranges), from which the new species differs particularly by the shape of the ventral process of the aedeagus (ventral process much more sinuate in lateral view and less broad in ventral view), by the coloration of the legs (A. silvana: femora and tibiae practically completely black), the glossy head and elytra (A. silvana: head and elytra with pronounced microsculpture and matt), as well as by the shorter and more slender elytra. The only other species of the A. silvana group recorded from East Nepal is A. kleebergi Assing, 2006 (Rolwaling Himal), from which A. arunica differs by a shorter and slightly less oblong pronotum (A. kleebergi: pronotum 1.3-1.4 $\mathrm{mm}$ long), the coloration of the legs and maxillary palpi (A. kleebergi: tibiae completely black or nearly so; femoral bases not yellow; maxillary palpomeres II and III blackish-brown to black), the much finer and less dense punctation of the elytra, the absence of an oblong impression on the elytra, as well as the longer, more strongly sinuate, and more slender ventral process of the aedeagus.

The remaining species known from East Nepal belong to other species groups. They are of distinctly smaller size and paler coloration, and/or their pronotum is subject to a pronounced sexual dimorphism. Moreover, their genitalia are of completely different shapes. For illustrations of the previously described Himalayan Amaudera species see Assing (2003, 2005a, 2006a, 2015c).

Distribution and natural history: The type locality is situated in the Arun valley in East Nepal. The reduced hind wings and the restricted distributions of other species of the $A$. silvana group suggest that $A$. arunica is endemic to this region.

\section{Amaurodera kraepelini FAuvEL, 1905 (Map 1)}

Amaurodera kraepelini FAUveL, 1905: 85.

Amaurodera kraepelini rougemonti PACE, 1987: 204; syn. nov.

Amaurodera smetanai PACE, 1992a: 129; syn. nov.

Amaurodera yaoana PACE, 1992b: 257 f.; syn. nov.

Material examined: Thailand: $30^{\top} \sigma^{\star}$, NE Bangkok, Khao Yai National Park, 750-850 m, 26.XI.-3.XII.1985, leg. Burckhardt \& Löbl (MHNG, cAss); 1 o , NE Bangkok, Khao Yai National Park, E Heo Suwat Waterfalls, 800-900 m, 11.XII.1985, leg. Burckhardt \& Löbl (MHNG); 1 ơ $^{\star}$, Chiang Mai, Doi Chiang Dao, $450 \mathrm{~m}$, 7.V.1987, leg. Schwendinger (MHNG); 1 ㅇ, Chiang Mai, Doi Saket, 1130 m, 4.XII.1987, leg. Schwendinger (cAss); 1 ㅇ, Chiang Rai, 10 km W Wiang Pa Pao, Ban Huay Yan Sal, 780 m, 28.I.1988, leg. Schwendinger (MHNG); 1 ex., Doi Pha Hom Pok, Bhoo Muan waterfall, $20^{\circ} 02^{\prime} \mathrm{N}, 99^{\circ} 14^{\prime} \mathrm{E}, 800 \mathrm{~m}$, leaf litter sifted, 25.I.2014, leg. Ob (cAss); 2 exs., Doi Pha Hom Pok, Pong Nam Dang waterfall, $20^{\circ} 00^{\prime} \mathrm{N}, 99^{\circ} 10^{\prime} \mathrm{E}, 710 \mathrm{~m}$, on rocks in waterfall, 26.I.2014, leg. Ob (cAss); 5 exs., same data, but leaf litter sifted (cAss); 1 ex., Doi Pha Hom Pok,Tad Mok waterfall, $20^{\circ} 04^{\prime} \mathrm{N}, 99^{\circ} 16^{\prime} \mathrm{E}, 700 \mathrm{~m}$, litter, 27.I.2014, leg. $\mathrm{Ob}$ (cAss). Indonesia: Bali: 12 exs., Bedugul, $1200 \mathrm{~m}$, leaf litter sifted, 13.VI.1994, leg. Wunderle (cWun, cAss); 7 exs., Batukaru, 700-800 m, flood debris, 12.VI.1994, leg. Wunderle (cWun, cAss).

Comment: The original description of Amaurodera kraepelini is based on an unspecified number of syntypes from "Tjompea" [recte: Tjampea near Bogor) in West Java (FAuvel 1905). In referring to a female syntype from the Fauvel collection as the "holotype" [sic], PACE (1987) unintentionally designated this specimen as the lectotype. In the same paper he described A. kraepelini rougemonti based on fifteen type specimens collected in two localities ("L. Bouyaio", "Batukaru") in Bali, stating that this subspecies was distinguished from the nominal form by dark-brown coloration, the pronotum being 


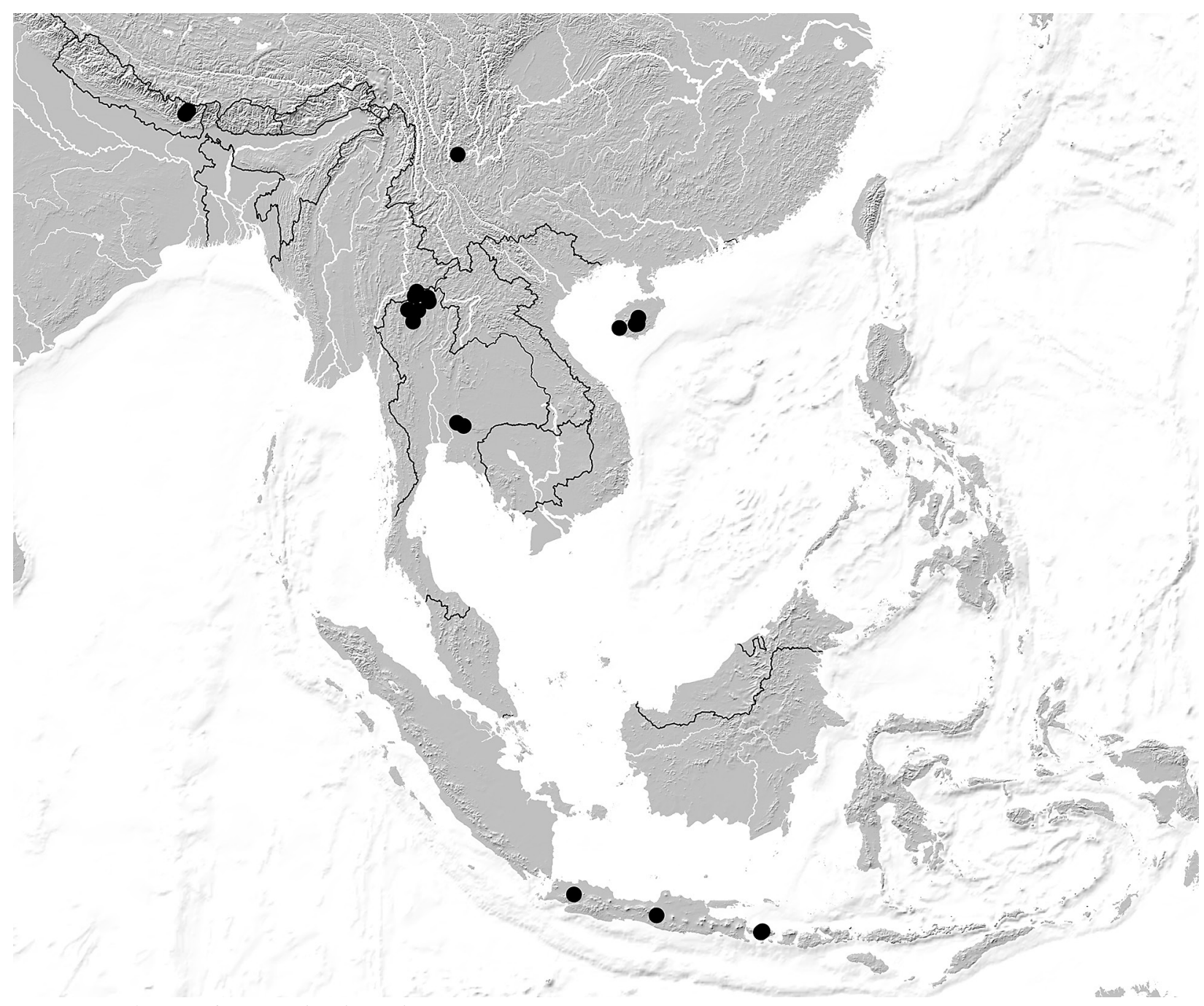

Map 1: Distribution of Amaurodera kraepelini.

broader than the head, by more slender antennomeres, and by a larger apical cuticular invagination of the spermatheca. Subsequently, PACE (1992a, b) described A. smetanai from Nepal and A. yaoana from Thailand. The latter was recently synonymized with the former by Assing (2015c).

A comparative study of material from most of the extensive range of $A$. smetanai and A. kraepelini, including the locality where nearly all the type specimens of $A$. rougemont $i$ were collected, revealed no evidence that this material should represent two species. The aedeagus is identical; the spermatheca is subject to some variability, but this variation does not correspond to a distinct distribution pattern. Moreover, in external characters, including those emphasized by PACE (1987), A. kraepelini is subject to pronounced intraspecific variation; this even applies to material from the same region. The only variation that appears to be related to distribution is the relative length and width of the elytra. In the material from Bali, they are generally narrower and shorter than in material seen from other regions. In consequence, both $A$. rougemonti and A. smetanai (including its previously established synonym A. yaoana) are placed in synonymy with A. kraepelini.
The currently known distribution of this widespread species extends from the Himalaya across southern China (Yunnan, Hainan) and Thailand to Java and Bali (Map 1).

\section{Amaurodera gilvios spec. nov.}

(Figs 128, 133, 389-390, 395)

Type material: Holotype $\sigma^{\star}$ : “Thailand: Chanthaburi, Khao Sabap Nat. Park, 150-300 m, 23.-24.XI.85, Burckhardt-Löbl / Holotypus o Amaurodera gilvios sp. n., det. V. Assing 2015” (MHNG).

Paratype ㅇ: same data as holotype (cAss).

Etymology: The specific epithet is a noun in apposition composed of the Latin adjective gilvus (yellow) and the Latin noun os (leg). It alludes to the uniformly yellowish legs, a character distinguishing this species from most other Amaurodera species known from Thailand.

Description: Body length 4.0-4.3 mm; length of forebody 1.8-2.0 mm. Coloration: forebody pale reddish-brown; abdomen: tergites III-IV and VIII-X pale-reddish, 
tergite $\mathrm{V}$ pale-reddish or with somewhat darker disc, tergite VI dark-brown, tergite VII dark-brown with reddish posterior margin; legs, antennae, and maxillary palpi yellowish.

Head (Fig. 128) weakly transverse, broadest across eyes, with sexual dimorphism; punctation sparse and extremely fine; interstices without microreticulation. Eyes large and bulging, but noticeably shorter than distance from posterior margin of eye to posterior constriction of head. Antenna (Fig. 133) 2.1-2.2 mm long and very slender.

Pronotum (Fig. 128) 0.70-0.77 mm long, approximately 1.4 times as long as broad, and slightly narrower than head; with two erect lateral setae on either side anteriorly; dorsal surface matt; dorsal and lateral surface not meeting at an angle posteriorly; microreticulation reaching lateral carinae only in posterior half; narrow median furrow long, but reaching neither anterior nor posterior margins.

Elytra (Fig. 128) 0.57-0.58 times as long as pronotum; punctation fine and sparse; interstices seemingly without microsculpture, traces of microreticulation visible only at high magnication (at least $100 \mathrm{x}$ ); pubescence short and depressed. Hind wings present. Metatarsomere I approximately as long as the combined length of II and III, or slightly longer.

Abdomen narrower than elytra; punctation fine and rather sparse on anterior, even sparser on posterior tergites; interstices with microsculpture composed of transverse meshes; posterior margin of tergite VII with palisade fringe; posterior margin of tergite VIII distinctly serrate.

$0^{7}$ : head with shallow, but extensive median impression; median lobe of aedeagus (Figs 389-390) $0.6 \mathrm{~mm}$ long and of distinctive shape, apically flattened dorso-ventrally; ventral process suborbicular in apical portion; crista apicalis pronounced.

क: head without dorsal impression; spermatheca as in Fig. 395.

Comparative notes: This species is characterized particularly by the distinctive shape of the median lobe of the aedeagus. It is additionally distinguished from other Amaurodera species known from Thailand by the uniformly yellowish legs and the shape of the spermatheca, from most species also by the uniformly pale-reddish abdominal tergites III-IV.

Distribution and natural history: Khao Sa Bap National Park (approximately at $12^{\circ} 33^{\prime} \mathrm{N}, 102^{\circ} 12^{\prime} \mathrm{E}$ ) is situated to the southeast of Chanthaburi in southeastern Thailand. The type specimens were collected at an altitude of 150-300 m.

\section{Amaurodera reticulata spec. nov.}

(Figs 123, 134, 391-394)

Type material: Holotype $0^{*}$ : "Thailand: NE Bangkok, Khao Yai Nat. Park, 750-850 m, 26.XI.-3.XII.85, Burckhardt-Löbl / Holotypus o Amaurodera reticulata sp. n., det. V. Assing 2015” (MHNG).

Paratype $\sigma^{*}$ : same data as holotype (cAss).

Etymology: The specific epithet (Latin, adjective) alludes to the distinct microreticulation of the elytra, one of the characters distinguishing this species from other congeners known from Thailand.

Description: Body length 4.2-4.3 mm; length of forebody $2.0-2.1 \mathrm{~mm}$. Coloration: forebody dark-reddish; abdomen: tergites III-IV pale-reddish, tergites V-VIII dark-brown with the posterior margins and the anterior margin of tergite $\mathrm{V}$ reddish; legs yellowish with the apical halves of the metafemora slightly darker; antennae dark-yellowish to yellowish-brown; maxillary palpi yellowish.

Head (Fig. 123) as long as broad, broadest across eyes, with sexual dimorphism; punctation sparse and extremely fine; interstices with nearly obsolete microreticulation, traces of which are visible only at high magnification $(100 \mathrm{x})$. Eyes moderately large and bulging, approximately 0.8 times as long as distance from posterior margin of eye to posterior constriction of head. Antenna (Fig. 134) $2.3 \mathrm{~mm}$ long and very slender; antennomere IX approximately twice as long as broad.

Pronotum (Fig. 123) 0.78-0.80 mm long, approximately 1.4 times as long as broad, and slightly narrower than head; dorsal and lateral surface not meeting at an angle posteriorly; microreticulation reaching lateral carinae only in posterior half; narrow median furrow long, but reaching neither anterior nor posterior margins.

Elytra (Fig. 123) 0.57-0.58 times as long as pronotum; punctation fine and rather dense; interstices with distinct microreticulation; pubescence short and depressed. Hind wings present. Metatarsomere I approximately as long as the combined length of II and III.

Abdomen narrower than elytra; punctation fine and rather sparse on anterior, even sparser on posterior tergites; tergites III-VI with distinct microsculpture composed of transverse meshes, tergite VII with practically obsolete microreticulation (traces may be visible at high magnification); posterior margin of tergite VII with palisade fringe; posterior margin of tergite VIII distinctly serrate.

$\sigma^{7}$ : head with shallow, but extensive median impression; median lobe of aedeagus (Figs 391-394) 0.53-0.55 mm long and of distinctive shape; ventral process ventromedially with a pair of lateral angular projections; crista apicalis pronounced.

o: unknown. 
Comparative notes: Among the species with uniformly reddish abdominal tergites III-IV and a sexual dimorphism of the head, A. reticulata is characterized by the distinct microreticulation of the elytra and the abdominal tergites III-VI, nearly uniformly yellowish legs, and a rather small aedeagus with a bidentate ventral process.

Distribution and natural history: Khao Yai National Park is situated some $100 \mathrm{~km}$ to the northeast of Bangkok in central Thailand. The specimens were collected at an altitude of 750-850 m, together with A. meorum.

\section{Amaurodera dentata spec. nov.}

(Figs 130, 135, 396-399)

Type material: Holotype $\sigma^{*}$ : "Thailand: Phetchaburi, Kaeng Krachan Nat. Pk, 450 m, 19.XI.1985, BurckhardtLöbl / Holotypus o A Amaurodera dentata sp. n., det. V. Assing 2015” (MHNG).

Paratypes: $20^{\top} o^{\star}, 3$ 우 ㅇ, 7 sex?: same data as holotype (MHNG, cAss).

Etymology: The specific epithet (Latin, adjective: with tooth/teeth) alludes to the distinct median tooth on the ventral face of the ventral process of the aedeagus.

Description: Body length 4.0-4.5 mm; length of forebody $2.0-2.2 \mathrm{~mm}$. Coloration: forebody reddish to reddish-brown; abdomen: tergites III-IV reddish-yellow, tergites V-VIII dark-brown to blackish-brown with the anterior margin of tergite $\mathrm{V}$ and the posterior margins of tergites VII and VIII reddish-yellow or reddish; legs yellowish, with the profemora dark-yellowish to brown and the apical halves of the meso- and metafemora brown; antennae yellowish; maxillary palpi yellowish to brown, with palpomere IV pale-yellowish.

Head (Fig. 130) weakly transverse, broadest across eyes, with sexual dimorphism; punctation sparse and extremely fine; interstices without microreticulation. Eyes large and bulging, but shorter than distance from posterior margin of eye to posterior constriction of head. Antenna (Fig. 135) 2.1-2.3 mm long and very slender. Pronotum $0.72-0.77 \mathrm{~mm}$ long, $1.35-1.40$ times as long as broad, and as broad as, or slightly narrower than head; with two erect lateral setae on either side anteriorly; dorsal and lateral surface not meeting at an angle posteriorly; microreticulation reaching lateral carinae only in posterior half; narrow median furrow long, but reaching neither anterior nor posterior margins.

Elytra (Fig. 130) 0.56-0.60 times as long as pronotum; punctation moderately fine and moderately dense; interstices with nearly obsolete microreticulation visible only at high magnification (at least $100 \mathrm{x}$ ); pubescence short and depressed. Hind wings present. Metatarsomere I approximately as long as the combined length of II and III, or slightly longer.
Abdomen narrower than elytra; punctation fine and sparse on anterior, even sparser on posterior tergites; interstices with microsculpture composed of transverse meshes; posterior margin of tergite VII with palisade fringe; posterior margin of tergite VIII distinctly serrate.

$\sigma^{*}$ : head with shallow, but extensive median impression; median lobe of aedeagus (Figs 396-397) approximately $0.75 \mathrm{~mm}$ long; ventral process distinctly angular in the middle (lateral view); crista apicalis conspicuously long. \%: head without dorsal impression; spermathecal capsule (Figs 398-399) with strongly dilated distal portion and short proximal portion.

Comparative notes: Regarding its primary sexual characters, A. dentata is similar to A. angularis Assing, 2015 from North India (Darjeeling), from which it is distinguished by the coloration of the legs and abdominal tergite $\mathrm{V}$ (A. angularis: legs uniformly yellowish; tergite $\mathrm{V}$ reddish-yellow, not darker than tergites III and IV), by the larger aedeagus (A. angularis: $0.6 \mathrm{~mm}$ ) with a relatively longer, apically and basally less strongly sinuate (lateral view), and less strongly dentate ventral process and with a longer crista apicalis, and by the larger distal portion and basally less strongly curved proximal portion of the spermathecal capsule. Based on the available evidence, these differences are interpreted as interspecific variation. However, the possibility they in fact reflect intraspecific variation cannot be ruled out with certainty. Material from the region between the type localities of both species would be required to confirm, or reject, the hypothesis that $A$. dentata represents a distinct species. For illustrations of A. angularis see Assing (2015c).

Distribution and natural history: Kaeng Krachan National Park (approximately at $12^{\circ} 58^{\prime} \mathrm{N}, 99^{\circ} 21^{\prime} \mathrm{E}$ ) is situated some $50 \mathrm{~km}$ to the southwest of Phetchaburi in central western Thailand, close to the border with Burma. The type specimens were collected at an altitude of $450 \mathrm{~m}$.

\section{Amaurodera parvoculata spec. nov. \\ (Figs 131, 136, 400-404)}

Type material: Holotype $\sigma^{\star}$ : “Thailand: Chiang Mai, Doi Inthanon, 1650 m, 7.XI.1985, Burckhardt-Löbl / Holotypus $\sigma^{*}$ Amaurodera parvoculata sp. n., det. V. Assing 2015” (MHNG).

Paratypes: 15 exs.: same data as holotype (MHNG, cAss); 1 : "Thailand [2] - Doi Inthanon, Huay Saai Leung waterfall, $18^{\circ} 31^{\prime} \mathrm{N}, 98^{\circ} 27^{\prime} \mathrm{E}, 1010 \mathrm{~m}, 19 . X I I .2013$, leg. Ob” (cAss).

Etymology: The specific epithet (adjective) is composed of the Latin adjectives parvus (small) and oculata (with eyes) and alludes to the relatively small eyes, one of the characters distinguishing this species from the similar A. dentata and the sympatric A. thailandensis. 
Description: Body length 4.5-4.8 mm; length of forebody 2.1-2.3 mm. Coloration: forebody reddish to dark-brown; abdomen: tergites III-IV pale-reddish, tergite V reddish, with the posterior two-thirds dark-red to dark-brown, tergites VI-VIII dark-brown with the posterior margins of tergites VII and VIII reddish; legs dark-yellowish, with the profemora dark-yellowish to pale-brown and the apical halves of the meso- and metafemora slightly darker, dark-yellowish to pale-brown; antennae reddish to reddish-brown; maxillary palpi brown, with palpomere IV pale-yellowish.

Head (Fig. 131) approximately 1.1 times as long as broad, broadest across eyes, with sexual dimorphism; punctation sparse and extremely fine; interstices without microreticulation. Eyes of relatively small size, approximately half as long as distance from posterior margin of eye to posterior constriction of head. Antenna (Fig. 136) 2.7-2.8 mm long and very slender.

Pronotum (Fig. 131) 0.88-0.94 mm long, approximately 1.45 times as long as broad, and slightly broader than head; with two erect lateral setae on either side anteriorly; dorsal and lateral surface not meeting at an angle posteriorly; microreticulation reaching lateral carinae only in posterior half; narrow median furrow long, but reaching neither anterior nor posterior margins.

Elytra (Fig. 131) 0.51-0.53 times as long as pronotum; punctation moderately fine and moderately dense; interstices with nearly obsolete microreticulation barely visible even at high magnification $(100 \mathrm{x})$; pubescence moderately short and depressed. Hind wings present. Metatarsomere I slightly longer than the combined length of II and III.

Abdomen narrower than elytra; punctation fine and sparse on anterior, even sparser on posterior tergites; interstices with microsculpture composed of transverse meshes; posterior margin of tergite VII with palisade fringe; posterior margin of tergite VIII distinctly serrate.

$0^{\top}$ : head with shallow, but extensive median impression; median lobe of aedeagus (Figs 400-402) 0.70-0.73 mm long; ventral process with median carina and distinctly angular in the middle (lateral view); crista apicalis pronounced.

: head without dorsal impression; spermathecal capsule (Figs 403-404) $0.28-0.30 \mathrm{~mm}$ long, with moderately dilated distal portion and short proximal portion.

Comparative notes: Regarding its coloration and primary sexual characters, A. parvoculata is similar to A. dentata, from which it is readily distinguished by much smaller eyes, significantly longer antennae, the paler abdominal tergite $\mathrm{V}$, a longer and more oblong pronotum, shorter elytra, the smaller median lobe of the aedeagus with a shorter crista apicalis, a ventral process with a shorter apical portion (lateral view), and by the less dilated distal portion of the spermathecal capsule.

Distribution and natural history: The specimens were collected in two localities in Doi Inthanon, North Thai- land, at altitudes of 1010 and $1650 \mathrm{~m}$, in one locality together with A. fasciata.

\section{Amaurodera thailandensis PACE, 1986 \\ (Figs 137-138, 144, 406-410)}

Material examined: Thailand: $2 \sigma^{\top}$, Doi Inthanon, Mae Ya Waterfall, $18^{\circ} 26^{\prime} \mathrm{N}, 98^{\circ} 36^{\prime} \mathrm{E}, 580 \mathrm{~m}$, along stream, 12.I.2014, leg. Ob (cAss); $10^{\star}$, Doi Inthanon, $18^{\circ} 35^{\prime} \mathrm{N}$, $98^{\circ} 29^{\prime} \mathrm{E}, 2440 \mathrm{~m}$, peat bog, litter in swampy area, 14.I.2014, leg. Ob (cAss); 1 ơ, Chiang Mai, Doi Inthanon, $1080 \mathrm{~m}$, 14.II.1987, leg. Schwendinger (MHNG); 1 ơ $^{\top}$, same data, but $1020 \mathrm{~m}, 17 . \mathrm{II} .1987$ (cAss); 1 o $^{\star}, 1$ 웅, Chiang Mai, Doi Suthep, 1580 m, leaf litter, 13.XI.1995, leg. Wunderle (cWun, cAss); $3 o^{x} o^{x}, 1$ 으, Chiang Mai, Doi Suthep, $890 \mathrm{~m}$, pitfall traps, III.1986, leg. Schwendinger (MHNG, cAss); $1 \sigma^{\star}$ [teneral], 2 ㅇ ㅇ , Doi Suthep, 1120 m, pitfall trap, I.1986, leg. Schwendinger (MHNG, cAss); 1 o', Doi Suthep, 1100 m, pitfall trap, IV.1986, leg. Schwendinger (MHNG); $10^{\star}$, Chiang Mai, Doi Saket, $1130 \mathrm{~m}$, 4.XII.1987, leg. Schwendinger (MHNG); 1 우, Chiang Mai prov., Doi Chiang Dao, 450 m, 7.V.1987, leg. Schwendinger (MHNG).

Comment: The original description is based on a male holotype from Doi Pui and a female paratype from Doi Inthanon (PACE 1986). As can be inferred from the illustration of the spermatheca (PACE 1986: figure 105), the paratype is not conspecific with the holotype, but belongs to one of the species allied to A. fasciata and A. meorum. The male from Doi Saket is only tentatively attributed to this species. It is distinguished from material seen from other localities by larger body size, smaller eyes (Fig. 145) and an aedeagus of slightly different shape.

Redescription: Body length 4.0-4.7 mm; length of forebody $2.0-2.2 \mathrm{~mm}$. Coloration: forebody dark-reddish to reddish-brown; abdomen: tergites III-IV pale-reddish (IV rarely darker), tergites V-VIII dark-brown to blackish-brown with the anterior margin of tergite $\mathrm{V}$ and the posterior margins of tergites VII and VIII reddish; legs yellowish, with the profemora yellowish to pale-brown (sometimes with the bases yellowish, the tibiae sometimes yellowish-brown, and the apical halves of the meso- and metafemora pale-brown; antennae reddish with antennomeres III-VIII usually somewhat darker; maxillary palpi reddish to dark-reddish, with palpomere IV pale-yellowish

Head (Fig. 144) approximately as long as broad, broadest across eyes, with sexual dimorphism; punctation sparse and extremely fine; interstices with very shallow microreticulation composed of transverse meshes visible only at high magnification $(100 \mathrm{x})$. Eyes of moderate size, approximately 0.7 times as long as distance from posterior margin of eye to posterior constriction of head. Antenna (Fig. 137-138) 2.3-2.5 mm long. 
Pronotum (Fig. 144) $0.81-0.87 \mathrm{~mm}$ long, approximately 1.45 times as long as broad, and approximately as broad as, or slightly narrower than, head; with two or three erect lateral setae on either side anteriorly; dorsal and lateral surface not meeting at an angle posteriorly; microreticulation reaching lateral carinae only in posterior half; narrow median furrow long, but reaching neither anterior nor posterior margins.

Elytra (Fig. 144) 0.56-0.60 times as long as pronotum; punctation fine and rather sparse; interstices with shallow microreticulation visible only at high magnification $(100 \mathrm{x})$; pubescence moderately long and depressed. Hind wings present. Metatarsomere I slightly longer than the combined length of II and III.

Abdomen narrower than elytra; punctation fine and sparse on anterior, even sparser on posterior tergites; interstices with microsculpture composed of transverse meshes; posterior margin of tergite VII with palisade fringe; posterior margin of tergite VIII distinctly serrate.

$\sigma^{*}$ : head with shallow, but extensive median impression; median lobe of aedeagus (Figs 406-409) 0.63-0.68 mm long; ventral process somwhat bulging, but not angular in the middle (lateral view); crista apicalis pronounced.

o : head without dorsal impression; spermathecal capsule (Fig. 410) $0.27-0.30 \mathrm{~mm}$ long, with distinctly dilated distal portion and moderately long proximal portion.

Comparative notes: Amaurodera thailandensis is of similar coloration as A. dentata and allied species, but distinguished particularly by the different shape of the aedeagus, especially the absence of a median tooth or angle on the ventral face of the ventral process (lateral view).

Distribution and natural history: The species was collected in four mountain ranges (Doi Inthanon, Doi Suthep/Doi Pui, Doi Saket, Doi Chiang Dao) in Chiang Mai Province, North Thailand. The female from Chiang Dao is hypothesized to be conspecific with the three males from Doi Inthanon and Doi Suthep based on the similar external characters and the similar spermatheca. However, males from Doi Chiang Dao would be required to confirm this hypothesis. Some of the specimens were collected along streams, in a peat bog, and from leaf litter, partly together with $A$. fasciata. The altitudes range from 580 to $2440 \mathrm{~m}$.

\section{Amaurodera fasciata spec. nov.}

(Figs 139, 146, 411-414)

Type material: Holotype $0^{\star}:$ "Thailand [37] - Doi Inthanon, Khun Huay Hang, $18^{\circ} 34^{\prime} \mathrm{N}, 98^{\circ} 31^{\prime} \mathrm{E}, 1290$ m, along stream, 11.I.2014, leg. Ob / Holotypus o Amaurodera fasciata sp. n., det. V. Assing 2015" (cAss).

Paratypes: $2 \sigma^{\star} \sigma^{\star}, 5$ 우 우: same data as holotype (cAss); $2 \sigma^{\top} \sigma^{*}, 3$ 우 ㅇ: “Thailand [2] - Doi Inthanon, Huay Saai Leung waterfall, $18^{\circ} 31^{\prime} \mathrm{N}, 98^{\circ} 27^{\prime} \mathrm{E}, 1010 \mathrm{~m}, 19 . X I I .2013$, leg. Ob” (cAss); $2 o^{\star} o^{\star}, 2$ 우: “Thailand [32] - Doi Inthanon, Siribuhm Waterfall, $18^{\circ} 33^{\prime} \mathrm{N}, 98^{\circ} 31^{\prime} \mathrm{E}, 1330 \mathrm{~m}$, debris, 9.I.2014, leg. Ob” (cAss); 1 \%: “Thailand [34] - Doi Inthanon, route to Mae Wang, $18^{\circ} 35^{\prime} \mathrm{N}, 98^{\circ} 31^{\prime} \mathrm{E}$, $1580 \mathrm{~m}$, 9.I.2014, leg. Ob” (cAss); $2 \mathrm{o}^{\star} \mathrm{o}^{\star}$ : “Thailand [1] - Doi Inthanon, Maeaum, $18^{\circ} 32^{\prime} \mathrm{N}, 98^{\circ} 31^{\prime} \mathrm{E}, 1560 \mathrm{~m}$, sifted near stream, 18.XII.2013, leg. Ob” (cAss); $10^{\star}, 1$ ㅇ: "N-Thailand, Chiang Mai, Do Inthanon, Do Pui, 1100$1500 \mathrm{~m} \mathrm{NN}, 10.11 .1995$ P. Wunderle" (cWun, cAss); 20 exs.: "Thailand: Chiang Mai, Doi Suthep, 1400 m, 5.XI.1985, Burckhard-Löbl” (MHNG, cAss); 1 ex.: same data, but "1450 m, 4.XI.1985" (MHNG); 6 exs.: same data, but "1550 m, 4.XI.1985" (MHNG, cAss); 1 9 : “Thailand 27.XII.86, prov. Chiang Mai, Doi Suthep 1320 m, P. Schwendinger" (cAss); 1 o $^{\top}$ : “Thailand, Chiang Mai, Doi Suthep, $1580 \mathrm{~m} \mathrm{NN}$, Laubstreu, 13.11.1995 P. Wunderle" (cWun).

Etymology: The specific epithet (Latin, adjective: striped) alludes to the usually slightly infuscate posterior margins of the abdominal tergites III and IV.

Description: Body length 4.5-5.0 mm; length of forebody 2.3-2.5 mm. Coloration: forebody reddish to darkbrown, often with the pronotum slightly paler than head and elytra; abdomen: tergites III-IV pale reddish, usually with the posterior portion of the paratergites and at least the sides of the posterior margins weakly to distinctly infuscate, rarely completely dark-brown, tergites V-VIII dark-brown to blackish-brown, usually with the anterior margin of tergite $\mathrm{V}$ and the posterior margins of tergites V-VIII reddish; legs yellowish with the profemora usually at least slightly and at least partly darker and with the apical halves of the meso- and metafemora weakly to distinctly infuscate; antennae dark-yellowish to pale-brown; maxillary palpi reddish to brown, with the terminal palpomere yellowish.

Head (Fig. 146) oblong, 1.10-1.13 times as long as broad, broadest across eyes, without appreciable sexual dimorphism; punctation sparse and extremely fine; interstices with practically obsolete microreticulation barely visible even at higher magnification. Eyes of moderate size, approximately 0.7 times as long as distance from posterior margin of eye to posterior constriction of head. Antenna (Fig. 139) 2.7-2.9 mm long; antennomere IX twice as long as broad.

Pronotum (Fig. 146) 0.90-0.95 mm long, 1.45-1.50 times as long as broad, and approximately as broad as, or slightly broader than head, with or without weakly pronounced sexual dimorphism; with three or four erect lateral setae on either side anteriorly; dorsal and lateral surface not meeting at a distinct angle posteriorly; microreticulation immediately near lateral carinae shallow; narrow median furrow long, but reaching neither anterior nor posterior margins.

Elytra (Fig. 146) 0.52-0.56 times as long as pronotum; punctation fine and moderately sparse; interstices with shallow microreticulation; pubescence moderately long 
and depressed. Hind wings present. Metatarsomere I approximately as long as the combined length of II and III.

Abdomen narrower than elytra; punctation fine and very sparse on all tergites; tergites III-V with shallow, but distinct microsculpture composed of transverse meshes, only traces of microsculpture visible on tergites VIVIII even at high magnification; posterior margin of tergite VII with palisade fringe; posterior margin of tergite VIII distinctly serrate.

$\sigma^{*}$ : pronotum sometimes shallowly impressed on either side of anterior portion of median sulcus; median lobe of aedeagus (Figs 411-412) 0.65-0.72 mm long; ventral process strongly bulging, but not angular in the middle (lateral view); crista apicalis of moderate size.

\%: pronotum not or only indistinctly impressed on either side of anterior portion of median sulcus; spermatheca (Figs 413-414) 0.25-0.29 mm long, with weakly dilated distal portion and rather short proximal portion of the capsule, and with very small apical cuticular invagination.

Intraspecific variation: The material from Doi Inthanon is distinguished from that from Doi Suthep by on average darker coloration and slight differences in the shapes of the crista apicalis of the aedeagus and of the spermatheca. Since no other characters were found suggesting that these populations represent distinct species, these differences are interpreted as intraspecific variation.

Comparative notes: Amaurodera fasciata is distinguished from all the preceding species recorded from Thailand by the different coloration of the abdominal tergites III-IV, by the absence of a sexual dimorphism of the head, the sexually dimorphic pronotum, the shape of the median lobe of the aedeagus, and the smaller apical cuticular invagination of the spermatheca.

Distribution and natural history: The specimens were collected in several localities in Doi Inthanon and Doi Suthep, North Thailand, at altitudes of 1010-1580 m, in one locality together with $A$. thailandensis.

\section{Amaurodera meorum PACE, 1992}

(Figs 140, 147, 415-419)

Type material examined: Holotype $\sigma^{*}$ : "Thailand, Doi Suthep, III-1987, Rougemont / Holotypus Amaurodera meorum m., det. R. Pace 1987 / Amaurodera meorum sp. n., det. R. Pace 1987" (MCSNV).

Comment: The original description is based on two type specimens from Doi Suthep. Although the paratype is a female, the spermatheca was not illustrated by PACE (1992b).

Additional material examined: Thailand: $10^{\star}$, Chiang Mai, Doi Suthep, 1600 m, 4.XI.1985, leg. Burckhardt \&
Löbl (cAss); 10 exs., Chiang Mai, Doi Inthanon, 1080 m, 24.II.1987, leg. Schwendinger (MHNG, cAss); 3 exs., same data, but $1020 \mathrm{~m}$, 17.II.1987 (MHNG, cAss); 4 o $^{\star} 0^{\star}$, Doi Inthanon, Mae Pan Waterfall, $18^{\circ} 32^{\prime} \mathrm{N}, 98^{\circ} 27^{\prime} \mathrm{E}, 1090 \mathrm{~m}$, submontane primary forest, litter sifted, 16.I.2014, leg. $\mathrm{Ob}$ (cAss); $10^{\star}$, Chiang Rai, $10 \mathrm{~km} \mathrm{~W}$ Wiang Pa Pao, Ban Huay Ya Sai, 780 m, 28.I.1988, leg. Schwendinger (cAss); 1 ㅇ, Chiang Mai, 54 km NE Chiang Mai, Mae Nang Kaeo, 900 m, 3.XI.1985, leg. Burckhardt \& Löbl (MHNG); 8 exs., NE Bangkok, Khao Yai National Park, 750-850 m, 26.XI.-3.XII.1985, leg. Burckhardt \& Löbl (MHNG, cAss); 39 exs., NE Bangkok, Khao Yai Nat. Park, Khao Khieo, 1150 m, 28.XI.1985, leg. Burckhardt \& Löbl, (MHNG, cAss); 1 ơ, 2 우 ㅇ, Nakon Rachasima prov., Khao Yai National Park, 1020 m, 24.XII.1992, leg. Schwendinger (MHNG, cAss).

Redescription: Body length 4.3-5.0 mm; length of forebody $2.1-2.5 \mathrm{~mm}$. Coloration: forebody reddish to reddish-brown, sometimes with the pronotum slightly paler than head and elytra; abdomen: tergites III-IV pale reddish, with the posterior tergal margins and the posterior portions of the paratergites of segments II and III more or less distinctly infuscate, tergites V-VIII dark-brown to blackish-brown, usually with the anterior margin of tergite $\mathrm{V}$ and the posterior margins of tergites V-VIII reddish; legs yellowish with the apical halves of the meso- and metafemora infuscate; antennae dark-yellowish to pale-brown; maxillary palpi yellowish to brown, with the terminal palpomere always yellowish. Head (Fig. 147) oblong, 1.05-1.10 times as long as broad, broadest across eyes, without sexual dimorphism; punctation sparse and extremely fine; interstices with shallow microreticulation. Eyes of moderate size, approximately 0.8 times as long as distance from posterior margin of eye to posterior constriction of head. Antenna (Fig. 140) 2.5-2.8 mm long; antennomere IX twice as long as broad. Pronotum (Fig. 147) $0.88-0.98 \mathrm{~mm}$ long, approximately 1.5 times as long as broad, and slightly broader than head, with weakly pronounced sexual dimorphism; usually with two setae on either side anteriorly; dorsal and lateral surface meeting at an angle posteriorly; microreticulation reaching lateral margins only posteriorly; narrow median furrow long, but reaching neither anterior nor posterior margins.

Elytra $0.52-0.54$ times as long as pronotum; punctation fine and moderately sparse; interstices with shallow microreticulation; pubescence moderately long and depressed. Hind wings present. Metatarsomere I approximately as long as the combined length of II and III.

Abdomen narrower than elytra; punctation fine and very sparse on all tergites; tergites III-VIII with shallow microreticulation composed of transverse meshes; posterior margin of tergite VII with palisade fringe; posterior margin of tergite VIII distinctly serrate.

$\sigma^{*}$ : pronotum mostly shallowly impressed on either side of anterior portion of median sulcus; median lobe of aedeagus (Figs 415-418) 0.58-0.64 mm long; ventral 
process weakly sinuate, nearly straight, in lateral view; crista apicalis of moderate size.

ㅇ: pronotum not, or on average more shallowly, impressed than in male on either side of anterior portion of median sulcus; spermatheca (Fig. 419) 0.33-0.38 mm long, with moderately dilated distal portion and moderately long, but variable proximal portion of the capsule, and with very small apical cuticular invagination.

Intraspecific variation: The specimens from Khao Yai National Park are distinguished from those from other localities by a more strongly bulging ventral process of the aedeagus (lateral view) (Fig. 415), but otherwise no convincing evidence was found suggesting that they should represent a distinct species.

Comparative notes: Amaurodera meorum is distinguished from the similar and sympatric A.fasciata particularly by the smaller aedeagus with a less strongly sinuate ventral process in lateral view, the smaller crista apicalis of the aedeagus, the longer proximal portion and more distinctly dilated distal portion of the spermathecal capsule, and additionally, though less distinctly, by the less oblong head and the usually more distinctly infuscate posterior margins of the abdominal tergites III-IV.

Distribution and natural history: This species is currently known from several localities in northern and central Thailand. The specimens were collected at altitudes between 750 and $1600 \mathrm{~m}$, partly together with other congeners.

\section{Amaurodera yunnanensis PACE, 1998}

Material examined: Thailand: $1 c^{\star}, 1$, , Doi Pha Hom Pok, Kiew Lom, $20^{\circ} 03^{\prime} \mathrm{N}, 9^{\circ} 09^{\prime} \mathrm{E}, 1935 \mathrm{~m}$, primary evergreen forest, leaf litter sifted, 22.I.2014, leg. Ob (cAss).

Comment: This species was previously known only from the Chinese province Yunnan. The above specimens represent the first records from Thailand.

\section{Amaurodera soror CAMERoN, 1939}

Material examined: Nepal: 2 exs., Seti province, Bajhang district, $24 \mathrm{~km}$ NE Chainpur, Dhalaun env., $29^{\circ} 42^{\prime} \mathrm{N}$, $81^{\circ} 22^{\prime} \mathrm{E}, 2400-2600$ m, 26.VI.2009, leg. Kopetz (NME, cAss).

Comment: This species is widespread in the Himalayan region. For a distribution map see Assing (2006a).

\section{Amaurodera cf. discoidea PACE, 2008}

Material examined: Malaysia: Sarawak: $1 \sigma^{\star}, 20 \mathrm{mi}$ SW Kuching, Kampong Segu, 4.VI.1968, leg. Taylor (MHNG).

Comment: The original description of this species is based on five type specimens from two localities in Brunei and Sabah. The aedeagus of the above male resembles that illustrated by PACE (2008) for A. discoidea, but the coloration slightly differs from that mentioned in the original description. Other characters referred to in the original descriptions are irrelevant for an identification of Amaurodera species.

\section{Amaurodera disparicollis spec. nov. \\ (Figs 141, 150-151, 423-429)}

Type material: Holotype ơ: "Sumatra: Jambi, km 15 Sungaipenuh to Tapan, 1450 m, 9.XI.1989, Agosti, Löbl, Burckh. \#10 / Holotypus o Amaurodera disparicollis sp. n., det. V. Assing 2015” (MHNG).

Paratype + : same data as holotype (cAss).

Etymology: The specific epithet (Latin, adjective: with different pronotum) alludes to the pronounced sexual dimorphism of the pronotum.

Description: Body length 5.5-5.8 mm; length of forebody 2.6-2.7 mm. Coloration: forebody brown to dark-brown; abdomen reddish-brown to brown, with segments VIVII slightly darker; legs yellowish, with the profemora pale-brown, the mesofemora brown with yellowish bases, and the metafemora brown with the basal third yellowish; antennae uniformly yellowish or pale-brown with the apical antennomeres yellowish; maxillary palpi yellowish-brown with the terminal palpomere yellowish.

Head (Figs 150-151) oblong, 1.06-1.10 times as long as broad, broadest across eyes, with moderate sexual dimorphism; punctation sparse and extremely fine; interstices without microreticulation. Eyes of moderate size, 0.6-0.7 times as long as distance from posterior margin of eye to posterior constriction of head. Antenna (Fig. 141) 3.1-3.2 mm long; antennomere IX twice as long as broad.

Pronotum (Figs 150-151) 1.04-1.06 mm long, 1.361.41 times as long as broad, and 1.06-1.09 times as broad as head, with rather pronounced sexual dimorphism; dorsal and lateral surface meeting at an obtuse angle posteriorly; anterior one-sixth to one-fifth of dorsal surface with very shallow microreticulation and glossy; microreticulation reaching lateral margins neither anteriorly nor posteriorly; narrow median furrow anteriorly terminating at some distance from anterior margin of pronotum.

Elytra (Figs 150-151) 0.55-0.56 times as long as pronotum; punctation extremely fine and moderately sparse; 
interstices with nearly obsolete microreticulation, traces of which may be visible at high magnification $(100 \mathrm{x})$; pubescence moderately long and semi-erect. Hind wings present. Metatarsomere I approximately as long as the combined length of II and III.

Abdomen narrower than elytra; punctation fine and very sparse on all tergites; tergites III-V with shallow, nearly obsolete microsculpture composed of transverse meshes, tergites VI-VIII without appreciable microreticulation (except near anterior margins); posterior margin of tergite VII with palisade fringe; posterior margin of tergite VIII distinctly serrate.

$\sigma^{*}$ : head shallowly impressed along the middle; pronotum (Figs 423-424) antero-laterally with an oblique elevation on either side, antero-median portion impressed and extensively glossy; median lobe of aedeagus (Figs 427-428) large, $1.0 \mathrm{~mm}$ long; ventral process rather broad in ventral view; paramere $0.93 \mathrm{~mm}$ long, with rather short, broad, and flattened apical lobe.

i : head with shallow median impression, this impression somewhat shorter than in male; pronotum (Figs 425-426) without antero-lateral elevations, in antero-median portion not impressed and much less extensively glossy; spermathecal capsule (Fig. 429) with weakly dilated distal portion and with large and proximally distinctly dilated proximal portion.

Comparative notes: This species is characterized particularly by relatively large size, long antennae, the secondary sexually dimorphic head and pronotum, and a large median lobe of the aedeagus. Previously, the sole representative of the genus known from Sumatra was A. nigra CAmeron, 1925, which is distinguished from A. disparicollis by smaller size and darker coloration alone.

Distribution and natural history: The type locality (approximately $2^{\circ} 02^{\prime} \mathrm{S}, 101^{\circ} 18^{\prime} \mathrm{E}$ ) is situated in the southwest of Sumatra (Indonesia), near the border between Jambi and Sumatera Barat. The specimens were collected at an altitude of $1450 \mathrm{~m}$, together with the following species and a male of an unnamed species.

\section{Amaurodera spinans spec. nov.}

(Figs 142, 148, 430-431)

Type material: Holotype ơ: "Sumatra: Jambi, km 15 Sungaipenuh to Tapan, 1450 m, 9.XI.1989, Agosti, Löbl, Burckh. \#10 / Holotypus o Amaurodera spinans sp. n. det. V. Assing 2015” (MHNG).

Etymology: The specific epithet is the present participle of the Latin verb spinare (to sting) and alludes to the long, slender, and apically very acute ventral process of the aedeagus.

Description: Body length $5.2 \mathrm{~mm}$; length of forebody $2.5 \mathrm{~mm}$. Coloration: body dark-brown; legs yellowish, with the profemora and the apical portions of the mesoand metafemora brown; antennae pale-brown with the basal and the apical antennomeres reddish-yellow; maxillary palpi yellowish-brown with the terminal palpomere yellowish.

Head (Fig. 148) oblong, approximately 1.09 times as long as broad, broadest across eyes, without sexual dimorphism; punctation sparse and extremely fine; interstices with nearly obsolete microreticulation visible only at high magnification $(100 \mathrm{x})$. Eyes of moderate size, approximately 0.7 times as long as distance from posterior margin of eye to posterior constriction of head. Antenna (Fig. 142) $3.1 \mathrm{~mm}$ long; antennomere IX nearly twice as long as broad.

Pronotum (Fig. 148) $0.95 \mathrm{~mm}$ long, 1.34 times as long as broad, and 1.04 times as broad as head, without sexual dimorphism; dorsal and lateral surface not meeting at an angle posteriorly; antero-lateral portions with two longer and numerous shorter, more or less erect setae; antero-median portion with slightly less pronounced microreticulation and slightly less matt than remainder of dorsal surface; microreticulation reaching sublateral carina neither anteriorly nor posteriorly; narrow median furrow anteriorly terminating at some distance from anterior margin of pronotum.

Elytra (Fig. 148) 0.51 times as long as pronotum; punctation extremely fine and moderately sparse; interstices with nearly obsolete microreticulation visible only at high magnification $(100 \mathrm{x})$; pubescence moderately long and semi-erect. Hind wings present. Metatarsomere I approximately as long as the combined length of II and III.

Abdomen narrower than elytra; punctation fine and very sparse on all tergites; tergites III-V with shallow microsculpture composed of transverse meshes, tergites VI-VIII with nearly obsolete microreticulation visible only at high magnification; posterior margin of tergite VII with palisade fringe; posterior margin of tergite VIII distinctly serrate.

$\sigma^{*}$ : median lobe of aedeagus (Figs 430-431) slender, $0.7 \mathrm{~mm}$ long; ventral process very long, slender, and apically acute; paramere $0.58 \mathrm{~mm}$ long, with rather short, broad, and flattened apical lobe.

o: unknown.

Comparative notes: Amaurodera spinans is distinguished from the syntopic $A$. disparicollis by somewhat smaller size, a shorter pronotum, relatively shorter elytra, the unmodified male head and pronotum, the more pronounced microreticulation of the antero-median portion of the pronotum, and the completely different morphology of the aedeagus.

Distribution and natural history: The type locality is identical to that of $A$. disparicollis (see above). 


\section{Amaurodera varicollis spec. nov.}

(Figs 143, 149, 432-434)

Type material: Holotype $o^{\star}$ : “Sumatra: N Sum. \#29a, 5 km W Berastagi, Tongkoh, 1450 m, 3.XII.1989, Löbl, Agosti, Burckhardt / Holotypus ơ Amaurodera varicollis sp. n., det. V. Assing 2015” (MHNG).

Paratypes: $50^{\star} o^{\star}, 1$ : : same data as holotype (MHNG, cAss).

Etymology: The specific epithet (Latin, adjective: with variable pronotum) alludes to the variable morphology of the pronotum.

Description: Body length 4.2-5.3 mm; length of forebody 2.1-2.5 mm. Coloration: body brown to dark-brown with the anterior abdominal segments sometimes slightly paler; legs yellowish with (the apices of) the profemora sometimes, and with the apical portions of the meso- and metatibiae always more or less distinctly infuscate; antennae yellowish-brown to brown, with the basal and the apical antennomeres usually paler dark-yellowish; maxillary palpi yellowish.

Head (Fig. 149) oblong, 1.06-1.16 times as long as broad, broadest across eyes, with more or less pronounced sexual dimorphism; punctation sparse and extremely fine; microsculpture subject to sexual dimorphism. Eyes relatively small, slightly more than half as long as distance from posterior margin of eye to posterior constriction of head. Antenna (Fig. 143) 3.0-3.2 mm long and very slender; antennomere IX more than twice as long as broad; antennomeres IV-VII approximately five times as long as broad.

Pronotum (Fig. 149) 0.84-0.99 mm long and of rather variable shape, 1.32-1.45 times as long as broad, and 1.02-1.09 times as broad as head, with rather variable, more or less pronounced sexual dimorphism; dorsal and lateral surface not meeting at an obtuse angle posteriorly; microreticulation reaching lateral margins neither anteriorly nor posteriorly; narrow median furrow anteriorly terminating at some distance from anterior margin of pronotum.

Elytra (Fig. 149) 0.50-0.55 times as long as pronotum; punctation extremely fine and moderately sparse; interstices with shallow or nearly obsolete microreticulation; pubescence moderately long and semi-erect. Hind wings present. Metatarsomere I approximately as long as the combined length of II and III.

Abdomen narrower than elytra; punctation fine and very sparse on all tergites; tergites with shallow microreticulation; posterior margin of tergite VII with palisade fringe; posterior margin of tergite VIII distinctly serrate.

$\sigma^{*}$ : head shallowly impressed along the middle and with nearly obsolete to distinct microsculpture; pronotum in antero-median portion more or less distinctly impressed, with more or less reduced microreticulation, and more or less glossy; median lobe of aedeagus (Figs 432-433) of rather variable size, $0.7-0.8 \mathrm{~mm}$ long, with conspicuously prominent crista apicalis; paramere 0.6-0.7 mm long, with rather short, broad, and flattened apical lobe.

o: head with shallow median impression, this impression somewhat shorter and shallower than in male, dorsal surface with nearly obsolete microreticulation; pronotum in antero-median portion only slightly more glossy than on remainder of dorsal surface; spermathecal capsule (Fig. 434) $0.32 \mathrm{~mm}$ long, with weakly dilated distal portion and with large and proximally distinctly dilated proximal portion.

Comparative notes: Amaurodera varicollis differs from other congeners known from Sumatra particularly by the variable pronotum and by the shape of the aedeagus. The spermatheca somewhat resembles that of A. kraepelini, from which A. varicollis is distinguished by much longer and more slender antennae, longer legs, the coloration (much paler antennae and legs; yellowish maxillary palpi), a more slender head, a sexually dimorphic pronotum, an aedeagus with a much more prominent crista apicalis, and a spermatheca with an even more dilated proximal, a stouter median, and a more dilated distal portion with a larger and deeper apical cuticular invagination.

Distribution and natural history: The type locality is situated to the west of Berastagi $\left(3^{\circ} 10^{\prime} \mathrm{N}, 98^{\circ} 31^{\prime} \mathrm{E}\right)$ in Sumatera Utara, North Sumatra (Indonesia). The specimens, some of which are apparently slightly teneral, were collected at an altitude of $1450 \mathrm{~m}$.

\subsubsection{Unidentified and unnamed species}

\section{Amaurodera spec. 1}

Material examined: Thailand: 1 ㅇ, Doi Pha Hom Pok, Tad Luang waterfall, $19^{\circ} 51.785^{\prime} \mathrm{N}, 9^{\circ} 06.521^{\prime} \mathrm{E}, 1100 \mathrm{~m}$, litter along stream sifted, 27.I.2014, leg. Ob (cAss).

The above female belongs to the group of species allied to A. meorum.

\section{Amaurodera spec. 2}

Material examined: Thailand: 1 , Doi Pha Hom, Huay Nam Saw, $20^{\circ} 04^{\prime} \mathrm{N}, 99^{\circ} 11^{\prime} \mathrm{E}, 1530 \mathrm{~m}$, litter samples along stream, 23.I.2014, leg. Ob (cAss).

The above female belongs to the group of species allied to A. fasciata.

\section{Amaurodera spec. 3}

Material examined: Thailand: 1 , Nan province, Doi Phu Kha National Park, 1700 m, 6.X.1991, leg. Schwendinger (MHNG). 
The above female most likely represents an undescribed species distinguished from all other congeners known from Thailand not only by the completely different spermatheca, but also by the completely different sculpture of the pronotum (anterior fourth glossy, without pronounced microsculpture) and the chaetotaxy of the pronotum (anteriorly with an oblique row of three erect setae with granulose insertions on either side). Despite these conspicuous characters, the species remains unnamed for want of males. Doi Phu Kha National Park is situated in the extreme northeast of Thailand, not far from the border with Laos.

\section{Amaurodera spec. 4}

Material examined: Indonesia: 1 , West Sumatra, Panti, 250 m, 19.XI.1989, leg. Agosti, Löbl \& Burckhardt (MHNG).

Comment: The above female probably belongs to an undescribed species characterized by small body size, pale coloration, a relatively weakly oblong pronotum, and a minute $(0.12 \mathrm{~mm})$ spermatheca with very short and distinctly dilated distal and proximal portions of the capsule.

\subsection{Tetrabothrus BeRnhaueR, 1915}

\subsubsection{General remarks}

Including the new species described below and the newly proposed synonymies, Tetrabothrus currently includes 30 species (see checklist). The distribution of the genus ranges from the south of the East Palaearctic region (Himalaya, China, Japan) across the Oriental into the Australian region. Some of the species (T. canescens, T.neoguineensis, T.papuanus, T.pubescens, T. semialatus) are of doubtful identity, as their descriptions are based on females; a reliable identification of most Tetrabothrus species is possible only based on the morphology of the aedeagus. Several taxa are currently known only from their respective type localities. Based on available zoogeographic data, some species appear to have restricted distributions, whereas others are remarkably widespread. The latter is especially true of T. clavatus, which is distributed in most of the south of the East Palaearctic and across the Oriental regions. This species appears to be present also in the Australian region (New Guinea, Australia), but only females have been recorded so far.

\subsubsection{Checklist}

\begin{tabular}{|c|c|}
\hline Species & Distribution \\
\hline $\begin{array}{l}\text { bicolor CAMERON, } 1939 \\
=\text { chinensis PACE, 2012; syn. nov. }\end{array}$ & Burma; Vietnam; China: Shaanxi/Chongqing/Hubei \\
\hline borneensis CAMERON, 1943 & $\begin{array}{l}\text { Malaysia: Borneo: Sarawak, Sabah; Indonesia: Borneo: Kali- } \\
\text { mantan Tengah }\end{array}$ \\
\hline brevalatus Assing, 2015 & China: Yunnan \\
\hline breviatus spec. nov. & China: Sichuan \\
\hline canescens PACE, 2010 & Indonesia: Java \\
\hline cavus Assing, 2015 & China: Yunnan, Shaanxi \\
\hline $\begin{array}{l}\text { clavatus BERNHAUER, } 1915 \\
=\text { quadricollis CAMERON, 1950; syn. nov. } \\
=\text { japonicus NAKANE, 1991; syn. nov. } \\
=\text { vietnamiculus PACE, 2013; syn. nov. } \\
=\text { rubricollis AsSING, 2015; syn. nov. }\end{array}$ & $\begin{array}{l}\text { Japan; South Korea; China: Sichuan, Jiangxi, Guangdong, } \\
\text { Anhui, Guizhou, Zhejiang; Thailand; Laos; Vietnam; Malay- } \\
\text { sia: Malay Peninsula, Sarawak, Sabah; Brunei; Indonesia: } \\
\text { Sumatra, Sulawesi Utara; [Australia: Phillip Island] }\end{array}$ \\
\hline claviger (FAUVEL, 1878) & Australia: Queensland \\
\hline collucatus spec. nov. & Laos \\
\hline curtipennis Assing, 2007 & East Nepal \\
\hline femoralis PACE, 2014 & Malaysia: Sabah \\
\hline indicus Cameron, 1939 & North India: West Bengal; Sri Lanka \\
\hline inflexus Assing, 2015 & $\begin{array}{l}\text { India: Arunachal Pradesh; China: Yunnan, Hunan, Guizhou, } \\
\text { Guangxi; Thailand; Laos }\end{array}$ \\
\hline laticornis (WASMANN, 1896) & North India; Nepal \\
\hline
\end{tabular}




\begin{tabular}{|c|c|}
\hline Species & Distribution \\
\hline malaysianus PACE, 2013 & $\begin{array}{l}\text { Malaysia: Malay Peninsula, Borneo: Sabah; Indonesia: } \\
\text { Borneo: Kalimantan Tangah }\end{array}$ \\
\hline micropterus PACE, 1992 & Central Nepal \\
\hline neoguineensis PACE, 2012 & Indonesia: West Papua \\
\hline nepalensis PACE, 1992 & Nepal \\
\hline nilgiricus spec. nov. & India: Tamil Nadu \\
\hline papuanus PACE, 2000 & Papua New Guinea \\
\hline pubescens BERnHaUeR, 1915 & Indonesia: Java, [Sumatra] \\
\hline $\begin{array}{l}\text { puetzi Assing, } 2009 \\
=\text { taiwanensis PACE, 2010; syn. nov. }\end{array}$ & China: Yunnan, Guangdong; Taiwan; Laos \\
\hline punctiventris spec. nov. & Malaysia: Borneo: Sabah \\
\hline rougemonti PACE, 1998 & Hong Kong; Taiwan \\
\hline semiapterus PACE, 2010 & Taiwan \\
\hline septentrionalis Кіsнімото, 1997 & Japan: Hokkaidô, Honshû, Shikoku \\
\hline sulawesicus spec. nov. & Indonesia: Sulawesi Utara \\
\hline uttaricus Assing, 2007 & India: Uttar Pradesh \\
\hline validus Maruyama and Kishimoto, 1999 & Japan: Honshû \\
\hline xizangensis YAN \& LI, 2015 & China: Xizang \\
\hline
\end{tabular}

\subsubsection{Descriptions and additional records}

\section{Tetrabothrus septentrionalis KISHIMOTO, 1997}

Material examined: Japan: $1 \sigma^{\star}$, Honshû, Wakayama Pref., Toragamine pass, Minawegawa-mura, $590 \mathrm{~m}$, 15.VII.1999, leg. Puthz (cAss); 1 ơ, Honshû, Yamanashi Pref., Mt. Fuji, N-slope, Subatu line, 2050 m, forest, 1.VIII.1999, leg. Puthz (cAss); 1 o*, Honshû, Shizuoka Pref., Mt. Fuji, E-slope, end of Asami line, $2000 \mathrm{~m}$, 2.VIII.1999, leg. Puthz (cAss).

Comment: The distribution of this species is confined to Japan (Hokkaidô, Honshû, Shikoku) (Maruyama \& Кіsнімото 1999).

\section{Tetrabothrus nilgiricus spec. nov. (Figs 152-153, 435-436)}

Type material: Holotype $\sigma^{\top}$ [in rather poor condition; most of antennae, left hind leg and right metatarsus missing]: "S India; Tamil Nadu; Nilgiri Hills, 11 km SE Kotagiri; $1000 \pm 100 \mathrm{~m}$; $11^{\circ} 24^{\prime} \mathrm{N} 76^{\circ} 56^{\prime} \mathrm{E}$; Kunchappanai, P. Pacholátko leg.; 3.-15.v.2002 / Holotypus o Tetrabothrus nilgiricus sp. n., det. V. Assing 2015” (NHMB).

Comment: The specific epithet is an adjective derived from Nilgiri Hills, the mountain range where the type locality is situated.
Description: Small species species; body length $4.6 \mathrm{~mm}$; length of forebody $1.9 \mathrm{~mm}$. Coloration: head and pronotum dark-brown; elytra brown; abdomen dark-brown, with the apex (segments VII-X) and the posterior margins of tergites III-VI dark-reddish; legs yellowish, with the apices of the meso- and metafemora infuscate; antennomeres I-V blackish-brown (remainder of antennae missing); maxillary palpi dark-yellowish with yellowish terminal palpomere.

Head (Fig. 152) distinctly transverse, extensively impunctate along middle; punctation in lateral dorsal portions very fine and sparse. Eyes large, approximately 0.7 times as long as distance from posterior margin of eye to posterior constriction of head.

Pronotum (Fig. 152) 1.14 times as broad as long and 1.08 times as broad as head, strongly convex in crosssection; punctation very fine and sparse.

Elytra (Fig. 152) as long as pronotum; punctation very fine and sparse. Hind wings fully developed.

Abdomen (Fig. 153) narrower than elytra and with rather deep anterior impressions on tergites III-VI; tergites IIIVI with a lateral seta and two postero-lateral setae (at posterior margin) on either side, otherwise impunctate; tergite VII with three lateral setae on either side; tergite VIII with rather numerous setae at and near posterior margin; posterior margin of tergite VII with palisade fringe; posterior margin of tergite VIII weakly concave in the middle. 
$\sigma^{7}$ : median lobe of aedeagus (Figs 435-436) $0.57 \mathrm{~mm}$ long; ventral process strongly curved, apically acute and very slender; paramere $0.6 \mathrm{~mm}$ long, its apical lobe of moderate length and slender.

Comparative notes: Tetrabothrus nilgiricus is distinguished from T.indicus, its geographically closest congener, by distinctly smaller size ( $T$. indicus: length of forebody $2.0-2.4 \mathrm{~mm}$ ), darker coloration (T. indicus: head and pronotum pale-reddish to reddish-brown; elytra pale reddish with the postero-lateral portions more or less distinctly darker; antennae with at least antennomeres I-III reddish), the different punctation pattern of the pronotum (T. indicus: posterior margins of tergites III-VI each with four postero-lateral setae on either side), and by the shapes of the ventral process and of the crista apicalis of the aedeagus.

Distribution: The type locality is situated in the Nilgiri Hills, Tamil Nadu, South India. The holotype was collected at an altitude of approximately $1000 \mathrm{~m}$.

\section{Tetrabothrus laticornis (WASMANN, 1896)}

Material examined: India: 1 , Meghalaya, Tura peak, $25^{\circ} 30^{\prime} \mathrm{N}, \quad 90^{\circ} 14^{\prime} \mathrm{E}, 600-1000 \mathrm{~m}, 12 .-22 . V I .2007$, leg. Dembický (ZFMK).

Comment: Tetrabothrus laticornis has been recorded from North India and Nepal (Assing 2006d).

\section{Tetrabothrus micropterus PACE, 1992}

Type material examined: Paratype + : "Nepal: Ulleri, $83^{\circ} 14^{\prime} \mathrm{E}, \quad 28^{\circ} 21^{\prime} \mathrm{S}$ [sic; recte: $28^{\circ} 21^{\prime} \mathrm{N}$ ], $6,100 \mathrm{ft}$., 18.V.1954. Keith H. Hyatt. / Dry soil in deciduous forest. / B.M.Nepal Expdt., B.M. 1954-540. / Paratype / Paratypus Tetrabothrus micropterus m., det. R. Pace 1988 / Tetrabothrus micropterus sp. n., det. R. Pace 1988" (BMNH).

Comment: The known distribution of this species is confined to Central Nepal; it is mapped in Assing (2006d).

\section{Tetrabothrus bicolor CAMERON, 1939}

Tetrabothrus bicolor CAMERON, 1939a: 460.

Tetrabothrus chinensis PACE, 2012a: 79 f.; syn. nov.

Type material examined: T. bicolor: see Assing (2015d). T. chinensis: see Assing (2015b).

Comment: A re-examination of the type material of T. bicolor and T.chinensis revealed that both names refer to the same species; hence the synonymy proposed above. The aedeagi of the lectotype of T. bicolor and of the holotype of T. chinensis are identical (see Assing 2015d: figures 31-32 and PACE 2012a: figures 20-21). The species is currently known from three localities in Burma, North Vietnam, and China (border region between Shaanxi, Chongqing, and Hubei).

\section{Tetrabothrus puetzi Assing, 2009}

Tetrabothrus taiwanensis PACE, 2010: 24; syn. nov.

Type material examined: Holotype $\sigma^{\star}$ : “Taiwan, Taitung Hsien, Foothills of Hsinkangshan nr. Chengkung, 350-400 m, 19.VII.93, A. Smetana [T155] / Holotypus Tetrabothrus taiwanensis mihi, det. R. Pace 2005 / Tetrabothrus taiwanensis mihi, det. R. Pace 2005 / Tetrabothrus puetzi Assing, det. V. Assing 2015” (MCSNV).

Additional material examined: Laos: 1 , , Phongsaly province, Ban Sano Mai, $21^{\circ} 21^{\prime} \mathrm{N}, 102^{\circ} 03^{\prime} \mathrm{E}, 1150 \mathrm{~m}$,

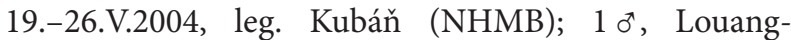
phrabang province, $5 \mathrm{~km}$ W Ban Song Cha, $1200 \mathrm{~m}$, 12.-16.V.1999, Kubáň (cAss); 2 우, Oudomxai province, $17 \mathrm{~km}$ ENE Oudom Xai, $20^{\circ} 45^{\prime} \mathrm{N}, 102^{\circ} 09^{\prime} \mathrm{E}, 1100 \mathrm{~m}$, 1.-19.V.2002, leg. Kubáň (NHMB).

Comment: Tetrabothrus puetzi was originally described from the Chinese province Yunnan and subsequently reported also from Guangdong (Assing 2009, YAN \& Li 2015b). The original description of T. taiwanensis is based on a male holotype and a male paratype from the environs of Chengkung in Taitung Hsien (PACE 2010). YAN \& LI (2015b) already suspected that T. taiwanensis was a synonym of T. puetzi. An examination of the holotype of T. taiwanensis confirmed this suspicion; hence the synonymy proposed above. The above specimens from Laos represent new country records.

\section{Tetrabothrus pubescens BERNHAUER, 1915 (Figs 154-156)}

Tetrabothrus pubescens BERNHAUER, 1915b: $241 \mathrm{f}$.

Type material examined: Syntype ${ }^{\circ}:$ "Banjoewangi, Java 1910, Mac Gillavry / Tetrabothrus pubescens Brh, Typus / Chicago NHMus, M. Bernhauer Collection / Syntypus Tetrabothrus pubescens Bernhauer, rev. V. Assing 2016" (FMNH)

Comment: The original description is based on an unspecified number of syntypes from "Java: Bajoewangi (Mac Gillavry), Preanger (P.F. Sijthoff)” (Bernhauer 1915b). The sole syntype located in the Bernhauer collection is a female and consequently not designated as 
the lectotype. The depository of the type material from Preanger is unknown.

The external characters (Figs 154-156) are practically identical to those of the holotypes of T. indicus and of T. femoralis PACE, 2014 (Borneo: Sabah). Coloration: body reddish with the elytra, except for the base, darker; antennae uniformly reddish; legs yellow with the apices of all femora black. Tergite VII without non-setiferous punctation anteriorly. Males from Java would be required for a reliable identification and for clarifying if $T$. indicus and/or T. femoralis are junior synonyms of T. pubescens. Not only the external characters, but also the lateral aspect of the median lobe of the aedeagus of T. indicus (Figs 437-439), T. rougemonti (PACE 1998: figures 211-212), T. femoralis (PACE 2014: figures 120-121), and T. inflexus (Figs 440-441) are highly similar. However, based on currently available material, these species seem to be distinguished by the ventral aspect of the ventral process of the aedeagus (broad and strongly sinuate in T. rougemonti and T. femoralis; narrow, small, and with sinuate lateral margins in T. inflexus; weakly sinuate in T. indicus). Moreover, T. inflexus is distinguished from the other species by generally darker coloration of the body and particularly by blackish-brown antennomeres IV-X (more or less uniformly reddish in T. pubescens, T. indicus, $T$. rougemonti, and T. femoralis).

Aside from Java, T. pubescens has been recorded from Java, Sumatra, and from the Philippines. However, the reference specimens from the Philippines are not conspecific with the type material (see the section on Tetrabothrus spec. 2) and no material from Sumatra has been revised. At present, T. pubescens is reliably known only from Java.

\section{Tetrabothrus indicus CAMERON, 1939 (Figs 437-439)}

Tetrabothrus indicus CAMERon, 1939a: $459 \mathrm{f}$.

Type material examined: Lectotype $\sigma^{\star}$ [dissected prior to present study], present designation: "818 / Samsingh 1800', Kalimpong, Bengal. XII.1933, Balwant Singh. / In soil under elephant dung. / R.R.D. 638 / Tetrabothrus indicus Cam, Type / M.Cameron. Bequest. B.M. 1955-147 / Tetrabothrus indicus Cam., det. R. Pace 1989, Holotypus / Lectotypus o Tetrabothrus indicus Cameron, desig. V. Assing 2015” (BMNH).

Material examined: Sri Lanka: $2 o^{\star} o^{\star}$, S Wellawaya, $300 \mathrm{~m}$, 25.I.1970, leg. Mussard, Besuchet \& Löbl (MHNG, cAss).

Comment: The original description is based on an unspecified number of syntypes from "Bengal: Kalimpong: Samsingh, alt. 1800 feet. On soil under elephant dung" (CAMERon 1939a). The sole syntype in the Cameron collection is designated as the lectotype. The two males from Sri Lanka are distinguished from the holotype by the slightly different shape of the crista apicalis of the aedeagus and by slightly darker coloration. However, since no additional distinguishing characters were found, these differences are attributed to intraspecific variation.

Confirmed records of this species are known only from West Bengal (type locality) and from Sri Lanka. The record from Thailand by PACE (2012c) most likely refers to T. inflexus.

\section{Tetrabothrus inflexus Assing, 2015 (Figs 440-441)}

Material examined: India: $1 \sigma^{\star}$, Arunachal Pradesh, Dirang env., $27^{\circ} 21^{\prime} \mathrm{N}, 92^{\circ} 13^{\prime} \mathrm{E}$, ca. $1800 \mathrm{~m}, 8 .-22 . V .2006$, leg. Pacholátko (BMNH); Thailand: 1 \% NW-Thailand, $23 \mathrm{~km}$ SE Pai, W Mae Hong Son, 10.-20.V.2006, leg. Grimm (SMNS); 1 , , NE Bangkok, Khao Yai National Park, Khao Khieo, 1150 m, 28.XUI.1985, leg. Burckhardt \& Löbl (cAss); 2 ` o , 1 우, Chiang Mai, Doi Suthep, $1180 \mathrm{~m}$, pitfall traps, VII.1986, leg. Schwendinger (MHNG, cAss); 1 ㅇ, Chiang Mai, 54 km NE Chiang Mai, Mae Nang Kaeo, 900 m, 3.XI.1985, leg. Burckhardt \& Löbl (MHNG); 6 exs., Tak Province, Umphang District, Mae Chan/Mae Klong confluence, Thung Yai Wildlife Sanctuary, $15^{\circ} 30^{\prime} \mathrm{N}, 98^{\circ} 48^{\prime} \mathrm{E}, 300$ m, 27.IV.-6.V.1988, leg. Brendell (BMNH, cAss); 9 exs., Tak Province, Umphang District, Song Bae stream, Thung Yai Wildlife Sanctuary, $15^{\circ} 28^{\prime} \mathrm{N}, 98^{\circ} 48^{\prime} \mathrm{E}, 300 \mathrm{~m}, 18 .-27 . I V .1988$, leg. Brendell (BMNH, cAss). Laos: 1 , Houa Phan province, Phou Pane mountain, $20^{\circ} 13^{\prime} \mathrm{N}, 104^{\circ} 00^{\prime} \mathrm{E}, 1480-1510 \mathrm{~m}$, 22.IV.14.V.2008, leg. Kubáň (NMP); 11 exs., Louangphrabang, Thong Khan, $19^{\circ} 35^{\prime} \mathrm{N}, 101^{\circ} 58^{\prime} \mathrm{E}, 750 \mathrm{~m}, 11 .-21 . V .2002$, leg. Kubáň (NHMB, cAss); 1 ㅇ, Bolikhamxai prov., 8 km Ban Nape, $18^{\circ} 21^{\prime} \mathrm{N}, 105^{\circ} 08^{\prime} \mathrm{E}, 600$ m, 1.-18.V.2002, leg. Kubáň (NHMB).

Comment: Tetrabothrus inflexus was previously known only from the Chinese provinces Yunnan, Guizhou, Hunan, and Guangxi (Assing 2015b, YAN \& Li 2015b). The above material represents the first records from India, Thailand, and Laos. The aedeagus of a male from Laos is illustrated in Figs 440-441.

\section{Tetrabothrus rougemonti PACE, 1998}

Tetrabothrus rougemonti PACE, 1998: $961 \mathrm{ff}$.

Type material examined: Holotype $\sigma^{*}$ : "Hong Kong, Tai Po V.1996, G. de Rougemont / Holotypus Tetrabothrus rougemonti m., det. R. Pace 1996 / Tetrabothrus rougemonti sp. n., det. R. Pace 1996" (MHNG).

Comment: The original description of T. rougemonti is based on a male holotype and a female paratype from Hong Kong (PACE 1998). The holotype was examined in order to investigate the status of T. inflexus, whose aedea- 
gus is similar to that of T. rougemonti. The comparison revealed no differences in coloration or other external characters. The aedeagi of all the males of T. inflexus examined thus far, however, are constantly distinguished from that of the holotype of T. rougemonti by a more strongly bent, apically longer (lateral view), and more slender (ventral view) ventral process (Figs 440-441). Nevertheless, the possibility that specimens with an aedeagus of intermediate conditions may be found and that the observed differences may eventually have to be interpreted as intraspecific variation cannot be ruled out with certainty.

\section{Tetrabothrus malaysianus PACE, 2013}

Tetrabothrus malaysianus PACE, 2013: $50 \mathrm{f}$

Material examined: Malaysia: $1 \delta^{*}$, Borneo, Sabah, Danum Valley, $4^{\circ} 58^{\prime} \mathrm{N}, 117^{\circ} 47^{\prime} \mathrm{E}$, flight interception trap, VI.1999, leg. Mendel (BMNH). Indonesia: 25 exs., Borneo, Kalimantan Tengah, confluence of Busang and Rekut, $0^{\circ} 03^{\prime} \mathrm{S}, 113^{\circ} 59^{\prime} \mathrm{E}$, flight interception trap, VIII.2001, leg. Brendell (BMNH, cAss).

Comment: The original description is based on a unique male from "Malaysia, Hulu Perak, Bangunan, Camp c/o Kampung Semelor, E shore Lake Tasek-Temengor, $230 \mathrm{~m}$ " (PACE 2013). The aedeagus of the above material is in agreement with that illustrated by PACE (2013). It somewhat resembles that of T. clavatus in lateral view, from which T. malaysianus is readily distinguished by much darker coloration of the body, the coloration of the legs (yellowish with infuscate femoral apices), much darker antennae, a differently shaped pronotum, the presence of non-setiferous punctation in the anterior portion of tergite VII, the almost acutely pointed posterior margin of the male sternite VIII, and by the shape of the median lobe of aedeagus (particularly in ventral view).

The above material represents the first records since the original description, the first records from Borneo, and (specimens from Kalimantan Tengah) the first record from Indonesia.

\section{Tetrabothrus breviatus spec. nov.}

(Figs 472-475)

Type material: Holotype $0^{\star}$ : "China: Sichuan Prov., Baoxing, 12.VI.2014, Wenxian Shan Park, above Panda Pavilon, $1200 \mathrm{~m}, 30^{\circ} 22^{\prime} 12^{\prime \prime} \mathrm{N} 102^{\circ} 48^{\prime} 57^{\prime \prime} \mathrm{E}$, / sift \#14, mixed forest with Pinus, broadleaved trees; trunk bases, debris below small rock, J. Hájek \& J. Růžička leg. / Holotypus o Tetrabothrus breviatus sp. n., det. V. Assing 2015” (NMP).
Comment: The specific epithet is the past participle of the Latin verb breviare (to shorten) and alludes to the short elytra.

Description: Body length $6.0 \mathrm{~mm}$; length of forebody $2.3 \mathrm{~mm}$. Coloration: head blackish-brown; pronotum and elytra dark-brown, with the humeral portions of the elytra paler; abdomen blackish-brown, with the posterior margins of segments III-VI and the apex (segments VII-X) dark-reddish; legs dark-yellowish, with the apices of the metafemora and the metatibiae brown; antennae dark-brown with blackish antennomere I; maxillary palpi yellowish-red.

Head (Fig. 472) moderately transverse, 1.17 times as broad as long, small in relation to pronotum and remainder of body, extensively impunctate in the middle; punctation in lateral dorsal portions fine and moderately sparse. Eyes shorter than distance from posterior margin of eye to posterior constriction of head. Antenna $1.4 \mathrm{~mm}$ long.

Pronotum (Fig. 472) weakly transverse, 1.06 times as broad as long and 1.15 times as broad as head, moderately convex in cross-section; punctation very fine and moderately dense in lateral portions; midline broadly impunctate; pubescence long and semi-erect.

Elytra (Fig. 472) short, approximately 0.75 times as long as pronotum; punctation fine and moderately dense; pubescence long and semi-erect. Hind wings not examined, possibly reduced. Metatarsomere I slightly longer than the combined length of metatarsomeres II and III. Abdomen (Fig. 473) as broad as elytra and with rather deep anterior impressions on tergites III-VI; tergites IIIVI with a lateral seta and one or two marginal setae on either side, otherwise impunctate; tergite VII with a transverse series of six setae posteriorly (but directly at posterior margin); tergite VIII with numerous setae at and near posterior margin; posterior margin of tergite VII with a weakly pronounced palisade fringe; posterior margin of tergite VIII weakly convex.

$\sigma^{*}$ : median lobe of aedeagus (Figs 474-475) $0.61 \mathrm{~mm}$ long; ventral process relatively long, weakly curved in lateral view, relatively slender in ventral view, and with long and acute apex.

Comparative notes: Tetrabothrus breviatus is distinguished from all of its congeners by the shape of the median lobe aedeagus (particularly the shape of the ventral process), from most of them also by its rather short elytra and the weakly pronounced palisade fringe at the posterior margin of tergite VII. It additionally differs from Tetrabothrus species with similarly short elytra as follows:

- from T. micropterus (Nepal) by a relatively smaller and less transverse head, much darker coloration (T. micropterous: body yellowish-red), and by the uniformly yellowish pro- and mesofemora (apically infuscate in T. micropterus); 


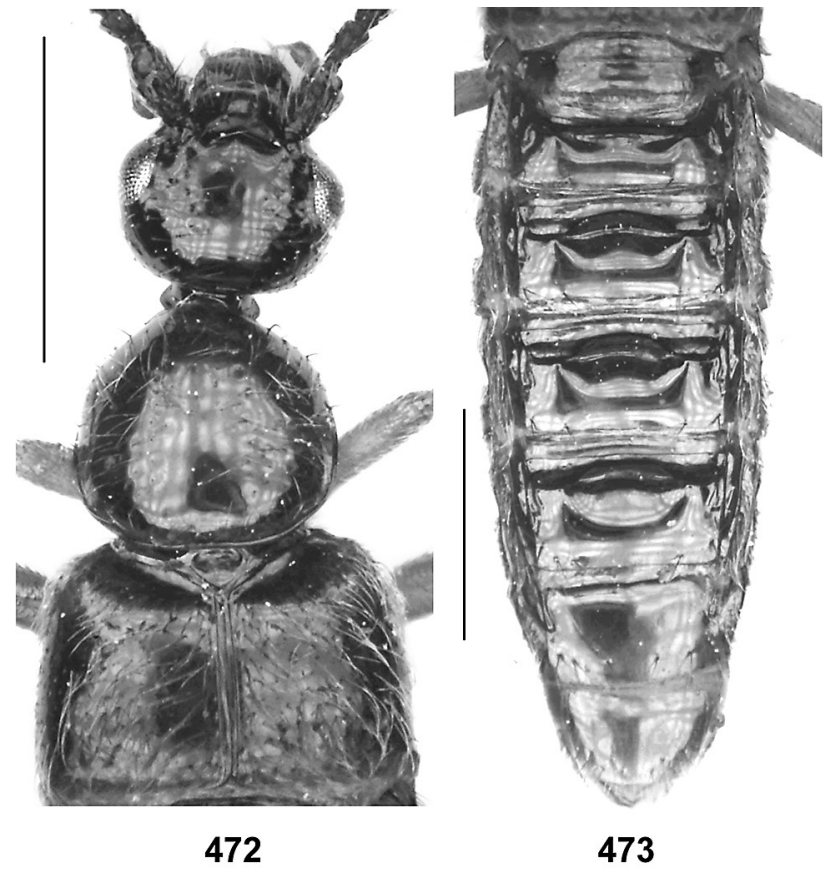

Figs 472-475. Tetrabothrus breviatus: forebody (472); abdomen view (474-475). Scale bars: 472-473: $1.0 \mathrm{~mm}$; 474-475: $0.2 \mathrm{~mm}$.

- from T. curtipennis (Nepal) by the coloration (T. curtipennis: antennae reddish; all femora yellowish with distinctly infuscate apices; metatibiae pale yellowish), a more slender body, a relatively much smaller and much less transverse head, and denser punctation of the pronotum;

- from T. brevalatus (China: Yunnan) by a relatively smaller and less transverse head, much paler coloration of the femora (T. brevalatus: femora dark-reddish), a distinctly more convex (cross-section) and less transverse pronotum, and slightly longer elytra;

- from T. semiapterus (Taiwan; male unknown) by a relatively smaller and less transverse head, a broader pronotum, the darker coloration of the antennae (reddish in T. semiapterus), darker metatibiae, and more distinct punctation of the forebody.

Distribution and natural history: The type locality is situated some $120 \mathrm{~km}$ to the west of Chengdu, Sichuan (China). The holotype was sifted in a mixed forest from around trunk bases or from debris below a small rock at an altitude of $1200 \mathrm{~m}$.

\section{Tetrabothrus collucatus spec. nov.} (Figs 157-158, 442-443)

Type material: Holotype $0^{\top}:$ "Laos-N (Louangphrabang),

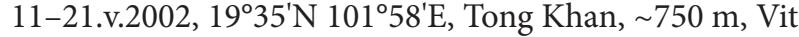
Kubán leg. / Holotypus ơ Tetrabothrus collucatus sp. n., det. V. Assing 2015" (NHMB).

Paratypes: $10^{\star}, 3$ 우 온 same data as holotype (NHMB, cAss).
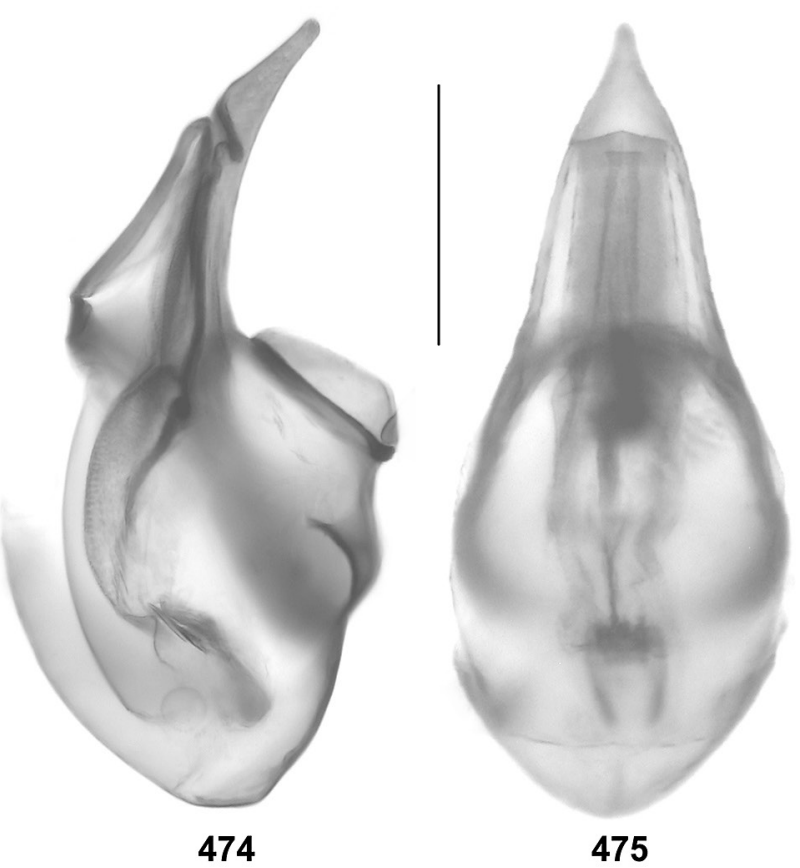

(473); median lobe of aedeagus in lateral and in ventral

Comment: The specific epithet is the past participle of the Latin verb collucare (to shorten, to clip) and alludes to the short apex of the ventral process of the aedeagus.

Description: Body length $4.8-5.9 \mathrm{~mm}$; length of forebody 2.1-2.5 mm. Coloration: body blackish-brown with the posterior margins of the abdominal segments darkreddish; legs with the profemora and the apical third of the meso- and metafemora dark-brown to blackish, the basal portions of the meso- and metafemora yellowish, the tibia pale-brown to dark-brown, and the tarsi dark-yellowish to pale-brown; antennae blackish with antennomeres I-III and XI brown to dark-brown; maxillary palpi yellowish-red.

Head (Fig. 157) strongly transverse, 1.30-1.35 times as broad as long, extensively impunctate in the middle; punctation in lateral dorsal portions very fine and sparse. Eyes large, approximately as long as distance from posterior margin of eye to posterior constriction of head, or nearly so. Antenna (Fig. 158) 1.2-1.3 mm long.

Pronotum (Fig. 157) approximately 1.15 times as broad as long and approximately 1.12 times as broad as head, strongly convex in cross-section; punctation very fine and sparse.

Elytra (Fig. 157) approximately 0.9 times as long as pronotum; punctation very fine and sparse. Hind wings fully developed. Metatarsomere slightly longer than the combined length of metatarsomeres II and III.

Abdomen slightly narrower than elytra and with rather deep anterior impressions on tergites III-VI; tergites IIIVI with a lateral seta and two fine and rather short postero-lateral setae (at posterior margin) on either side, otherwise impunctate; tergite VII with two lateral setae on either side; tergite VIII with numerous setae at and 
near posterior margin; posterior margin of tergite VII with palisade fringe; posterior margin of tergite VIII truncate.

$0^{7}$ : median lobe of aedeagus (Figs 442-443) approximately $0.5 \mathrm{~mm}$ long; ventral process weakly curved in lateral view, broad in ventral view, and with short apex; paramere slightly longer than median lobe, its apical lobe of moderate length and somewhat conical.

Comparative notes: Tetrabothrus collucatus differs from all its geographically close congeners of similar coloration particularly by the distinctive shape of the ventral process of the aedeagus.

Distribution: The type locality is situated to the southwest of Luang Prabang in North Laos at an altitude of approximately $750 \mathrm{~m}$.

\section{Tetrabothrus clavatus BERNHAUER, 1915 (Map 2)}

Tetrabothrus clavatus BerNHAUER, 1915b: 242.

Tetrabothrus quadricollis CAMERON, 1950: 118 f.; syn. nov.

Tetrabothrus japonicus NaKane, 1991: 111 f.; syn. nov.

Tetrabothrus vietnamiculus PACE, 2013: 375; syn. nov.

Tetrabothrus rubricollis Assing, 2015: 138 ff.; syn. nov.

Type material examined: T. clavatus: Holotype $q$ : "Sumatra, Manna, M. Knappert / Tetrabothrus clavatus Brnh., Typus unic. / Chicago NHMus, M. Bernhauer Collection / Holotypus Tetrabothrus clavatus Bernhauer, rev. V. Assing 2016 / Tetrabothrus clavatus Bernhauer, det. V. Assing 2016" (FMNH).

T. quadricollis: Holotype o: "Malaya, Kuala Lumpur, at light, Jan: 27th, 1936. H. M. Pendlebury. / Ex Coll. F.M.S. Museum [overleaf] / T. quadricollis Cam. Type / M. Cameron. Bequest. B.M. 1955-147 / Syntype / Type / Holotypus Tetrabothrus quadricollis Cameron, rev. V. Assing 2015 / Tetrabothrus clavatus Bernhauer, det. V. Assing 2016" (BMNH).

Paratype o: "Malaya, Kuala Lumpur, at light, April 27th, 1932. H. M. Pendlebury. / Ex Coll. F.M.S. Museum [overleaf] / M. Cameron. Bequest. B.M. 1955-147 / Syntype / Syntype Tetrabothrus quadricollis Cam., det. R.G. Booth 2015 / Paratypus Tetrabothrus quadricollis Cameron, rev. V. Assing 2015” (BMNH).

Additional material examined: China: 1 ex., Jiangxi, Jinggang Shan, Luofu, $26^{\circ} 40^{\prime} \mathrm{N}, 114^{\circ} 14^{\prime} \mathrm{E}, 310 \mathrm{~m}$, at light, 25+27.IV.2011, leg. Fikáček \& Hájek (NMP); 1 ex., Guangdong, W Qixing, Heishiding nature reserve, $23^{\circ} 28^{\prime} \mathrm{N}, 111^{\circ} 54^{\prime} \mathrm{E}, 190 \mathrm{~m}$, forested stream valley, at light, 1.-3.V.2011, leg. Fikáček \& Hájek (cAss). Thailand: $1 \sigma^{\star}$, Chanthaburi, Khao Sabap National Park, 150-300 m, 23.-24.XI.1985, leg. Burckhardt \& Löbl (MHNG); 1 ex., Fang, $19^{\circ} 55^{\prime} \mathrm{N}$, $99^{\circ} 12^{\prime} \mathrm{E}, 300 \mathrm{~m}$, leg. Král (NHMB). Laos: $10^{\top}, 1$ ex., Boli Kham Xai province, $8 \mathrm{~km}$ NE Ban Nape, $18^{\circ} 21^{\prime} \mathrm{N}, 105^{\circ} 08^{\prime} \mathrm{E}, 600 \mathrm{~m}, 1 .-18 . V .2001$, leg. Pacholátko
(NHMB, cAss); $10^{*}$, Vientiane province, Vang-Vieng, $19^{\circ} 55^{\prime} \mathrm{N}, 102^{\circ} 26^{\prime} \mathrm{E}, 300$ m, V.-VI.200 [sic], leg. Kolibác (cAss). Malaysia: $10^{\star}$, Sarawak (Borneo), 4th division, Gn. Mulu National Park, V-VIII.1978, leg. Hammond \& Marshall (BMNH); $10^{\star}, 2$ 우, Sabah, $10 \mathrm{~km} \mathrm{SSE}$ Telupid, Karamuak river, at light, 1.-7.IX.1977, leg. Bacchus (BMNH); 1 o $^{*}$ Sabah, Mt. Kinabalu National Park, $7500 \mathrm{ft}$, at light, 20.VIII.1982, leg. Stork (cAss); $10^{\star}$, Sabah, Sandakan-Keningau road, 250 ft, 19.X.1977, leg. Bacchus (cAss). Indonesia: $10^{\star}$, Sulawesi Utara, Dumoga-Bone National Park, 220 m, light trap, II.1985, leg. Barlow (BMNH); 1 ㅇ, same data, but 200 m, III.1985 $(\mathrm{BMNH})$. Brunei: $10^{*}, 1$ \% , Lamunin, Bukit Sulang, $4^{\circ} 38^{\prime} \mathrm{N}, 114^{\circ} 45^{\prime} \mathrm{E}, 6$.VIII.-12.IX.1982, leg. Stork (BMNH). Identification doubtful: 1 우, Australia, Phillip Island, leg. Semper (BMNH).

Comment: Tetrabothrus clavatus was described from a unique holotype "Ein einziges Stück" from "Sumatra: Manna" (Bernhauer 1915b). The specimen, a female, was located in the Bernhauer collection at the FMNH. The original description of T. quadricollis is based on type material from "Kuala Lumpur. At light". In stating "Type in my collection", CAMERoN (1950) designated a holotype. Only one of the two type specimens in the Cameron collection has Cameron's type label attached to it; this specimen, a female, consequently is the holotype, whereas the other, a male, is a paratype. In external characters, particularly the distinctive shape of the pronotum, the punctation pattern of the abdomen, and the coloration, type material of T. clavatus and T. quadricollis are identical, suggesting that they belong to the same widespread species, of which T. clavatus is the senior name. The aedeagus of the paratype of T. quadricollis is identical to that of T.japonicus, which was described from a male holotype and a male paratype from Kyushu, Japan (NAKANE 1991), and subsequently revised and illustrated by Maruyama \& Кishimoto (1999). Thus, T. japonicus, together with its junior synonym T. vietnamiculus PACE, 2013 (Assing 2015d), is placed in synonymy with the senior name T. clavatus. As can be inferred from the details indicated in the original description of T. canescens PACE, 2010, which is based on a unique female from Java deposited in the natural history museum in Genova, this name too may be a synonym of T. clavatus, just like T. neoguineensis PACE, 2012 from New Guinea (see comment in the section on T. neoguineensis).

An examination of material of T. clavatus from various regions revealed some intraspecific variation of the characters emphasized by Assing (2015b) as distinguishing T. rubricollis from T. japonicus (i.e., T. clavatus). A re-examination of the female holotype of T. rubricollis revealed that, in external characters, it is within the range of intraspecific variation of T. clavatus, suggesting that both names are synonymous.

Tetrabothrus clavatus is the most widespread species of the genus, its distribution ranging from Japan (Honshû, 
Shikoku, Kyûshû, Ryukyu Islands) to South Korea, China, Thailand, Vietnam, Malaysia, and Indonesia (material examined and Assing 2015d, Hlaváč et al. 2011, Maryuama \& Кishimoto 1999), possibly even to Australia (Map 2). In China, it was previously known from Anhui, Guizhou, and Zhejiang provinces (YAN \& Li 2015b). YAN \& Li (2015b) also indicate Fujian prov- ince, but do not indicate any primary records from there. The above specimens from Laos represent a new country record, those from Sarawak, Sabah, and Brunei the first records from Borneo.

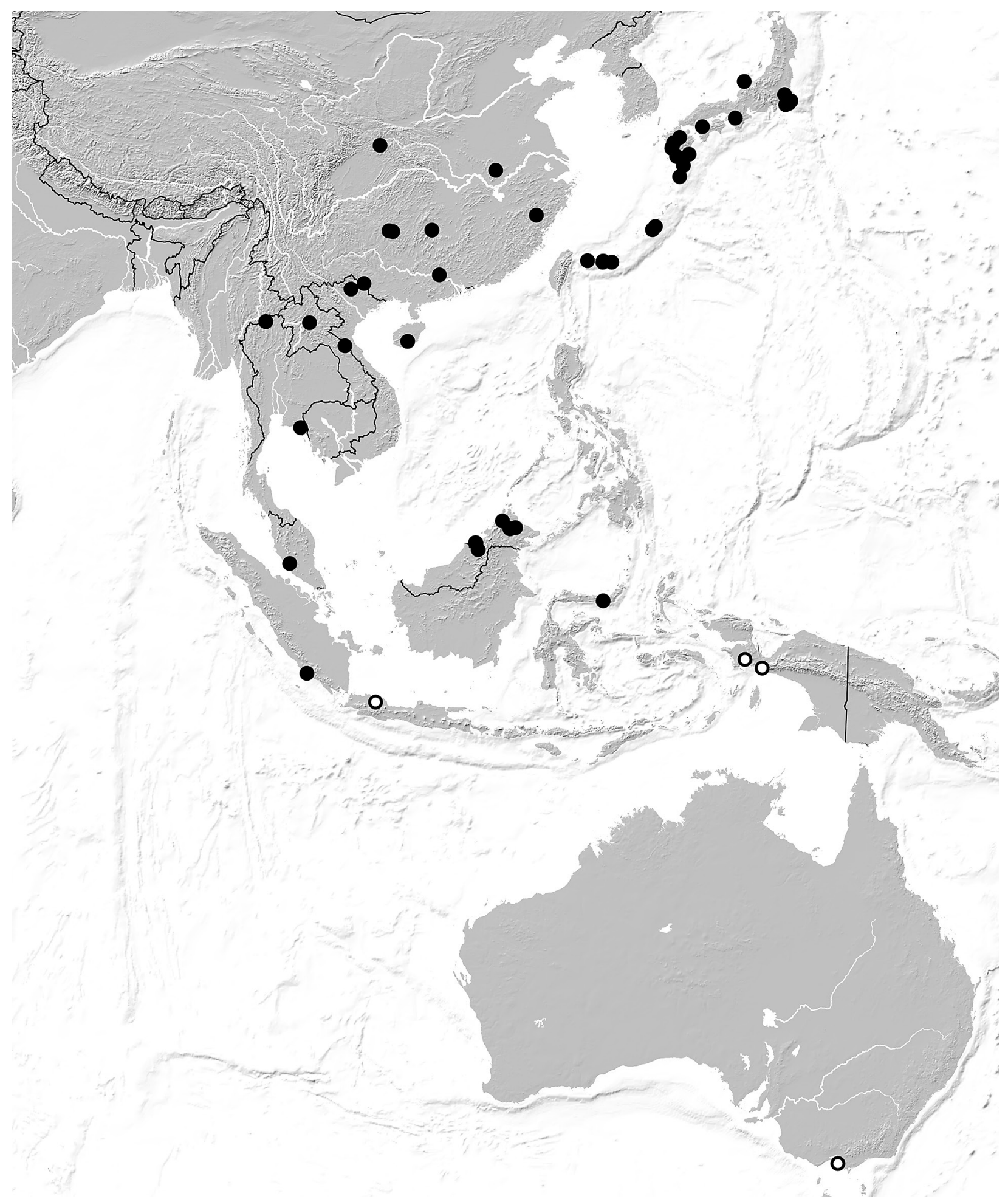

Map 2: Distribution of Tetrabothrus clavatus based on revised material and reliable literature records taken from MARYUAMA \& Kisнiмото (1999) and YAn \& Li (2015b) (filled circles), as well as on a female-based record from Australia and localities of suspected synonyms (T. canescens, T. neoguineensis) (open circles). 
Tetrabothrus neoguineensis PACE, 2012

(Fig. 159, Map 2)

Tetrabothrus neoguineensis PACE, 2012c: 337.

Type material examined: Holotype ${ }^{\circ}$ : "Indonesia

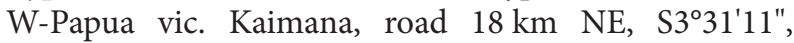
E133ํํ'15", 50-80 m, 21.-25.II.2011 leg. A. Skale (014) / Holotypus Tetrabothrus neoguineensis mihi, det. R. Pace 2011 / Tetrabothrus neoguineensis n. sp., det. R. Pace 2011" (NME).

Paratype ㅇ: "Indonesia W-Papua $130 \mathrm{~km}$ SE Kaimana, Omba (=Yamor) river, $10-20 \mathrm{~km}$ from coast, $\mathrm{S}^{\circ} 05^{\prime} 49^{\prime \prime}$, E13454'09", 10-20 m, 9.-11.II.2011 leg. A. Skale (008) / Paratypus Tetrabothrus neoguineensis mihi, det. R. Pace 2011 / Tetrabothrus neoguineensis n. sp., det. R. Pace 2011" (NME).

Comment: The original description is based two females from West Papua (PACE 2012c); the localities are shown in Map 2. The status of this species is highly doubtful. An examination of the type specimens revealed that they are highly similar to T. clavatus and distinguished only by the darker coloration of the pronotum and the antennae. The holotype is illustrated in Fig. 159. However, males from New Guinea would be needed to confirm that they are indeed conspecific with T. clavatus.

Tetrabothrus borneensis CAMERON, 1943

(Figs 160-162, 444-449)

Tetrabothrus borneensis CAMERon, 1943: 140.

Type material examined: Holotype + : “Mt Poi, 5000' / TeT. borneensis Cam. Type / M. Cameron. Bequest. 1955147 / Holotype / Holotype Tetrabothrus borneensis Cam., det. R.G. Booth 2015" (BMNH)

Additional material examined: Malaysia: $1 \sigma^{\top}$ [teneral], Borneo, Sabah, Sandakan, S Lokan, flight interception trap, III.1997, leg. Chung (BMNH); 9 exs., Sabah, Sandakan, Sepilok, X.1996, leg. Chung (BMNH, cAss); 2 exs., same data, but III.1997 (BMNH). Indonesia: 9 exs., Borneo, Kalimantan Tengah, confluence of Busang and Rekut, $0^{\circ} 03^{\prime} \mathrm{S}, 113^{\circ} 59^{\prime} \mathrm{E}$, flight interception trap, VIII.2001, leg. Brendell \& Mendel (BMNH, cAss).

Comment: The original description is based on a unique type specimen from "Mt. Poi [= Mount Pueh; $\left.1^{\circ} 48^{\prime} \mathrm{N}, 109^{\circ} 41^{\prime} \mathrm{E}\right]$, altitude 5,000 ft." (CAMERoN 1943). A dissection of the holotype revealed that it is a female. Remarkably, when distinguishing Tetrabothrus femoralis from T. borneensis, PACE (2014) states that the "aedeagus of this new species is more similar to that of T. indicus CAMERon, 1939 from Bengal, than to that of T. borneensis CAMEron, 1943 from Borneo, of which I have seen specimens of the type series", although there appears to be only a single (undissected) female type specimen.

Redescription: Species of variable size; body length 4.3-5.8 mm; length of forebody $1.8-2.4 \mathrm{~mm}$. Coloration variable: body reddish to blackish-brown; elytra usually at least indistinctly bicoloured with the anterior portion paler than the posterior portion; legs pale-reddish to brown; antennae blackish-brown with reddish antennomeres I-III.

Head (Fig. 160) strongly transverse, distinctly narrowed behind eyes, extensively impunctate in the middle; punctation in lateral dorsal portions very fine and sparse. Eyes large and bulging, approximately three times as long as postocular region in dorsal view, or nearly so. Antenna (Fig. 161) 1.0-1.3 mm long.

Pronotum (Fig. 160) of somewhat variable shape, 1.121.17 times as broad as long and 1.05-1.17 times as broad as head, strongly convex in cross-section; punctation very fine and of variable density.

Elytra (Fig. 160) approximately 0.9 times as long as pronotum; punctation very fine and rather dense; pubescence long and suberect. Hind wings fully developed. Metatarsomere approximately as long as the combined length of metatarsomeres II and III.

Abdomen (Fig. 162) narrower than elytra and with moderately deep anterior impressions on tergites III-VI; tergite III with two, tergites IV-VI with four setiferous punctures at posterior margin; tergite VII without nonsetiferous punctation and with pronounced palisade fringe at posterior margin; tergite VIII with numerous setae at and near posterior margin; posterior margin of tergite VII with palisade fringe; posterior margin of tergite VIII truncate.

$\sigma^{\star}$ : posterior margin of sternite VIII nearly truncate in the middle (Fig. 449); median lobe of aedeagus (Figs 444-448) of variable size, $0.43-0.55 \mathrm{~mm}$ long; ventral process rather short, its shape not very distinctive and somewhat variable; paramere longer than median lobe, its apical lobe of moderate length.

Intraspecific variation: This species is subject to pronounced intraspecific variation of size, coloration, shape of pronotum, size of the median lobe of the aedeagus, and the shape of the ventral process of the aedeagus. In the material from Sabah, the size of the median lobe of the aedeagus ranges from 0.48 to $0.55 \mathrm{~mm}$ and the apex of the ventral process tends to be longer and more slender in lateral view, whereas in the males from Kalimantan Tengah the length of the median lobe ranges from 0.43 to $0.47 \mathrm{~mm}$ and the apex of the ventral process tends to be shorter. The holotype differs from the examined nontype material by paler coloration, sparse punctation of the pronotum, and slightly greater body size.

Comparative notes: Tetrabothrus borneensis is not very distinctive regarding its external characters and characterized particularly by the shape of median lobe of the 
aedeagus. The aedeagus somewhat resembles that of T. puetzi (China, Taiwan), from which T. borneensis is readily distinguished by much paler legs with undilated femora alone.

Distribution and natural history: The examined material was collected in four localities in Borneo, one in Sarawak (type locality), two in Sabah (Malaysia), and one in Kalimantan Tengah (Indonesia). The species was doubtfully recorded from the Danum Valley (Sabah) based on three females by PACE (2014). The examined non-type material was collected with flight interception traps. One specimen collected in March is teneral.

\section{Tetrabothrus punctiventris spec. nov.}

(Figs 163-166)

Type material: Holotype $\sigma^{\top}$ [teneral]: "Sabah, Mt. Kinabalu, 1550-1650 m, 24.IV.1987, Burckhardt-Löbl / Holotypus o Tetrabothrus punctiventris sp. n., det. V. Assing 2016" (MHNG).

Comment: The specific epithet (adjective) alludes to the dense and distinctive non-setiferous punctation on tergites VII and VIII.

Description: Body length $5.4 \mathrm{~mm}$; length of forebody $2.2 \mathrm{~mm}$. Coloration: body pale-brown, with the posterior margins of the abdominal segments yellowish; legs pale-yellowish; antennae bicoloured, with antennomeres IV-VIII dark-brown, I-III yellowish, and IX-XI dark-yellowish; maxillary palpi yellowish.

Head (Fig. 163) strongly transverse, 1.3 times as broad as long, with weakly marked posterior angles, extensively impunctate in the middle; punctation in lateral dorsal portions fine and rather dense. Eyes large, approximately as long as distance from posterior margin of eye to posterior constriction of head. Antenna (Fig. 164) $1.4 \mathrm{~mm}$ long.

Pronotum (Fig. 163) 1.15 times as broad as long and 1.08 times as broad as head, somewhat flattened in postero-median portion of disc; punctation fine and rather dense, except along the impunctate midline; pubescence long and depressed to suberect.

Elytra (Fig. 163) long, approximately 1.1 times as long as pronotum; punctation fine and rather dense. Hind wings fully developed. Metatarsomere as long as the combined length of metatarsomeres II and III.

Abdomen (Fig. 165) narrower than elytra and with deep anterior impressions on tergites III-VI; tergites III-VI each with four setiferous punctures at posterior margins; tergite VII (Fig. 166) with coarse and moderately dense non-setiferous punctation in anterior three-fourths, posterior margin with palisade fringe; tergite VIII with very dense and moderately coarse non-setiferous punctation in anterior three-fourths (much denser and less coarse than that of tergite VII), posteriorly with a pair of setiferous punctures.

$\sigma^{*}$ : posterior margin of sternite VIII produced, broadly truncate in the middle; median lobe of aedeagus (Fig. 450-451) $0.53 \mathrm{~mm}$ long, with pronounced crista apicalis; ventral process subapically angled in lateral view; paramere nearly $0.7 \mathrm{~mm}$ long, its apical lobe of moderate length and somewhat conical.

Comparative notes: Tetrabothrus punctiventris is distinguished from its congeners particularly by the dense and extensive non-setiferous punctation of tergites VII and VIII, the medially depressed pronotum, the coloration of the antennae, as well as by the shape of the aedeagus, above all the pronounced crista apicalis. It additionally differs from T. malaysianus, the only other species with non-setiferous punctation on tergite VII known from Borneo, by the uniformly yellowish legs, the much paler coloration of the body, and the medially truncate posterior margin of the male sternite VIII.

Distribution and natural history: The type locality is situated in northern Borneo (Malaysia: Sabah). The slightly teneral holotype was collected at an altitude of 1550-1650 m, probably by sifting.

\section{Tetrabothrus sulawesicus spec. nov. (Figs 167-169, 342-454)}

Type material: Holotype ơ: "Indonesia: Sulawesi-Utara, Dumoga-Bone N.P., November 1985 / Plot A, ca 200 m, Lowland forest / Flight interception trap / R. Ent. Soc. Lond., Project Wallace, B.M. 1985-17 / Holotypus o Tetrabothrus sulawesicus sp. n., det. V. Assing 2016" (BMNH).

Paratypes: 1 ㅇ: same data as holotype (cAss); $10^{\text {`: }}$ same data, but "October 1985" (BMNH); 1 : : same data, but "24 Februar 1985" (BMNH); $10^{*}, 1$ o : same data, but “April 1985 / Plot B, ca 300 m” (BMNH, cAss).

Comment: The specific epithet (adjective) is derived from Sulawesi, the Indonesian island where the species was discovered.

Description: Body length 4.5-6.0 mm; length of forebody 1.9-2.5 mm. Coloration: head and pronotum variable, bright-reddish to blackish-brown; elytra blackish-brown; abdomen variable, reddish to black; legs bicoloured: femora pale yellowish with the apices - especially those of the metafemora rather broadly - brown to blackishbrown, tibiae and tarsi brown; antennae black with antennomeres I-III and at least the apex of XI reddish; maxillary palpi yellowish.

Head (Fig. 167) strongly transverse, 1.25-1.30 times as broad as long; posterior angles obsolete; punctation extremely fine and moderately dense, except along the impunctate middle of the dorsal surface; pubescence long 
and pale. Eyes large, approximately as long as distance from posterior margin of eye to posterior constriction of head. Antenna (Fig. 168) 1.2-1.3 mm long.

Pronotum (Fig. 167) weakly transverse, 1.06-1.15 times as broad as long and 1.02-1.08 times as broad as head, strongly convex in cross-section; punctation fine and moderately dense; pubescence pale, long, and suberect. Elytra (Fig. 167) 0.85-0.90 times as long as pronotum; punctation denser and less fine than that of pronotum; pubescence very long and suberect. Hind wings fully developed. Metatarsomere as long as the combined length of metatarsomeres II and III.

Abdomen (Fig. 169) narrower than elytra and with moderately deep anterior impressions on tergites IIIVI; tergites III-VII each with four setiferous punctures at posterior margins; tergite VII without non-setiferous punctation, posterior margin with palisade fringe; tergite VIII with dense fine setiferous punctures near anterior margin, otherwise impunctate.

$\sigma^{*}$ : posterior margin of sternite VIII strongly produced, convexly pointed in the middle (Fig. 454); median lobe of aedeagus (Figs 452-453) 0.53-0.58 mm long; ventral process subapically weakly curved in lateral view and rather narrow in ventral view; paramere nearly $0.6 \mathrm{~mm}$ long, its apical lobe of moderate length and slender.

Comparative notes: Tetrabothrus sulawesicus is reliably distinguished from other congeners with bicoloured legs and without non-setiferous punctation on tergite VII (and VIII) only by the shape of the median lobe of the aedeagus, from most species also by the more strongly pointed posterior margin of the male sternite VIII. It additionally differs from T. clavatus, the only other representative of the genus recorded from Sulawesi, by smaller and less bulging eyes, bicoloured legs, and darker antennomeres IV-IX.

Distribution and natural history: The type locality, today Bogani Nani Wartabone National Park, is situated on Minahassa Peninsula in the north of Sulawesi, Indonesia. The specimens were collected with flight interception traps in lowland forests at altitudes of 200 and $300 \mathrm{~m}$.

\subsubsection{Unidentified and unnamed species}

\section{Tetrabothrus spec. 1}

Material examined: Malaysia: 1 \%: "F.C. Drescher, G. Tangkoeban Prahoe, 4000-5000 Voet, Preanger, Java, V.1933" (BMNH); 1 \% : same data, but "XI.1934".

Comment: The above females are distinguished from T. pubescens by distinctly larger body size, smaller eyes, a more transverse pronotum, and less distinctly bicoloured legs.

\section{Tetrabothrus spec. 2}

Material examined: Philippines: 1 ㅇ, Luzon, Mt. Makiling, leg. Baker (FMNH); 1 क [teneral], Mindoro, Subaan, leg. Staudinger (FMNH).

Comment: The above specimens were standing as T. pubescens in the BERNHAUER collection at the FMNH. However, they most likely belong to a different species; they have the tibiae brown and the apices of the femora more extensively infuscate than the examined syntype.

\subsection{Genus Zyras StePhens, 1835, subgenus Zyras}

\subsubsection{General remarks}

The nominal subgenus of the speciose genus Zyras currently includes approximately 160 species, the vast majority of which is distributed in the southern East Palaearctic and Oriental regions. The fauna of China, Taiwan, and Hong Kong was revised recently and includes about 50 named species (Assing 2016).

\subsubsection{Descriptions and additional records}

\section{Zyras (Zyras) perforatus (CHAMPION, 1921)}

Material examined: Nepal: 1 , , Bagmati, Rasuwa district, Langtang, Syabru, 2200-2600 m, 25.V.1999, leg. Pejcha (NMP); 1 ㅇ, Kathmandu, Shivapuri Lekh, slope west of Bagmati River, 2000-2300 m, 22.-23.V.2005, leg. Schmidt (NME).

Comment: The known distribution of Z. perforatus is confined to North India (from Uttar Pradesh to Sikkim) and Nepal (Hlaváč et al. 2011).

\section{Zyras (Zyras) pindarae (CHAMPION, 1921)}

Material examined: Nepal: 1 ex., N-slope of Manaslu, upper Bhudi Gandaki valley, Shvala env., 3300-3400 m, 30.-31.V.2006, leg. Schmidt (NME); 1 ex., Manaslu, Dudh Pokhari Lekh, upper Dordi Khola valley, 23002600 m, 15.-17.IV.2003, leg. Schmidt (NME); 1 ex., Manaslu, E-slope of Ngali Khola valley, $28^{\circ} 22^{\prime} \mathrm{N}, 84^{\circ} 29^{\prime} \mathrm{E}$, 2000-2300 m, 15.V.2005, leg. Schmidt (cAss).

Comment: This species was originally described from North India (Uttar Pradesh) and subsequently also recorded from several localities in Central Nepal (HLAváč et al. 2011; PACE 1992a). 


\section{Zyras (Zyras) manjushri PACE, 1992}

Material examined: Nepal: $1 \sigma^{*}$, Narayani, Chitwan, Gynganagar, light trap, 9.V.2005, leg. Ahrens (NME).

Comment: This species has been recorded only from Nepal (HLAváč et al. 2011).

\section{Zyras (Zyras) illecebrosus LAST, 1982}

(Figs 170-172, 455-456)

Two paratypes were examined earlier (Assing 2016). The external and male sexual characters of one of them are illustrated in Figs 170-172, 455-456.

\section{Zyras (Zyras) gibbus PACE, 2010}

(Figs 173-177)

This species was redescribed by Assing (2016). However, since the holotype was received only after the submission of the manuscript, it was not figured. The external characters of the holotype are illustrated in Figs 173-177.

\section{Zyras (Zyras) caloderoides Assing, 2016}

Material examined: Thailand: $10^{\star}$, Chiang Mai, Doi Puim $18^{\circ} 49^{\prime} \mathrm{N}, 98^{\circ} 54^{\prime} \mathrm{E}, 1600$ m, 2.-6.V.1996, leg. Horák (NMP).

This recently described species was previously known only from southeastern Yunnan (China). The above male represents the first record from Thailand.

\section{Zyras (Zyras) fratrumkadooriorum PACE, 1998}

Zyras (Zyras) fratrumkadooriorum PACE, 1998: 968. Zyras (Zyras) chumphonensis PACE, 2004: 292; syn. nov.

Type material examined: Z. fratrumkadooriorum: see Assing (2016).

Z. chumphonensis: Holotype $0^{*}$ : "Thailand: Chumphon prov., Pha To env., 948'N, 9847'E, 27.III.-14.IV.1996, P. Průdek / Holotypus Zyras chumphongensis [sic] mihi, det. R. Pace 2004 / Zyras chumphongensis [sic], det. R. Pace 2004 / Zyras fratrumkadooriorum Pace, det. V. Assing 2015” (cSch).

Additional material examined: China: $1 \sigma^{\star}$, Yunnan, Xishuangbanna, $23 \mathrm{~km}$ NW Jinghong, Na Ban env., $22^{\circ} 09^{\prime} \mathrm{N}, 100^{\circ} 40^{\prime} \mathrm{E}, 730 \mathrm{~m}$, Malaise trap, 28.VI.2008, leg. Weigel (NME).

Comment: The original description of $Z$. chumphonensis is based on a unique male from "Thailand, Chumphon prov., Pha To env." (PACE 2004). The specimen is in rather poor condition (antennomeres VIII-XI of left antenna and X-XI of right antennae missing; eyes and legs deformed; coloration somewhat modified probably as a result of improper treatment during original dissection). A comparison of the types of $Z$. chumphonensis and $Z$. fratrumkadooriorum revealed that both names refer to the same species, so that $Z$. chumphonensis is placed in synonymy with $Z$. fratrumkadooriorum. For a redescription and illustrations of this species see Assing (2016).

Zyras fratrumkadooriorum is currently known from Hong Kong, the Chinese province Yunnan, and Thailand.

\section{Zyras (Zyras) shaanxiensis PACE, 1998}

Material examined: China: $1 o^{x}$, Sichuan, Wolong National Nature Reserve, Yinchanggou, Panda Valley, $30^{\circ} 58^{\prime} \mathrm{N}, 103^{\circ} 08^{\prime} \mathrm{E}, 2300 \mathrm{~m}$, sifted, 24.VI.2014, leg. Hájek \& Růžička (NMP).

Comment: Zyras shaanxiensis is widspread and not uncommon in the Daba Shan, the Qinling Shan (including adjacent mountain ranges), and in Sichuan, with two female-based records also from Yunnan (Assing 2016).

\section{Zyras (Zyras) schuelkei Assing, 2016}

Material examined: China: 7 exs., Guangxi, 29 km SSW Shangsi, Shiwada Shan National Forest Park, $21^{\circ} 51^{\prime} \mathrm{N}$, $107^{\circ} 54^{\prime} \mathrm{E}, 300 \mathrm{~m}$, secondary broad-leaved evergreen forest, baited pitfall traps (rotten cheese and fish), 5.-9.IV. 2013, leg. Fikáček et al. (NMP, cAss).

Comment: This recently described species was previously known from Sichuan and Fujian provinces (Assing 2016).

\section{Zyras (Zyras) maculicollis Assing, 2016}

Material examined: China: 1 , Sichuan, $22 \mathrm{~km} \mathrm{NE}$ Baoxing, Dengchigou Monastery, $30^{\circ} 32^{\prime} \mathrm{N}, 102^{\circ} 56^{\prime} \mathrm{E}$, 1880 m, bamboo grove, 13.VI.2014, leg. Hájek \& Růžička (NMP).

Comment: Zyras maculicollis had been recorded only from Hubei and Jiangxi provinces (Assing 2016). The above female is of somewhat darker coloration than the types, but otherwise no differences were found suggesting that it should represent a distinct species. 


\section{Zyras (Zyras) quasar DvoŘák, 1996}

(Figs 178-180, 457-458)

Zyras (Pella) quasar DvoŘAK, 1996: $6 \mathrm{f}$.

Comment: The holotype of $Z$. quasar was studied earlier on (Assing 2015d). The original description neither provides adequate illustrations, nor does it mention morphological characters allowing a reliable identification. Therefore, a full redescription is given and important external and sexual characters are figured. The holotype had been dissected prior to the present study and is somewhat damaged (left fore- and hindleg completely missing; left mesotarsus and right metatarsus missing; abdominal tergite VIII broken).

Redescription: Rather small species species; body length $5.7 \mathrm{~mm}$; length of forebody $2.4 \mathrm{~mm}$. Coloration: head dark-brown with reddish anterior portion; pronotum dark-brown; elytra dark-brown, with humeral portions diffusely and slightly paler; abdomen: tergites II-IV reddish, $\mathrm{V}$ reddish in anterior half and somewhat infuscate in posterior half, VI dark-brown, VII reddishbrown with reddish anterior portion, VIII reddish with slightly darker anterior half; legs pale-yellowish; antennae blackish with (parts of) antennomeres I-II and the apex of XI slightly paler; maxillary palpi dark-brown with yellowish terminal palpomere.

Head (Fig. 178) distinctly transverse, broadly impunctate along middle; punctation in lateral dorsal portions moderately coarse and very sparse. Eyes large, approximately twice as long as postocular region in dorsal view. Antenna (Fig. 179) 1.8 mm long; antennomere IV weakly transverse; antennomeres $\mathrm{V}-\mathrm{X}$ of gradually increasing width and increasingly transverse; $\mathrm{X}$ approximately 1.5 times as broad as long; XI longer than the combined length of IX and X.

Pronotum (Fig. 178) 1.12 times as broad as long, and 1.21 times as broad as head, moderately convex in crosssection; punctation rather sparse and slightly irregularly distributed; midline moderately broadly impunctate.

Elytra (Fig. 178) approximately 0.85 times as long as pronotum; punctation defined, moderately dense, equally distributed, and fine. Hind wings fully developed.

Abdomen (Fig. 180) narrower than elytra and with moderately deep anterior impressions on tergites III-V; anterior impressions of tergites III-V and anterior portion of tergite VI each with a transverse series of moderately sparse and moderately coarse non-setiferous punctures; tergite III with a lateral setiferous puncture on either side, with approximately 10 setiferous punctures at posterior margin, and with sparse non-setiferous micropunctation on disc; tergites IV and V each with a median pair of setiferous punctures, with a lateral setiferous puncture on either side, and with approximately 15 setiferous punctures at posterior margin; tergite VI with a transverse row of four setiferous punctures in the middle, with a lateral setiferous puncture on either side, and with approximately 15 setiferous punctures at posterior margin; tergite VII with a transverse band of numerous non-setiferous punctures at anterior margin, with a transverse row of four setiferous punctures at posterior third, with a lateral setiferous puncture on either side, and with several setiferous punctures at posterior margin; tergite VIII with approximately 20 long black setae in posterior fourth; integument without microsculpture and very glossy; posterior margin of tergite VII with palisade fringe; posterior margin of tergite VIII concave in the middle.

$\sigma^{*}$ : median lobe of aedeagus rather small, $0.46 \mathrm{~mm}$ long, and shaped as in Figs 457-458; paramere approximately as long as median lobe, its apical lobe short.

Comparative notes: Zyras quasar is not very distinctive. Among the species of similar coloration, this species is characterized by the combination of relatively small body size, antennae with transverse antennomeres IV-X and a rather long antennomere XI, finely punctate elytra, the punctation pattern of the abdomen, and a relatively small aedeagus with a broad ventral process and small apical lobes of the parameres.

Distribution: The confirmed distribution is confined to the type locality in Vietnam. Zyras quasar has been reported also from Burma, Thailand, and Malaysia, but, in view of frequent misidentifications of Zyras sensu strictu species, these records are most likely incorrect.

\section{Zyras (Zyras) porrectus spec. nov. \\ (Figs 181-183, 459-460)}

Type material: Holotype $\sigma^{*}$ [slightly teneral]: "China: Sichuan Prov., Baoxing, 1020-1280 m, Wenxian Shan Park, 30²2'12"N 102 $48^{\prime} 57^{\prime \prime}-49^{\prime} 02^{\prime \prime} \mathrm{E}$, / 12.VI.2014, individually from vegetation; mixed forest with Pinus; forest margin, J. Hájek, J. Růžička \& M. Tkoč leg. / Holotypus o Zyras porrectus sp. n. det. V. Assing 2015” (NMP).

Paratypes: $1 \sigma^{\star}$ [slightly teneral], 1 i [apical antennomeres of both antennae missing]: same data as holotype (NMP, cAss).

Etymology: The specific epithet is the past participle of the Latin verb porrigere (to elongate) and alludes to the conspicuously long antennomere XI.

Description: Rather large species; body length $8.0-9.0 \mathrm{~mm}$; length of forebody $3.8-4.0 \mathrm{~mm}$. Coloration: head and pronotum black; elytra yellowish, with the postero-lateral portions blackish; abdomen blackish, with the posterior margins of all tergites and parts of the paratergites dark-yellowish; legs pale-yellowish; antennae blackish, with antennomere I brown to dark-brown, and antennomere II and base of III pale-reddish.

Head (Fig. 181) distinctly transverse, broadly impunctate along middle; punctation in lateral dorsal portions 
coarse and rather sparse. Eyes much longer than postocular region in dorsal view. Antenna (Fig. 182) slender, 3.0-3.2 mm long; antennomeres IV-VI weakly oblong, VII as long as broad to weakly transverse, VIII-X weakly transverse, and XI conspicuously elongate, longer than the combined length of VIII-X.

Pronotum (Fig. 181) 1.17-1.21 times as broad as long, and 1.18-1.20 times as broad as head, rather weakly convex in cross-section, laterally with a more or less pronounced impression on either side; punctation rather sparse and irregularly distributed, laterally and/or anterolaterally and near posterior margin with rather extensive impunctate areas; midline moderately broadly impunctate; lateral margins and antero-lateral portion with five long black setae on either side.

Elytra (Fig. 181) approximately 0.95 times as long as pronotum; punctation defined, dense, and rather coarse. Hind wings fully developed. Metatarsomere I approximately as long as the combined length of II-IV.

Abdomen (Fig. 183) narrower than elytra and with shallow anterior impressions on tergites III-V; anterior impressions of tergites III-V and anterior portion of tergite VI each with an irregular transverse series of sparse, but coarse non-setiferous punctures; tergite III with a median pair of setiferous punctures and with a lateral and a postero-lateral setiferous puncture on either side; tergite IV with a median pair of setiferous punctures at posterior margin, and with a lateral and a posterolateral setiferous puncture on either side, additionally with a variable number of non-setiferous punctures laterally; tergite $\mathrm{V}$ with a lateral setiferous puncture on either side and with six setiferous punctures at posterior margin, additionally with an irregular transverse series of non-setiferous punctures on disc; tergite VI with a lateral setiferous puncture on either side and with six setiferous punctures at posterior margin, additionally with a cluster of few non-setiferous punctures laterally; tergite VII with a transverse band of rather fine non-setiferous punctures in anterior fourth or third, with few setiferous punctures laterally, and with a median pair of granulose setiferous punctures; tergite VIII with some setiferous punctures bearing long black setae in posterior fourth, otherwise impunctate; integument without microsculpture and very glossy; posterior margin of tergite VII with palisade fringe; posterior margin of tergite VIII concave in the middle.

$\sigma^{*}$ : posterior concavity of tergite VIII pronounced; sternite VIII somewhat longer than tergite VIII, its posterior margin convex; median lobe of aedeagus (Fig. 459-460) approximately $1.1 \mathrm{~mm}$ long; ventral process rather slender in ventral view; apical lobe of paramere moderately long and rather slender.

i: posterior concavity of tergite VIII shallow; posterior margin of sternite VIII weakly concave in the middle.

Comparative notes and comment: This species is characterized by the shape of the aedeagus, the conspicuously long antennomere XI, the abdominal punctation pattern, and the combination of rather large size, coloration pattern, and an irregularly punctate pronotum. It is readily distinguished from $Z$. fratrumkadooriorum, the only other species with a similarly long antennomere XI recorded from China, by much larger body size alone (Z. fratrumkadooriorum: body length 4.3-5.0 mm; length of forebody 1.9-2.1 mm).

Using the key in Assing (2016), Z. porrectus would key out at couplet 48 together with the widespread Z. notaticornis PACE, 1998, from which the new species additionally differs by larger body size, a less convex pronotum (cross-section), much darker antennae (Z. notaticornis: antennomeres $\mathrm{V}-\mathrm{X}$ dark-brown, XI reddish) and the coloration of the elytra (Z. notaticornis: elytra reddish with the postero-lateral portions more extensively infuscate).

Since the apical antennomeres of both antennae of the only female available are missing, it is at present uncertain if the elongate antennomere XI represents a secondary male character or not.

Distribution and natural history: The type locality is situated very close to Baoxing in Sichuan. The partly teneral specimens were collected from vegetation in a mixed forest with pine at an altitude of 1020-1280 m.

\section{Zyras (Zyras) wunderlei spec. nov. (Figs 184-186, 461-465)}

Type material: Holotype $\sigma^{*}$ : "Indonesia, Central Bali, Pupuan, Wasserfall, $700 \mathrm{~m}$, Uferschotter, 14.06.94 P. Wunderle / Holotypus o Zyras wunderlei sp. n. det. V. Assing 2015” (cAss).

Etymology: This species is dedicated to my friend and long-time field companion Paul Wunderle (Mönchengladbach), who collected the holotype.

Description: Body length $6.8 \mathrm{~mm}$; length of forebody $3.3 \mathrm{~mm}$. Coloration: head and pronotum dark-brown; elytra reddish-brown; abdomen dark-brown, with segments VIII-X and the posterior portion of tergite VII paler; legs pale-yellowish; antennae brown, with antennomeres I-II and the base of III reddish and antennomeres IX-XI pale-yellowish (except for the infuscate base of IX); maxillary palpi dark-yellowish with the terminal palpomere pale-yellowish.

Head (Fig. 184) distinctly transverse, with rather coarse and dense punctation, except for a small patch in median portion, and with rather dense, long, erect, and dark pubescence. Eyes somewhat longer than postocular region in dorsal view. Antenna (Fig. 185) 2.3 mm long; antennomeres IV approximately as long as broad, $\mathrm{V}$ indistinctly transverse, VI-X of increasing width and increasingly transverse, $\mathrm{X}$ slightly more than half as broad as long, and XI of conical shape and short, distinctly shorter than the combined length of IX and X. 
Pronotum (Fig. 184) 1.16 times as broad as long, and 1.22 times as broad as head, rather weakly convex in crosssection; lateral margins weakly sinuate in posterior half (dorsal view); punctation dense, moderately coarse, and rather shallow; pubescence dense, long, erect, and dark. Elytra (Fig. 184) 0.78 times as long as pronotum; punctation defined, very dense, and moderately coarse; interstices much narrower than diameter of punctures; pubescence dense, long, erect, and pale-brown. Hind wings fully developed. Metatarsomere I nearly as long as the combined length of II-IV.

Abdomen (Fig. 186) broad, slightly broader than elytra and with moderately deep anterior impressions on tergites III-V; all sternites with dense and long, semierect to erect brown pubescence; anterior impressions of tergites III-V each with a transverse series of sparse and fine non-setiferous punctures; tergites III-IV with numerous setiferous punctures bearing long and semierect dark setae at posterior margin and in lateral portions, with scattered setiferous punctures on disc, and with interspersed micropunctation; tergite $\mathrm{V}$ with setiferous punctures bearing long and semi-erect dark setae at posterior margin and on disc, and with interspersed micropunctation; tergite VI with a transverse band of numerous and moderately coarse non-setiferous punctures anteriorly, and with setiferous punctures bearing long and semi-erect setae in posterior two-thirds; tergite VII with a broad transverse band of numerous and moderately coarse non-setiferous punctures in anterior third and with setiferous punctures not arranged in distinct series in posterior two-thirds; tergite VIII with numerous dark long setae in posterior two-fifths; posterior margin of tergite VII with palisade fringe; tergite VIII (Fig. 464) with dense long pubescences posteriorly, posterior margin with small and shallow median concavity.

$0^{\text {t: }}$ sternite VIII (Fig. 465) much longer than tergite VIII, with dense and long pubescence in posterior half, its posterior margin convex; median lobe of aedeagus (Figs 461-462) $1.0 \mathrm{~mm}$ long; ventral process rather slender and apically acute; paramere (Fig. 463) approximately as long as median lobe and with very short and apically obliquely truncate apical lobe.

Comparative notes and comment: As can be inferred from external (robust body; broad abdomen; dense punctation with long and erect pubescence) and the male sexual characters (apical lobe of paramere very short), $Z$. wunderlei belongs to the group of species allied to Z. hirtus (KRAATZ, 1859), which, aside from Z. hirtus, includes several named and unnamed species from the southern East Palaearctic and the Oriental regions, such as Z. setosivestis ScheERPeLtz, 1965 (Myanmar; male unknown), Z. funestus (Dvořák, 1996) (Vietnam; male unknown), and Z. flexus Assing, 2016 (China). In size and habitus, Z. wunderlei is similar to Z. funestus and Z. flexus, but distinguished as follows:
- from Z. funestus by much paler legs (Z. funestus: apical halves of femora dark-brown), paler apical antennomeres IX-XI (Z.funestus: antennomeres IX-X dark-brown, XI reddish), longer and less strongly incrassate antennae with less transverse antennomeres V-X (Z.funestus: antenna approximately $2.0 \mathrm{~mm}$ long), a larger and more transverse pronotum (Z. funestus: pronotum 1.1 times as broad as long), and by the distinctly finer punctation of the abdominal tergites VI and VII;

- from Z. flexus by much paler legs (Z. flexus: apical halves of femora dark-brown), the coloration of the antennae (Z. flexus: antennomeres I-X black, XI yellow), coarser and denser punctation of the head, the median concavity of the posterior margin of tergite VIII (absent in $Z$. flexus), and by the distinctly larger aedeagus with an apically less strongly bent ventral process. For illustrations of Z. funestus and Z. flexus see Assing (2015d) and Assing (2016), respectively.

Distribution and natural history: The type locality is situated in central Bali, Indonesia. The holotype was collected from scree near a waterfall.

\subsubsection{Unnamed species}

Zyras (Zyras) spec.

Material examined: Thailand: $1 \%$ : "N-Thailand, Chiang Mai, Doi Suthep, 1580 m NN, Laubstreu, 13.11.1995 P. Wunderle" (cAss).

Comment: The above female undoubtedly represents an undescribed species. It is readily distinguished from all named species of Zyras sensu strictu by conspicuous coloration, habitus, and punctation alone.

\subsection{Genus Pedinopleurus Cameron, 1939}

\section{Pedinopleurus chapmani CAMERon, 1939}

Material examined: Vietnam: 2 우, Bac Kan prov., entrance of $\mathrm{Ba}$ Be National Park, $22^{\circ} 25^{\prime} \mathrm{N}, 105^{\circ} 38^{\prime} \mathrm{E}$, 180-220 m, at light, 16.-20.V.2014, leg. Weigel (NME, cAss); 1 o, 2 우, + Cuc Phuong, 2.-11.V.1991, leg. Strnad (NMP, cAss).

Comment: The original description is based on at least two type specimens from "Hoa Binh" (CAMERON $1939 b)$. The known distribution is confined to Vietnam. 
Pedinopleurus notabilis (SILVESTRI, 1946)

(Figs 187-189)

Urodonia notabilis SILVESTRI, 1946, $321 \mathrm{f}$.

Pedinopleurus notabilis: HLAváč et al. (2011).

Pedinopleurus setosicauda Dvořák, 1996: 4 f.; syn. nov.

Material examined: China: 1 , Yunnan, Xishuangbanna, $20 \mathrm{~km}$ NW Jinghong, Man Dian, $22^{\circ} 07^{\prime} \mathrm{N}, 100^{\circ} 40^{\prime} \mathrm{E}$, 720 m, light trap, 26.V.2008, leg. Weigel (NME). Laos: 1 ex., Houa Phan prov., Phou Pane mountain, $20^{\circ} 13^{\prime} \mathrm{N}$, $104^{\circ} 00^{\prime} \mathrm{E}, 1480-1510$ m, 22.IV.-14.V.2008, leg. Kubáň (NMP).

Comment: The original description of P. notabilis is based on several specimens collected in a nest of "Termes malaccensis ad Yen-Bay (Tonkino)” (SIlvestri 1946). Pedinopleurus setosicauda was described from four type specimens from two localities in North Vietnam (Dvoř́́k 1996). The details indicated in the descriptions of P. notabilis and P. setosicauda do not provide any evidence that the two names should refer to different species; hence the synonymy proposed above. The forebody, antenna, and abdominal segments IX-X are illustrated in Figs 187-189.

The additional material listed above represents the first records from China and Laos.

\subsection{Description of a new genus}

\section{Aenictoides gen. nov.}

(Figs 190-196, 466-471)

Type species: Aenictoides derivata sp. n.

Etymology: The generic name (gender: feminine) alludes to the conspicuous habitus strongly resembling its hypothesized host ants of the genus Aenictus SHUCKARD, 1840 .

Description: Habitus highly derived, conspicuously myrmecoid, slender. Head (Figs 190-191) dorsally with conspicuous impressions, latero-dorsally strongly bulging and with dense and pronounced puncturoid microsculpture (i.e., extremely dense non-setiferous micropunctation); between antennal insertions with a pair of pronounced oblique keels; whole ventral surface with dense puncturoid microsculpture. Antenna (Fig. 192) strongly modified, with extremely enlarged and dorso-apically deeply excavate antennomere I (Figs 191-192); antennomeres II and III strongly dilated apically, wedge-shaped; antennomere II strongly depressed; antennomere III distinctly flattened, antennomeres IV-X gradually becoming less depressed and more oval in cross-section. Maxilla (Fig. 466) with long galea; maxillary palpus four-jointed, with distinctly flattened palpomeres II and III, palpomere III approximately
2.5 times as long as broad. Labium (Fig. 467) with short, broad, and weakly bifid ligula. Mentum anteriorly nearly truncate. Mandibles only with the basal tooth, without additional molar teeth, apically curved and acute.

Pronotum (Figs 190-191) slender, dorsally with pronounced, deep and broad median impression extending along its full length, laterally with pronounced bulging elevations; median impression with coarse puncturelike impressions with puncturoid microsculpture, these impressions separated from each other by narrow sharp ridges; laterally with less coarse puncture-like impressions with dense puncturoid microsculpture. Prosternum with dense puncturoid microsculpture, with a short longitudinal median carina reaching neither anterior nor posterior margins and with a long transverse carina.

Elytra (Figs 190-191) of subquadrate shape and with coarse puncture-like impressions with puncturoid microsculpture. Mesoventrite (Fig. 193) short, somewhat bulging anterior to mesocoxal cavities, without distinct median process, and with dense puncturoid microsculpture. Metaventrite (Fig. 193) with puncturoid microsculpture only in impressions and in mesocoxal cavities, otherwise glossy; glossy portion nearly completely and broadly separating mesocoxal cavities. Legs slender; mesofemora moderately, metafemora strongly club-shaped (i.e., subapically distinctly dilated) (Figs 194-195); metatrochanter (Fig. 196) strongly developed.

Abdomen (Figs 194-196) of conspicuously myrmecoid shape, with segments III and IV shaped like a petiole and postpetiole and with segments V-VIII together shaped like a gaster of an aenictine ant worker; all segments without distinct paratergites; whole surface of segment III and tergite IV with puncturoid microsculpture; sternite IV glossy; tergite $\mathrm{V}$ with puncturoid microsculpture, sternite $\mathrm{V}$ with coarse punctation and glossy; tergite $\mathrm{VI}$ with dense puncturoid microsculpture anteriorly, on remainder of surface with less dense microsculpture and with coarse punctures; sternite VI glossy and with coarse punctures; tergite VII with dense puncturoid microsculpture and coarse punctation; sternite VII glossy, except for the macropunctures; tergite VIII and sternite VIII with large puncture-like impressions with dense puncturoid microsculpture, these impressions separated by a network of narrow ridges.

$\sigma^{*}$ : median lobe of aedeagus (Figs 468-469) slender, weakly sclerotized, and without sclerotized structures; paramere (Figs 470-471) broad and with small apical lobe.

Comparative notes: Based on the long galea, the new genus belongs to the Lomechusini. According to Maruyama (pers. comm.), Aenictoides may be allied to the lomechusine genus Malaybergius KISTNER, 1993, from which it differs by numerous characters, particularly the much more myrmecoid habitus (especially the derived shape of the abdomen), the completely different morphology of the antennae, the conspicuous puncturoid 
microsculpture on various parts of the body, the derived punctation of the whole body, the pronounced impressions and lateral elevations on the head and pronotum, the shape of the ligula, the morphology of the ventral aspect of the thorax, and the club-shaped meso- and metafemora.

\section{Aenictoides derivata spec. nov.}

(Figs 190-196, 466-471)

Type material: Holotype $0^{*}$ : "Thailand [3] - Doi Inthanon, Mae Aeb stream, $18^{\circ} 32^{\prime} \mathrm{N}, 98^{\circ} 36^{\prime} \mathrm{E}, 550 \mathrm{~m}$, stream bank, 20.XII.2013, leg. Ob / Holotypus ơ Aenictoides derivata sp. n. det. V. Assing 2015” (cAss).

Etymology: The specific epithet is the past participle of the Latin verb derivare and alludes to the conspicuously derived habitus, punctation, antennae, and legs.

Description: Body length $4.1 \mathrm{~mm}$; length of forebody $1.9 \mathrm{~mm}$. Coloration: head bicoloured, posteriorly blackish, frons, clypeus, and mouthparts reddish; pronotum reddish-brown; elytra reddish-brown, with the posterolateral portions extensively dark-brown; abdomen yellowish-red; legs yellowish with the dilated apical portions of the meso- and metafemora and parts of the metatibiae and metatarsi weakly to distinctly infuscate; antennae reddish with antennomeres I and XI brown.

Head (Figs 190-191) distinctly transverse, 1.3 times as broad as long, broadest across eyes; posterior portion of trapezoid shape, i.e., lateral margins behind eyes converging, straight, posterior angles rather marked, and posterior margin truncate; posterior constriction 0.37 times as broad as head; impressed median dorsal portion with a transverse row of four coarse punctures with puncturoid microsculpture, anterior to this row with a pair of punctures; posteriorly with an oblong impression with puncturoid microsculpture reaching posterior margin; median dorsal portion glossy, except for the impressions and elevations. Antenna (Fig. 192) $1.4 \mathrm{~mm}$ long; antennomeres II weakly oblong, III approximately as long as broad, IV-X approximately twice as broad as long, and XI oval, shorter than the combined length of IX and $\mathrm{X}$.

Pronotum (Figs 190-191) 1.02 times as long as broad and 0.9 times as broad as head, distinctly narrowed anteriad; posterior angles marked; lateral elevations glossy, median impressions with puncturoid microsculpture; lateral elevations with sparse granulose setiferous punctation. Elytra (Figs 190-191) 0.84 times as long as pronotum; humeral angles marked; punctation very coarse and dense (separated by narrow ridges) in anterior and sutural portions, less dense and less coarse on remainder of disc. Scutellum large, with dense puncturoid microsculpture and matt. Hind wings present. Metatarsomere I slightly longer than the combined length of II and III.
Abdomen (Figs 194-196) as characterized in the description of the genus; posterior margin of tergite VII with palisade fringe.

$\sigma^{*}$ : posterior margin of tergite VIII weakly, but distinctly concave; posterior margin of sternite VIII convex; median lobe of aedeagus (Figs 468-469) $0.68 \mathrm{~mm}$ long, very slender, with bisinuate ventral process in lateral view; internal sac without sclerotized structures; paramere (Figs 470-471) $0.53 \mathrm{~mm}$ long, broad, and of derived shape.

o: unknown.

Comparative notes: Aenictoides derivata is readily distinguished from all other species of Lomechusini by its conspicuous habitus and other derived external characters alone.

Distribution and natural history: The type locality is situated in Doi Inthanon, Chiang Mai province, North Thailand. The holotype was sifted from litter between rocks at an altitude of $550 \mathrm{~m}$. The species is most likely associated with ants of the genus Aenictus (Maruyama, e-mail 6 July, 2015).

\section{Acknowledgements}

My thanks are due to the colleages indicated in the material section for the loan of material from the collections under their care, in particular to Paul Wunderle for the generous permission to retain the holotype of Zyras wunderlei. Munetoshi Maruyama (Fukuoka) provided helpful comments on the the new genus Aenictoides. Alfred Newton (Chicago) cross-checked all the new names against his unpublished database. Benedikt Feldmann (Münster) proof-read the manuscript.

\section{References}

Assing, V. 2003: A review of the Himalayan species of Amaurodera (Coleoptera: Staphylinidae: Aleocharinae). - Entomological Problems 33 (1): 5-20.

Assing, V. 2005a: A review of the Himalayan species of Amaurodera (Coleoptera: Staphylinidae: Aleocharinae). II. New species and additional records. - Stuttgarter Beiträge zur Naturkunde Serie A (Biologie), Nr. 680: 1-12.

Assing, V. 2005b: On the western Palaearctic species of Drusilla LeAch, with special reference to the species of the eastern Mediterranean (Coleoptera: Staphylinidae, Aleocharinae). - Koleopterologische Rundschau 75: 111-149.

Assing, V. 2005c: A revision of the Middle Asian species of Drusilla LEACH (Insecta: Coleoptera: Staphylinidae: Aleocharinae). - Entomologische Blätter $101(1)$ : 43-56. 
Assing, V. 2005d: A review of the Himalayan species of Amaurodera (Coleoptera: Staphylinidae: Aleocharinae). II. New species and additional records. - Stuttgarter Beiträge zur Naturkunde Serie A 680: $1-12$.

Assing, V. 2006a: A new species and new records of Amaurodera Fauvel from Nepal (Coleoptera: Staphylinidae, Aleocharini). - Beiträge zur Entomologie, Keltern 56 (1): 155-160.

Assing, V. 2006b: A revision of the Palaearctic species of Orphnebius Motschulsky (Insecta: Coleoptera: Staphylinidae: Aleocharinae). - Entomological Problems 36 (1): 1-26.

Assing, V. 2006c: On the Orphnebius species of China (Insecta: Coleoptera: Staphylinidae: Aleocharinae). Entomological Problems 36 (2): 75-84.

Assing, V. 2006d: On the Himalayan species of Tetrabothrus Bernhauer (Insecta: Coleoptera: Staphylinidae: Aleocharinae). - Entomological Problems 36 (2): 49-54.

Assing, V.2006e: New species and records of Staphylinidae from Turkey IV, with six new synonymies (Coleoptera: Staphylinidae). - Koleopterologische Rundschau 76: 223-276.

Assing, V. 2009: New species and additional records of Lomechusini from the Palaearctic region (Coleoptera: Staphylinidae: Aleocharinae). - Stuttgarter Beiträge zur Naturkunde Serie A, Neue Serie 2: 201-226.

Assing, V. 2011: A new species of Orphnebius Mотschulsky from Nepal (Coleoptera: Staphylinidae: Aleocharinae: Lomechusini). - Linzer Biologische Beiträge 43 (1): 275-278.

Assing, V. 2014: On the Staphylinidae of Israel II, with a revision of some species of Dinusa SAUlcy (Coleoptera: Staphylinidae: Aleocharinae). - Linzer Biologische Beiträge 46 (2): 1179-1210.

Assing, V. 2015a: On the Orphnebius fauna of the East Palaearctic region. VI. Six new species from China and Taiwan, and additional records (Coleoptera: Staphylinidae: Aleocharinae: Lomechusini). - Linzer Biologische Beiträge 47 (1): 101-125.

Assing, V. 2015b: On the Tetrabothrus fauna of China (Coleoptera: Staphylinidae: Aleocharinae: Lomechusini). - Linzer Biologische Beiträge 47 (1): 127-143.

Assing, V. 2015c: New species and additional records of Lomechusini from the Palaearctic region, primarily from China (Coleoptera: Staphylinidae: Aleocharinae). - Contributions to Entomology 65 (2): 243-262.

Assing, V. 2015d: On the Lomechusini fauna of Vietnam (Coleoptera: Staphylinidae: Aleocharinae). - Linzer Biologische Beiträge 47 (2): 1257-1282.

Assing, V. 2015e: On the Orphnebius fauna of the East Palaearctic region. VI. Six new species from China and Taiwan, and additional records (Coleoptera: Staphylinidae: Aleocharinae: Lomechusini). - Linzer Biologische Beiträge 47 (1): 101-125.
Assing, V. 2016: A revision of Zyras Stephens sensu strictu of China, Taiwan, and Hong Kong, with records and (re-)descriptions of some species from other regions (Coleoptera: Staphylinidae: Aleocharinae: Lomechusini). - Stuttgarter Beiträge zur Naturkunde A, Neue Serie 9: 87-175.

Bernhauer, M. 1915a: Neue Staphyliniden der indomalaiischen Fauna, insbesondere der Sunda-Insel Borneo (9. Beitrag). - Verhandlungen der KaiserlichKöniglichen Zoologisch-Botanischen Gesellschaft in Wien 65: 134-158.

Bernhauer, M. 1915b: Neue Staphyliniden aus Java und Sumatra (7. Beitrag zur indo-malayischen Staphylinidenfauna). - Tijdschrift voor Entomologie 58: 213-243.

Bernhauer, M. 1929: Zur Kenntnis der Gattungen Astilbus Sтерн., Orphnebius Мотsсн. und Deroleptus Bernh. - Zoologischer Anzeiger 82: 142-155.

Blackwelder, R. E. 1952: The generic names of the beetle family Staphylinidae, with an essay on genotypy. - Bulletin of the United States National Museum 200: iv +483 pp.

Cameron, M. 1925: Descriptions of new species of oriental Staphylinidae. - Annali del Museo Civico di Storia Naturale di Genova 52: 34-49.

Cameron, M. 1939a: The Fauna of British India, including Ceylon and Burma. Coleoptera. Staphylinidae. - Vol. IV. Parts I-II. - London: $691 \mathrm{pp}$.

Cameron, M. 1939b: New species of Staphylinidae from Tonkin. - Revue Française d'Entomologie 6(1): 22-26.

Cameron, M. 1943: New species of Staphylinidae (Col.) from Borneo. - Entomologist's Monthly Magazine 79: 39-42, 139-143, 183.

Cameron, M. 1946: New species of Oriental Staphylinidae (Col.). - Annals and Magazine of Natural History 12 (11): 682-694.

Cameron, M. 1950: New species of Staphylinidae (Col.) from the Malay Peninsula. - Annals and Magazine of Natural History 3 (12): 1-40, 89-131.

DvořÁK, M. 1996: Einige neue myrmekophile oder termitophile Arten des Tribus Zyrasini aus Südasien (Coleoptera, Staphylinidae, Aleocharinae). - Coleoptera Schwanfelder Coleopterologische Mitteilungen 23: 1-15.

Fauvel, A. 1905: Staphylinides de Java, recueillis par M. le Dr. K. Kraepelin et M. le Dr. Koningsberger en 1904. - Mitteilungen aus dem Naturhistorischen Museum, Hamburg 22: 75-86.

Gistel, J. N. F. X. 1857: Achthundert und zwanzig neue oder unbeschriebene wirbellose Thiere. - Straubing: Verlag der Schorner'schen Buchandlung: 94 pp.

HLAváč, P. 2005: Revision of the myrmecophilous genus Lomechusa (Coleoptera: Staphylinidae: Aleocharinae). - Sociobiology 46 (2): 203-250. 
Hlaváč, P.; Newton, A. F. \& Maruyama, M. 2011: World catalogue of the species of the tribe Lomechusini (Staphylinidae: Aleocharinae). - Zootaxa 3075: $1-151$.

ICZN 1999: International Code of Zoological Nomenclature. Fourth Edition. - London: XXIX + 306 pp.

JÁszay, T. \& Hlaváč, P. 2013: A taxonomic revision of the myrmecophilous genus Lomechusoides Tоттеnнам, 1939 (Coleoptera: Staphylinidae: Aleocharinae). Part I. Redescription of the genus, definition of species groups and the revision of the amurensis WASMANN 1897 species group. - Zootaxa 3683 (1): 65-81.

Maruyama, M. 2006: Revision of the Palearctic species of the myrmecophilous genus Pella (Coleoptera, Staphylinidae, Aleocharinae). - National Science Museum Monographs 32: 1-207.

Maruyama, M. \& Kishimoto, T. 1999: A revision of the Japanese species of the genus Tetrabothrus (Coleoptera, Staphylinidae, Aleocharinae). - Elytra 27 (2): 503-517.

NAKANE, T. 1991: Notes on some little-known beetles (Coleoptera) in Japan. 8. - Kita-Kyushû no Konchû 38 (2): 111-115.

PACE, R. 1986: Aleocharinae della Thailandia e della Birmania riportate da G. de Rougemont (Coleoptera, Staphylinidae). - Bolletino del Museo Civico di Storia Naturale di Verona 11 (1984): 427-468.

PACE, R. 1987: Aleocharinae dell'Asia sudorientale raccolte da G. de Rougemont (Coleoptera, Staphylinidae). - Bolletino del Museo Civico di Storia Naturale di Verona 13 (1986): 139-237.

Pace, R. 1992a: Aleocharinae nepalesi del Museo di Ginevra. Parte VI: Myrmedoniini (Coleoptera, Staphylinidae). - Revue Suisse de Zoologie 99 (1): 125-145.

PACE, R. 1992b: Aleocharinae della Thailandia (Coleoptera, Staphylinidae). - Bolletino del Museo Civico di Storia Naturale di Verona 16(1989): 227-268.

PACE, R. 1998: Aleocharinae della Cina: Parte IV (Coleoptera, Staphylinidae). - Revue Suisse de Zoologie 105 (4): 911-982.

PACE, R. 2000: Aleocharinae della Thailandia (Coleoptera, Staphylinidae). - Bollettino del Museo Regionale di Scienze Naturali, Torino 17 (1): 39-86.

PACE, R. 2001: Aleocharinae nuove o poco note dell'India (Coleoptera, Staphylinidae). - Nouvelle Revue d'Entomologie (N.S.) 18 (1): 31-47.

PACE, R. 2004: Aleocharinae di Thailandia, Cambogia, Laos e Malaysia (Coleoptera, Staphylinidae). Belgian Journal of Entomology 6: 243-302.

PACE, R. 2007: Le specie del genere Orphnebius Motschulscky [sic], 1858, nel Borneo (Coleoptera, Staphylinidae). - Revue Suisse de Zoologie 114 (4): 743-769.
PACE, R. 2010: Thamiaraeini, Lomechusini, Oxypodini, Hoplandriini e Aleocharini di Taiwan (Coleoptera, Staphylinidae). - Bollettino del Museo Civico di Storia Naturale di Verona 34: 19-54.

PACE, R. 2012a: Biodiversità delle Aleocharinae della Cina: Lomechusini e Thamiaraeini (Coleoptera, Staphylinidae). - Beiträge zur Entomologie, Keltern 62 (1): 77-102.

PACE, R. 2012b: New data, two new genera and new species of Aleocharinae from Indian and Chinese subregions (Coleoptera: Staphylinidae). - In: Hartmann, M. \& WEIPERT, J. (eds), Biodiversität und Naturausstattung im Himalaya, Erfurt 4: 283-296.

PACE, R. 2012c: New data, new species, and two new genera of Aleocharinae from the Oriental Region (Insecta: Coleoptera: Staphylinidae). - Vernate 31: 319-360.

PACE, R. 2013: New distributional data, new species and three new genera of Aleocharinae from Malaysia, Vietnam and Taiwan (Coleoptera: Staphylinidae). Tropical Zoology 26 (1): 33-63.

PACE, R. 2014: Aleocharinae from Sabah (Borneo) collected by Guillaume de Rougemont (Coleoptera, Staphylinidae). - Linzer Biologische Beiträge 46 (1): 727-794.

PACE, R. 2015: Aleocharinae from Sabah (Borneo) in the collections of the Oxford University Museum of Natural History (Coleoptera, Staphylinidae). - Lavori della Società Veneziana di Scienze Naturali 40: 11-24.

Peyron, E. 1857: 1. Myrmedonia Erichsonis Peyron. - In: FAIRMAIRE, L.: Rapport sur la session extraordinaire tenue a Montpellier au mois de Juin 1857. - Annales de la Société Entomologique de France 5: 619-647.

Peyron, E. 1858: Catalogue des coléoptères des environs de Tarsous (Caramanie), avec la description des espèces nouvelles. - Annales de la Société Entomologique de France 6: 353-434.

Schülke, M. \& Smetana, A. 2015: Staphylinidae, pp. 304-1134. - In: LöBL, I. \& LöBL, D. (eds), Catalogue of Palaearctic Coleoptera. Volume 2. Hydrophiloidea - Staphylinoidea. Revised and updated edition. - Leiden: Brill: xxvi + 1702 pp.

Silvestri, F. 1946: Prima nota su alcuni termitofili dell'Indocina. - Bollettino del Laboratorio di Entomologia Agraria di Portici 6: 313-330.

YAN, Z.-Q. \& LI, L.-Z. 2015a: New species and additional records of Amaurodera FAUvel in southern China (Coleoptera, Staphylinidae, Aleocharinae). - Zootaxa 3931 (2): 272-278.

YAN, Z.-Q. \& Li, L.-Z. 2015b: New species and additional records of Tetrabothrus BERNHAUER from China (Coleoptera, Staphylinidae, Aleocharinae) - Zootaxa 4007 (2): 276-282. 